SAND96-2538

Unlimited Release

UC-721

\title{
Hydrogen Generation by Metal Corrosion in Simulated Waste Isolation Pilot Plant Environments
}

\author{
RECEIVED \\ APR 161997 \\ OSTI
}

M.R. Telander,

R.E. Westerman (Retired)

Battelle Pacific Northwest Laboratory

Battelle Blvd.

Richland, WA 99352

Prepared by

Sandia National Laboratories

Albuquerque, New Mexico 87185 and Livermore, California 94550

for the United States Department of Energy

under Contract DE-AC04-94AL85000

Approved for public release; distribution is unlimited.

Printed March 1997

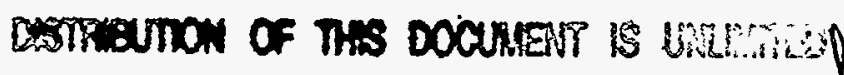

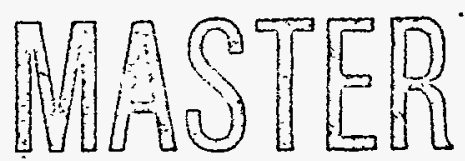


Issued by Sandia National Laboratories, operated for the United States Department of Energy by Sandia Corporation.

NOTICE: This report was prepared as an account of work sponsored by an agency of the United States Government. Neither the United States Government nor any agency thereof, nor any of their employees, nor any of their contractors, subcontractors, or their employees, makes any warranty, express or implied, or assumes any legal liability or responsibility for the accuracy, completeness, or usefulness of any information, apparatus, product, or process disclosed, or represents that its use would not infringe privately owned rights. Reference herein to any specific commercial product, process, or service by trade name, trademark, manufacturer, or otherwise, does not necessarily constitute or imply its endorsement, recommendation, or favoring by the United States Government, any agency thereof, or any of their contractors or subcontractors. The views and opinions expressed herein do not necessarily state or reflect those of the United States Government, any agency thereof, or any of their contractors.

Printed in the United States of America. This report has been reproduced directly from the best available copy.

Available to DOE and DOE contractors from

Office of Scientific and Technical Information

P.O. Box 62

Oak Ridge, TN 37831

Prices available from (615) 576-8401, FTS 626-8401

Available to the public from

National Technical Information Service

U.S. Department of Commerce

5285 Port Royal Rd

Springfield, VA 22161

NTIS price codes

Printed copy: A10

Microfiche copy: A01 


\title{
Hydrogen Generation by Metal Corrosion in Simulated Waste Isolation Pilot Plant Environments
}

\section{FINAL REPORT}

\author{
M. R. Telander and R. E. Westerman \\ Prepared for \\ Sandia National Laboratories \\ Waste Isolation Pilot Plant Gas Generation Program \\ Albuquerque, New Mexico under \\ US Department of Energy Contract DE-AC06-76RLO 1830 \\ by the Pacific Northwest Laboratory \\ Operated for the US Department of Energy \\ by Battelle Memorial Institute
}

\begin{abstract}
The corrosion and gas-generation characteristics of four material types: low-carbon steel (the current waste packaging material for the Waste Isolation Pilot Plant), Cu-base and Ti-base (alternative packaging) materials, and Al-base (simulated waste) materials were determined in both the liquid and vapor phase of Brine A, a brine representative of an intergranular Salado Formation brine. Test environments consisted primarily of anoxic brine with overpressures of $\mathrm{N}_{2}, \mathrm{CO}_{2}, \mathrm{H}_{2} \mathrm{~S}$, and $\mathrm{H}_{2}$. Limited tests of low-carbon steel were also performed in simulated-backfill environments and in brine environments with $\mathrm{pH}$ values ranging from 3 to 11. Low-carbon steel reacted at a slow, measurable rate with anoxic brine, liberating $\mathrm{H}_{2}$ on an equimolar basis with $\mathrm{Fe}$ reacted. Presence of $\mathrm{CO}_{2}$ caused the initial reaction to proceed more rapidly, but $\mathrm{CO}_{2}$-induced passivation stopped the reaction if the $\mathrm{CO}_{2}$ were present in sufficient quantities. Addition of $\mathrm{H}_{2} \mathrm{~S}$ to a $\mathrm{CO}_{2}$-passivated system caused reversal of the passivation. Low-carbon steel immersed in brine with $\mathrm{H}_{2} \mathrm{~S}$ showed no reaction, apparently because of passivation of the steel by formation of FeS. Addition of $\mathrm{CO}_{2}$ to an $\mathrm{H}_{2} \mathrm{~S}$-passivated system did not reverse the passivation. $\mathrm{Cu}$ - and Ti-base materials showed essentially no corrosion when exposed to brine and overpressures of $\mathrm{N}_{2}, \mathrm{CO}_{2}$, and $\mathrm{H}_{2} \mathrm{~S}$ except for the rapid and complete reaction between $\mathrm{Cu}$-base materials and $\mathrm{H}_{2} \mathrm{~S}$. The Al-base materials reacted at approximately the same rate as low-carbon steel when immersed in anoxic Brine A; considerably more rapidly in the presence of $\mathrm{CO}_{2}$ or $\mathrm{H}_{2} \mathrm{~S}$; and much more rapidly when iron was present in the system as a brine contaminant. High-purity $\mathrm{Al}$ was much more susceptible to corrosion than the 6061 alloy. No significant reaction took place on any material in any environment in the vapor-phase exposures.
\end{abstract}




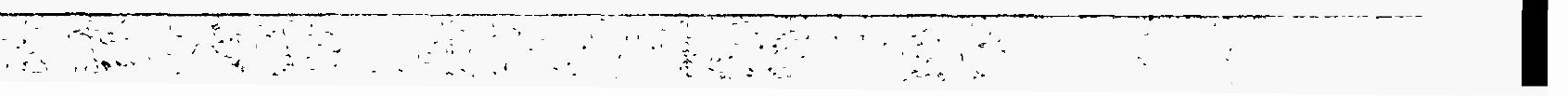




\section{ACKNOWLEDGMENTS}

The authors acknowledge the excellent programmatic guidance of the present work provided by Drs. L. H. Brush and M. A. Molecke, Sandia National Laboratories; the technical assistance of D. J. Criswell, S. M. Faber, R. F. Klein, S. P. Pednekar, N. D. Stice, and R. B. Watson, PNL, in the performance of the experimental work; the contributions of K. H. Pool, PNL, and his analytical laboratory staff, for makeup. and analysis of the test brines as well as valuable insights into the chemistry of the test environments; D. E. McCready, PNL, for his skill and dedication in performing XRD analyses; R. E. Brinson and M. W. Goheen, PNL, for their cooperation in performing the many gas analyses required; B. L. Hopkins, Westinghouse Hanford Corporation, for performing the He leak checks of the test containers; and B. O. Barnes, for his assistance with the Quality Assurance (QA) aspects of the program. 


\section{CONTENTS}

EXECUTIVE SUMMARY ES-1

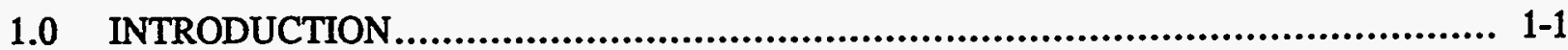

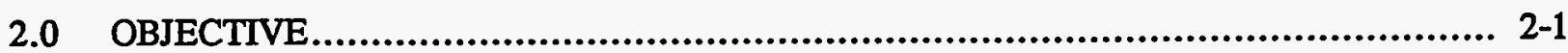

3.0 SCOPE OF WORK .................................................................... $3-1$

4.0 TECHNICAL BACKGROUND ....................................................... 4-1

4.1 Al-Base Materials: Mechanistic Considerations ..................................... 4-1

4.2 Al-Base Materials: Thermodynamic Considerations.................................... 4-3

4.3 Al-Base Materials: Kinetic Considerations .......................................... 4-5

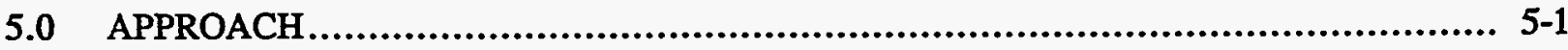

5.1 Testing Methods ................................................................ $5-1$

5.1.1 Seal-Welded-Container Test Method........................................... 5-1

5.1.2 Autoclave Test Method ....................................................... 5-5

5.1.3 Constant-pH Test Method .................................................... 5-5

5.2 Materials ................................................................................. $5-7$

5.2.1 Low-Carbon Steels ............................................................ 5-7

5.2.2 Alternative Packaging Materials ................................................ 5-9

5.2 .3 Al-Base Materials ............................................................ 5-10

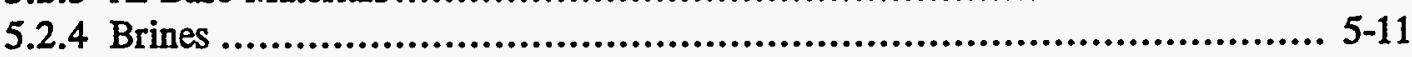

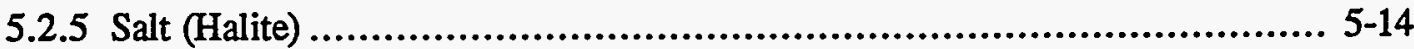

5.2 .6 Bentonite................................................................... 5-14

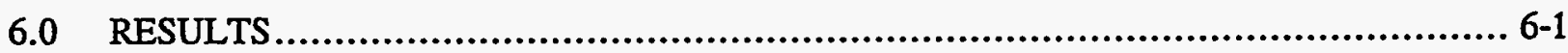

6.1 Low-Carbon Steel Tests ........................................................... 6-2

6.1.1 Seal-Welded-Container Tests ................................................. 6-3

6.1.1.1 Anoxic Brine (Brine $\left./ \mathrm{N}_{2}\right)$ Tests .......................................... 6-3

6.1.1.2 Brine $/ \mathrm{CO}_{2}$ Tests ......................................................... 6-7

6.1.1.3 Brine/ $\mathrm{H}_{2} \mathrm{~S}$ Tests (With Eventual $\mathrm{CO}_{2}$ Addition) ...................... 6-18

6.1.1.4 Anoxic ERDA-6 Brine (ERDA-6 Brine/ $\mathrm{N}_{2}$ ) Tests.................... 6-22 


\section{DISCLAMMER}

Portions of this document may be illegible in electronic image products. Images are produced from the best available original document. 


\section{CONTENTS (Continued)}

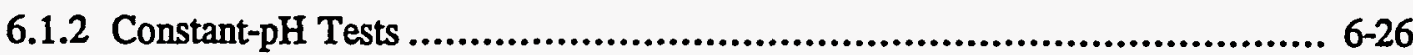

6.1.2.1 Measurement of $\mathrm{pH}$ in Brines ....................................... 6-29

6.1.2.2 Test Results ......................................................... 6-32

6.1.3 High-Pressure Autoclave Tests..................................................... 6-35

6.1.3.1 High $\mathrm{H}_{2}$ Pressure Tests .................................................. 6-35

6.1.3.2 High $\mathrm{N}_{2}$ Pressure Tests ................................................ 6-37

6.1.3.3 High $\mathrm{CO}_{2}$ Pressure Tests ............................................. 6-38

6.1.4 Simulated-Backfill Autoclave Tests ................................................. 6-38

6.1.4.1 Test AUT-12 .......................................................... 6-41

6.1 .4 .2 Test AUT-13 ...................................................... $6-42$

6.2 Alternative Packaging Material Tests ..................................................... 6-44

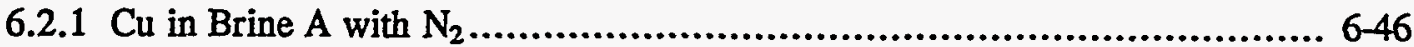

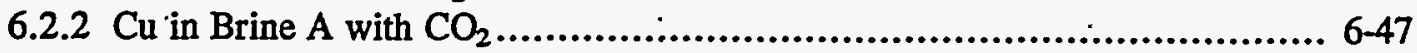

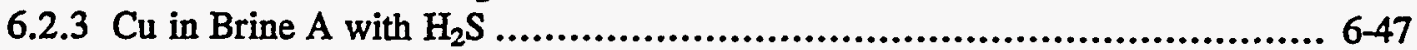

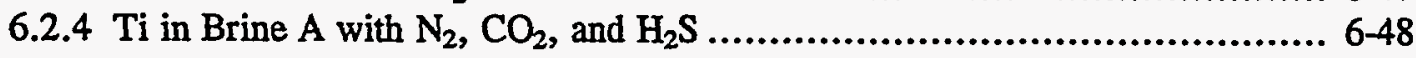

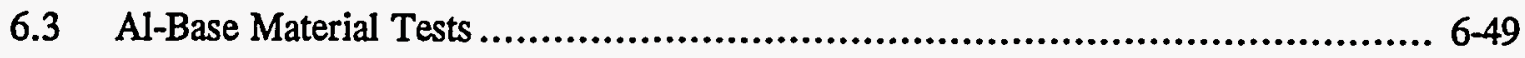

6.3.1 Anoxic Brine $\left(\right.$ Brine $\left./ \mathrm{N}_{2}\right)$ Tests ................................................. 6-50

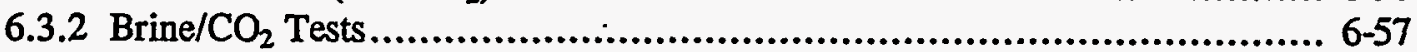

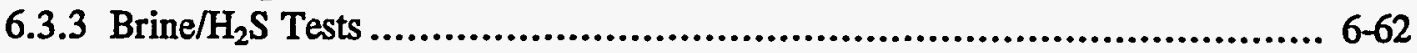

6.3.4 Summary of Corrosion Rates of Al-Base Materials ................................ 6-64

6.3.5 Analysis of Corrosion Products of Al-Base Materials ............................... 6-68

6.3.6 Corrosion of Steel in the Presence of Al-Base Materials............................. 6-71

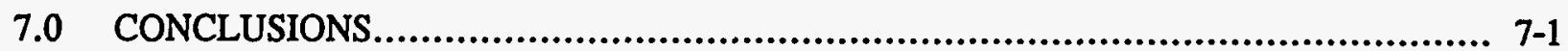

7.1 Steel with $\mathrm{N}_{2}$ Overpressure ................................................................ 7-1

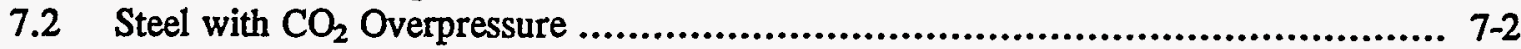

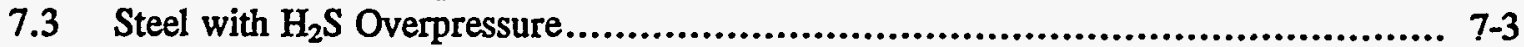

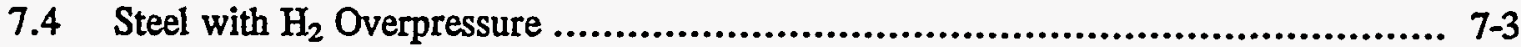

7.5 Alternative Packaging Materials.............................................................. 7-4

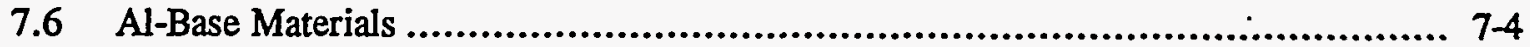

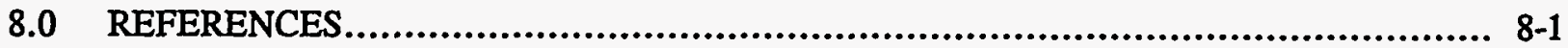

, $\quad$ V 


\section{CONTENTS (Continued)}

APPENDIX A-1: PRESSURE HISTORIES, TESTS OF LOW-CARBON STEEL IN BRINE A WITH CONTROLLED $\mathrm{CO}_{2}$ (AND EVENTUAL $\mathrm{H}_{2} \mathrm{~S}$ ) ADDITIONS, SEAL-WELDED CONTAINER TEST METHOD

APPENDIX A-2: PRESSURE HISTORIES, TESTS OF LOW-CARBON-STEEL IN BRINE A WITH $\mathrm{H}_{2} \mathrm{~S}$ (AND EVENTUAL $\mathrm{CO}_{2}$ ) ADDITIONS, SEAL-WELDED CONTAINER TEST METHOD

APPENDIX A-3: PRESSURE HISTORIES, TESTS OF LOW-CARBON STEEL IN MODIFIED ERDA-6 BRINE WITH $\mathrm{N}_{2}$, SEAL-WELDED CONTAINER TEST METHOD A-6

APPENDIX A-4: PRESSURE HISTORIES, TESTS OF AI-BASE MATERIALS $(99.99 \%$ Al AND 6061 ALLOY) IMMERSED IN BRINE A AND IN VAPOR PHASE OF BRINE A, WITH $\mathrm{N}_{2}, \mathrm{CO}_{2}$, AND $\mathrm{H}_{2} \mathrm{~S}$, SEAL-WELDED CONTAINER TEST METHOD A-8

APPENDIX B-1: INDIVIDUAL SPECIMEN DATA, TESTS OF LOW-CARBON STEEL IN BRINE A WITH CONTROLLED $\mathrm{CO}_{2}$ (AND EVENTUAL $\mathrm{H}_{2} \mathrm{~S}$ ) ADDITIONS, SEAL-WELDED CONTAINER TEST METHOD B-1

APPENDIX B-2: INDIVIDUAL SPECIMEN CORROSION-RATE DATA, TESTS OF LOW-CARBON STEEL IN BRINE A WITH $\mathrm{H}_{2} \mathrm{~S}$ (AND EVENTUAL $\mathrm{CO}_{2}$ ) ADDITIONS, SEAL-WELDED CONTAINER TEST METHOD B-8

APPENDIX B-3: INDIVIDUAL SPECIMEN CORROSION-RATE DATA, TESTS OF LOW-CARBON STEEL IN MODIFIED ERDA-6 BRINE WITH $\mathrm{N}_{2}$, SEAL-WELDED CONTAINER TEST METHOD

APPENDIX B-4: INDIVIDUAL SPECIMEN CORROSION-RATE DATA, TESTS OF LOW-CARBON STEEL IN MODIFIED ERDA-6 BRINE UNDER CONSTANT-pH CONDITIONS B-16

APPENDIX B-5: INDIVIDUAL SPECIMEN CORROSION-RATE DATA, TESTS OF LOW-CARBON STEEL IN BRINE A UNDER HIGH $\mathrm{H}_{2}$ PRESSURES, AUTOCLAVE TEST METHOD B-19

APPENDIX B-6: INDIVIDUAL SPECIMEN CORROSION-RATE DATA, TESTS OF LOW-CARBON STEEL IN BRINE A UNDER HIGH $\mathrm{N}_{2}$ PRESSURES, AUTOCLAVE TEST METHOD B-21 


\section{CONTENTS (Continued)}

APPENDIX B-7: INDIVIDUAL SPECIMEN CORROSION-RATE DATA, TESTS OF LOW-CARBON STEEL IN BRINE A UNDER HIGH $\mathrm{CO}_{2}$ PRESSURES, AUTOCLAVE TEST METHOD

APPENDIX B-8: INDIVIDUAL SPECIMEN CORROSION-RATE DATA, TESTS OF LOW-CARBON STEEL EMBEDDED IN SIMULATED BENTONITESALT BACKFILL CONTACTING BRINE A

APPENDIX B-9: INDIVIDUAL SPECIMEN CORROSION-RATE DATA, TESTS OF LOW-CARBON STEEL EMBEDDED IN SIMULATED BENTONITESALT BACKFILL SUSPENDED IN VAPOR PHASE OF BRINE A B-28

APPENDIX B-10: INDIVIDUAL SPECIMEN DATA, TESTS OF ALTERNATIVE PACKAGING MATERIALS (Cu- AND Ti-BASE MATERIALS) IMMERSED IN BRINE A, SEAL-WELDED CONTAINER TEST METHOD B-30

APPENDIX B-11: INDIVIDUAL SPECIMEN DATA, TESTS OF ALUMINUM-BASE MATERIALS (99.99\% Al AND 6061 ALLOY) IMMERSED IN BRINE A AND IN VAPOR PHASE OF BRINE A, SEAL-WELDED CONTAINER TEST METHOD B- -43

APPENDIX C: $\quad$ ESTIMATION OF $\mathrm{H}_{2}$ GENERATION RATES RESULTING FROM CORROSION OF Al-BASE MATERIALS IMMERSED IN BRINE A

Figures

5-1. Seal-welded test container with specimen rack in place

5-2. Seal-welded test container, fully charged, ready for placement in oven

6-1. Pressure-time curves, low-carbon steel anoxic brine tests

6-2. Pressure-time curves, low-carbon steel/brine- $\mathrm{CO}_{2}$ tests. 6-10

6-3. Pressure-time curves, controlled- $\mathrm{CO}_{2}$-addition tests $6-12$

6-4. Pressure-time curves, low-carbon steel/ $/ \mathrm{H}_{2} \mathrm{~S}$ tests 6-20 


\section{CONTENTS (Continued)}

6-5. Pressure-time curves, containers 44 and 45 , compared with segments of pressure-time curves taken from Figure 6-1

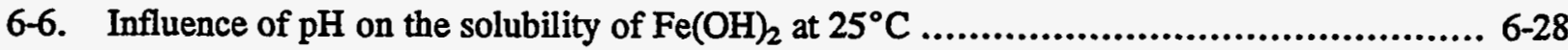

6-7. Test arrangements, tests AUT-12 and AUT-13 ....................................... $6-40$

6-8. Method of mounting specimens on specimen rack for alternative packaging materials tests.

6-9. Method of racking Al-base material specimens for immersed-specimen tests $6-51$

6-10. Pressure-time curves, $\mathrm{Al}$-base materials in anoxic brine (Brine $\left.\mathrm{A} / \mathrm{N}_{2}\right), 30 \pm 5^{\circ} \mathrm{C}$ 6-52

6-11. Post-test appearance of $99.99 \%$ Al specimens from Brine $A / N_{2}$ tests 6-55

6-12. Post-test appearance of 6061 alloy specimens from Brine $A / N_{2}$ tests $6-56$

6-13. Pressure-time curves, Al-base materials in Brine A with $\mathrm{CO}_{2}, 30 \pm 5^{\circ} \mathrm{C}$ 6-58

6-14. Post-test appearance of $99.99 \% \mathrm{Al}$ specimens from $\mathrm{Brine} \mathrm{A} / \mathrm{CO}_{2}$ tests $6-60$

6-15. Post-test appearance of 6061 alloy specimens from Brine $\mathrm{A} / \mathrm{CO}_{2}$ tests 6-61

6-16. Pressure-time curves, Al-base materials in Brine A with $\mathrm{H}_{2} \mathrm{~S}, 30 \pm 5^{\circ} \mathrm{C}$ 6-63

6-17. Post-test appearance of $99.99 \% \mathrm{Al}$ specimens from Brine $\mathrm{A} / \mathrm{H}_{2} \mathrm{~S}$ tests 6-65

6-18. Post-test appearance of 6061 alloy specimens from Brine $\mathrm{A} / \mathrm{H}_{2} \mathrm{~S}$ tests 6-66

\section{Tables}

3-1. Test matrix, low-carbon steel tests using seal-welded test containers

3-2. Test matrix, low-carbon steel tests using high-pressure autoclave systems $3-4$

3-3. Test matrix, tests of low-carbon steel in anoxic ERDA- 6 brine under constant $\mathrm{pH}$ conditions. 


\section{CONTENTS (Continued)}

3-4. Test matrix, alternative packaging materials tests..................................... $3-5$

3-5. Test matrix, tests of Al-base materials using seal-welded test containers ..................... 3-6

5-1. Compositions of low-carbon steels, weight percent.................................... $5-8$

5-2. Composition of alternative packaging materials used in corrosion/gas-generation study ...

5-3. Composition of Al-base materials used in corrosion/gas generation study ..................... 5-11

5-4. Composition of Brine A used in tests.................................................. 5-12

5-5. Composition of ERDA-6 brine used in tests ............................................. 5-13

6-1. Summary of initial test conditions, controlled- $\mathrm{CO}_{2}$-addition tests ........................ $6-11$

$6-2$. Summary of $\mathrm{H}_{2} \mathrm{~S}$ additions to test containers............................................ $6-14$

6-3. Identification by XRD of reaction products formed during "limited- $\mathrm{CO}_{2}$-addition with $\mathrm{H}_{2} \mathrm{~S}$ addition" tests ....................................................................... 6-17

6-4. Composition of gas in plenum of containers $40,41,42$, and 43 at conclusion of test

6-5. Summary of corrosion-rate results, constant-pH tests, based on weight change data ......... 6-33

6-6. Corrosion of low-carbon steels with $\mathrm{H}_{2}$ overpressure .................................... 6-36

6-7. Corrosion of low-carbon steels with $\mathrm{N}_{2}$ overpressure .................................. $6-37$

6-8. Corrosion of low-carbon steels with $\mathrm{CO}_{2}$ overpressure .................................. 6-39

6-9. Average corrosion rates of specimens from test AUT-12 ............................. $6-41$

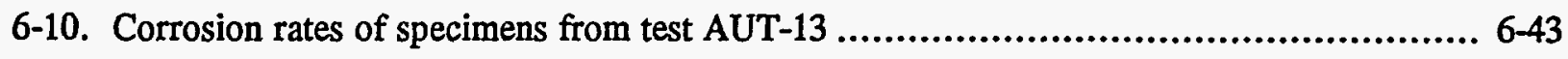

6-11. Initial conditions, alternative packaging material tests $1 \mathrm{~A}$ through $19 \mathrm{~A} \ldots \ldots \ldots \ldots \ldots \ldots \ldots . . . \ldots 66$

6-12. Compositions of gas in test containers at conclusion of 24-month Ti-base material tests 


\section{CONTENTS (Continued)}

6-13. Summary of $\mathrm{H}_{2}$ generation rates, Al-base material tests, 24-month test duration............. 6-67

6-14. Al-base material corrosion products analyzed for crystalline constituents by XRD .......... 6-69

6-15. Penetration of low-carbon-steel specimens in Al-base material corrosion tests................ 6-72 


\section{EXECUTIVE SUMMARY}

A mined geologic repository site for demonstrating the safe management and disposal of defense-related transuranic (TRU) waste is being developed by the US Department of Energy near Carlsbad, New Mexico. The site, designated the Waste Isolation Pilot Plant (WIPP), is located in the bedded salt of the Salado Formation, at a depth of $655 \mathrm{~m}(2150 \mathrm{ft})$ below the land surface.

If brine should enter the repository and contact the low-carbon steel waste containers (and metallic items in the waste), the possibility exists that corrosion product $\mathrm{H}_{2}$ could pressurize the facility. The rate of $\mathrm{H}_{2}$ formation and the ultimate $\mathrm{H}_{2}$ pressure attained would be dependent on the amount of brine available, the corrosion products formed, and the kinetics of the specific corrosion reactions involved.

Sandia National Laboratories (SNL), WIPP Gas Generation Program, issued a subcontract to Pacific Northwest Laboratory (PNL) ${ }^{a}$ authorizing the performance of laboratory experiments to assist in resolving the gas generation and performance assessment-related questions. The present report summarizes the laboratory corrosion results obtained through the program conclusion.

The experimental work focused on the corrosion/gas generation characteristics of four material types: low-carbon steel (the current packaging material), Cu-base materials, Ti-base materials, and Al-base materials. The $\mathrm{Cu}$ - and Ti-base materials are considered to be alternative packaging materials should low-carbon steels prove unusable. The Al-base materials were intended to represent metallic $\mathrm{Al}$ and $\mathrm{Al}$ alloys present in the waste. Four basic test environments were used in the tests: Brine A (a $\mathrm{Na}, \mathrm{Mg}, \mathrm{K}$ chloride-sulfate brine simulating a WIPP intergranular Salado Formation brine) with an $\mathrm{N}_{2}$ overpressure; Brine A with a $\mathrm{CO}_{2}$ overpressure; Brine A with an $\mathrm{H}_{2} \mathrm{~S}$ overpressure; and Brine $\mathrm{A}$ with an $\mathrm{H}_{2}$ overpressure. Test specimens were exposed to the test environments in the entirely immersed condition as well as the vapor-phase-only condition.

Limited testing was done with steel specimens embedded in nearly pure particulate halite $(\mathrm{NaCl})$ obtained from the WIPP site, and in a simulated backfill material consisting of a mixture of $70 \%$ halite and $30 \%$ bentonite. In addition, tests of low-carbon steel were performed in simulated modified ERDA- 6 brine environments with $\mathrm{pH}$ values ranging from $\mathrm{pH} 3$ to $\mathrm{pH} 11$. All testing was done at $30^{\circ} \mathrm{C}$. The experimental work involved a determination of the rate at which pressure $\left(\mathrm{H}_{2}\right.$ gas) builds in test containers; the gravimetric determination of the metal lost from the test specimens because of the corrosion reaction; correlation between $\mathrm{H}_{2}$ formed and metal reacted, where possible; identification of the corrosion products formed; and post-test determination of the compositions of gases and brines in the test containers.

It was shown that the long-term (last 12 months of 24-month corrosion tests) corrosion rate of steel in anoxic Brine A with a 10 -atm overpressure of $\mathrm{N}_{2}$ is $0.71 \mu \mathrm{m} / \mathrm{yr},{ }^{b}$ producing $0.10 \mathrm{~mol} \mathrm{H} / \mathrm{m}^{2}$ -

a Pacific Northwest Laboratory is operated by Battelle Memorial Institute for the US Department of Energy under Contract DE-AC06-76RLO 1830.

b A corrosion rate (or "penetration rate") expressed in $\mu \mathrm{m} / \mathrm{yr}$ may be converted to mil/yr (mpy) by dividing by 25.4 . 
steel-yr. The corrosion product was not adherent and was not identifiable by $\mathrm{x}$-ray diffraction analysis (XRD); its principal metallic constituents were $\mathrm{Fe}$ and $\mathrm{Mg}$. The long-term corrosion rate was approximately linear, but the rate is expected to continually decrease with time.

The effect of gas pressure on reaction kinetics of low-carbon steel in Brine $\mathbf{A}$ was determined for $\mathrm{H}_{2}, \mathrm{~N}_{2}$, and $\mathrm{CO}_{2}$ over the range 2 to $127 \mathrm{~atm}$ for $\mathrm{H}_{2}, 10$ to $131 \mathrm{~atm}$ for $\mathrm{N}_{2}$, and 10 to $62 \mathrm{~atm}$ for $\mathrm{CO}_{2}$. Increasing the pressure of $\mathrm{H}_{2}$ from 2 to $127 \mathrm{~atm}$ had little effect on the corrosion rate observed. Increasing the pressure of $\mathrm{N}_{2}$ from 10 to $131 \mathrm{~atm}$ increased the corrosion rate, but by less than a factor of 2. A dichotomy existed in the case of $\mathrm{CO}_{2}$ overpressures, in that increasing the gas overpressure increased the initial corrosion rate and also increased the probability of passivation due to the formation of an impermeable corrosion product film $\left(\mathrm{FeCO}_{3}\right.$ or a close crystallographic relative).

In the low-carbon steel corrosion studies, the molar equivalency between Fe reacted and $\mathrm{H}_{2}$ formed was satisfactory in both the $\mathrm{N}_{2}$ /immersed and the $\mathrm{CO}_{2} /$ immersed tests. Steel exposed to the vapor phase over Brine $A$ only, with either $\mathrm{N}_{2}$ or $\mathrm{CO}_{2}$ present, showed essentially no evidence of corrosion.

Steel specimens exposed to an $\mathrm{H}_{2} \mathrm{~S}$ pressure of $5 \mathrm{~atm}$, either immersed in Brine A or suspended in Brine A vapor, showed essentially no reaction. The lack of reaction of the immersed specimens was attributed to the passivating effect of a layer of mackinawite (FeS) on the specimen surfaces.

Tests were conducted to determine the effect of $\mathrm{pH}$ on the corrosion/gas generation behavior of low-carbon steel in a saturated anoxic brine. A modified ERDA- 6 brine (a Na, $\mathrm{K}$ chloride-sulfate brine) was used in the tests. The $\mathrm{pH}$ was controlled at levels of (approximately) 3, 5, 7,9 and 11 by means of $\mathrm{pH}$-stats. The corrosion rates were lowest at the highest $\mathrm{pH}$ levels. At $\mathrm{pH} 3$ the average rate

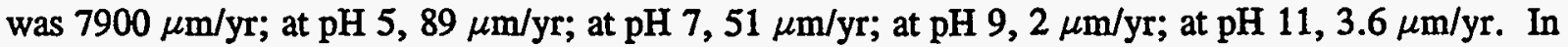
separate seal-welded container tests with no $\mathrm{pH}$ adjustment, the corrosiveness of ERDA- 6 brine and Brine A were observed to be comparable.

Limited anoxic corrosion studies were performed in which steel specimens were embedded in particulate salt (halite) that had been obtained from the Salado Formation in the WIPP underground workings. The particulate salt was either (a) contacting a pool of Brine A in a test autoclave (a "wicking" test) or (b) suspended above the Brine A (an attempt to form a "vapor transport" test). The corrosion rates observed in the former test were similar to those observed in tests in which steel specimens were immersed in Brine $A$ with a $\mathrm{N}_{2}$ overpressure. In the latter test, the intended vapor-transport process was compromised by an unexpected condensation-drip process from the underside of the autoclave head. The corrosion rates were relatively low, because of (a) lack of reactant $\mathrm{H}_{2} \mathrm{O}$, or (b) the low-Mg test environment resulting from the condensed $-\mathrm{H}_{2} \mathrm{O}$ drip.

In two autoclave experiments similar to those just described, steel specimens were embedded in a simulated backfill medium consisting of $70 \%$ halite and $30 \%$ bentonite. Precautions were taken in these tests to prevent condensation from dripping on the mass of simulated backfill. Specimens embedded in backfill contacting the brine (a "wicking" test) showed corrosion rates higher by a factor of -2 than specimens exposed to anoxic brine alone. Specimens embedded in simulated backfill exposed to the vapor phase only showed an average corrosion rate $-1 / 3$ that expected from immersion in anoxic brine. 
Alternative packaging materials (Cu-base and Ti-base alloys) showed essentially no corrosion when exposed to environments of Brine $A$ and overpressures of $\mathrm{N}_{2}, \mathrm{CO}_{2}$, and $\mathrm{H}_{2} \mathrm{~S}$, except for the rapid and complete reaction between immersed specimens of $\mathrm{Cu}$-base materials and $\mathrm{H}_{2} \mathrm{~S}$. The alternative packaging materials showed essentially no evidence of reaction when exposed to the overpressure gas and Brine A vapor. Cu-base materials would appear to be a poor choice for use in the WIPP repository if $\mathrm{H}_{2} \mathrm{~S}$ is expected to be present in the environment, for example, through generation by microbial sulfate-reduction processes. It appears as though Ti-base materials could be used without concern for significant gas production.

There is a concern that Al-base-material scrap contained in the TRU waste could react with brine and generate $\mathrm{H}_{2}$. The corrosion/gas-generation rates of two Al-base materials, high-purity (99.99\%) $\mathrm{Al}$ and 6061 alloy, were therefore investigated in Brine $\mathrm{A}$ with $\mathrm{N}_{2}, \mathrm{CO}_{2}$, and $\mathrm{H}_{2} \mathrm{~S}$ overpressures for time periods up to 24 months. In anoxic brine (brine/ $\mathrm{N}_{2}$ test), the corrosion rates of the Al-base materials approximated the corrosion rate of low-carbon steel. The corrosion rate of $99.99 \%$ $\mathrm{Al}$ was estimated to be twice that of the 6061 alloy. With $\mathrm{CO}_{2}$ or $\mathrm{H}_{2} \mathrm{~S}$ present, the corrosion rates of the Al-base materials increased to approximately 10 times that observed in the brine/ $\mathrm{N}_{2}$ test, with the corrosion rate of $99.99 \% \mathrm{Al}$ material ranging from about equal to that of the 6061 alloy $\left(\mathrm{CO}_{2}\right)$ to about four times that of the 6061 alloy $\left(\mathrm{H}_{2} \mathrm{~S}\right)$. With Fe present in solution, the corrosion rate in all tests escalated dramatically, to about 30 times that of the brine/ $\mathrm{N}_{2}$ test. The relatively high corrosion rates with $\mathrm{CO}_{2}$ and $\mathrm{H}_{2} \mathrm{~S}$ present are ascribed to a lower system $\mathrm{pH}$. The high rates with $\mathrm{Fe}$ present are ascribed to the deposition of $\mathrm{Fe}$ on the Al-base-material surface, where it can function as a cathode in electrolytic corrosion cells. Corrosion was, in general, highly nonuniform, and evidence was present of crevice-corrosion tendencies.

Steel specimens included in the Al-base-material corrosion tests (to serve as a source of $\mathrm{Fe}^{++}$) were examined to determine their corrosion rates in the corroding Al environments. Their corrosion rates were relatively high for the first 13 months of exposure, suggesting strong $\mathrm{Fe}^{++}$ion scavenging by the corroding Al-base materials, but essentially nil in all cases for the final 11 months of exposure. The precise reason for this is not known, but a relatively corrosion-resistant film could either form on (through corrosion reactions), or be deposited on, the steel specimen surfaces, effectively halting further reaction. 
This page intentionally left blank. 


\subsection{INTRODUCTION}

A mined geologic repository for demonstrating the safe management and disposal of defenserelated transuranic (TRU) waste is being developed by the US Department of Energy near Carlsbad, New Mexico. The site, designated the Waste Isolation Pilot Plant (WIPP), is located in the bedded salt of the Salado Formation, at a depth of $655 \mathrm{~m}(2150 \mathrm{ft})$ below the land surface. Eight storage panels of seven rooms each will be mined. The panels, access ways, and shafts will be sealed before the site is decommissioned.

At the present time, a large quantity of transuranic (TRU) wastes are being temporarily stored in steel drums and steel waste boxes at waste generator sites. Under current plans, these wastes would be transported to and emplaced within the WIPP site without additional modification of the original packaging. Additional metal pieces (Fe- and Al-base alloys, for example) are contained within the waste containers as contaminated waste materials.

A number of scenarios have been advanced whereby brine could intrude into the repository (Guzowski, 1990). Should brine contact the metallic waste containers (and certain of the metallic wastes within the containers), anoxic corrosion product $\mathrm{H}_{2}$ would be expected to form (Lappin et al., 1989, Brush et al., 1991, Brush et al., 1992, Brush, 1990). The amount of $\mathrm{H}_{2}$ and the ultimate $\mathrm{H}_{2}$ pressure attained would be dependent on the amount of brine available for reaction, the corrosion products formed, and the kinetics of the corrosion reactions involved. The effect of microbes in the brine/waste repository environment and the possible formation of $\mathrm{CO}_{2}$ and/or $\mathrm{H}_{2} \mathrm{~S}$ by microbial activity have also been cited as being potentially important gas-generation processes.

Butcher (1990) has discussed the potential negative effects of gas pressure on the WIPP site. This pressure will tend to retard room closure; it can contribute to fractures within the disturbed rock zone; it has the potential of leaking from the site, possibly causing perceptual, technical, or regulatory concerns; it can contribute to two-phase gas-driven flow from the repository; and it could possibly degrade the repository sealing system.

The site-pressurization concerns led to a selection of alternative container materials; that is, materials that would not be expected to generate significant quantities of gas in the WIPP repository environment. A Waste Container Materials Panel was convened by the WIPP Project in 1990 (EATF, 1991) to make a preliminary selection of alternative packaging materials. Of the metallic 
container materials considered, copper-base and titanium-base alloys were judged to offer the best combination of properties when fabricability, availability, technology status, cost, and gas-generation potential were taken into account. Though no programmatic decision has yet been made regarding the use of these alternative materials, verification of their corrosion and gas-generating characteristics has been considered to be an important task in support of the WIPP Project so that their use could be invoked if deemed necessary.

Past studies have not permitted an unambiguous resolution of the WIPP gas generation and repository pressurization question, because of 1) use of test temperatures different from those expected in WIPP disposal rooms, 2) inadequate test durations, 3) inadequate backpressure of corrosion product gases, and 4) an inadequate simulation of the brine chemistry specific to the WIPP site. For these reasons, the Sandia National Laboratories (SNL) WIPP Gas Generation Program, on behalf of the WIPP Project, issued a subcontract to Pacific Northwest Laboratory (PNL) authorizing the performance of laboratory experiments to assist in resolving the gas-generation question as it relates to corrosion of low-carbon steel, alternative packaging materials, and Al-base materials.

This final project report summarizes all available results obtained since the receipt of work authorization at PNL in November 1989 through the end of the experimental and data analysis portions of the project (September 30, 1995). The initial results, obtained from the project inception through December 1992, were reported in the progress report Telander and Westerman (1993). The present final report does not duplicate all of the data and all of the data analyses reported in the earlier progress report. However, data obtained from experimental work that is considered to be closely related to experiments concluded since December 1992, as well as all of the technical conclusions drawn from the earlier work, are reported herein for completeness. Because of the many references required to the earlier progress report in the present work, the earlier report will be simply referred to as "SAND92-7347," rather than the relatively indirect "Telander and Westerman 1993." 


\subsection{OBJECTIVE}

The objective of the present WIPP-PNL project is to determine the rate of hydrogen generation and the hydrogen pressurization potential associated with the reaction of steel drum and waste box materials, alternative packaging materials, and metal wastes contained in drums and waste boxes with simulated, repository-relevant WIPP environments. 
This page intentionally left blank. 


\subsection{SCOPE OF WORK}

The initial (and major) effort in the present project was directed toward characterizing the behavior of low-carbon steels in simulated WIPP environments: namely, environments consisting of liquid Brine $A$ or water vapor in equilibrium with Brine $A$, with overpressures of $\mathrm{N}_{2}, \mathrm{CO}_{2}, \mathrm{H}_{2}$, or $\mathrm{H}_{2} \mathrm{~S}$ gas. Four lots (heats) of steel were included in the tests: two lots of ASTM A366, representative of 55-gallon steel waste drums, and two lots of ASTM A570, representative of steel waste boxes and steel waste components. The $\mathrm{N}_{2}$ overpressure was used in the anoxic test environments in which only the brine constituents were to react with the metal specimens. Because microbial degradation activity on organic-matrix waste materials isolated in the WIPP repository may produce significant quantities of $\mathrm{CO}_{2}$ and $\mathrm{H}_{2} \mathrm{~S}$, these species were included in selected tests. The test matrices describing the gas-generation studies performed involving low-carbon steels are presented in Tables 3-1, 3-2, and 3-3. As shown in Table 3-2, the original studies were extended to include tests with environments of halite obtained from the WIPP site, and environments of simulated backfill material $(70 \%$ halite, 30\% bentonite). Also, as shown in Table 3-3, the low-carbon steel tests were extended to include the effects of $\mathrm{pH}$ on the corrosion and gas generation rate. Discussions of specific low-carbon-steel tests and test results in the present report will be keyed to these matrices by test environment and container (test) identification.

The scope of work of the present study was extended beyond low-carbon-steel studies in 1991 to include an assessment of the anoxic corrosion and gas-generation behavior of four alternative WIPP metal packaging materials. These materials are unalloyed copper, cupronickel 90-10, Ti Grade 2 (a grade of commercial-purity Ti), and Ti Grade 12 (a crevice-corrosion-resistant Ti-base alloy containing $0.7-0.9 \% \mathrm{Ni}$ and $0.2-0.4 \% \mathrm{Mo}$ ). As in the case of the low-carbon-steel studies, the corrosion rates of these materials was investigated in brine environments with overpressures of $\mathrm{N}_{2}, \mathrm{CO}_{2}$, and $\mathrm{H}_{2} \mathrm{~S}$. The test matrix describing the gas-generation studies performed on alternative materials is presented in Table 3-4.

Concern regarding the possible generation of $\mathrm{H}_{2}$ gas by Al-base materials contained in the packaged waste led to the initiation in 1993 of a study of the corrosion and gas-generating characteristics of Al-base materials. Specimens of both high-purity $\mathrm{Al}$ and $6061 \mathrm{Al}$ alloy were 
exposed to Brine A with overpressures of $\mathrm{N}_{2}, \mathrm{CO}_{2}$, and $\mathrm{H}_{2} \mathrm{~S}$. In selected tests specimens of steel were present in the brine, for purposeful introduction of $\mathrm{Fe}^{++}$ion contamination. The test matrix for these tests is shown in Table 3-5.

Throughout this report, "psig" refers to psi gauge and "psia" refers to psi absolute, where psig +14.7 is equivalent to psia. The term "atm" always refers to atmospheres pressure absolute. In describing pressure differences "psi" is used.

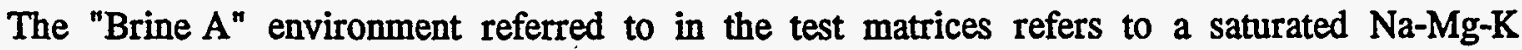
chloride-sulfate brine intended to simulate intergranular Salado Formation brines at or near the stratigraphic horizon of the WIPP repository. The "ERDA-6" environment referred to in Tables 3.1 and 3.2 is a modification of a brine originally found in a brine pocket within the boundaries of the WIPP site (Molecke, 1983). The chemistry of the original brine was modified by eliminating its $\mathrm{Ca}^{++}, \mathrm{Mg}^{++}$, and $\mathrm{HCO}_{3}^{-}$constituents, making it essentially a saturated Na-K chloride-sulfate brine. Throughout this document, the terms "Brine $A^{\text {" }}$ or "ERDA- 6 brine" refer to laboratory-simulated brines, not brines obtained from the WIPP site. The brines are discussed in detail in Section 5.2.4 of this report. 
Table 3-1. Test Matrix, Low-Carbon Steel Tests Using Seal-Welded Test Containers. Pressures given in table are approximate. Test temperature $=30 \pm 5^{\circ} \mathrm{C}$.

\begin{tabular}{|c|c|c|c|c|c|c|c|}
\hline \multirow[b]{2}{*}{ Test Type } & \multirow{2}{*}{$\begin{array}{l}\text { Overpres- } \\
\text { sure Gas }\end{array}$} & \multirow{2}{*}{$\begin{array}{l}\text { Container } \\
\text { (or Test) } \\
\text { Identification }\end{array}$} & \multicolumn{2}{|c|}{$\begin{array}{c}\text { Test Time, } \\
\text { Months }\end{array}$} & \multirow{2}{*}{$\begin{array}{l}\text { Initial Gas } \\
\text { Overpressure } \\
\text { or Amount }\end{array}$} & \multirow{2}{*}{$\begin{array}{l}\text { Stecl Lots } \\
\text { in Test }\end{array}$} & \multirow[b]{2}{*}{-Remarks } \\
\hline & & & Aim & Actusal & & & \\
\hline \multirow[t]{6}{*}{$\begin{array}{l}\text { Specimens } \\
\text { immersed in } \\
\text { Brine A }\end{array}$} & \multirow[t]{2}{*}{$\mathbf{N}_{2}$} & $\begin{array}{r}1,2 \\
9,10 \\
17,18 \\
25,26\end{array}$ & $\begin{array}{r}3 \\
6 \\
12 \\
24\end{array}$ & $\begin{array}{r}3 \\
6 \\
12 \\
24\end{array}$ & \multirow[t]{2}{*}{10 atm } & \multirow[t]{11}{*}{$\mathbf{J}, \mathbf{K}, \mathbf{L}, \mathbf{M}$} & Results described in SAND92-7347 \\
\hline & & 46,47 & 6 & 6 & & & $\begin{array}{l}\text { Purpose of test was to produce corro- } \\
\text { sion product for analysis/identification }\end{array}$ \\
\hline & \multirow[t]{2}{*}{$\mathrm{CO}_{2}$} & $\begin{array}{r}3,4^{b} \\
11, b 12^{b} \\
19, b 20^{b} \\
27, b 28^{b}\end{array}$ & $\begin{array}{r}3 \\
6 \\
12 \\
24\end{array}$ & $\begin{array}{r}3 \\
6 \\
12 \\
24\end{array}$ & $12 \mathrm{~atm}$. & & Results described in SAND92-7347 \\
\hline & & $\begin{array}{r}33 \\
34 \\
35 \\
36 \\
37 \\
38^{c}\end{array}$ & - & 38.5 & $\begin{array}{l}0.32 \mathrm{~mol} / \mathrm{m}^{2} \text { steel } \\
0.16 \mathrm{~mol} / \mathrm{m}^{2} \text { steel } \\
0.063 \mathrm{~mol} / \mathrm{m}^{2} \text { steel } \\
0.032 \mathrm{~mol} / \mathrm{m}^{2} \text { steel } \\
0.016 \mathrm{~mol} / \mathrm{m}^{2} \text { steel } \\
0.00 \mathrm{~mol} / \mathrm{m}^{2} \text { steel }\end{array}$ & & $\begin{array}{l}\text { All tests except Test } 36 \text { had } \mathrm{H}_{2} \mathrm{~S} \\
\text { addition at } 19.2 \text { months }\end{array}$ \\
\hline & \multirow[t]{2}{*}{$\mathrm{H}_{2} \mathrm{~S}$} & $40^{b}$ & - & 14 & \multirow[t]{2}{*}{$5 \mathrm{~atm}$} & & No $\mathrm{CO}_{2}$ addition made \\
\hline & & $41^{b}$ & & 35.3 & & & $\mathrm{CO}_{2}$ addition was made at 16.2 months \\
\hline \multirow[t]{4}{*}{$\begin{array}{l}\text { Specimens in } \\
\text { vapor phase, } \\
\text { Brine A }\end{array}$} & $\mathrm{N}_{2}$ & $\begin{array}{r}5,6 \\
13,14 \\
21,22 \\
29,30\end{array}$ & $\begin{array}{r}3 \\
6 \\
12 \\
24\end{array}$ & $\begin{array}{r}3 \\
6 \\
12 \\
24\end{array}$ & \multirow[t]{2}{*}{10 atm } & & \multirow[t]{2}{*}{ Results described in SAND92-7347 } \\
\hline & $\mathrm{CO}_{2}$ & $\begin{array}{r}7,8 \\
15,16 \\
23,24 \\
31,32\end{array}$ & $\begin{array}{r}3 \\
6 \\
12 \\
24\end{array}$ & $\begin{array}{r}3 \\
6 \\
12 \\
24\end{array}$ & & & \\
\hline & \multirow[t]{2}{*}{$\mathbf{H}_{2} \mathbf{S}$} & 42 & - & 14 & \multirow[t]{2}{*}{$5 \mathrm{~atm}$} & & No $\mathrm{CO}_{2}$ addition made \\
\hline & & 43 & & 35.3 & & & $\mathrm{CO}_{2}$ addition was made at 16.2 months \\
\hline $\begin{array}{l}\text { Specimens } \\
\text { immersed in } \\
\text { ERDA-6 } \\
\text { brine }\end{array}$ & $\mathrm{N}_{2}$ & $\begin{array}{l}44 \\
45\end{array}$ & - & 10 & $10 \mathrm{~atm}$ & & $\begin{array}{l}\text { Purpose of test was to compare corro- } \\
\text { sion rates between Brine } A \text { and } \\
\text { ERDA- } 6 \text { brine environments }\end{array}$ \\
\hline \multicolumn{8}{|c|}{$\begin{array}{l}\mathrm{J}=\text { ASTM A366; } \mathrm{K}=\text { ASTM A366; } \mathrm{L}=\text { ASTM A570; } \mathrm{M}=\text { ASTM A570. } \\
\text { Containers equipped with 300-psig full-range gauges. All other SWC tests equipped with 200-psig full-range gauges. } \\
\text { Part of test series directed toward determining the effect of } \mathrm{CO}_{2} \text {, but contains only } \mathrm{N}_{2} \text { as a control. }\end{array}$} \\
\hline
\end{tabular}


Table 3-2. Test Matrix, Low-Carbon Steel Tests Using High-Pressure Autoclave Systems. Brine $\mathrm{A}$ was used in all tests. Pressures given in table are approximate. Test temperature $=30 \pm 5^{\circ} \mathrm{C}$.

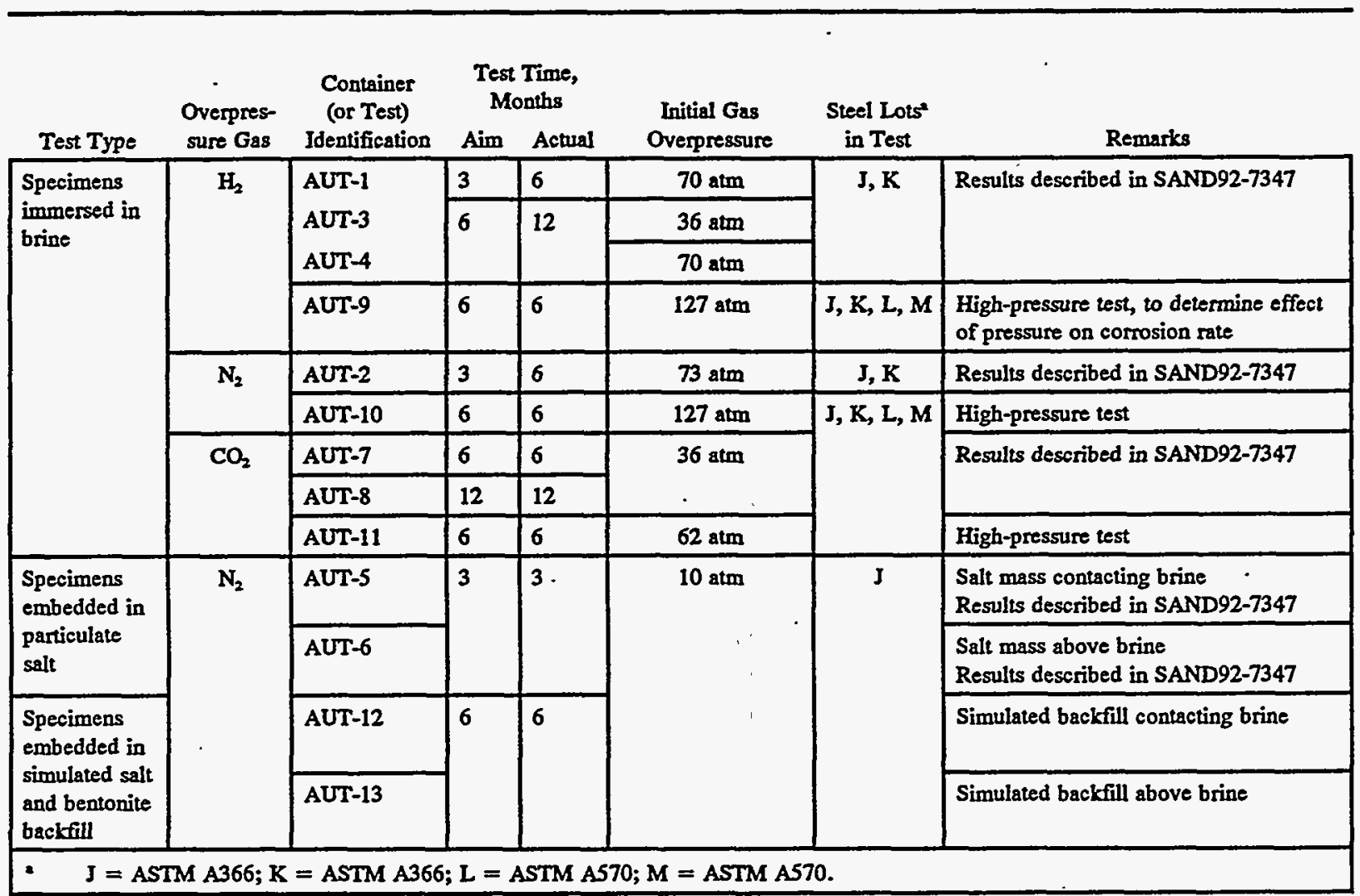

Table 3-3. Test Matrix, Tests of Low-Carbon Steel in Anoxic ERDA-6 Brine Under Constant pH Conditions. Tests were conducted in glass vessels. Specimens were completely immersed. Test temperature $=30 \pm 5^{\circ} \mathrm{C}$.

\begin{tabular}{|c|c|c|c|c|c|}
\hline \multirow[b]{2}{*}{ Materiai } & \multirow{2}{*}{$\begin{array}{l}\text { Overpres- } \\
\text { sure Gas }\end{array}$} & \multicolumn{3}{|c|}{$\begin{array}{c}\text { Test Time, } \\
\text { Months (Days) }\end{array}$} & \multirow[b]{2}{*}{ Remarks } \\
\hline & & pH & Aim & Actual & \\
\hline \multirow{2}{*}{$\begin{array}{l}\text { Low-carbon steel } \\
\text { lots J, K, L, M }\end{array}$} & \multirow[t]{2}{*}{$\mathrm{N}_{2}, 1 \mathrm{~atm}$} & 3 & 6 & (5.6) & Test terminated prematurely because of high corrosion rate \\
\hline & & $\begin{array}{l}5 \\
7 \\
9 \\
11\end{array}$ & $\begin{array}{l}6 \\
6 \\
6 \\
6\end{array}$ & $\begin{array}{l}6 \\
6 \\
6 \\
6\end{array}$ & Tests attained aim test duration \\
\hline
\end{tabular}


Table 3-4. Test Matrix, Alternative Packaging Materials Tests. Specimens immersed in Brine $\mathrm{A}$ in seal-welded test containers. Pressures given in table are approximate. Temperature $=30 \pm 5^{\circ} \mathrm{C}$.

\begin{tabular}{|c|c|c|c|c|c|}
\hline \multirow[b]{2}{*}{ Material } & \multirow{2}{*}{$\begin{array}{l}\text { Overpres- } \\
\text { sure Gas }\end{array}$} & \multirow{2}{*}{$\begin{array}{l}\text { Container } \\
\text { (or Test) } \\
\text { Identification }\end{array}$} & \multicolumn{2}{|c|}{$\begin{array}{l}\text { Test Time, } \\
\text { Months }\end{array}$} & \multirow[b]{2}{*}{ Remarks } \\
\hline & & & Aim & Actual & \\
\hline \multirow{9}{*}{$\begin{array}{l}\text { Copper and } \\
\text { cupronickel } 90-10\end{array}$} & \multirow{3}{*}{$\begin{array}{c}\mathrm{N}_{2} \\
10 \mathrm{~atm}\end{array}$} & $1 \mathrm{~A}$ & 6 & 10 & Results described in SAND92-7347 \\
\hline & & 7A & 12 & 15 & \\
\hline & & $13 \mathrm{~A}$. & 24 & 24 & Long-term test concluded \\
\hline & \multirow{3}{*}{$\begin{array}{c}\mathrm{CO}_{2} \\
10 \mathrm{~atm}\end{array}$} & $2 A$ & 6 & 10 & Results described in SAND92-7347 \\
\hline & & $8 A^{*}$ & 12 & 15 & \\
\hline & & $14 A^{*}$ & 24 & 24 & Long-term test concluded \\
\hline & \multirow{3}{*}{$\begin{array}{l}\mathrm{H}_{2} \mathrm{~S} \\
5 \mathrm{~atm}\end{array}$} & 3A & 6 & 9 & Results described in SAND92-7347 \\
\hline & & $9 A^{*}$ & 12 & 15 & $\begin{array}{l}\mathrm{H}_{2} \text { vented, container re-pressurized with } \\
\mathrm{H}_{2} \mathrm{~S} \text { at } 9 \text { months. Described in } \\
\text { SAND92-7347 }\end{array}$ \\
\hline & & $15 \mathrm{~A}^{\mathrm{a}}$ & 24 & 24 & $\begin{array}{l}\mathrm{H}_{2} \text { vented, container re-pressurized with } \\
\mathrm{H}_{2} \mathrm{~S} \text { at } 9 \text { months. Long-term test } \\
\text { concluded }\end{array}$ \\
\hline \multirow{6}{*}{$\begin{array}{l}\text { Ti Grade } 2 \text { and } \\
\text { Ti Grade } 12\end{array}$} & \multirow{3}{*}{$\begin{array}{c}\mathrm{N}_{2} \\
10 \mathrm{~atm}\end{array}$} & $4 A$ & 6 & 10 & Results described in SAND92-7347 \\
\hline & & $10 \mathrm{~A}$ & 12 & 15 & \\
\hline & & $16 A$ & 24 & 24 & Long-term test concluded \\
\hline & \multirow{3}{*}{$\begin{array}{c}\mathrm{CO}_{2} \\
10 \mathrm{~atm}\end{array}$} & $5 A$ & 6 & 10 & Results described in SAND92-7347 \\
\hline & & $11 \mathrm{~A}$ & 12 & 15 & . \\
\hline & & $17 A^{2}$ & 24 & 24 & Long-term test concluded \\
\hline \multirow[t]{3}{*}{$\cdot$} & \multirow{3}{*}{$\begin{array}{l}\mathrm{H}_{2} \mathrm{~S} \\
5 \mathrm{~atm}\end{array}$} & $6 A$ & 6 & 9 & Results described in SAND92-7347 \\
\hline & & $12 A$ & 12 & 15 & \\
\hline & & $18 A^{2}$ & 24 & 24 & Long-term test concluded \\
\hline None & $\begin{array}{c}\mathrm{H}_{2} \mathrm{~S} \\
5 \mathrm{~atm}\end{array}$ & $19 A$ & Open & 24 & "Control" container \\
\hline
\end{tabular}

- Tests equipped with 300-psig full-range gauges. All others equipped with 200-psig full-range gauges. 
Table 3-5. Test Matrix, Tests of Al-Base Materials Using Seal-Welded Containers. ' Brine A was used in all tests. Pressures given in table are approximate. Temperature $=30 \pm 5^{\circ} \mathrm{C}$.

\begin{tabular}{|c|c|c|c|c|c|c|}
\hline \multirow[b]{2}{*}{ Material } & \multirow[b]{2}{*}{ Test Type } & \multirow{2}{*}{$\begin{array}{l}\text { Overpres- } \\
\text { sure Gas }\end{array}$} & \multirow{2}{*}{$\begin{array}{l}\text { Container } \\
\text { (or Test) } \\
\text { Identification }\end{array}$} & \multicolumn{2}{|c|}{$\begin{array}{l}\text { Test Time, } \\
\text { Months }\end{array}$} & \multirow[b]{2}{*}{ Remarks } \\
\hline & & & & Aim & Actual & \\
\hline \multirow[t]{3}{*}{$\begin{array}{l}99.99 \% \mathrm{Al} \\
6061 \text { Alloy }\end{array}$} & \multirow[t]{6}{*}{$\begin{array}{l}\text { Specimens } \\
\text { immersed } \\
\text { in brine }\end{array}$} & $\begin{array}{c}\mathrm{N}_{2} \\
10 \mathrm{~atm}\end{array}$ & $\begin{array}{r}1 \mathrm{~B} \\
10 \mathrm{~B}^{*} \\
\end{array}$ & $\begin{array}{r}6 \\
12 \\
\end{array}$ & $\begin{array}{l}13 \\
24 \\
\end{array}$ & \multirow{3}{*}{$\begin{array}{l}\text { A decision was made to extend all } \\
\text { Al-base material tests to } 13 \text { and } \\
24 \text { months after the tests had been } \\
\text { initiated }\end{array}$} \\
\hline & & $\begin{array}{c}\mathrm{CO}_{2} \\
10 \mathrm{~atm}\end{array}$ & $\begin{array}{r}2 B \\
11 B^{2}\end{array}$ & $\begin{array}{r}6 \\
12\end{array}$ & $\begin{array}{l}13 \\
24\end{array}$ & \\
\hline & & $\begin{array}{l}\mathrm{H}_{2} \mathrm{~S} \\
5 \mathrm{~atm}\end{array}$ & $\begin{array}{r}3 \mathrm{~B} \\
12 \mathrm{~B}^{*}\end{array}$ & $\begin{array}{r}6 \\
12\end{array}$ & $\begin{array}{l}13 \\
24\end{array}$ & \\
\hline \multirow{3}{*}{$\begin{array}{l}99.99 \% \text { Al } \\
6061 \text { Alloy } \\
\text { Low-carbon steel } \\
\text { (Lot J) }\end{array}$} & & $\begin{array}{c}\mathrm{N}_{2} \\
10 \mathrm{~atm}\end{array}$ & $\begin{array}{r}4 B \\
13 B^{2} \\
\end{array}$ & $\begin{array}{r}6 \\
12 \\
\end{array}$ & $\begin{array}{l}13 \\
24\end{array}$ & \multirow{3}{*}{$\begin{array}{l}\text { Steel specimens were included in these } \\
\text { tests to determine the effect of } \mathrm{Fe} \\
\text { contamination on the corrosion rate of } \\
\text { the Al-base materials }\end{array}$} \\
\hline & & $\begin{array}{c}\mathrm{CO}_{2} \\
10 \mathrm{~atm}\end{array}$ & $\begin{array}{r}5 B \\
14 B^{*}\end{array}$ & $\begin{array}{r}6 \\
12\end{array}$ & $\begin{array}{l}13 \\
24\end{array}$ & \\
\hline & & $\begin{array}{l}\mathrm{H}_{2} \mathrm{~S} \\
5 \mathrm{~atm}\end{array}$ & $\begin{array}{r}6 \mathrm{~B} \\
15 \mathrm{~B}^{*}\end{array}$ & $\begin{array}{r}6 \\
12\end{array}$ & $\begin{array}{l}13 \\
24\end{array}$ & \\
\hline \multirow[t]{3}{*}{$\begin{array}{l}99.99 \% \text { Al } \\
6061 \text { Alloy }\end{array}$} & \multirow{3}{*}{$\begin{array}{l}\text { Specimens } \\
\text { in vapor } \\
\text { phase } \\
\text { over brine }\end{array}$} & $\begin{array}{c}N_{2}, \\
10 \mathrm{~atm}\end{array}$ & $\begin{array}{r}7 \mathrm{~B} \\
16 \mathrm{~B}^{\mathrm{a}}\end{array}$ & $\begin{array}{r}6 \\
12\end{array}$ & $\begin{array}{l}13 \\
24\end{array}$ & \\
\hline & & $\begin{array}{c}\mathrm{CO}_{2} \\
10 \mathrm{~atm}\end{array}$ & $\begin{array}{r}8 B \\
17 B^{2} \\
\end{array}$ & $\begin{array}{r}6 \\
12 \\
\end{array}$ & $\begin{array}{l}13 \\
24 \\
\end{array}$ & \\
\hline & & $\begin{array}{l}\mathrm{H}_{2} \mathrm{~S} \\
5 \mathrm{~atm}\end{array}$ & $\begin{array}{r}9 \mathrm{~B} \\
18 \mathrm{~B}^{\mathrm{a}}\end{array}$ & $\begin{array}{r}6 \\
12\end{array}$ & $\begin{array}{l}13 \\
24\end{array}$ & · \\
\hline $\begin{array}{l}\text { Containers } \\
\text { range gauge }\end{array}$ & pped with & 00-psig full & ange gauges. & other & SWC tes & s were equipped with 200-psig full- \\
\hline
\end{tabular}




\subsection{TECHNICAL BACKGROUND}

The present study focused on the corrosion and gas-generation characteristics of low-carbon steel, Cu-base materials, Ti-base materials, and Al-base materials in simulated WIPP environments consisting of brine with overpressures of $\mathrm{N}_{2}, \mathrm{CO}_{2}, \mathrm{H}_{2}$, and $\mathrm{H}_{2} \mathrm{~S}$. If it is assumed that a significant amount of a given metal is present in a WIPP-relevant environment, gas generation is considered to be of no consequence if 1) thermodynamic considerations preclude the formation of gas pressures higher than the lithostatic pressure at the WIPP repository horizon, or 2) the reaction rate of the metal is so slow that insufficient gas is produced over the life of the repository to cause a concern. A review of the technical literature was made to obtain preliminary insights into the thermodynamics and kinetics of the reactions of low-carbon steels, Cu-base materials, Ti-base materials, and Al-base materials with anoxic chloride brines and brines with $\mathrm{CO}_{2}$ and $\mathrm{H}_{2} \mathrm{~S}$ present. The results of the review of low-carbon steels, Cu-base materials; and Ti-base materials were presented in the prior report, SAND92-7347, and will not be repeated here. However, the Al-base-material corrosion work had not been initiated at the time that report was issued, so a discussion of the behavior of Al-base materials in brine environments was not included in that report. Because of their strong relevance to gas generation within the WIPP repository, the mechanistic considerations, thermodynamic characteristics, and kinetic behavior of Al-base materials in brine environments will be described in the following three subsections of this report.

\subsection{Al-Base Materials: Mechanistic Considerations}

Aluminum is a reactive metal that has a high affinity for oxygen. The metal demonstrates a high degree of corrosion resistance in a wide variety of environments because of the protective character of the oxide film that forms on the metal surface. In this manner aluminum is similar to stainless steels and titanium alloys (Shreir, 1963, Hatch, 1984). Aluminum oxide dissolves in strong acids and alkalis. Such environments cause a loss of protective film and a general dissolution of the metal. Generally, the oxide film is stable over a pH range of 4 to 9 (Hatch, 1984). 
Aluminum alloys have a reasonably high degree of corrosion resistance to chloride brines. This resistance permits their use (for example) in a wide range of seawater applications. When corrosion occurs, it is a pitting-type attack, initiating at weak spots in the oxide film. The localized corrosion resulting is caused by a local electrochemical cell, usually because of the presence of cathodic microconstituents in the metal surface, such as $\mathrm{CuAl}_{2}, \mathrm{FeAl}_{3}$, and Si. The presence of $\mathrm{O}_{2}$ as an electron acceptor at the cathode greatly facilitates pitting corrosion (Hatch, 1984).

It is reported that very high purity $\mathrm{Al}$ is far superior to commercial alloys in regard to resistance to pitting corrosion. Of the commercial alloys, the $5 \mathrm{XXX}$ Series (Al-Mg family) has the best resistance to pitting. In the $6 \mathrm{XXX}$ Series (Al-Mg-Si family) pitting is often observed in conjunction with intergranular corrosion (Hatch, 1984).

A well-known phenomenon frequently contributing to the poor corrosion performance of $\mathrm{Al}$ alloys in a variety of environments (especially environments containing $\mathrm{Cl}^{-}$) involves the deposition of reducible metals onto the surface of the $\mathrm{Al}$ alloy by a replacement reaction, with the subsequent functioning of the deposit as a relatively efficient cathode in a localized electrochemical cell. Ions of the "heavy metals," $\mathrm{Cu}, \mathrm{Co}, \mathrm{Pb}, \mathrm{Ni}, \mathrm{Sn}$, and $\mathrm{Hg}$ are the ones most often cited as being harmful to Al-base alloys (Schweitzer, 1989).

Especially relevant in this regard is the work described by Cook and McGeary (1964). They showed that $\mathrm{Fe}$ is also able to deposit on an Al-alloy substrate from a concentrated chloride brine solution and increase the corrosion rate of the underlying alloy if the solution is anoxic and if the iron present in the solution is in the form of ferrous ion. Ferric ion will not enhance the corrosion rate, even in deaerated neutral brine, because it is present only at extremely low activities as a hydrated ferric oxide. Cook and McGeary suggest that only the most electronegative Al alloys, notably those with a significant $\mathrm{Zn}$ concentration, are able to bring about the deposition of metallic $\mathrm{Fe}$ and the increase in the $\mathrm{Al}$ alloy corrosion rate.

All of the "heavy metals" noted, including Fe, are apt to be found in the waste material in the WIPP site, so the corrosion of Al-base materials might be routinely accelerated in the WIPP site relative to corrosion occurring in brine uncontaminated by Fe. Unfortunately, the corrosion results found in the literature are strictly qualitative in nature, as none of the referenced work attempted to quantify the corrosion enhancement associated with deposition of a heavy metal. However, the ironinduced service failure cited by Cook and McGeary suggests a corrosion rate of an Al-2.5\% $\mathrm{Zn}$ alloy 
of approximately $1.5 \mathrm{~mm} /$ year (0.060 in./year) in a $10 \mathrm{wt} \%$ chloride brine solution. This corrosion rate is estimated to be at least a factor of 100 higher than that which would be expected in the absence of ferrous ion, based on the corrosion of similar alloys in seawater without ferrous ion present (ASM, 1987).

\subsection{Al-Base Materials: Thermodynamic Considerations}

When $\mathrm{Al}$ alloys react with water over a $\mathrm{pH}^{-}$range of approximately 4 to 9 , alumina trihydrate, $\mathrm{Al}_{2} \mathrm{O}_{3} \cdot 3 \mathrm{H}_{2} \mathrm{O}$, is commonly found to be the reaction product (Shreir, 1963, Hatch, 1984). This reaction product, which tends to passivate the $\mathrm{Al}$ alloy surface, forms according to the reaction

$$
2 \mathrm{Al}+6 \mathrm{H}_{2} \mathrm{O}=\mathrm{Al}_{2} \mathrm{O}_{3} \cdot 3 \mathrm{H}_{2} \mathrm{O}+3 \mathrm{H}_{2}
$$

Because of the extremely high reactivity of $\mathrm{Al}$ metal, the reaction strongly tends to the right, with the potential for producing a high equilibrium $\mathrm{H}_{2}$ pressure. If thermodynamic values for the Gibbs free energy formation at $25^{\circ} \mathrm{C}$ are assigned to $\mathrm{H}_{2} \mathrm{O}$ and $\mathrm{Al}_{2} \mathrm{O}_{3} \cdot 3 \mathrm{H}_{2} \mathrm{O}$ (Garrels and Christ, 1965), the following equilibrium constant results:

$$
\frac{\mathrm{f}_{\mathrm{F}_{2}}^{3}}{\mathrm{f}_{\mathrm{H}_{2} \mathrm{O}}^{6}}=3.7 \times 10^{153}
$$

If the fugacity of $\mathrm{H}_{2} \mathrm{O}$ is assigned the value $0.03 \mathrm{~atm}$ (Brush, 1990), then

$$
\mathrm{f}_{\mathrm{H}_{2}}=1 \times 10^{48} \mathrm{~atm}
$$

This equilibrium pressure is obviously much greater than that required to overcome the lithostatic forces operative at the WIPP repository horizon.

The preceding discussion assumed that the corrosion product was $\mathrm{Al}_{2} \mathrm{O}_{3} \cdot 3 \mathrm{H}_{2} \mathrm{O}$. Initial laboratory studies at PNL involving the exposure of Al-base materials to Brine A with overpressures of $\mathrm{N}_{2}$, 
$\mathrm{CO}_{2}$, and $\mathrm{H}_{2} \mathrm{~S}$ have shown that the situation is much more complex, and that a wide range of corrosion products are formed when Al-base materials contact anoxic chloride brines. Some, but not all, of the corrosion products in the PNL studies were identifiable by XRD ( $x$-ray diffraction analysis). In no case was alumina trihydrate the corrosion product observed in these studies. Complex hydrated oxide/hydroxide combinations containing $\mathrm{Cl}$ were the compounds commonly observed. The thermodynamic characteristics of these complex compounds are not known. In order to obtain some insights into the $\mathrm{H}_{2}$ pressure possible from reactions other than that described in Equation (1), the equilibrium $\mathrm{H}_{2}$ pressures resulting from the formation of aluminum hydroxide $\left[\mathrm{Al}(\mathrm{OH})_{3}\right]$ and aluminum chloride oxide $(\mathrm{AlClO})$ were calculated:

$$
\begin{gathered}
2 \mathrm{Al}+6 \mathrm{H}_{2} \mathrm{O}=2 \mathrm{Al}(\mathrm{OH})_{3}+3 \mathrm{H}_{2} \\
2 \mathrm{Al}+4 \mathrm{H}_{2} \mathrm{O}+2 \mathrm{NaCl}=2 \mathrm{AlClO}+2 \mathrm{NaOH}+3 \mathrm{H}_{2}
\end{gathered}
$$

The values of the Gibbs free energy of formation for $\mathrm{H}_{2} \mathrm{O}$ and $\mathrm{NaOH}$ at $25^{\circ} \mathrm{C}$ were obtained from Garrels and Christ (1965), and the values for $\mathrm{NaCl}$ and $\mathrm{AlClO}$ at $30^{\circ} \mathrm{C}$ were taken from JANAF (1985). Assigning these values, and the value $f_{\mathrm{K} 2 \mathrm{O}}=0.03 \mathrm{~atm}$, results in the following equilibrium constants and $\mathrm{H}_{2}$ pressures:

- For Equation (4) $\left[\mathrm{Al}(\mathrm{OH})_{3}\right.$ product]:

$$
\begin{aligned}
& \frac{f_{\mathrm{H}_{2}}^{3}}{\mathrm{f}_{\mathrm{H}_{2} \mathrm{O}}^{6}}=1.6 \times 10^{147} \\
& \mathrm{f}_{\mathrm{H}_{2}}=8 \times 10^{45} \mathrm{~atm}
\end{aligned}
$$


- For Equation (5) [AlClO product]:

$$
\begin{gathered}
\frac{f_{\mathrm{H}_{2}}^{3} \cdot a_{\mathrm{NaOH}}^{2}}{f_{\mathrm{H}_{2} \mathrm{O}}^{4} \cdot a_{\mathrm{NaCl}}^{2}}=2 \times 10^{88} \\
\mathrm{f}_{\mathrm{H}_{2}}=2 \times 10^{27} \mathrm{~atm}
\end{gathered}
$$

For the calculation of $f_{\mathrm{H}_{2}}$ associated with the formation of AlClO [Equation (9)], it was assumed that the activity of $\mathrm{NaCl}$ and $\mathrm{NaOH}$ were both unity. For $\mathrm{NaCl}$, it is a reasonable assumption, as the brine approximates a saturated brine with respect to $\mathrm{NaCl}$. For $\mathrm{NaOH}$, the assumption of unit activity makes the calculated value of the fugacity of $\mathrm{H}_{2}$ [Equation (9)] less than it actually would be (i.e., conservatively low), as the solution is not expected to become saturated with respect to $\mathrm{NaOH}$ and the $\mathrm{a}_{\mathrm{NaOH}}$ is therefore expected to be $<1$ in Equation (8).

All of the foregoing results lead to the conclusion that, on a thermodynamic basis, the reaction of Al-base materials with the water constituent of a repository brine will produce $\mathrm{H}_{2}$ pressures that are far in excess of that which can be contained by the repository.

\subsection{Al-Base Materials: Kinetic Considerations}

It is difficult to estimate, or even gain a reasonable insight into, the corrosion resistance of Al-base materials in anoxic chloride brines under WIPP repository conditions from the available technical literature. This is primarily because the combination of anoxic repository conditions and unique repository brine composition precludes in-depth, detailed comparisons with available data. The behavior of $\mathrm{Al}$ alloys in seawater is of some interest, however, and will be reviewed here briefly.

The behavior of Al alloys in seawater has received very extensive investigation, and many tables of corrosion rates of $\mathrm{Al}$ alloys in seawater exist. It is reported (ASM, 1987) that the corrosion rate of $\mathrm{Al}$ alloys in seawater increases with oxygen content, decreasing $\mathrm{pH}$, and decreasing 
temperature. The corrosion rate at great ocean depths is not dissimilar from corrosion near the ocean surface, as the lower $\mathrm{pH}$ and lower temperatures in deep water compensate for the oxygen concentration difference.

The tabulated seawater corrosion data suggest that Al-base materials will demonstrate significant corrosion rates under WIPP repository conditions. For example, specimens of 6061 alloy were reported to corrode to the extent of $26 \mathrm{~g} \mathrm{Al} / \mathrm{m}^{2}$-year when immersed in seawater near Harbor Island, North Carolina, during a 2-year corrosion test (ASM, 1987). If $\mathrm{Al}_{2} \mathrm{O}_{3}$ is assumed to be the corrosion product, and if it is further assumed that $\mathrm{O}_{2}$ does not take part in the cathodic reduction reaction (or, equivalently, that the corrosion rate does not vary with $\mathrm{O}_{2}$ fugacity), this corrosion rate is equivalent to the production of $1.5 \mathrm{~mol} \mathrm{H}_{2} / \mathrm{m}^{2}$-year, a rate which is a factor of 15 higher than the production of $\mathrm{H}_{2}$ observed in tests of low-carbon steel exposed to anoxic Brine $\mathrm{A}$, when equivalent metal areas are compared (SAND92-7347). While it must be acknowledged that the comparison made between seawater corrosion and repository corrosion is extremely simplistic, the comparison does suggest that the generally "good" corrosion resistance of Al alloys in seawater may not be "good," in a relative sense, under repository conditions.

As a final note on the kinetics of corrosion of Al-base materials, it is well known that the corrosion rate escalates rapidly outside the $\mathrm{pH}$ range of approximately 4 to 9 . While it is improbable that the $\mathrm{pH}$ of a repository brine could attain a value $<4$ through purposeful adjustment of the composition of the backfill material, it would be possible to exceed a pH of 9 through the use of an alkaline grout. The impact of such a pH change might have to be assessed in terms of its impact on the corrosion of Al-base materials in the repository waste. 


\subsection{APPROACH}

All of the $\mathrm{H}_{2}$-generation studies were performed using laboratory test equipment and laboratory facilities. Each test followed one of three basic testing methods, dictating the type of reaction vessel employed. The test methods, the metallic test materials, and the brines used in the testing program are described in this section of the report.

\subsection{Testing Methods}

Three test methods were used in the program: the seal-welded-container test method, the autoclave test method, and the constant-pH test method.

\section{o}

\subsubsection{Seal-Welded-Container Test Method}

Tests performed in the presence of brine and low-to-intermediate gas pressures (e.g., 0 to $20 \mathrm{~atm}$ ) made use of seal-welded containers made of Hastelloy C-22 ${ }^{\circ}$, a corrosion-resistant $\mathrm{Ni}-\mathrm{Cr}-\mathrm{Mo}$ alloy (Figures 5-1 and 5-2). The specimen rack shown in Figure 5-1 was used for low-carbon-steel tests. The alternative packaging material tests and the Al-base material tests used somewhat different specimen arrangements; these are described in Section 6.2. In all tests the same basic specimen support rack was used. The rack shown in Figure 5-1 is in the position used for immersed-specimen testing. For vapor-phase testing the rack would be inverted.

Because the course of the reaction was monitored by the pressure of $\mathrm{H}_{2}$ retained within the container by means of the pressure gauge, and because atmospheric gases must be rigorously excluded from the test environment, it was imperative that the containers be leak-free. To that end, the containers were of all-welded construction (with the exception of the gauge's pipe-thread joint with

- Hastelloy C-22 is a registered trademark of Haynes International, Kokomo, Indiana. 


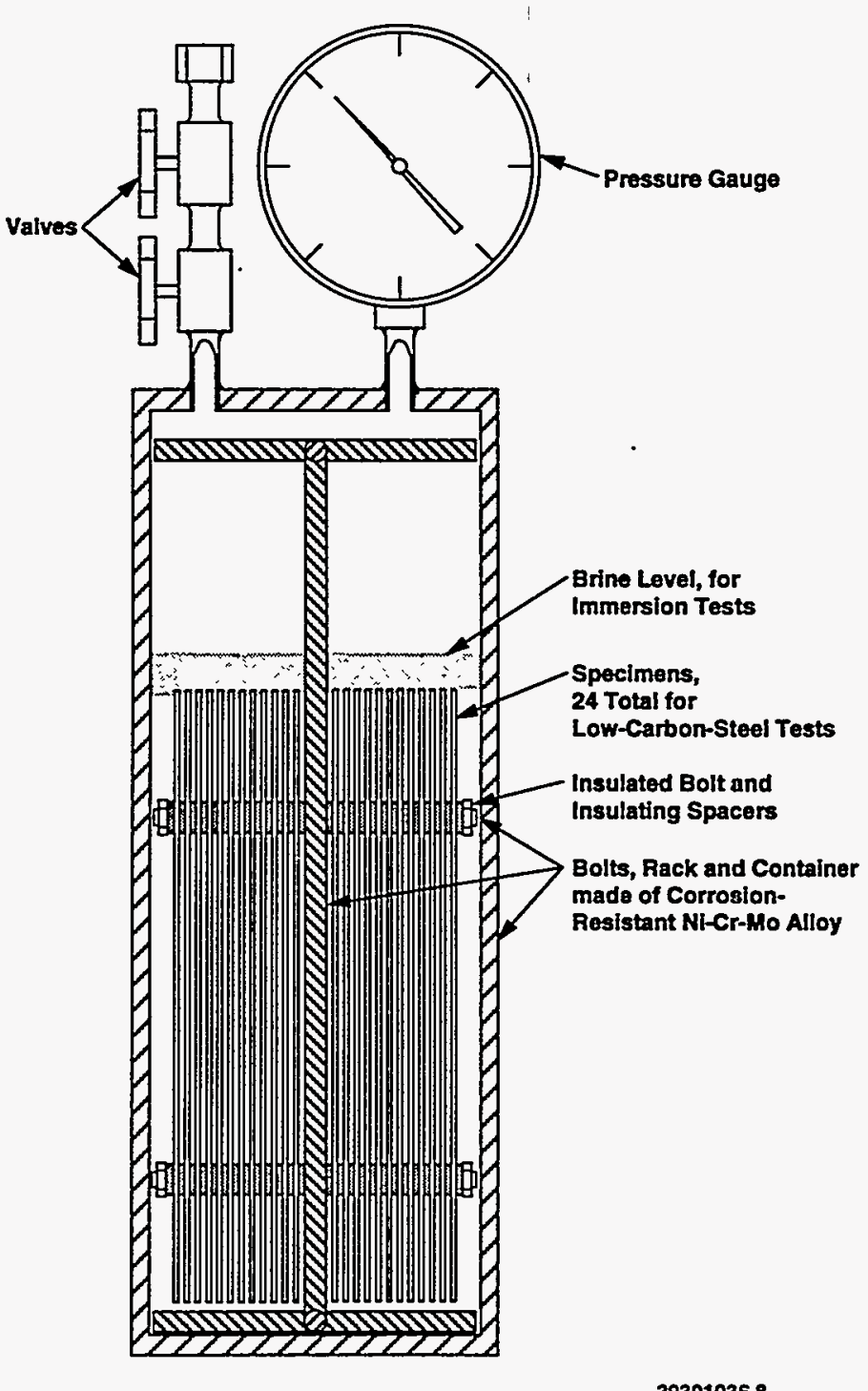

39301035.8

Figure 5-1. Seal-welded test container with specimen rack in place. Inside dimensions (typical): $28.9 \mathrm{~cm}$ (11.4 in.) high, $10.2 \mathrm{~cm}$ (4.0 in.) diameter. 


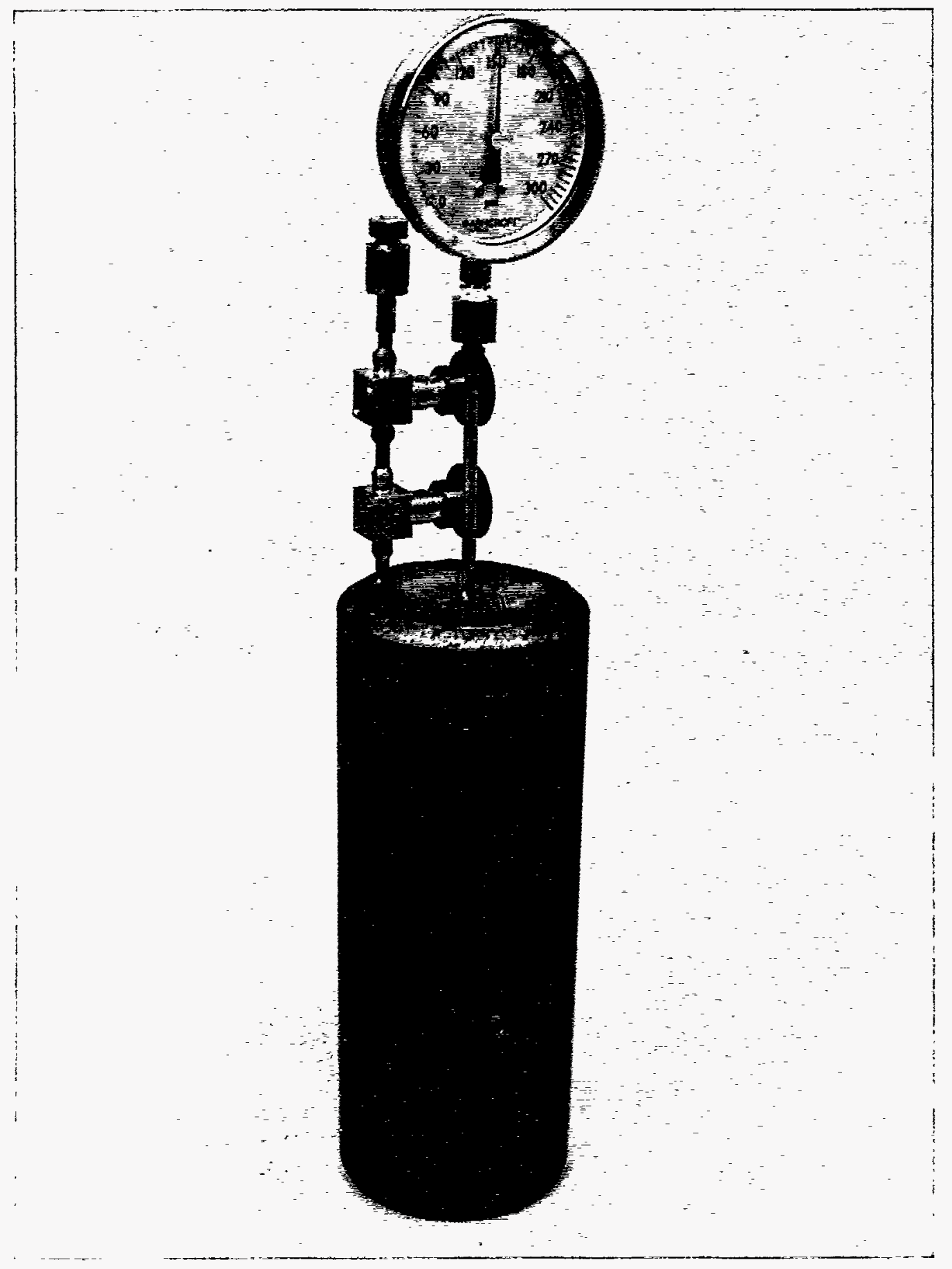

sic

Figure 5-2. Seal-welded test container, fully charged, ready for placement in oven. 
the body of the container, which was made up very tightly, with Teflon ${ }^{\oplus}$ tape applied to the threads): The pre-weighed test specimens (of large area, to expedite rapid quantification of gas generation) and the brine were placed in the container before welding the top on the container. The sealed containers were then pressurized with $\mathrm{He}$ gas to $4.4 \mathrm{~atm}$ (50 psig). Two additional He fills with intermediate evacuations were made to ensure minimization of contamination with residual air. After the third He fill, the containers were given a standard He leak-check test capable of sensing a He leak rate of $1.2 \times 10^{-10} \mathrm{~atm}-\mathrm{cc} / \mathrm{s}$. A container that did not pass the leak test was not used. If the leak test was successfully passed, the He was evacuated from the container and the appropriate overpressure gas was added. The containers were then placed in forced-convection (incubator) ovens maintained at 30 $\pm 5^{\circ} \mathrm{C}$, and the course of the gas-generating reaction monitored by observing the pressure changes on the pressure gauges. Gas samples could be obtained from the containers at any time for gas analysis, though taking such a sample perturbed the container gas inventory and gas pressure. For this reason, gas sampling was generally performed at the conclusion of a test, after the final pressure readings had been obtained.

In the seal-welded-container tests, two methods were used to determine the rates of the corrosion and gas-generation reactions: 1) determination of the container gas pressure as a function of time and 2) determination of the amount of metal lost from each specimen at the conclusion of a test by gravimetric methods. The former method had the advantage of yielding real-time information on the course of the gas-generating reaction. Confidence in the results obtained in any given test environment was dependent on accurate pressure gauge information and accurate estimations of specimen area and the plenum volume (vapor space) of the test container. The result obtained represents the gross integrated reaction of the specimen assembly, without quantifying the contribution of each specimen, hence each lot of material, to the $\mathrm{H}_{2}$ being generated. The latter method had the advantage of being capable of specifying the contribution of each specimen to the $\mathrm{H}_{2}$ generated during the test.

A detailed analysis of the accuracy of the pressure gauges and sources of variability in the gravimetric data are presented in SAND92-7347.

- Registered trademark, E. I. Du Pont de Nemours, Wilmington, Delaware. 
At the conclusion of a test, the container was opened by means of a milling operation that removed the top closure weld. The specimens were quickly lifted from the container, removed from the specimen rack, rinsed, and placed in desiccators. X-ray diffraction (XRD) analyses of the corrosion products were typically performed on selected specimens, usually within $24 \mathrm{~h}$ if there was judged to be a possibility of oxidation of the corrosion product by contact with air. The brine from the test container was retained for chemical analysis. The corrosion product was stripped from the specimens by means of an inhibited acid solution, and the amount of metal lost from each specimen was determined. The gravimetric analysis permitted an estimate to be made of the metal loss from (or penetration of) each specimen. The metal-loss data were compared with the quantity of $\mathrm{H}_{2}$ generated and the corrosion product formed, for determination and corroboration of the overall corrosion/gas generation processes.

\subsubsection{Autoclave Test Method}

Tests performed at high gas overpressures, e.g., pressures greater than $\sim 20 \mathrm{~atm}$, utilized heavy-wall autoclave systems. The autoclaves were typically of 3.8-L capacity. Because the autoclaves had high-pressure gasket seals, they could not be expected to be as gas tight as the seal-welded containers. However, pressure-time data could be obtained from an autoclave pressure gauge when the autoclave was extremely well sealed. Otherwise, the data from an autoclave system consisted of the gravimetric results and the analysis of the corrosion product film by XRD or other methods.

While autoclave systems were often employed for high-pressure studies, they had additional uses associated with their relatively large volume. For example, if it were considered necessary to keep major components of a test separate, as in the case of a mass of salt containing test specimens suspended in the vapor phase over a pool of brine, an autoclave was able to provide the flexibility and volume required.

\subsubsection{Constant-pH Test Method}

The constant-pH tests were performed in glass resin kettles, each of $3 \mathrm{~L}$ capacity. A plexiglass cover was clamped over each vessel, with a neoprene O-ring placed between the vessel and the cover. Polyethylene tube fittings screwed into the cover were used for insertion of thermocouples and tubing 
for $\mathrm{N}_{2}$ sparge gas and delivery of acid and basic solutions for maintenance of constant $\mathrm{pH}$. A ringshaped specimen holder for supporting the corrosion specimens, a rectangular specimen for $E_{\text {corr }}$ measurements, a glass electrode, and a chloride SIE (Specific Ion Electrode) were also placed within each vessel. (The specific functions of the electrodes in measuring brine $\mathrm{pH}$ are described in detail in Section 6.1.2.1.)

Each test vessel was placed on a magnetic stirrer plate, and the brine (ERDA-6) was stirred with a Teflon-coated magnet placed within the vessel. Heating was done by means of a heating tape wound around the vessel. All tubing and metal components contacted by brine were made of alloy $600(76 \% \mathrm{Ni}, 16 \% \mathrm{Cr}, 8 \% \mathrm{Fe})$ to avoid brine contamination. The $\mathrm{N}_{2}$ sparge gas was high purity $\left(>99.93 \% \mathrm{~N}_{2}\right)$. The test coupons were suspended from the support ring by lengths of Teflon tape.

Each vessel was filled with $2.36 \mathrm{~L}$ of brine at the beginning of the test exposure. With this quantity of brine there was a vapor-phase plenum region $\sim 50 \mathrm{~mm}$ deep within which the specimen support ring could reside without contacting the brine. Eight corrosion specimens, two each of lots $J$, $\mathrm{K}, \mathrm{L}$, and $\mathrm{M}$ were included (fully immersed) in each test. The specimens measured $25 \mathrm{~mm} \times$ $51 \mathrm{~mm}$ (1.0 in. $\times 2.0 \mathrm{in}$.) and each specimen had two $4.8 \mathrm{~mm}$ (3/16 in.) holes for suspension.

The $\mathrm{pH}$ of the brine was maintained by automatic or manual additions of acid $(1 \underline{\mathrm{M}} \mathrm{HCl})$ or base (1 $\mathrm{M} \mathrm{NaOH})$. Automatic addition, required, for example, in the low-pH tests, was done automatically by pH-stats. ${ }^{1}$ The $\mathrm{N}_{2}$-sparged solution was delivered directly to the test vessel by the pH-stat pumps through polytetraflouroethylene (PTFE) tubing.

The glass electrode and the chloride SIE were left inside the test vessel, partially immersed in brine, for the entire 6-month test duration. The electrode leads were passed through gas-tight seals in the vessel lid. Neither electrode required a leaking liquid junction. The calibration of the internal electrodes was checked on a weekly basis by drawing out small $(10 \mathrm{~mL})$ samples and checking the $\mathrm{pHCl}$ on a pair of freshly calibrated electrodes. As a rule, the potential measured in situ and the externally measured potential did not differ by more than $10 \mathrm{mV}$.

1 Model 1488, FMS, Inc., Watertown, MA. 


\subsection{Materials}

The $\mathrm{H}_{2}$-generation study focused on three major material classes: low-carbon steel, intended to closely represent the drum steel and the waste-box steel materials while approximately representing the steel wastes within the containers; alternative packaging materials, consisting of unalloyed $\mathrm{Cu}$ and $\mathrm{Ti}$ and selected $\mathrm{Cu}$ - and Ti-base alloys; and Al-base materials, representing Al-base scrap material present in the waste.

\subsubsection{Low-Carbon Steels ${ }^{2}$}

The drums and waste boxes containing the TRU waste will make by far the greatest contribution of metallic Fe to the WIPP repository (Brush, 1990). This Fe will be in the form of low-carbon steel, ranging in composition from the low-C, low-Mn material used in the fabrication of the Department of Transportation (DOT) $17-\mathrm{C}$ drums $(0.04$ to $0.1 \% \mathrm{C}, 0.25$ to $0.5 \% \mathrm{Mn})$ to the somewhat more highly alloyed material used in the waste boxes (for example, ASTM A36 steel, with $0.25 \% \mathrm{C}$ maximum and 0.8 to $1.2 \% \mathrm{Mn}$; and ASTM A569 steel, with $0.15 \% \mathrm{C}$ and $0.60 \% \mathrm{Mn}$ maximum). The steel waste contained within the waste boxes can be expected to range widely in composition, from low-carbon steel (for example, nails, wire, structural steel) to highly alloyed material (for example, tools, high-strength fasteners, machine components).

Ideally, a corrosion or a gas-generation study would utilize test specimens and a test environment that exactly duplicate the field conditions. In the present case, this was not possible, as a wide range of steel compositions will exist in the repository, and the compositions cannot ever be known with a high degree of certainty. It was therefore necessary to simulate the WIPP site conditions by using a range of steel compositions approximating the range of material compositions expected in the WIPP site. To this end, four lots (heats) of steel were obtained for test specimens, two lots each of ASTM A366 (standard specification for cold-rolled sheet), representative of steel waste drums, and ASTM A570 (standard specification for hot-rolled carbon steel sheet and strip), representative of steel

2 The term "low-carbon steels" is a broad material classification, generally considered to include steels having less than $0.25 \% \mathrm{C}, 1.65 \% \mathrm{Mn}$, and $0.60 \% \mathrm{Cu}$, along with small amounts of other elements (ASM, 1978). According to this definition, the drum materials and the waste box materials are "low-carbon steels." 
waste boxes and other steel waste materials. The two lots of ASTM A366 steel were designated "J" and "K," and the two lots of ASTM A570 steel were designated " $L$ " and "M." The thickness of the as-received material is given below:

$\begin{array}{cll}\text { Lot } & & \begin{array}{c}\text { Thickness, } \\ \mathrm{mm}(\mathrm{in} .)\end{array} \\ \mathrm{J} & & 0.70(0.028) \\ \mathrm{K} & & 0.86(0.034) \\ \text { - L } & & 1.5(0.059) \\ \mathrm{M} & & 1.6(0.063)\end{array}$

The compositions of the four lots of steel are presented in Table 5-1. Two values are presented for the $\mathbf{C}$ content of each lot of steel, representing analyses provided by 1 ) the steel vendor and 2) an independent testing laboratory. ${ }^{3}$ The discrepancies in $C$ concentration noted for the $J$ and $K$ lots between the two analyses are not considered important to the results of the study.

Table 5-1. Compositions of Low-Carbon Steels, Weight Percent

\begin{tabular}{|c|c|c|c|c|}
\hline \multirow[b]{2}{*}{ Specie } & \multicolumn{2}{|c|}{ ASTM A366 } & \multicolumn{2}{|c|}{ ASTM A570 } \\
\hline & Lot J & Lot $\mathrm{K}$ & Lot L & Lot $\mathrm{M}$ \\
\hline $\mathrm{C}$ & $0.06 / 0.10$ & $0.05 / 0.09$ & $0.13 / 0.14$ & $0.13 / 0.13$ \\
\hline $\mathrm{Mn}$ & 0.30 & 0.30 & 0.77 & 0.75 \\
\hline $\mathbf{S i}$ & 0.08 & 0.07 & 0.11 & 0.10 \\
\hline $\mathbf{P}$ & 0.015 & 0.015 & 0.017 & 0.020 \\
\hline$S$ & 0.012 & 0.009 & 0.015 & 0.015 \\
\hline $\mathrm{Cu}$ & 0.015 & 0.020 & 0.015 & 0.040 \\
\hline $\mathrm{Fe}$ & bal & bal & bal & bal \\
\hline
\end{tabular}

${ }^{3}$ Koon-Hall Testing Corporation, 5687 S.E. International Way \#A, Portland, OR 97222. 
In all of the calculations conducted in the present work equating molar equivalencies of corrosion reactants and corrosion products, and in all calculations equating corrosion (penetration) rates with metal lost, the steels were treated as though they were pure $\mathrm{Fe}$, with a molecular weight of 55.85 and a density of $7.86 \mathrm{~g} / \mathrm{cm}^{3}$.

Additional information on the low-carbon steels employed in the tests, and justification for their use, is presented in SAND92-7347.

\subsubsection{Alternative Packaging Materials}

The potential for gas pressurization of the WIPP underground facility due to corrosion of packaging materials and metal waste has necessitated consideration of several different options for waste form modification. One possible option involves repackaging the waste in containers that do not have the gas-generation characteristics of mild steel. To identify suitable alternative materials for waste packaging, an expert panel referred to as the Waste Container Materials Panel (WCMP) was convened in 1990 by the DOE WIPP Project Office, as a part of the Engineered Alternatives Task Force (EATF) activities. The panel evaluated a wide range of metallic, ceramic, cementitious, polymeric, and coating materials for their applicability to WIPP containers (EATF, 1991).

An important criterion for the selection of suitable metallic materials was absence or significant minimization of gas-generation tendency. Additional criteria were fabricability, availability, fabrication capacity (industrial production capacity), status of technology development, cost, and mechanical properties. The overall ranking of materials indicated that the $\mathrm{Cu}$-base and Ti-base material classes offered the best combination of material properties and overall economic incentive for replacing carbon steel as a metallic container material at the WIPP site. Cu-base materials, though obviously susceptible to attack by and reaction with certain chemical species such as nitrates and sulfides, offer a high degree of thermodynamic stability in near-neutral aqueous solutions; and Ti-base materials are extremely corrosion resistant in a wide variety of low- and intermediate-temperature brines because of the protection afforded by their oxide film (SAND92-7347). Unalloyed $\mathrm{Cu}$ (oxygen-free, electronic) and unalloyed $\mathrm{Ti}$ ( $\mathrm{Ti}$ Grade 2) were accordingly selected from the candidate material list for an investigation of their corrosion/gas-generation characteristics in simulated WIPP environments. In addition, cupronickel 90-10 was chosen for study, as its mechanical properties are far superior to 
unalloyed $\mathrm{Cu}$ due to the presence of $10 \% \mathrm{Ni}$. Ti Grade 12, a Ti-Ni-Mo alloy, was also selected because of its well known resistance to crevice corrosion. The chemical compositions of the specific materials procured for study are presented in Table 5-2.

Table 5-2. Composition of Alternative Packaging Materials Used in Corrosion/Gas-Generation Study

\begin{tabular}{|c|c|c|c|c|c|c|c|c|c|c|c|}
\hline \multirow[b]{2}{*}{ Material } & \multicolumn{11}{|c|}{ Weight Percent, or (ppm) } \\
\hline & $\mathrm{Cu}$ & $\mathrm{Ti}$ & $\mathbf{N i}$ & $\mathrm{Zn}$ & Mn & Mo & $\mathrm{Fe}$ & $\mathrm{Pb}$ & 0 & $\mathbf{S}$ & C \\
\hline Unalloyed $\mathrm{Cu}(\mathrm{C10100})$ & 99.99 & - & - & - & - & - & - & (3) & (2) & (10) & - \\
\hline Cupronickel 90-10 (C70600) & 87.58 & - & 10.4 & 0.2 & 0.5 & - & 1.3 & 0.01 & - & 0.005 & 0.01 \\
\hline Ti Grade 2 (R50400) & - & $\mathrm{Bal}$ & - & - & - & - & 0.16 & - & 0.13 & - & 0.01 \\
\hline Ti Grade 12 (R53400) & - & Bal & 0.80 & - & - & 0.30 & 0.14 & - & 0.12 & - & 0.01 \\
\hline
\end{tabular}

a Unified Numbering System (UNS) designations are in parentheses.

\subsubsection{Al-Base Materials}

$\mathrm{Al}$ and $\mathrm{Al}$ alloys contained within TRU waste drums emplaced within the WIPP repository would be capable of reacting with a brine environment to form $\mathrm{H}_{2}$. The corrosion and gas-generation rates will depend to some extent on the specific Al-base material(s) present in the waste. In order to cover the range of anticipated Al-base materials, it was decided by the Sandia National Laboratories technical staff that the waste would be represented by two specimen materials, viz., unalloyed $\mathrm{Al}$ of 99.99\% purity, expected to simulate relatively pure Al-base materials, and 6061 alloy, a Si-Mn-Mg$\mathrm{Cu}-\mathrm{Cr}$ alloy representative of structural $\mathrm{Al}$ alloys present in the waste. The compositions of the materials are presented in Table 5-3.

The 99.99\% pure Al was supplied in sheet stock, approximately $1.2 \mathrm{~mm}(0.047 \mathrm{in}$.) thick. The 6061 alloy was supplied in the form of sheet stock approximately $1.4 \mathrm{~mm}(0.055 \mathrm{in}$.) thick. The material had been solution annealed and artificially aged (T6 temper) prior to its receipt at PNL. 
Table 5-3. Composition of Al-Base Materials Used in Corrosion/Gas Generation Study

\begin{tabular}{|c|c|c|c|c|c|c|c|c|c|c|c|}
\hline \multirow[b]{2}{*}{ Material } & \multicolumn{11}{|c|}{ Weight Percent, or (ppm) } \\
\hline & $\mathbf{S i}$ & $\mathrm{Fe}$ & $\mathrm{Cu}$ & $\mathbf{M n}$ & $\mathbf{M g}$ & $\mathrm{Cr}$ & $\mathrm{Zn}$ & $\mathrm{Ti}$ & B & $\mathrm{Ca}$ & $\mathrm{Al}$ \\
\hline $99.99 \%$ pure Al & (15) & (7) & (3) & $(0.2)$ & $(0.5)$ & (0.3) & - & - & (5) & (0.3) & bal \\
\hline $\begin{array}{l}6061 \text { Alloy } \\
(\text { A96061) }\end{array}$ & 0.64 & 0.46 & 0.32 & 0.036 & 0.96 & 0.19 & 0.023 & 0.012 & - & - & bal \\
\hline
\end{tabular}

\subsubsection{Brines}

Two brines were used in the present study. One brine, designated "Brine A," was based on the WIPP Brine A composition described by Molecke (1983). Brine A is a high $\mathrm{Mg}, \mathrm{K}$, and $\mathrm{Na}$ chloride-sulfate brine and is used as a simulant for intergranular Salado Formation brine that might intrude into the WIPP repository horizon. The composition of Brine A, as well as the average value and range of compositions of the three lots of brine made up for usage at PNL in the present study, are given in Table 5-4.

Only the major constituents of Brine A as described by Molecke (1983) were used to make up the PNL simulant version. Omitted minor constituents, deemed to have little or no effect on the corrosiveness of the brine, were $\mathrm{Fe}, \mathrm{Cs}, \mathrm{Rb}, \mathrm{Li}, \mathrm{Sr}$, and $\mathrm{I}$. These minor elements totaled only $58 \mathrm{mg} / \mathrm{L}$ in the composition described by Molecke.

The second brine used in the study was chosen because of the peculiar requirements of the constant-pH tests. In these tests, the brine reactant was to be maintained at $\mathrm{pH}$ values ranging from 3 to 11. Because of the tendency for precipitation of $\mathrm{Mg}(\mathrm{OH})_{2}$ from solution at pHs $>8.6$, it was judged best to eliminate the $\mathrm{Mg}^{++}$constituent from the brine altogether, so that the presence or absence of $\mathrm{Mg}^{++}$in solution would not constitute an additional test variable. Accordingly, a WIPPrelevant brine was sought having a relatively low $\mathrm{Mg}^{++}$concentration. 
Table 5-4. Composition of Brine A Used in Tests

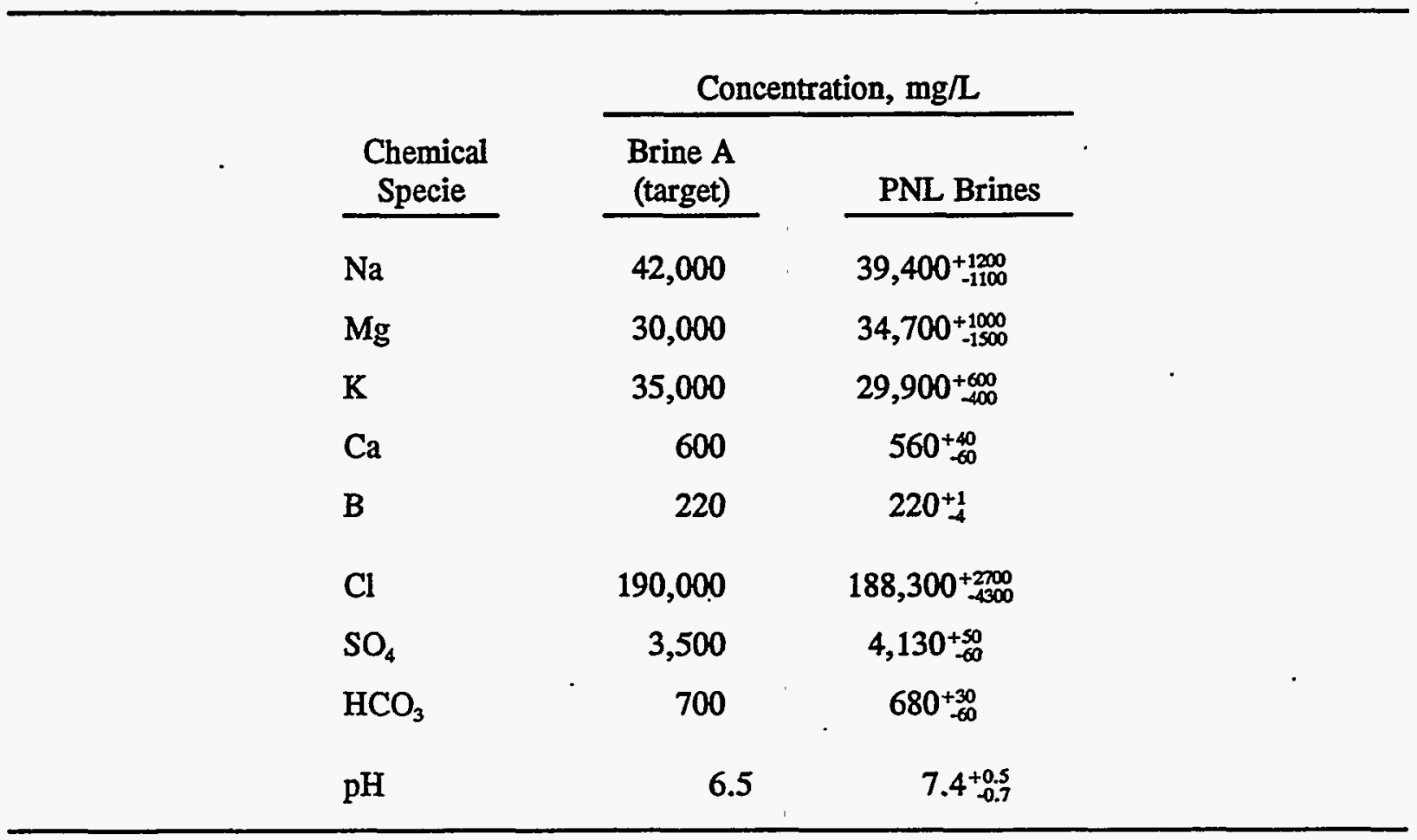

The second brine used in the study was designated "ERDA- 6 " brine, as it is a modification of a brine of the same name described by Molecke (1983). The brine described by Molecke was from a drill hole designated "ERDA-6" on the original WIPP Site. The hole lies approximately $8.6 \mathrm{~km}$ (5.3 mi) north-northeast of the present WIPP Site. The "ERDA-6" brine issued from a brine pocket encountered at a depth of about $826 \mathrm{~m}(2711 \mathrm{ft})$ in the Anhydrite II unit of the Castile formation.

The compositions of the ERDA- 6 brine, as reported by Molecke, and the PNL modification of the brine (involving elimination of $\mathrm{Mg}^{++}, \mathrm{Ca}^{++}, \mathrm{Sr}^{++}, \mathrm{Fe}^{3+}, \mathrm{HCO}_{3}^{-}$, and $\mathrm{F}^{-}$) are shown in Table 5-5.

The $\mathrm{Mg}^{++}, \mathrm{Ca}^{++}$, and $\mathrm{HCO}_{3}^{-}$activities were considered to be sensitive to $\mathrm{pH}$, and were eliminated for that reason; and the $\mathrm{Sr}^{++}, \mathrm{Fe}^{3+}$, and $\mathrm{F}$ were considered to be unimportant constituents. Only one batch of ERDA- 6 brine was made at PNL. 
Table 5-5. Composition of ERDA-6 Brine

\begin{tabular}{|c|c|c|c|}
\hline \multirow[b]{2}{*}{$\begin{array}{l}\text { Chemical } \\
\text { Specie }\end{array}$} & \multicolumn{3}{|c|}{ Concentration, $\mathrm{mg} / \mathrm{L}$} \\
\hline & $\begin{array}{c}\text { Flow } \\
\text { ERDA-6" }\end{array}$ & $\begin{array}{l}\text { Downhole } \\
\text { ERDA-6" }\end{array}$ & $\begin{array}{c}\text { PNL ERDA-6 } \\
\text { Simulation }\end{array}$ \\
\hline $\mathrm{Na}$ & 112,000 & 140,000 & 113,000 \\
\hline $\mathbf{K}$ & 3,800 & 4,800 & 3,770 \\
\hline $\mathbf{M g}$ & -450 & 270 & - \\
\hline $\mathrm{Ca}$ & 490 & 360 & - \\
\hline Sr & 18 & - & - \\
\hline $\mathrm{Fe}$ & 3.6 & 5.7 & - \\
\hline $\mathrm{Cl}$ & 170,000 & 180,000 & 164,000 \\
\hline $\mathrm{SO}_{4}$ & 16,000 & 14,000 & 16,100 \\
\hline B & 680 & 740 & 830 \\
\hline $\mathrm{HCO}_{3}$ & 2,600 & 1,800 & - \\
\hline $\mathrm{Br}$ & 880 & 720 & 830 \\
\hline $\mathrm{F}$ & - & 1.7 & - \\
\hline $\mathrm{pH}$ & 6.42 & 7.02 & $6.15^{b}$ \\
\hline
\end{tabular}

\footnotetext{
a Taken from Molecke (1983).

b Not corrected to take into account activities of brine constituents.
} 


\subsubsection{Salt (Halite)}

Four corrosion and gas-generation tests were conducted in which the specimens were packed in either particulate salt (halite) (tests AUT-5 and AUT-6) or in a mixture of salt (halite) and bentonite (tests AUT-12 and AUT-13). The salt used in the tests was shipped to PNL from SNL in two 1-gallon containers, identified as "WIPP Salt E140-N635." The salt was originally gathered from the floor of "E $140 \mathrm{drift}, 194 \mathrm{~m}$ (635 ft) north of the salt shaft." It was assumed to be essentially pure $(>95 \%) \mathrm{NaCl}$, and was not analyzed.

\subsubsection{Bentonite}

The bentonite used in tests AUT-12 and AUT- 13 was obtained from SNL. The material is a product of the American Colloid Company, Arlington Heights, Illinois, and is designated "Volclay GPG 30 bentonite." (American Colloid Company, 1995). Data sheet on file in the SWCF as WPO\# 39636. It is a hydrous aluminum silicate consisting primarily ( $>90 \%$ ) of the mineral montmorillonite. The material supplied had a particle size between 20 and 70 mesh.

A typical analysis (supplied by the vendor) is given below in weight percent:

$\begin{array}{cc}\mathrm{SiO}_{2} & 63.02 \\ \mathrm{Al}_{2} \mathrm{O}_{3} & 21.08 \\ \mathrm{Fe}_{2} \mathrm{O}_{3} & 3.25 \\ \mathrm{FeO} & 0.35 \\ \mathrm{MgO} & 2.67 \\ \mathrm{Na}_{2} \mathrm{O} & 2.57 \\ \mathrm{CaO} & 0.65 \\ \mathrm{H}_{2} \mathrm{O} & 5.64 \\ \text { ce elements } & 0.72\end{array}$




\subsection{RESULTS}

Three major efforts were undertaken in the present corrosion and gas-generation laboratory study: experiments directed toward determining the behavior of current packaging materials (lowcarbon steels in simulated WIPP environments); experiments directed toward determining the behavior of alternative packaging ( $\mathrm{Cu}$ - and Ti-base) materials in simulated WIPP environments; and experiments directed toward determining the behavior of Al-base (simulated scrap) materials in simulated WIPP environments. The experimental results associated with each major materials group will be discussed separately in this section of the report. The basic division in the experimental work is reflected in the summary test matrices for the project, presented in Tables 3-1 through 3-5. Reference may be made to these tables for information of a summary nature on any of the individual tests described in this section of the report.

Where possible, each test was designed to provide 1) time-dependent container pressure, from which $\mathrm{H}_{2}$ pressure data could be determined; 2) gas composition data, for quantification of corrosionproduct gas generation rates in conjunction with item 1 ; 3) corrosion rate (metal penetration) data, obtained gravimetrically after corrosion-product film stripping; and 4) corrosion product identification. Post-test brine analyses were also obtained. Items 1 and 2 have the most value and are most defensible when obtained from a demonstrably leak-tight container, such as the seal-welded containers used in the present tests. Information from items 1,2 , and 3 permit a comparison of the moles of $\mathrm{H}_{2}$ formed versus moles of metal reacted, to verify the legitimacy of the conclusions drawn. Item 4 provides insights into the potential protectiveness of the corrosion product film and also ensures that the appropriate reaction is being considered when the molar equivalency of metal and $\mathrm{H}_{2}$ are being compared.

In general, "stand-alone" work completed prior to the publication of SAND92-7347 is not duplicated in the present report. However, work completed prior to the publication of SAND92-7347 that is considered important to the understanding of work presented in the present report, or which is closely related to work presented in the present report, is included herein for completeness.

The raw data describing container pressure as a function of time for those seal-welded container tests for which such data are considered meaningful are contained in Appendix $A$ to this report. 
The individual specimen data for all tests may be found in Appendix B. These data details are presented to permit additional, independent evaluation and corroboration of the results presented and conclusions drawn in the present report and to facilitate statistical treatment of the data according to the specific future needs of the WIPP Project modelers. Such treatments were not attempted in the present report because of the many different approaches to the data that could be taken in such statistical analyses.

\subsection{Low-Carbon Steel Tests}

The corrosion and gas-generation behavior of low-carbon steels was evaluated in three environments: anoxic brine (brine $\left./ \mathrm{N}_{2}\right)^{4}$, brine $/ \mathrm{CO}_{2}$, and brine/ $\mathrm{H}_{2} \mathrm{~S}$. In each environment specimens were exposed either fully immersed in the brine (Brine A or ERDA-6 brine) or in the vapor phase over the brine. All tests were performed at $30 \pm 5^{\circ} \mathrm{C}$. The test conditions are summarized in Table 3-1.

All steel specimens were surface ground using 60-grit emery cloth to remove mill scale or other surface deposits. After grinding, they were dimensionally measured, degreased (using trisodium phosphate followed by a water rinse, and an absolute alcohol rinse), and weighed. The specimen dimensions were obtained to a minimum accuracy of $\pm 0.01 \mathrm{~mm}$ ( $\pm 0.0004 \mathrm{in}$.); the specimen weights (pre- and post-test) were obtained to $\pm 0.0001 \mathrm{~g}$. After the final degreasing and weighing operations, the specimens were stored in a desiccator until needed. At that time, the steel specimens exhibited a bright, clean, as-ground appearance.

Upon conclusion of a test, the specimens were removed from the test container, rinsed in deionized water and alcohol, and placed in a desiccator to minimize the possibility of further reactions. Selected specimens were held in reserve for analysis of corrosion products, usually accomplished by $\mathrm{x}$-ray diffraction (XRD). The corrosion product layer was removed from the remainder of the specimens by immersing the specimens in an inhibited $\mathrm{HCl}$ corrosion-product stripping solution per

4 Strictly speaking, each of the environments investigated consisted of anoxic brine, as $\mathrm{O}_{2}$ was excluded from the test containers. The term "anoxic brine" as used here to describe the environment having no reactive gas $\left(\mathrm{CO}_{2}, \mathrm{H}_{2} \mathrm{~S}\right)$ overpressure signifies that the reactant is anoxic brine alone, without an added reactive constituent. 
National Association of Corrosion Engineers (NACE) standard TM-01-69, 1976 revision. $^{5}$ The stripping solution is made by adding $12 \mathrm{ml}$ formaldehyde to $1 \mathrm{~L}$ of $50 \% \mathrm{HCl}$ solution. A final weighing was then performed so that the mass of metal lost from each specimen by corrosion could be calculated.

\subsubsection{Seal-Welded-Container Tests}

Each seal-welded container test described in this section of the report contained a rack of 24 test specimens, comprising six replicate test specimens of each of the four lots of low-carbon steel previously described in Section 5.2. The six test specimens of each lot of steel consisted of three wide specimens, $86 \mathrm{~mm}$ (3.4 in.) $\times 190 \mathrm{~mm}$ (7.5 in.), and three narrow specimens, $51 \mathrm{~mm}$ (2.0 in.) $\times 190 \mathrm{~mm}$ (7.5 in.). Each specimen had two holes, $8 \mathrm{~mm}$ (0.31 in.) in diameter, to accommodate the insulated rack supports. The narrow specimens were placed on the outer part of the rack to optimize material loading in the container. The total specimen area in each container lay in the range 0.60 to $0.64 \mathrm{~m}^{2}$. In the immersed-specimen tests, sufficient brine $(1.34$ to $1.40 \mathrm{~L})$ was added to the container to cover the tops of the specimens to a depth of $\sim 6.4 \mathrm{~mm}(\sim 0.25 \mathrm{in}$.). In the vapor-phase exposure tests, $0.25 \mathrm{~L}$ of brine was placed in the bottom of the test container. The level of the brine was below the racked specimens, though the brine unintentionally splashed on the bottoms of the specimens during container handling. The immersed-specimen containers had a calculated vaporspace plenum volume of $0.634 \mathrm{~L}$. The plenum volume in the vapor-phase exposure tests was $1.74 \mathrm{~L}$. The specimen area-to-plenum volume ratio was made large to promote a rapid response on the test container pressure gauge to the $\mathrm{H}_{2}$ generated by corrosion reactions.

\subsubsection{ANOXIC BRINE (BRINE/N $\mathrm{N}_{2}$ ) TESTS}

The anoxic brine tests were intended to provide basic information on the corrosion/gas-generation proclivity of low-carbon steel in the absence of reactants other than low-carbon steel and Brine A or ERDA- 6 brine. The anoxic brine immersed-specimen testing regimen using Brine $A$ as the test

5 Laboratory Corrosion Testing of Metals for the Process Industries, National Association of Corrosion Engineers, Houston, Texas 77084. The stripping solution was made by adding $12 \mathrm{ml}$ formaldehyde to $1 \mathrm{~L}$ of $50 \% \mathrm{HCl}$ solution. 
environment included test containers 1,$2 ; 9,10 ; 17,18 ; 25,26$; and 46,47 ; the vapor-phasespecimen testing regimen using Brine $A$ included test containers 5,$6 ; 13,14 ; 21,22$; and $29,30$. The immersed-specimen tests using ERDA-6 brine were test containers 44 and 45 . Proximate identification numbers (e.g., 1, 2) signify duplicate tests. These test container identification data are also contained in Table 3-1.

All of the pressure-time plots from the Brine $A / N_{2}$ test series, exclusive of tests 46 and 47 , are presented in Figure 6-1. The figure, and the corresponding raw data, were previously presented in SAND92-7347. The figure is presented here as well because the pressure-time results derived from the data, i.e., the last 12 months of the 24-month tests, were used to arrive at the basic long-term steel $\mathrm{H}_{2}$ generation rate of $0.10 \mathrm{~mol} \mathrm{H}_{2} / \mathrm{m}^{2}$ steel-yr, equivalent to a steel corrosion (penetration) rate of $0.71 \mu \mathrm{m} /$ year (SAND92-7347). A detailed assessment of the test results, including gas analysis results, specimen appearance, agreement between test containers and between gas generation and metal lost, brine analyses, the attempts to identify corrosion products by XRD, and the lack of corrosion/gas generation exhibited by vapor-phase specimens may be found in SAND92-7347.

The initial (unsuccessful) attempts to identify the corrosion product formed in the 12- and 24-month brine/ $\mathrm{N}_{2}$ tests were described in detail in SAND92-7347. An additional attempt, using both an XRD and a chemical analysis approach, was undertaken using corrosion products derived from anoxic brine tests of six months duration (tests 46 and 47, Table 3-1). The pressure-time histories of these tests closely matched those of equivalent earlier tests, supporting the assumption of equivalent corrosion products.

It is known that low-carbon-steel corrosion products derived from anoxic brine tests rapidly oxidize in the presence of air. The blue-green corrosion product obtained from the test container begins to convert to the red-orange corrosion product in a matter of minutes unless special care is taken to prevent $\mathrm{O}_{2}$ contact with the material. For the present corrosion product examination, container 46 was removed from its incubator oven after $\sim 6$ months test duration, shaken vigorously for several minutes, then inverted over a vacuum filtration device covered with a $\mathrm{N}_{2}$-filled plastic bag. The valve assembly was opened, allowing brine and particulate corrosion product to enter the filter. After about 30 seconds a substantial amount of corrosion product had collected on the filter paper. 


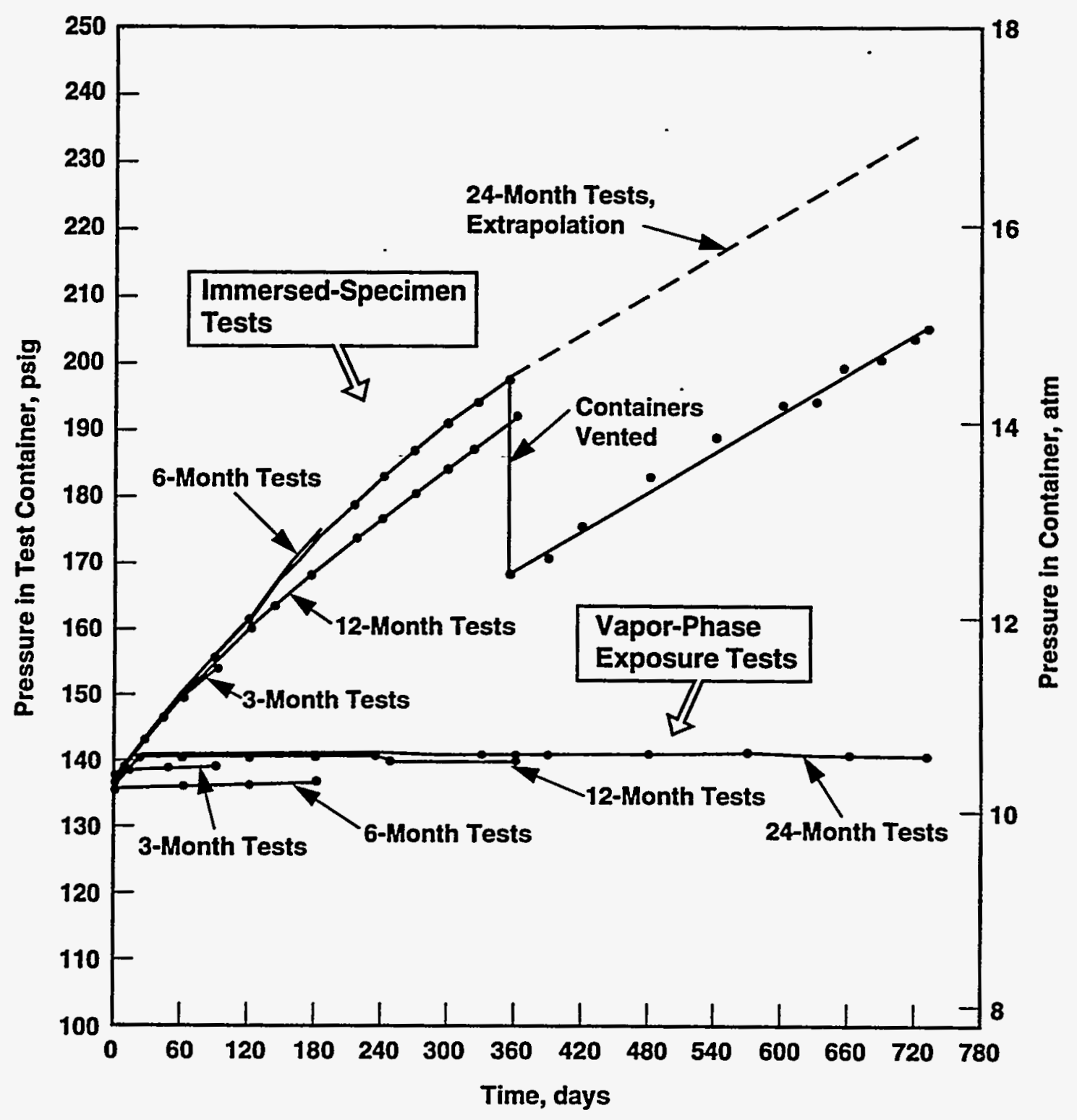

39301036.1

Figure 6-1. Pressure-time curves, low-carbon steel anoxic brine tests. Each curve represents two (duplicate) tests. 
The corrosion product was then washed thoroughly with deionized water from a $\mathrm{N}_{2}$-sparged wash bottle. When the washing was complete, the filter paper and corrosion product residue was transferred to an evacuatable desiccator, where it was stored under vacuum (for $\sim 2 \mathrm{~h}$ ) prior to obtaining the XRD pattern. The procedure was then repeated to obtain a corrosion product sample for chemical analysis.

XRD Results ${ }^{6}$

The diffraction pattern obtained from the corrosion product from test 46 was a very close match to that obtained from the 24-month brine/ $\mathrm{N}_{2}$ test (test 25), except that several additional peaks were present in the test 25 pattern. This finding implies the presence of an additional compound in the test 25 corrosion product.

The corrosion product from test 46 was not identifiable using $\mathrm{XRD}$, as no matching database entries were found (through Set 44, 1994). As previously reported (SAND92-7347), the corrosion product from test 25 was also not identifiable.

Chemical Analysis Results

Chemical analyses of samples of corrosion product taken from tests 46 and 47 were performed by inductively coupled argon plasma optical emission spectroscopy (ICAP) and ion chromatography (IC). The corrosion product specimen was dissolved in $2 \% \mathrm{HNO}_{3}$ solution prior to analysis.

The results of the chemical analyses are presented below (wt \%):

6 The $x$-ray diffractogram of the test 46 filter sample was compared to the Powder Diffraction File database, Sets 1-44 (PDF-2, International Centre for Diffraction Data, 1994). Comparison of the experimental pattern with this database was effected using the full-pattern, analog search/match algorithm resident in Jade+, Ver. 2.1 (Materials Data, Inc., Livermore, CA). Additional Comparison was made using the traditional D-I search/match algorithm of Micro-ID+, Ver. 2.0 (MDI). 


\begin{tabular}{|c|c|c|}
\hline Specie & Test 46 & Test 47 \\
\hline $\mathrm{Fe}$ & 38 & 37 \\
\hline $\mathrm{Mg}$ & 6.7 & 7.7 \\
\hline $\mathrm{Mn}$ & 0.18 & 0.11 \\
\hline $\mathbf{K}$ & $<0.2$ & $\sim 0.03$ \\
\hline $\mathrm{Na}$ & $<0.1$ & 0.05 \\
\hline $\mathrm{Ca}$ & $<0.022$ & 0.02 \\
\hline$S$ & $<0.07$ & 0.24 \\
\hline
\end{tabular}

The high $\mathrm{Mg}$ content of the corrosion product is reminiscent of the compound amakinite, an $\mathrm{Fe}, \mathrm{Mg}$ hydroxide, commonly found in the testing of ferritic materials in anoxic brines in past studies (Westerman èt al., 1988). The amakinite found at $150^{\circ} \mathrm{C}$, for example, when an ASTM type A216 steel was exposed to an anoxic high $\mathrm{Mg}$ salt/brine environment for 12 months, contained $25 \mathrm{wt} \% \mathrm{Fe}$ and $6 \mathrm{wt} \% \mathrm{Mg}$, for a compound of the composition $\mathrm{Fe}_{0.64} \mathrm{Mg}_{0.36}(\mathrm{OH})_{2}$, or, approximately, $\mathrm{Fe}_{2 / 3} \mathrm{Mg}_{1 / 3}(\mathrm{OH})_{2}$ (Westerman et al., 1988). Though the corrosion product chemical composition in the present test suggests amakinite, the XRD results do not show a match with amakinite, or any other related compound.

Although the corrosion product cannot be identified exactly, it will continue to be considered a close relative of, or some form of, $\mathrm{Fe}, \mathrm{Mg}(\mathrm{OH})_{2}$, because of its chemical similarity to amakinite and because amakinite has been found under similar steel-reaction circumstances.

\subsubsection{BRINE/CO ${ }_{2}$ TESTS}

The brine/ $/ \mathrm{CO}_{2}$ tests were intended to provide information on the corrosion and gas-generation proclivity of low-carbon steel in the presence of Brine $\mathrm{A}$ and $\mathrm{CO}_{2}$. The presence of $\mathrm{CO}_{2}$ in the WIPP at significant fugacities is considered to be a distinct possibility because it is an expected byproduct of the microbially mediated degradation of cellulosic materials and other organic materials that will presumably be disposed of in the WIPP in large quantities.

Two types of brine/ $\mathrm{CO}_{2}$ experiments were performed: experiments in which $\mathrm{CO}_{2}$ was present in the test containers in quantities so large that its complete consumption was not possible (the "excess- $\mathrm{CO}_{2}{ }^{\prime}$ tests); and tests in which the quantities of $\mathrm{CO}_{2}$ added to the test containers were controlled so as to permit the essentially complete consumption of the $\mathrm{CO}_{2}$ in some of the tests, but not 
in others (the "controlled- $\mathrm{CO}_{2}$-addition" tests). These tests will be discussed separately in the following subsections.

Excess- $\mathrm{CO}_{2}$ Tests

The excess $-\mathrm{CO}_{2}$ tests were intended to provide information on the corrosion and gas-generation characteristics of low-carbon steel in the presence of Brine $\mathrm{A}$ and excess $\mathrm{CO}_{2}$. The brine/CO immersed-specimen testing regimen included test containers 3,$4 ; 11,12 ; 19,20$; and 27,28 . The brine $/ \mathrm{CO}_{2}$ vapor-phase-specimen testing regimen included containers 7,$8 ; 15,16 ; 23,24 ;$ and 31,32 . Proximate identification numbers (e.g., 3, 4) signify duplicate tests.

In the immersed-specimen tests the $\mathrm{CO}_{2}$ was added to the test containers at an initial hypothetical starting pressure of $\sim 155$ psig $(\sim 170$ psia, or $\sim 12 \mathrm{~atm})$. This starting pressure is termed "hypothetical" because, in general, equilibration between the $\mathrm{CO}_{2}$ present in the plenum of the test container and $\mathrm{CO}_{2}$ present in the brine was not achieved for several days after test initiation, in spite of the fact that each container was agitated (by hand-shaking) for a period of 10 to 15 min after addition of the final $\mathrm{CO}_{2}$ charge. The average quantity of $\mathrm{CO}_{2}$ added to each of the immersed-specimen test containers was $19.3 \mathrm{~g}$, or $0.44 \mathrm{~mol}$. As the average steel area in each test container in this series of tests was $0.604 \mathrm{~m}^{2}$, the initial $\mathrm{CO}_{2}$ charge in each test container was equivalent to $0.73 \mathrm{~mol}$ per square meter of steel in an $\mathrm{FeCO}_{3}$-forming reaction.

The Henry's Law coefficient, $\mathrm{S}$, for $\mathrm{CO}_{2}$ in equilibrium with Brine A

$$
\mathrm{S}=\frac{\text { moles } \mathrm{CO}_{2} \text { per liter of brine }}{\text { pressure } \mathrm{CO}_{2} \text {, atm }}
$$

was experimentally determined to be equal to 0.012 at $20^{\circ} \mathrm{C}$, and 0.010 at $30^{\circ} \mathrm{C}$. During a $30^{\circ} \mathrm{C}$ test, assuming equilibrium conditions, the major portion of the $\mathrm{CO}_{2}(\sim 65 \%)$ would be expected to be present in the gas phase with the remainder ( $-35 \%)$ dissolved in the brine. The $\mathrm{H}_{2}$ generated by the corrosion reaction, on the other hand, would collect in the plenum region of the test container only, as it is essentially insoluble in the brine phase. As the $\mathrm{CO}_{2}$ is consumed by the corrosion reaction to form $\mathrm{FeCO}_{3}$, the pressure will tend to decrease in the plenum, but not to the extent that the pressure increases due to $\mathrm{H}_{2}$ formation because the brine phase will continually supply a fraction of the $\mathrm{CO}_{2}$ 
involved in the corrosion reaction. Thus, a pressure buildup in the plenum (caused by $\mathrm{H}_{2}$ generation) will be observed on the pressure gauge as the reaction proceeds, even though a mole of $\mathrm{CO}_{2}$ is consumed for each mole of $\mathrm{H}_{2}$ formed.

The pressure-time curves for the excess $-\mathrm{CO}_{2}$ tests are presented in Figure 6-2. This figure, along with the raw data, were originally published in SAND92-7347. The figure is duplicated here because of its relevance to associated steel-Brine $\mathrm{A}-\mathrm{CO}_{2}$ tests that will be discussed in the next section of the report. For additional details of the study that led to the pressure-time relationships shown in Figure 6-2, including gas and brine analyses, specimen appearance, XRD results, agreement between $\mathrm{H}_{2}$ formed and metal reacted, determination of amount of $\mathrm{CO}_{2}$ required to passivate the steel specimens, and the lot-to-lot differences in steel corrosion rates and the lack of corrosive attack of vapor-phase specimens, the report SAND92-7347 may be consulted.

\section{Controlled- $\mathrm{CO}_{2}$-Addition Tests (With Eventual $\mathrm{H}_{2} \mathrm{~S}$ Addition)}

The initiation of these tests, and a description of their progress for -300 days, was described in SAND92-7347. The tests have been completed since the publication of that document, so they will receive a relatively complete and detailed treatment here.

When the activity of $\mathrm{CO}_{2}$ dissolved in Brine $\mathrm{A}$ is increased, two opposing effects are manifested: 1) the brine becomes -a -more aggressive corrodant -toward steel due to effects already discussed [Equations (1) through (7), (SAND92-7347)]; and 2) the presence of $\mathrm{CO}_{2}$ tends to stop the reaction through the formation of a stable $\mathrm{FeCO}_{3}$ layer. The controlled- $\mathrm{CO}_{2}$-addition tests were intended to provide information on the amount of $\mathrm{CO}_{2}$ required/unit area of steel to attain a passivated state, such as was attained in the excess- $\mathrm{CO}_{2}$ tests after $\mathrm{CO}_{2}$ (initially at $\sim 12$ atm pressure) had reacted with the steel to the extent of $\sim 0.42 \mathrm{~mol} \mathrm{CO} / \mathrm{m}^{2}$ steel (SAND92-7347).

Once $\mathrm{CO}_{2}$-induced passivation was attained, the tests were to provide information as to whether or not $\mathrm{CO}_{2}$-passivated specimens could become depassivated by addition of $\mathrm{H}_{2} \mathrm{~S}$ to the system. This is considered likely on thermodynamic grounds because of the extreme stability of $\mathrm{FeS}$ (or $\mathrm{FeS}_{2}$ ) relative to $\mathrm{FeCO}_{3}$ (SAND92-7347). 


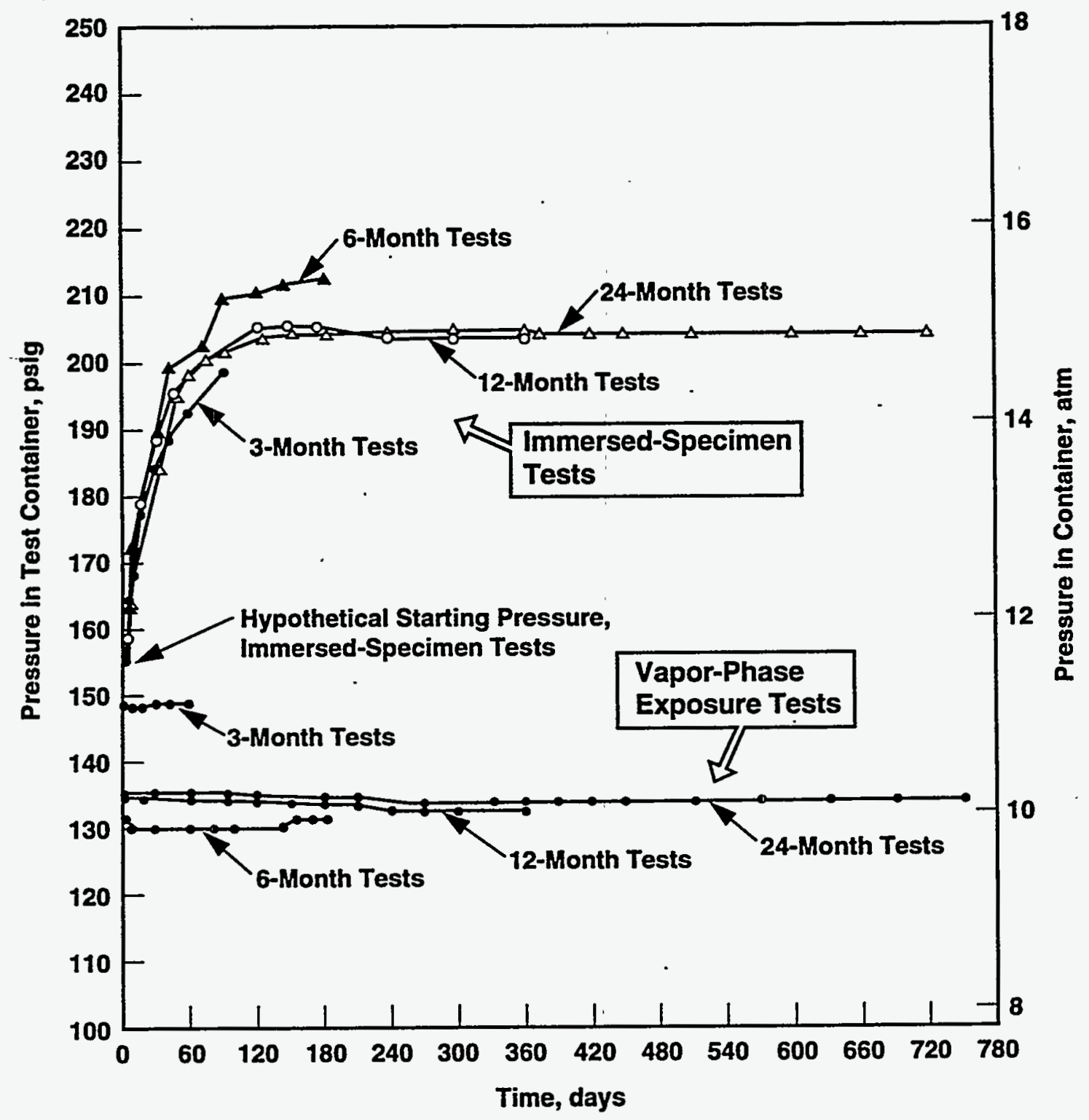

39301036.2

Figure 6-2. Pressure-time curves, low-carbon steel/brine- $\mathrm{CO}_{2}$ tests. Each curve represents two (duplicate) tests. 
The subject investigation comprised test containers 33 through 38 . The initial test conditions are summarized in Table 6-1. An $\mathrm{N}_{2}$ addition was made to test containers 36 through 38 so that the pressure gauges would provide a positive initial reading.

Table 6-1. Summary of Initial Test Conditions, Controlled- $\mathrm{CO}_{2}$-Addition Tests

\begin{tabular}{|c|c|c|c|c|c|}
\hline \multirow{2}{*}{\multicolumn{2}{|c|}{$\frac{\begin{array}{c}\text { Test } \\
\text { Container }\end{array}}{33}$}} & \multicolumn{2}{|c|}{$\begin{array}{c}\text { Initial } \mathrm{CO}_{2} \text { Charge } \\
\text { Pressure, atm (psia) } \\
\end{array}$} & \multirow{2}{*}{$\begin{array}{l}\begin{array}{c}\mathrm{N}_{2} \text { Pressure, } \\
\text { atm (psia) }\end{array} \\
\text { no } \mathrm{N}_{2}\end{array}$} & \multirow{2}{*}{$\frac{\begin{array}{c}\mathrm{Mol} \mathrm{CO} / \mathrm{m}^{2} \\
\text { steel }^{\mathrm{b}}\end{array}}{0.32}$} \\
\hline & & 7.8 & (115) & & \\
\hline & 34 & 3.8 & (56) & no $\mathrm{N}_{2}$ & 0.16 \\
\hline & 35 & 1.5 & (22) & no $\mathrm{N}_{2}$ & 0.063 \\
\hline & 36 & 0.75 & (11) & $2.0(30)$ & 0.032 \\
\hline & 37 & 0.39 & $(5.7)$ & $2.0(30)$ & 0.016 \\
\hline & 38 & 0 & $(0)$ & $3.1(45)$ & 0.0 \\
\hline \multicolumn{6}{|c|}{$\begin{array}{l}\text { Assumes plenum }=0.634 \mathrm{~L}, \mathrm{~T}=30^{\circ} \mathrm{C} \text {, insignificant } \mathrm{CO}_{2} \text { disso- } \\
\text { lution in brine at the time of } \mathrm{CO}_{2} \text { charging. } \\
\text { Total area of steel specimens in each test container }=0.629 \mathrm{~m}^{2} \text {. }\end{array}$} \\
\hline
\end{tabular}

The highest ratio of mol $\mathrm{CO}_{2} / \mathrm{m}^{2}$ steel $(0.32)$ employed in the test series was intended to approximate the $0.42 \mathrm{~mol} / \mathrm{m}^{2}$ value causing passivation in the excess- $\mathrm{CO}_{2}$ tests described in the preceding section of this report. Lesser quantities of $\mathrm{CO}_{2}$ were also used to determine if passivation, or temporary passivation, would develop under conditions of relatively low concentrations of $\mathrm{CO}_{2}$.

The pressure-time curves for the controlled- $\mathrm{CO}_{2}$-addition tests are shown in Figure 6-3. Prior to the $\mathrm{H}_{2} \mathrm{~S}$ addition made at 575 days, the $\mathrm{CO}_{2}$ and the Brine $\mathrm{A}$ were the only reactants present in the test containers. During this initial test period, it is apparent that at least some degree of passivity has been attained in the two test containers with the maximum amount of $\mathrm{CO}_{2}$ added (containers 33 and 34). Though the pressure-time curves for these two containers appear to attain a near-zero slope after a time period of $\sim 150$ days, the curve for container 34 indicates some degree of reaction to the end of the $\mathrm{CO}_{2}$-only (575-day) test duration shown in the figure. Thus, it appears as though a completely 


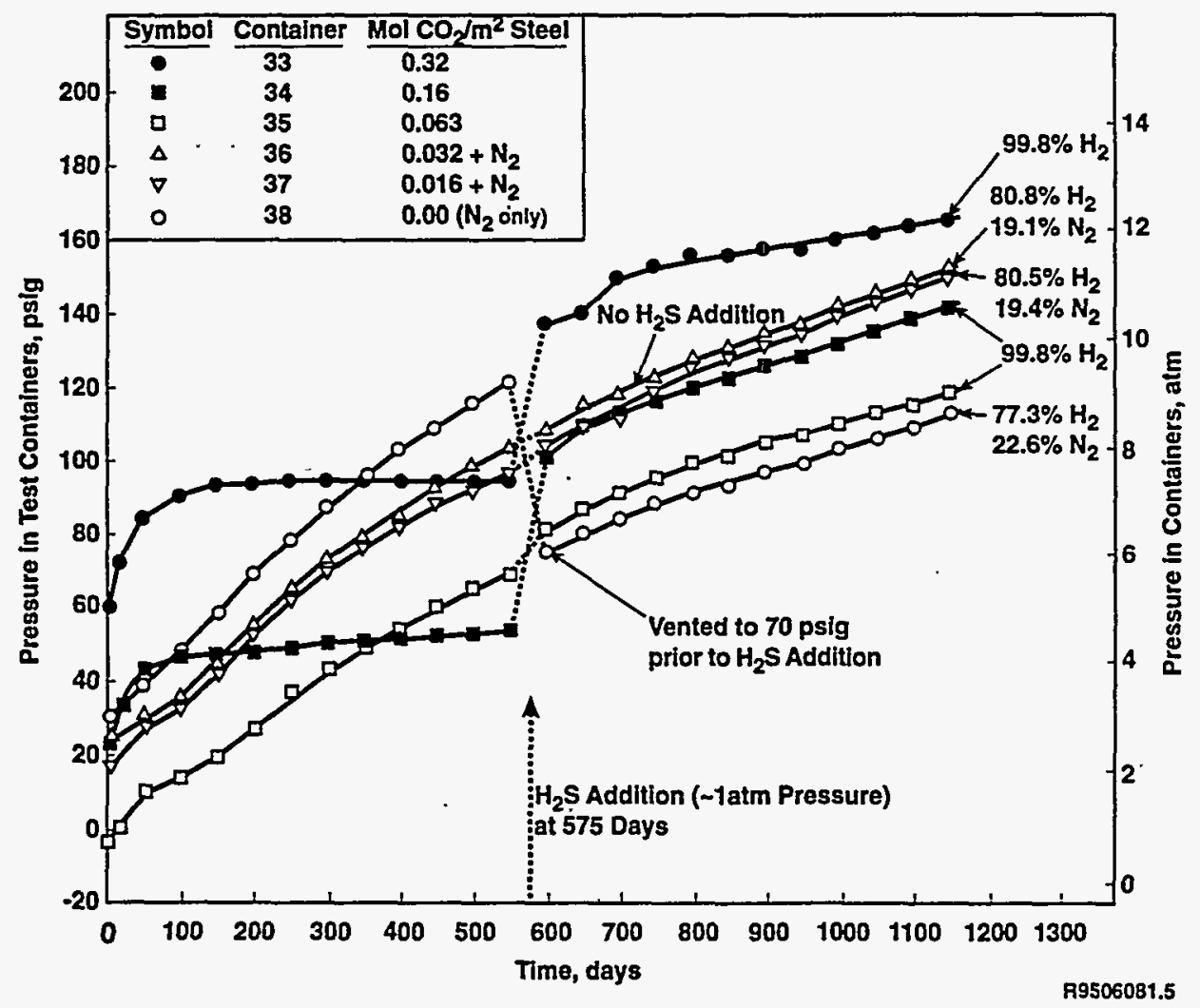

Figure 6-3. Pressure-time curves, controlled- $\mathrm{CO}_{2}$-addition tests. The final plenum gas analyses are given next to the last data points on the curves. Note the complete absence of $\mathrm{CO}_{2}$ or $\mathrm{H}_{2} \mathrm{~S}$ in the gas phase. The data in the vicinity of the $\mathrm{H}_{2} \mathrm{~S}$ addition at 575 days are not included in the figure because of the complications that would be introduced, which would make the figure difficult to interpret. These data may be found in Appendix A.?

7 The raw pressure-time data for the test containers 33 through 38 corresponding to the curves of Figure 6-3 are presented in Appendix A-1. The individual-specimen descriptions are presented in Appendix B-1. 
passive state was not ultimately achieved by the specimens in this test. A continual pressure increase was not observed in the excess- $\mathrm{CO}_{2}$ tests after passivation of the specimens was achieved (see Figure 6-2).

Assuming that all of the $\mathrm{H}_{2}$ resulting from the corrosion reaction collects in the plenum of the test container, that all of the $\mathrm{H}_{2}$ resulting from the corrosion reaction is accounted for, that passivation of the steel does not stop the corrosion reaction, and that the reaction

$$
\mathrm{Fe}+\mathrm{CO}_{2}+\mathrm{H}_{2} \mathrm{O}=\mathrm{FeCO}_{3}+\mathrm{H}_{2}
$$

is the only $\mathrm{H}_{2}$-producing reaction, then the reaction will stop when the $\mathrm{H}_{2}$ pressure in the plenum equals the original starting $\mathrm{CO}_{2}$ charge pressure (i.e., the $\mathrm{CO}_{2}$ pressure in the container plenum before its dissolution in the brine). ${ }^{8}$ The initial charge pressures are given in Table 6-1. From these data and associated assumptions it can be calculated that the reaction in container 33 has consumed $95 \%$ of the original $\mathrm{CO}_{2}$ charge at 250 days, that the reaction in container 34 has consumed the equivalent of $110 \%$ of the original $\mathrm{CO}_{2}$ charge at 250 days, and that the reaction in container 35 has consumed the equivalent of $220 \%$ of the original $\mathrm{CO}_{2}$ charge at 250 days. Obviously, an $\mathrm{Fe}-\mathrm{H}_{2} \mathrm{O}$ reaction is proceeding and producing $\mathrm{H}_{2}$ in the latter two cases cited. The containers with less $\mathrm{CO}_{2}$ than container 35 essentially behaved as though no $\mathrm{CO}_{2}$ had been added at all, as their pressure-time curves closely simulate that of the $\mathrm{CO}_{2}$-free control, container 38 .

The pressure-time curve of container 35 appeared to temporarily passivate in the time period 30-50 days. If it is assumed as before that $\mathrm{H}_{2}$ generated is equivalent to $\mathrm{CO}_{2}$ consumed, at 50 days the initial $\mathrm{CO}_{2}$ charge has been $110 \%$ consumed. This good agreement between apparent passivation and $\mathrm{CO}_{2}$ consumption suggests that a state of imperfect passivation was produced by the available $\mathrm{CO}_{2}$, perhaps produced by a siderite $\left(\mathrm{FeCO}_{3}\right)$ layer containing defects that could not remain "healed" due to the absence of a continuing supply of $\mathrm{CO}_{2}$. The defective film then everitually lost its

8 Strictly speaking, there will always be some $\mathrm{CO}_{2}$ remaining unreacted, as equilibrium conditions require a residual $\mathrm{CO}_{2}$ fugacity equal to $\sim 2 \times 10^{-4} f_{\mathrm{H} 2}$ (SAND92-7347). In the practical terms of the present test, this $\mathrm{CO}_{2}$ fugacity will not be sensed by the pressure gauges employed, nor will it affect the conclusions drawn in the subsequent discussion. 
protectiveness entirely, and permitted the competing $\mathrm{Fe}-\mathrm{H}_{2} \mathrm{O}$ reaction to proceed at a normal rate, as in the case of the Fe-anoxic brine (brine/ $\mathrm{N}_{2}$ ) tests or the case of container 38 .

If it is assumed 1) that container 33 represents truly passivated conditions, and 2) that container 34 represents almost-passivated conditions, then the conclusion can be drawn that the minimum amount of $\mathrm{CO}_{2}$ required to passivate steel under the test conditions employed (Brine $\mathrm{A}$ at $30^{\circ} \mathrm{C}$ ) is an amount lying between 0.32 and $0.16 \mathrm{~mol} \mathrm{CO} / \mathrm{m}^{2}$ steel.

An addition of $\mathrm{H}_{2} \mathrm{~S}$ was made to the controlled- $\mathrm{CO}_{2}$-addition tests to determine 1) if the passivating effect of $\mathrm{CO}_{2}$ would persist if $\mathrm{H}_{2} \mathrm{~S}$ were added to a $\mathrm{CO}_{2}$-passivated system (container 33 and, to a lesser extent, container 34), and 2) if the $\mathrm{H}_{2} \mathrm{~S}$ would have the same passivating effect on the steel in the controlled- $\mathrm{CO}_{2}$-addition tests as it exhibited in the case of a 5-atm $\mathrm{H}_{2} \mathrm{~S}$ addition test in which no other reactant was present except Brine A. (This study is described in the next section of this report.)

The amount of $\mathrm{H}_{2} \mathrm{~S}$ to be added to the test containers was arbitrarily selected to be that quantity that would result in an equilibrium $\mathrm{H}_{2} \mathrm{~S}$ partial pressure of $1 \mathrm{~atm}$ in the plenum of the test container. The amount added to each container is presented in Table 6-2. Container 36 was designated a control test, so no $\mathrm{H}_{2} \mathrm{~S}$ was added to that container.

Table 6-2. Summary of $\mathrm{H}_{2} \mathrm{~S}$ Additions to Test Containers

\begin{tabular}{cc}
\hline & Test Container \\
\hline 33 & $\begin{array}{c}\text { Pressure Increase (Quasi-Equilibrated) } \\
\text { Due to } \mathrm{H}_{2} \mathrm{~S} \text { Addition, atm (psi) }\end{array}$ \\
34 & $1.2(17)$ \\
35 & $1.4(21)$ \\
36 & $1.2(18)$ \\
37 & $0.0(0.0)$ \\
38 & $0.9(13)$ \\
\end{tabular}


Because of the simultaneous reaction of the $\mathrm{H}_{2} \mathrm{~S}$ with the contents of the containers (specimens plus existing reaction products), and because of $\mathrm{H}_{2} \mathrm{~S}$ does not dissolve immediately in the brine, the exact amount of $\mathrm{H}_{2} \mathrm{~S}$ added to each test container cannot be known with certainty. For this reason, Table 6-2 presents the pressure increase as an estimate associated with a state of quasi equilibrium.

The amount of $\mathrm{H}_{2} \mathrm{~S}$ added can be estimated quantitatively from knowledge of the pressure increase seen in the plenum of the container upon adding the $\mathrm{H}_{2} \mathrm{~S}$ to the individual containers. The average amount added was 0.11 mols $\mathrm{H}_{2} /$ container, or $0.18 \mathrm{mols} \mathrm{H}_{2} \mathrm{~S} / \mathrm{m}^{2}$ steel. This quantity of $\mathrm{H}_{2}$ is a factor of $\sim 3$ greater than that required to passivate steel in the Brine $\mathrm{A} / \mathrm{H}_{2} \mathrm{~S}$ studies previously reported (SAND92-7347), based on the amount of $\mathrm{H}_{2} \mathrm{~S}$ that had actually reacted with the steel to form the passive FeS layer. However, the $\mathrm{H}_{2} \mathrm{~S}$ partial pressure used in that study was $5 \mathrm{~atm}$, a factor of $\sim 5$ higher than the $\mathrm{H}_{2} \mathrm{~S}$ partial pressure present in the tests described here.

Immediately after the $\mathrm{H}_{2} \mathrm{~S}$ addition was made, the pressure began to drop in the containers initially having relatively small quantities of $\mathrm{CO}_{2}$ (containers 37 and 38 - see Appendix $\mathrm{A}$ for the detailed pressure-time data). This is ascribed to an on-going reaction, expected to be thermodynamically favored, between the $\mathrm{H}_{2} \mathrm{~S}$ addition and the ferrous-hydroxide-type corrosion products already present in the containers that would have formed in these tests in the absence of sufficient $\mathrm{CO}_{2}$ to passivate the steel specimens. This reaction will proceed without gas formation:

$$
\mathrm{Fe}(\mathrm{OH})_{2}+\mathrm{H}_{2} \mathrm{~S}=\mathrm{FeS}+2 \mathrm{H}_{2} \mathrm{O}
$$

The post- $\mathrm{H}_{2} \mathrm{~S}$-addition pressure immediately began to increase in the two canisters in which sufficient $\mathrm{CO}_{2}$ had initially been added to passivate the systems (containers 33 and 34). This pressure increase can be explained in at least two different ways:

- The $\mathrm{H}_{2} \mathrm{~S}$ could have damaged the passivating film of $\mathrm{FeCO}_{3}$ present on the steel specimens, allowing the $\mathrm{H}_{2} \mathrm{~S}$ to initiate a $\mathrm{H}_{2}$-producing reaction with the steel surfaces of the specimens producing $\mathrm{H}_{2}$ gas; and/or

- The $\mathrm{H}_{2} \mathrm{~S}$ could be reacting with the $\mathrm{FeCO}_{3}$ on the steel surfaces to form $\mathrm{FeS}, \mathrm{CO}_{2}$, and $\mathrm{H}_{2} \mathrm{O}$, according to the following thermodynamically favored reaction: 


$$
\mathrm{H}_{2} \mathrm{~S}+\mathrm{FeCO}_{3}=\mathrm{FeS}+\mathrm{CO}_{2}+\mathrm{H}_{2} \mathrm{O}
$$

Because the solubility of $\mathrm{CO}_{2}$ in the brine is significantly less than that of $\mathrm{H}_{2} \mathrm{~S},{ }^{9}$ the result would be a positive pressure change in the container even though there is no net increase in the moles of gas present in the system. The $\mathrm{CO}_{2}$ so released would be expected to eventually re-react with the steel surface, ending up either as adherent or loose (particulate) corrosion product.

The "control" container having no $\mathrm{H}_{2} \mathrm{~S}$ addition (container 36) behaved as expected, i.e., it . slowly increased in pressure as would be expected from a test essentially consisting of steel specimens immersed in anoxic Brine A.

The addition of $\sim 1 \mathrm{~atm}$ pressure of $\mathrm{H}_{2} \mathrm{~S}$ to the limited- $\mathrm{CO}_{2}$ tests clearly disrupted the passive state of the previously $\mathrm{CO}_{2}$-passivated specimens; and it did not bring about an $\mathrm{H}_{2} \mathrm{~S}$-induced passivity, as might be expected from the tests previously described (tests 40-43) which passivated in the presence of $5 \mathrm{~atm}$ pressure of $\mathrm{H}_{2} \mathrm{~S}$ in Brine A (SAND92-7347 and the next section of this report).

The XRD analyses of the reaction products formed on the surfaces of specimens (all lot $J$ steel) taken from each test container, as well as a specimen of particulate material taken from the (common) brine-dump vessel, which represented an averaged specimen of the non-adherent reaction products formed during the test exposures, are presented in Table 6-3.

From the table, it can be seen that specimens from containers 33 and 34 show both $\mathrm{FeCO}_{3}$ (siderite) and FeS (mackinawite) reaction products, on their surfaces, suggesting the not-unexpected reaction with the steel by both $\mathrm{CO}_{2}$ and $\mathrm{H}_{2} \mathrm{~S}$. Neither the $\mathrm{CO}_{2}$ nor the $\mathrm{H}_{2} \mathrm{~S}$ addition ultimately resulted in a passivated condition, and it is not known from the available information what gas fugacities, if any, would have been capable of causing a passivated state to exist once active corrosion had been initiated.

9 In the course of the present study, the Henry's law coefficient (expressed as mol gas/atm-L) for $\mathrm{CO}_{2}$ in Brine $\mathrm{A}$ was determined to be 0.010 at $30^{\circ} \mathrm{C}$; the corresponding value for $\mathrm{H}_{2} \mathrm{~S}$ was determined to be 0.050 . In a typical seal-welded container test, $\mathrm{CO}_{2}$ under equilibrium conditions will be distributed so that the major portion $(\sim 65 \%)$ will be in the plenum, with $35 \%$ in the brine. Because of its greater solubility in brine, $\mathrm{H}_{2} \mathrm{~S}$ will be distributed so that $\sim 73 \%$ resides in the brine, with only $\sim 27 \%$ in the container plenum. 
Table 6-3. Identification by XRD of Reaction Products Formed During "Limited- $\mathrm{CO}_{2}$-Addition with $\mathrm{H}_{2} \mathrm{~S}$ Addition" Tests. Lot J specimens were selected for analysis.

\begin{tabular}{|c|c|c|c|}
\hline \multirow[b]{2}{*}{$\begin{array}{l}\text { Source of } \\
\text { Specimen }\end{array}$} & \multicolumn{2}{|c|}{ Gas Added, $\mathrm{mol} / \mathrm{m}^{2}$ steel } & \multirow[b]{2}{*}{$\begin{array}{c}\text { Principal Reaction } \\
\text { Products }\end{array}$} \\
\hline & $\mathrm{CO}_{2}$ & $\mathrm{H}_{2} \mathrm{~S}$ & \\
\hline Container 33 & 0.32 & $\sim 0.18$ & $\begin{array}{l}\mathrm{FeCO}_{3} \\
\mathrm{FeS}\end{array}$ \\
\hline Container 34 & 0.16 & $\sim 0.18$ & $\begin{array}{l}\mathrm{FeCO}_{3} \\
\mathrm{FeS}\end{array}$ \\
\hline Container 35 & 0.063 & $\sim 0.18$ & $\begin{array}{l}\mathrm{Fe}_{2}(\mathrm{OH})_{3} \mathrm{Cl} \\
\mathrm{Fe}_{8}(\mathrm{O}, \mathrm{OH})_{16} \mathrm{Cl}_{1.3} \\
\mathrm{FeCO}_{3}\end{array}$ \\
\hline Container 36 & 0.032 & 0.00 & $\begin{array}{l}\mathrm{Fe}_{2}(\mathrm{OH})_{3} \mathrm{Cl} \\
\mathrm{Fe}_{8}(\mathrm{O}, \mathrm{OH})_{16} \mathrm{Cl}_{1.3}\end{array}$ \\
\hline Container 37 & 0.016 & $\sim 0.18$ & $\begin{array}{l}\mathrm{Fe}_{2}(\mathrm{OH})_{3} \mathrm{Cl} \\
\mathrm{Fe}_{8}(\mathrm{O}, \mathrm{OH})_{16} \mathrm{Cl}_{1.3}\end{array}$ \\
\hline Container 38 & 0.00 & $\sim 0.18$ & $\begin{array}{l}\mathrm{Fe}_{2}(\mathrm{OH})_{3} \mathrm{Cl} \\
\mathrm{Fe}_{8}(\mathrm{O}, \mathrm{OH})_{16} \mathrm{Cl}_{1.3}\end{array}$ \\
\hline \multicolumn{3}{|c|}{ Particulate material (mixed) } & $\begin{array}{l}\mathrm{FeO}(\mathrm{OH}) \\
\mathrm{FeCO}_{3}\end{array}$ \\
\hline
\end{tabular}

Containers 36, 37, and 38 show no $\mathrm{FeCO}_{3}$, which is not surprising, given the small amount of $\mathrm{CO}_{2}$ added to these tests. An unexplainable result of the analyses, however, relates to the lack of FeS corrosion product observed on the surfaces of specimens from containers 35,37 , and 38 , as well as the lack of a sulfide in the particulate corrosion product.

Container 36 is of additional interest. This container, nominally treated as an anoxic brine/ $\mathrm{N}_{2}$ container (as, for example, test containers 25 and 26, Table 3-1) except for the initial addition of a small amount of $\mathrm{CO}_{2}$, yielded an identifiable corrosion product, unlike past experience with anoxic brine/ $\mathrm{N}_{2}$ tests, whose corrosion products resisted identification (SAND92-7347). The corrosion product identified (container 36, Table 6-3) was Mg-free, unlike the corrosion products found in past studies (see Section 6.1.1.1 of this report). It must be noted that the XRD procedure that identified a corrosion product was not a procedure that utilized minimization of oxygen contact with the corrosion 
product prior to its analysis. Two additional tests (tests 46 and 47, Table 3-1) were initiated specifically to obtain further insights into the nature of the corrosion product from this kind of a test. The results of this investigation are also presented in Section 6.1.1.1.

If the initial addition of $\mathrm{CO}_{2}$ is ignored, and if the pressure buildup .in the plenum of container 36 is equated (as has been done in the past) to $\mathrm{H}_{2}$ buildup and equivalent metal reacted, then this test provides an excellent check on the previous long-term measurement of gas generation by steel under anoxic brine conditions (Figure 6-1). If the slope of the container 36 curve between 1 and 2 years is determined, excellent agreement is found with the 12-to-24 month reaction rate of Figure 6-1. If the final year of the 3.2-year container 36 test is examined similarly, it is found that the reaction rate is $\sim 70 \%$ that of the 1-to-2 year reaction rate. Thus, as was earlier suggested, the rate under the test conditions will continue to decrease with increasing test time, at least until some limiting rate is achieved.

\subsubsection{BRINE/ $\mathrm{H}_{2} \mathrm{~S}$ TESTS (WITH EVENTUAL $\mathrm{CO}_{2}$ ADDITION)}

The brine/ $\mathrm{H}_{2} \mathrm{~S}$ tests (with eventual $\mathrm{CO}_{2}$ addition) were intended to provide information on 1) the corrosion and gas generation proclivity of low-carbon steel in the presence of Brine $\mathrm{A}$ and $\mathrm{H}_{2} \mathrm{~S}$, and 2) the effect of $\mathrm{CO}_{2}$ additions on specimens pre-passivated by $\mathrm{H}_{2} \mathrm{~S}$. Like $\mathrm{CO}_{2}, \mathrm{H}_{2} \mathrm{~S}$ is a potential byproduct of microbial activity through sulfate reduction in the WIPP, so its presence in the site environment is considered to be a credible possibility. As has been shown [Equations (17) and (18), SAND92-7347], the thermodynamic tendency for reaction of $\mathrm{Fe}$ with $\mathrm{H}_{2} \mathrm{~S}$ - is strong. There is a possibility, however, of passivating steel in the presence of $\mathrm{H}_{2} \mathrm{~S}$ at sufficient activity to form stable, relatively unreactive sulfide layers (SAND92-7347, Section 4.3).

The brine/ $\mathrm{H}_{2} \mathrm{~S}$ tests of low-carbon steel were performed in test containers $40,41,42$, and 43 . In replicate test containers 40 and 41 , the specimens were exposed under immersed conditions; in test containers 42 and 43 the specimens were suspended in the vapor phase over Brine A. The method of racking the specimens in test containers was similar to that used in the anoxic brine (brine/ $\mathrm{N}_{2}$ ) and the $\mathrm{CO}_{2}$-brine tests previously described, and the amount of brine used in each test container was essentially the same as that used in the previous tests: $1.4 \mathrm{~L}$ in the immersed-specimen tests, $250 \mathrm{~mL}$ in the vapor-phase tests. The area of steel specimens present in each test container was $0.497 \mathrm{~m}^{2}$. 
The partial pressure of $\mathrm{H}_{2} \mathrm{~S}$ in these initial $\mathrm{Fe} / \mathrm{H}_{2} \mathrm{~S}$ tests was purposefully chosen to be a high value relative to $\mathrm{H}_{2} \mathrm{~S}$ concentrations expected in the WIPP. An arbitrary (equilibrium) partial pressure of $5 \mathrm{~atm}$ was selected for these tests. For $\mathrm{H}_{2} \mathrm{~S}$, the gas-charging method employed was similar to that used for $\mathrm{N}_{2}$ and $\mathrm{CO}_{2}$ in tests previously described, in that the $\mathrm{H}_{2} \mathrm{~S}$ gas was charged into the plenum of a previously evacuated test container with both steel specimens and Brine $\mathrm{A}$ already in place.

The $\mathrm{H}_{2} \mathrm{~S}$ gas dissolved much more rapidly into the brine than did the $\mathrm{CO}_{2}$. The Henry's Law coefficient, $\mathrm{S}$, for $\mathrm{H}_{2} \mathrm{~S}$ was determined to be $0.050 \mathrm{mols} / \mathrm{atm}-\mathrm{L}$ at the gas-charging temperature of $\sim 25^{\circ} \mathrm{C}$. As a consequence of the high solubility of the $\mathrm{H}_{2} \mathrm{~S}$ in Brine $\mathrm{A}$, the major amount of the $\mathrm{H}_{2} \mathrm{~S}$ charged into the immersed-specimen test containers is dissolved in the brine phase. Because $\mathrm{H}_{2} \mathrm{~S}$ shows significant non-ideal behavior, even at pressures as low as $5 \mathrm{~atm}$, a van der Waals relationship was used to determine the relationship between moles $\mathrm{H}_{2} \mathrm{~S}$ and pressure of $\mathrm{H}_{2} \mathrm{~S}$ throughout all of the $\mathrm{H}_{2} \mathrm{~S}$ investigations (Lange's Handbook, 1985), unless noted otherwise.

The pressure-time curves for tests 40 through 43 are shown in Figure 6-4. Specimens in containers 40 and 42 were exposed to Brine $A$ and $\mathrm{H}_{2} \mathrm{~S}$ only. Specimens in containers 41 and 43 were exposed to Brine $\mathrm{A}$ and $\mathrm{H}_{2} \mathrm{~S}$ only for 487 days. At that time $\mathrm{CO}_{2}$ was admitted into the test containers.

The raw data associated with the pressure-time curves of Figure 6-4 are presented in Appendix A-2; the individual specimen data are presented in Appendix B-2.

From the time of test initiation the $\mathrm{H}_{2} \mathrm{~S}$ appeared to have a strong passivating effect on the coupons in the immersed-specimen tests (40 and 41), and appeared to be essentially unreactive in the vapor-phase tests (42 and 43). After an initial period of activity lasting about 6 days, the specimens appeared to be essentially inert in all of the test environments. During the initial period of activity the immersed specimens appeared to generate some corrosion-product $\mathrm{H}_{2}$, as expected. The vaporphase tests appeared to simply show the effect of continued $\mathrm{H}_{2} \mathrm{~S}$ dissolution in the brine phase present (the vapor-phase test containers were not shaken after gas addition to expedite equilibration of gas between vapor space and brine, as this procedure would have caused the brine to contaminate the surfaces of the specimens).

The lack of continued reaction after a time period of about 6 days in the immersed-specimen test condition suggested that a sulfide phase had rapidly formed on the specimen surfaces and stopped further reaction from taking place. An examination of the specimens removed from container 40 after 


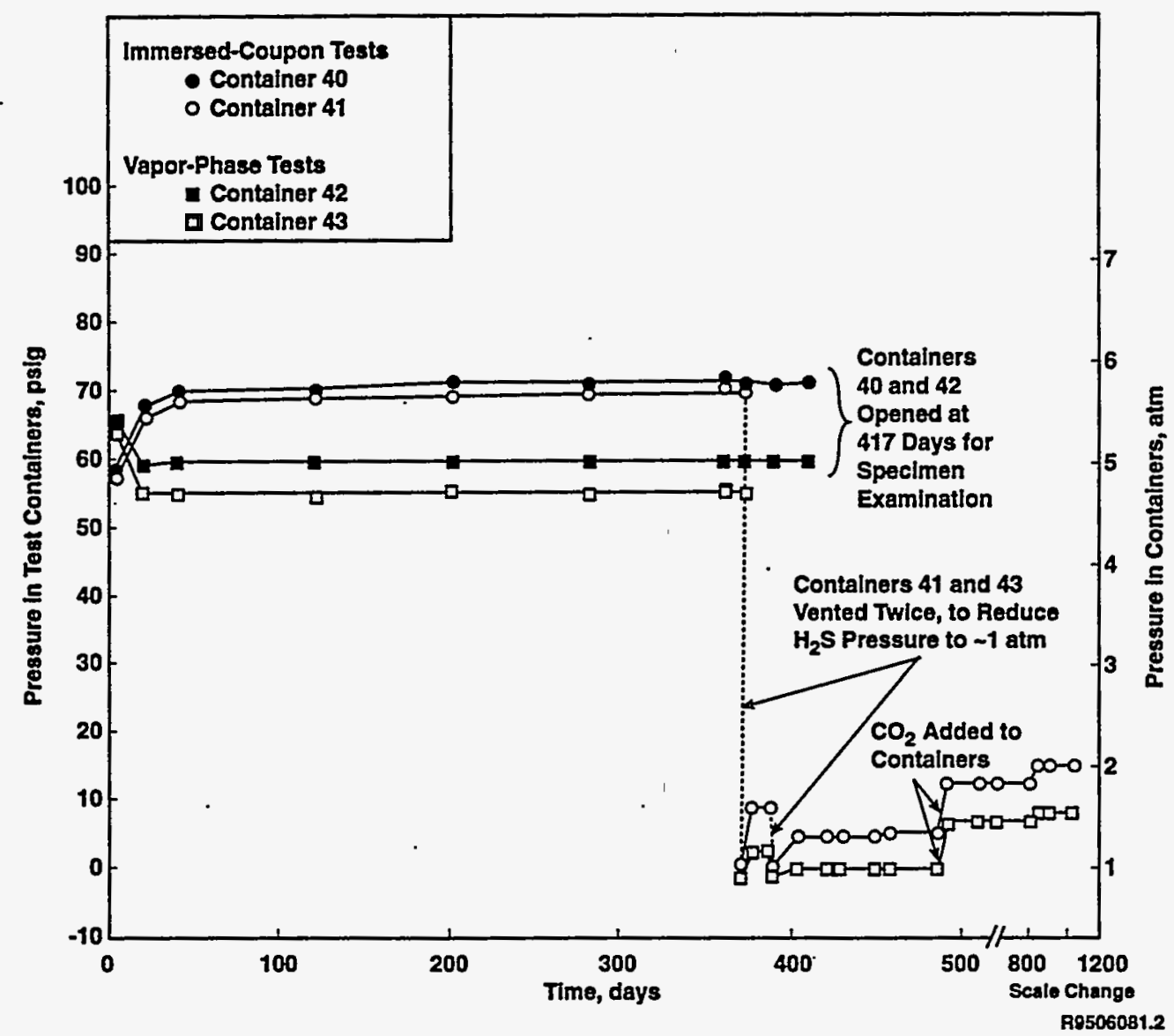

Figure 6-4. Pressure-time curves, low-carbon steel/ $\mathrm{H}_{2} \mathrm{~S}$ tests

417 days revealed that the specimens were coated with a thin, adherent reaction product. The specimens from container 40 were black; the reaction product film on specimens from container 42 was extremely thin, giving the specimen a grey tarnished appearance. In both cases, the reaction product was identified as FeS (mackinawite) by XRD analyses. The finding of a passive film consisting of the "low" sulfide FeS is not in agreement with the findings of other investigations, who attribute passivity primarily to the higher sulfides, viz. pyrrhotite, $\mathrm{Fe}_{1-x} \mathrm{~S}$, and pyrite, $\mathrm{FeS}_{2}$ (SAND92-7347, Section 4.3).

A $\mathrm{CO}_{2}$ addition was made to containers 41 and 43 , to determine whether the passive nature of the reaction product layer would be retained in the presence of this gas. After venting the containers 
to $\sim 1 \mathrm{~atm}$ total equilibrium pressure, $\mathrm{CO}_{2}$ was added until an equilibrium $\mathrm{CO}_{2}$ partial pressure of $\sim 1 / 2$ atm was attained. The test was allowed to continue for an additional period of 592 days.

It is evident from the curves of Figure 6-4 that the passive nature of the systems was not compromised by the $\mathrm{CO}_{2}$ addition, as the corrosion process, as evidenced by pressure buildup in the system, did not occur to any substantial extent for the duration of the test. A small pressure increase of 1 to 2 psi was observed in the test containers at 820 days; this was coincidental with the movement of the containers from one laboratory to another, and is attributed, at least in part, to jostling the mechanical pressure gauges to a new "equilibrium" reading (needle position).

The specimens from containers 41 and 43 exhibited the same visual appearance as those from containers 40 and 42 . Once again, XRD analysis showed FeS, mackinawite, to be the most significant reaction product on the specimen surfaces.

The composition of the gas in the plenum of the test containers at the conclusion of the tests is shown in Table 6-4. The immersed-specimen containers show, as expected, the greatest amount of reaction-product $\mathrm{H}_{2}$ present.

Table 6-4. Composition of Gas in Plenum of Containers $40,41,42$, and 43 at Conclusion of Test. Only the principal constituents are listed.

\begin{tabular}{|c|c|c|c|c|}
\hline \multirow[b]{2}{*}{ Specie } & \multicolumn{4}{|c|}{ Concentration, mole percent } \\
\hline & Container 40 & Container 41 & Container 42 & Container 43 \\
\hline $\mathrm{CO}_{2}$ & 3.7 & 17.3 & 0.50 & 34.1 \\
\hline $\mathrm{H}_{2}$ & 9.7 & 8.2 & 1.0 & 2.4 \\
\hline $\mathrm{H}_{2} \mathrm{~S}$ & 86.0 & 74.5 & 98.1 & 63.3 \\
\hline
\end{tabular}

The specimens from container 40 were stripped of their corrosion product, and the overall metal loss during the test was determined gravimetrically. It was determined that the amount of metal lost during the test was a total of $1.6 \mathrm{~g}$, or 0.056 moles of Fe were lost per $\mathrm{m}^{2}$ of steel exposed. The mackinawite-forming reaction 


$$
\mathrm{Fe}+\mathrm{H}_{2} \mathrm{~S}=\mathrm{FeS}+\mathrm{H}_{2}
$$

consumes a mole of $\mathrm{H}_{2} \mathrm{~S}$ per mole Fe reacted. Therefore, in the present test passivation occurred with the consumption of 0.056 moles $\mathrm{H}_{2} \mathrm{~S} / \mathrm{m}^{2}$ steel exposed. As in the case of $\mathrm{CO}_{2}$-brine tests, the amount of reactant required to passivate the steel surface is very likely to be a function of the fugacity of the $\mathrm{H}_{2} \mathrm{~S}$ present in the test environment, and this fugacity-passivity dependence may be a major reason for the lack of agreement between investigators as to what constitutes a passive film, and the test environments that do or do not produce passive steel surfaces (SAND92-7347, and Section 6.1.1.2 of this report).

The thermodynamic stability of iron sulfides relative to $\mathrm{FeCO}_{3}$ is consistent with the lack of disruption of the FeS film by $\mathrm{CO}_{2}$ shown in the present tests, and the disruption of the $\mathrm{FeCO}_{3}$ film by $\mathrm{H}_{2} \mathrm{~S}$ described in the previous section (Section 6.1.1.2) of this report.

\subsubsection{ANOXIC ERDA-6 BRINE (ERDA-6 BRINE/N ${ }_{2}$ ) TESTS}

Anoxic tests using low-carbon steel specimens immersed in ERDA- 6 brine were performed as adjunct tests to the constant-pH tests, described in the next subsection of this report. The constant-pH tests were to be done using constant-pH brine environments having $\mathrm{pH}$ values controlled at $3,5,7,9$, and 11. Because $\mathrm{Mg}$ was known to precipitate from solution at $\mathrm{pH}$ values greater than $\sim 8.6$, ERDA-6 brine (Molecke, 1983), a low-magnesium WIPP-relevant brine, was substituted for Brine A as a candidate brine for the constant-pH tests. It was further found in a PNL investigation that both the $\mathrm{Mg}$ and $\mathrm{Ca}$ constituents of ERDA- 6 brine essentially completely precipitated from solution at a $\mathrm{pH}$ value of 11 . To avoid having a brine of variable composition (other than $\mathrm{H}^{+}$concentration) in the constant-pH tests, it was decided to use an ERDA-6 brine modified to eliminate the $\mathrm{Mg}, \mathrm{Ca}$, and $\mathrm{HCO}_{3}$ constituents. The base composition of the modified ERDA- 6 brine used in the PNL studies is given in Table 5-5.

In order to interpret the results of the constant-pH tests, and apply the results of those tests broadly to the extensive tests using Brine $A$ test environments, it was necessary to obtain an 
information base relating the corrosion rates of low-carbon steels in anoxic modified ERDA- 6 brine to the corrosion rates of low-carbon steel in anoxic Brine $A$ environments. This requirement gave rise to the tests described here.

The seal-welded container tests using anoxic modified ERDA- 6 brine.(tests 44 and 45 ) were essentially identical in specimen type, specimen racking, brine quantity, and experimental procedure to the equivalent tests using Brine $A$ (e.g., tests $1,2,9,10,17,18,25$ and 26) described in Sections 5.1 and 6.1.1.1 of this report. A significant difference exists between the two tests in total specimen area: $0.604 \mathrm{~m}^{2}$ for the Brine A tests vs. $0.638 \mathrm{~m}^{2}$ for the ERDA- 6 brine tests.

The pressure-time plots of tests 44 and 45 are presented in Figure 6-5. Also included in the figure for comparison are curve segments taken from Figure 6-1, depicting pressure-time data from almost equivalent tests using a Brine $\mathrm{A}$ environment.

The raw pressure-time data for the ERDA- 6 brine curves of Figure 6-5 are presented in Appendix A-3; the individual-specimen data may be found in Appendix B-3.

If it is assumed 1) that pressure buildup in the test containers is directly proportional to metal loss through steel reaction and $\mathrm{H}_{2}$ generation, and 2) that the steel reaction rate is proportional to sample area, the curves of Figure 6-5 can, in theory, be used to draw conclusions concerning the reaction rates in the two different brine environments. In fact, the validity of the assumptions has been repeatedly shown in past related work (SAND92-7347).

If the 150- to 300-day period only is examined, the slopes of the curves of Figure 6-5 yield the data tabulated below:

\begin{tabular}{|c|c|c|}
\hline Curve & $\begin{array}{c}\text { Rate, } \\
\text { psi/year }\end{array}$ & $\begin{array}{c}\text { Average, } \\
\text { psi/year }\end{array}$ \\
\hline 24-month, Brine A & 54.8 & 507 \\
\hline 12-month, Brine A & 46.6 & \\
\hline
\end{tabular}

Container 44

44.7

Container 45

40.9

42.8 


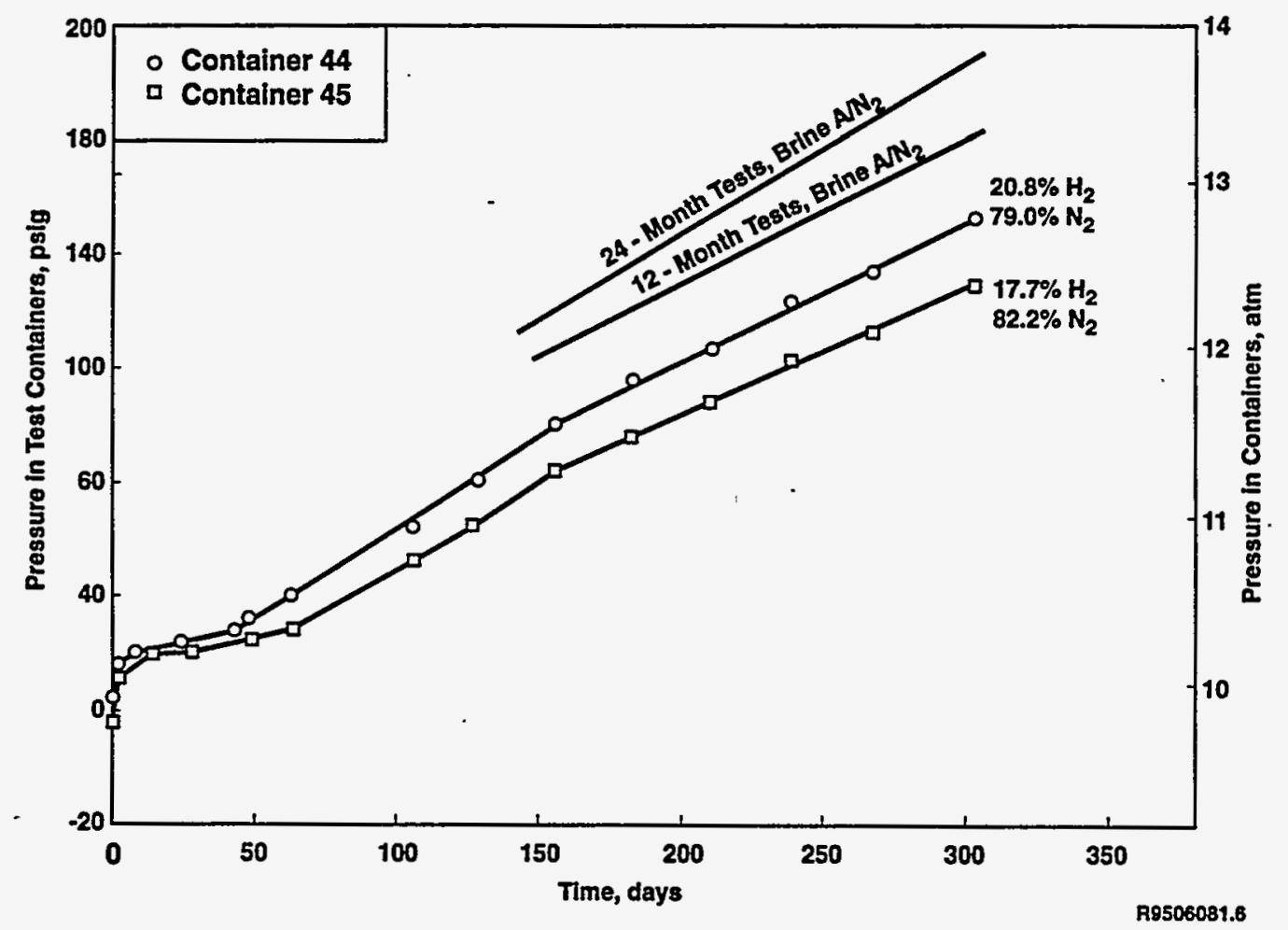

Figure 6-5. Pressure-time curves, containers 44 and 45 , compared with segments of pressure-time curves taken from Figure 6-1

Because the specimen area in containers 44 and 45 is greater than that of the Brine A tests, a downward adjustment has to be made in the average pressurization rate of containers 44 and 45 , if it is to be compared with the Brine $A$ data, i.e., the pressurization rate in the Brine $A$ containers (50.7 psi/year) must be compared with $42.8 \mathrm{psi} /$ year $\times 0.606 / 0.638$, or $40.5 \mathrm{psi} /$ year. This container-pressurization data comparison appears to make Brine A significantly more reactive than 
ERDA-6 brine. However, it appears in the present case that such a conclusion is not warranted, because the gravimetric (weight-change data) present a different picture.

Though past correlations between $\mathrm{H}_{2}$ generation data and $\mathrm{Fe}$ metal reacted have shown very good agreement, especially in the case of tests of 6 months duration or longer (SAND92-7347), the present ERDA- 6 brine tests have proved to be exceptions. If the metal lost to reaction (determined gravimetrically) is compared to $\mathrm{H}_{2}$ generated; the moles $\mathrm{H}_{2} /$ moles Fe reacted ratio for container 44 is only $\mathbf{0 . 5 5}$; for container 45 the ratio is $\mathbf{0 . 7 7}$. These ratios are considerably lower than the ratio of 0.90 for the 12-month anoxic Brine A tests (SAND92-7347). The reason for the apparent lack of accountability of corrosion-product $\mathrm{H}_{2}$ in tests 44 and 45 is not known. Possible reasons for lack of $\mathrm{H}_{2}$ accountability, and a discussion of the possible errors associated with both gas-pressure and gravimetric data, are presented in SAND92-7347. It is not obvious that a significant error-inducing factor is operative in the present case. However, the lack of agreement between $\mathrm{H}_{2}$ formed and $\mathrm{Fe}$ reacted plainly renders the foregoing analysis of the reactivity of Brine A relative to ERDA-6 brine based on pressure data alone highly questionable.

If the total Fe lost to reaction in containers 44 and $45(11.50 \mathrm{~g})$ is corrected assuming linear reaction kinetics, for the short test duration (10 months vs. the 12-month Brine $A$ tests) and the relatively large total specimen area $\left(0.638 \mathrm{~m}^{2}\right.$ vs. $0.604 \mathrm{~m}^{2}$ for the Brine $A$ tests), the following adjusted weight loss is obtained:

$$
11.50 \mathrm{~g} \times \frac{12}{10} \times \frac{0.604}{0.638}=13.1 \mathrm{~g} \mathrm{Fe}
$$

The result of the computation of Equation 15 must then be compared with the total of $12.1 \mathrm{~g}$ of Fe reacted in the 12-month Brine A tests (containers 17 and 18, SAND92-7347). From this gravimetric-based analysis, ERDA- 6 brine would be judged to be actually slightly more reactive than Brine A.

The ERDA- 6 brine seal-welded container test has obviously not yielded conclusive quantitative results regarding the reactivity of ERDA- 6 brine, relative to Brine $A$, toward low-carbon steel. It is apparent, however, that the basic reactivity difference between the two brines is slight, relative to 
other factors known to be important in affecting corrosion rates. The effects of $\mathrm{pH}$ on the corrosion/ gas-generation of low-carbon steel in ERDA- 6 brine are therefore assumed to be equally applicable to Brine A environments.

\subsubsection{Constant-pH Tests}

The constant-pH tests were designed to yield information on the corrosion/gas generation rates of low-carbon steel that would be expected under a variety of $\mathrm{pH}$-altering conditions in the WIPP repository, e.g., the effects of microbe metabolites, or the effects of purposeful pH-altering additions to the backfill material. A range of $\mathrm{pH}$ values from 3 to 11 was selected for the investigation, as it was considered highly unlikely that a brine $\mathrm{pH}$ would be encountered in the WIPP lying outside of this range.

Some background information is presented here on the relationship between $\mathrm{pH}$ and corrosion product solubility. The information will aid in the interpretation of the constant-pH test results.

The anodic reaction in the corrosion of $\mathrm{Fe}$ in aqueous solutions is

$$
\mathrm{Fe}=\mathrm{Fe}^{++}+2 \mathrm{e}^{-}
$$

In acidic solution, the reduction reaction is

$$
2 \mathrm{H}^{+}+2 \mathrm{e}^{-}=\mathrm{H}_{2}
$$

In an alkaline solution, the reduction reaction is

$$
2 \mathrm{H}_{2} \mathrm{O}+2 \mathrm{e}^{-}=2(\mathrm{OH})^{-}+\mathrm{H}_{2}
$$


Whether the cathodic reaction is given by Equation 17 or 18, the result is the same - as more Fe dissolves into the solution, the solution becomes more concentrated in $\mathrm{OH}^{-}$ions, resulting in an increased $\mathrm{pH}$. On reaching saturation, Fe will precipitate out of solution as $\mathrm{Fe}(\mathrm{OH})_{2}$. The concentration of iron in solution is determined by the equilibrium for the dissociation of $\mathrm{Fe}(\mathrm{OH})_{2}$ :

$$
\mathrm{Fe}(\mathrm{OH})_{2}=\mathrm{Fe}^{++}+2 \mathrm{OH}^{-}
$$

for which the solubility product, $\mathrm{K}$, may be written

$$
\mathrm{K}=\left[\mathrm{Fe}^{++}\right] \cdot\left[\mathrm{OH}^{-}\right]^{2}
$$

At $25^{\circ} \mathrm{C}, \log \mathrm{K}$ has the value -14.71 (Pourbaix, 1974), for concentrations expressed in mol/L. As $\log (\mathrm{OH})^{-}=-14+\mathrm{pH}$, we obtain

$$
\log \left[\mathrm{Fe}^{++}\right]=13.29-2 \mathrm{pH}
$$

At $\mathrm{pH}$ values $>10.53$, the dissolution reaction for $\mathrm{Fe}(\mathrm{OH})_{2}$ is not the reaction given by Equation 19, but

$$
\mathrm{Fe}(\mathrm{OH})_{2}=\mathrm{HFeO}_{2}^{-}+\mathrm{H}^{+}
$$

For Equation 22, the dependence of the concentration of the dihypoferrite ion, $\mathrm{HFeO}_{2}^{-}$, on $\mathrm{pH}$ (Pourbaix, 1974) is given by

$$
\log \left[\mathrm{HFeO}_{2}^{-}\right]=-18.3+\mathrm{pH}
$$


It may be seen, from Equation 23, that, as the solution $\mathrm{pH}$ increases, larger amounts of $\mathrm{Fe}$ can remain in solution without precipitation of $\mathrm{Fe}(\mathrm{OH})_{2}$. Further, because the formation of each $\mathrm{HFeO}_{2}^{-}$ ion consumes one $(\mathrm{OH})^{-}$anion, the $\mathrm{pH}$ of the solution decreases as more and more Fe dissolves into the solution. Thus, left to itself, the corrosion of $\mathrm{Fe}$ in an aqueous anoxic solution will lead to an equilibrium $\mathrm{pH}$. This situation is more readily visualized by means of the construction presented in Figure 6-6, which plots the log concentration (in $\mathrm{mol} / \mathrm{L}$ ) of $\mathrm{Fe}$ in solution in equilibrium with solid $\mathrm{Fe}(\mathrm{OH})_{2}$ at $25^{\circ} \mathrm{C}$.

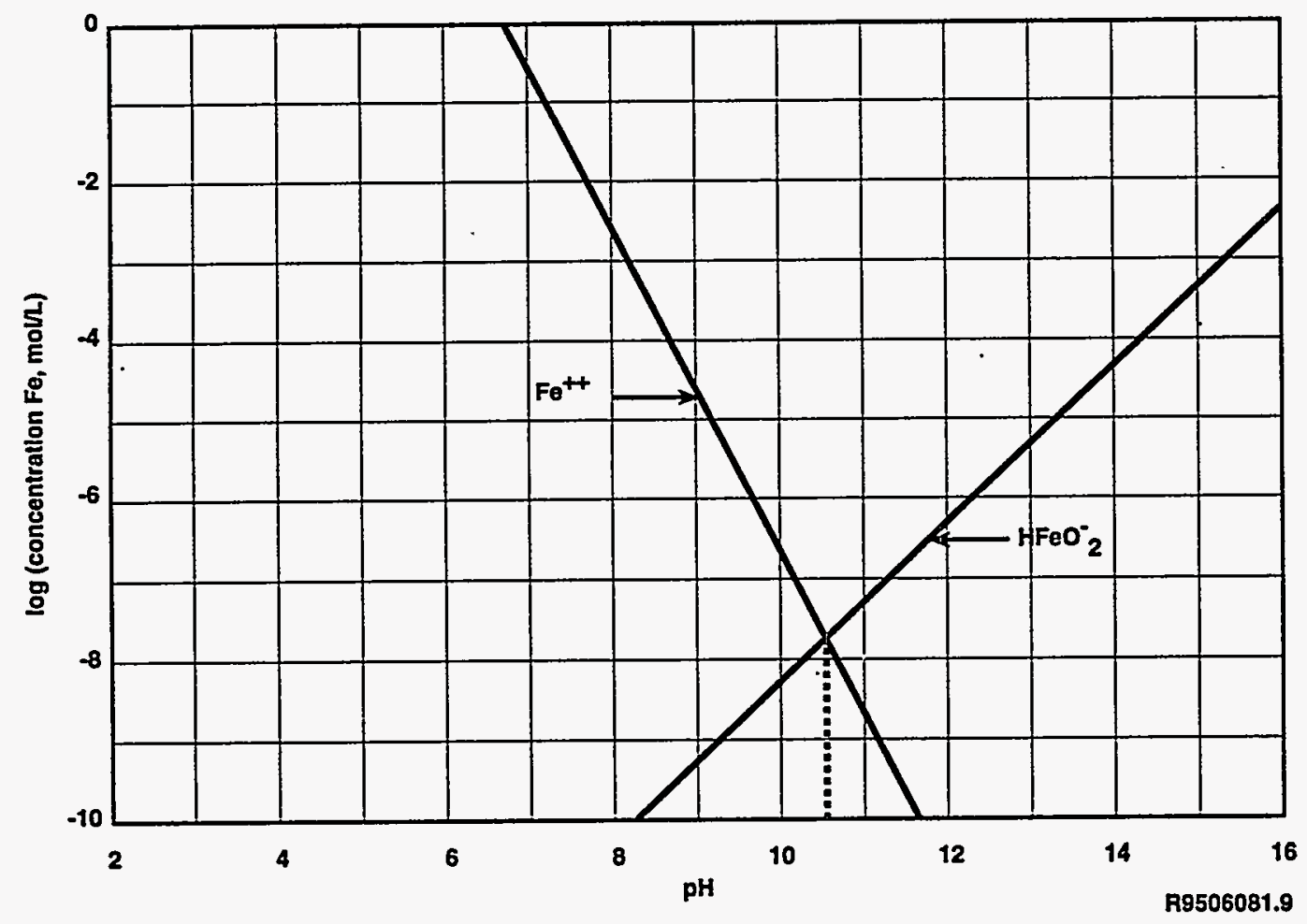

Figure 6-6. Influence of $\mathrm{pH}$ on the solubility of $\mathrm{Fe}(\mathrm{OH})_{2}$ at $25^{\circ} \mathrm{C}$ 
The figure shows that, at $\mathrm{pH}$ values $<10.53$, if the $\mathrm{pH}$ is not controlled by external means, the corrosion process will continue until the numerical value of the ion product $\left[\mathrm{Fe}^{++}\right] \cdot\left[\mathrm{OH}^{-}\right]^{2}$ reaches the solubility product value, given by the $\mathrm{Fe}^{++}$curve. Similarly, at $\mathrm{pH}$ values $>10.53$, the corrosion process will continue and the $\mathrm{pH}$ will decrease until the equilibrium associated with Equation 22 (the $\mathrm{HFeO}_{2}^{-}$curve) is established. At $\mathrm{pH}=10.53, \mathrm{Fe}^{++}$and $\mathrm{HFeO}_{2}^{-}$represent equal $\mathrm{Fe}$ concentrations in the solution.

If, on the other hand, the solution is maintained at a constant $\mathrm{pH}$, either by addition of an acid at $\mathrm{pH}$ values $<10.53$ or by addition of a base at $\mathrm{pH}$ values $>10.53$, Fe will continue to go into solution until the solution becomes saturated in Fe. Once this saturation level has been reached, further additions of acid or base are not required to keep the $\mathrm{pH}$ constant.

The numerical values used in the previous discussions are true only for dilute solutions. For concentrated solutions, such as Brine A and ERDA- 6 brine, concentrations of all dissolved substances must be replaced by their respective activities. Despite this reservation, the foregoing discussion and the representation of Figure 6-6 are expected to be at least qualitatively applicable to the present brine studies.

\subsubsection{MEASUREMENT OF pH IN BRINES}

Because the brines used in the present study are relatively complex solutions of high ionic strength $(\sim 6 \underline{M})$ and the solutions in reference electrodes are simple solutions of significantly different composition, the liquid-junction potential between the two solutions is expected to be high, and therefore needs to be known or eliminated if the brine $\mathrm{pH}$ is to be known with a satisfactory degree of accuracy. The measurement of $\mathrm{pH}$ in the brine can be accomplished by utilizing a chloride selective ion electrode (SIE), through the reasoning presented below.

As the name implies, the chloride SIE may be used to measure the chloride ion activity of a solution. It consists of a thin solid electrolyte disk of a composite of silver chloride dispersed in silver sulfide, $\mathrm{Ag}_{2} \mathrm{~S}$, matrix attached to one end of a chemically inert plastic tube. The inside of the tube is filled with an internal filling solution (e.g., Ag-saturated $\mathrm{KCl}$ solution). An AgCl-coated silver wire is immersed in the filling solution and serves as one terminal of the measuring cell. The SIE is immersed in the test solution along with a reference electrode for chloride activity 
measurement. Knauss, Wolery, and Jackson employed the chloride SIE for pH measurement in brines using a glass electrode immersed in the test brine as the other half of the measurement (Knauss, Wolery, and Jackson, 1990).

When used for $\mathrm{pH}$ measurement at the internal surface of the membrane of the SIE, the potential is fixed by the equilibrium between the silver in the internal solution and in the membrane. At the external surface, a - similar equilibrium is established between the membrane and the test solution. The portion of the total potential of the measuring cell that is due to the membrane/test solution interface is:

$$
\delta E=2.303 \frac{R T}{F} \log a_{A g+}
$$

Where $a_{A g+}$ is the silver ion activity in test solution. Since $a_{A^{+}}=K_{s p} / a_{C T}$, where $K_{s p}$ is the solubility product of $\mathrm{AgCl}$, the above equation becomes:

$$
\delta E=2.303\left[\log \mathrm{K}_{\mathrm{sp}}-\frac{\mathrm{RT}}{\mathrm{F}} \log \mathrm{a}_{\mathrm{cl}-}\right]
$$

The solubility of $\mathrm{Ag}$ in most common aqueous solutions is negligible (e.g., at $25^{\circ} \mathrm{C}$, the solubility product for $\mathrm{AgCl}$, with concentrations expressed in mole/L, is $1.56 \cdot 10^{-10}$ ), so the danger of changing the activities of other dissolved species in the test solution is minimal. There is still the problem of relating $\log \mathrm{a}_{\mathrm{Cr}}$ to $\mathrm{pH}$. Knauss, Wolery, and Jackson solve it in the following manner:

- Using the liquid-junction free cell:

$$
\text { glass } \mathrm{H}^{+} \text {electrode }\left|\mathrm{H}^{+}, \mathrm{Cl}^{-}\right| \text {solid state } \mathrm{Cl}-\mathrm{SIE}
$$

one can directly measure $a_{\mathrm{HC}}$. According to the Nernst equation, the potential across the cell is: 


$$
\mathrm{E}_{\mathrm{HCI}}=\mathrm{E}_{\mathrm{HC}}^{0}+2.303(\mathrm{RT} / \mathrm{F}) \cdot \mathrm{pHCl}
$$

where $\mathrm{E}_{\mathrm{HCl}}=$ potential difference between the glass electrode, which really is a $\mathrm{H}^{+} \mathrm{SIE}$, and the $\mathrm{Cl}^{-}$ SIE, where $\mathrm{E}_{\mathrm{HCl}}^{0}=$ standard potential of the cell, and

$$
\mathrm{pHCl}=\mathrm{pH}+\mathrm{pCl}=-\log \mathrm{a}_{\mathrm{H}+}-\log \mathrm{a}_{\mathrm{cl}}
$$

Operatively, the potential differences between a glass $\mathrm{pH}$-sensitive electrode and a $\mathrm{Cl}^{-} \mathrm{SIE}$ measured in two or more solutions of known $\mathrm{pHCl}$ are used to construct an $\mathrm{E}$ vs. $\mathrm{pHCl}$ calibration curve. [Known $\mathrm{pHCl}$ solutions which bracket the expected $\mathrm{pHCl}$ of unknowns can be prepared using solution compositions given by Knauss, Wolery, and Jackson (1990)]. The potential difference measured between the glass electrode and $\mathrm{Cl}^{-} \mathrm{SIE}$ immersed in an unknown solution is compared to the calibration curve, from which a $\mathrm{pHCl}_{\mathrm{x}}$ value for the unknown solution is obtained. The $\mathrm{pH}$ of the unknown solution, $\mathrm{pH}_{\mathrm{x}}$, is then calculated from the measured $\mathrm{pHCl}_{x}$ value from the relation

$$
\mathrm{pH}_{\mathrm{x}}=\mathrm{pHCl}_{\mathrm{x}}-\mathrm{pCl}_{\mathrm{x}}=\mathrm{pHCl}_{\mathrm{x}}+\log \left(\mathrm{y}_{\mathrm{Cl}} \cdot \mathrm{M}_{\mathrm{Cl}}\right)
$$

where $\mathrm{y}_{\mathrm{Cl}}$ - is the chloride activity coefficient and $\mathrm{M}_{\mathrm{Cl}}$ - is the molal concentration of $\mathrm{Cl}^{-}$in the unknown solution.

To calculate $\mathrm{y}_{\mathrm{C}}$, Knauss, Wolery, and Jackson used methods that were developed by Pitzer and coworkers (Pitzer, 1979) to calculate mean molal activity coefficients of dissolved salts. Because these hand calculations are tedious, Pitzer's procedure was incorporated by Jackson (Jackson, 1988) into a computer code, named EQ3/6 Brine Model, that would make the calculations from compositions entered, using equilibrium data included in the code. His experimental results, obtained with solutions of ionic strengths from 0.001 to $4.0 \underline{\mathrm{M}}$, showed that commercially available chloride SIE in combination with a glass electrode in solutions of a wide range of ionic strengths and pHs showed a Nernstian behavior, i.e., the relationship between potential and calculated $-\mathrm{pHCl}$ was linear 
with a slope equal to $2.303(\mathrm{RT} / \mathrm{F})$, and that $\mathrm{K}^{+}, \mathrm{Ca}^{2+}, \mathrm{Mg}^{2+}, \mathrm{SO}_{4}^{2-}, \mathrm{HCO}_{3}^{-}$, and $\mathrm{BO}_{3}^{3-}$ ions, commonly present in brines, do not interfere. Instead of EQ3/6, we used GMIN, a model developed by Felmy (Felmy, 1990) using the same approach and same Pitzer equations as Jackson. Felmy's model was used here because it employs more recent data and also because its author was immediately accessible for discussions. The two codes give nearly identical results.

Using the activities of Brine A constituents as.defined by GMIN, and assuming that the overall activity coefficient for $\mathrm{H}^{+}$ions is unity, we obtain for Brine $\mathrm{A}$

$$
\mathrm{pH}=\mathrm{pHCl}-\mathrm{pCl}=\mathrm{pHCl}+1.894
$$

Using a specific electrode pair (Orion 910100 glass electrode and Orion 941700 chloride SIE, Orion Research, Cambridge, Massachusetts 02139), and solutions described by Knauss, Jackson, and Wolery, the pHCl of Brine A was determined to be 6.71. Thus, the $\mathrm{pH}$ of Brine $\mathrm{A}$ is $6.71+1.894$, or 8.60 .

The constant-pH tests were performed at nominal $\mathrm{pH}$ values of $3,5,7,9$, and 11 . These pHs are termed "nominal" because, at the start of the program, it was thought that the modified ERDA-6 brine would have approximately the same $\mathrm{pCl}$ value (1.57) as that initially calculated for a certain Brine A composition. As the glass electrode-chloride SIE combination measures $\mathrm{pHCl}$, which equals $(\mathrm{pH}+\mathrm{pCl})$, in our tests we aimed at $\mathrm{pHCl}$ values of $1.43,3.43,5.43,7.43$, and 9.43 , respectively. However, since the $\mathrm{pCl}$ value is calculated rather than measured, the $\mathrm{pCl}$ value and the $\mathrm{pH}$ value are subject to change as the assumptions and empirical data underlying its calculation are modified in the future. Because of this uncertainty in correlating measured $\mathrm{pHCl}$ values with calculated $\mathrm{pH}$ values, in these tests particular $\mathrm{pHCl}$ values that were regularly spread apart and which covered the $\mathrm{pH}$ range from -3 to $\sim 11$ were used. The value of $\mathrm{pCl}$ was finally calculated to be 1.20 for the modified ERDA- 6 brine used in the present program, rather than the value of 1.57 initially obtained.

\subsubsection{TEST RESULTS}

The corrosion rates obtained in the constant-pH tests are presented in Table 6-5. The column

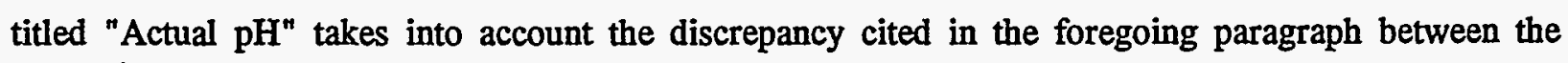


$\mathrm{pCl}$ values calculated for Brine $\mathrm{A}$ and ERDA-6 brine, and also takes into account the averaged value of pH so calculated maintained over the course of the experiment. The raw corrosion-rate data are presented in Appendix B-4.

As expected, the data of Table 6-5 show the corrosion rate to decrease with $\mathrm{pH}$, consistent with the findings of Simpson and Schenk (1989). It is not known whether the apparent increase in corrosion rate between $\mathrm{pH} 9$ and $\mathrm{pH}-11$ in the present work is real, or a manifestation of experimental

Table 6-5. Summary of Corrosion-Rate Results, Constant-pH Tests, Based on Weight Change Data

\begin{tabular}{|c|c|c|c|c|}
\hline Actual pH & $\begin{array}{l}\text { Test Duration, } \\
\text { mo. }\end{array}$ & Mat'l & $\begin{array}{l}\text { Corrosion Rate, } \\
\mu \mathrm{m} / \mathrm{yr}(\mathrm{mpy})^{e}\end{array}$ & $\begin{array}{l}\text { Average Corrosion } \\
\text { Rate, } \mu \mathrm{m} / \mathrm{yr}(\mathrm{mpy})^{\mathrm{b}}\end{array}$ \\
\hline 2.8 & 0.19 & $\begin{array}{l}J \\
K \\
L \\
M\end{array}$ & $\begin{array}{l}7900(310) \\
7100(280) \\
8900(350) \\
8100(320)\end{array}$ & $7900(310)$ \\
\hline 4.8 & 6 & $\begin{array}{l}\mathrm{J} \\
\mathrm{K} \\
\mathrm{L} \\
\mathrm{M}\end{array}$ & $\begin{array}{l}89(3.5) \\
110(4.4) \\
81(3.2) \\
71(2.8)\end{array}$ & $89(3.5)$ \\
\hline 7.0 & 6 & $\begin{array}{l}J \\
K \\
L \\
M\end{array}$ & $\begin{array}{l}36(1.4) \\
36(1.4) \\
64(2.5) \\
66(2.6)\end{array}$ & $51(2.0)$ \\
\hline 8.6 & 6 & $\begin{array}{l}J \\
K \\
L \\
M\end{array}$ & $\begin{array}{l}1.5(0.06) \\
1.8(0.07) \\
2.3(0.09) \\
2.5(0.10)\end{array}$ & $2.0(0.08)$ \\
\hline 10.6 & 6 & $\begin{array}{l}J \\
K \\
L \\
M\end{array}$ & $\begin{array}{l}1.8(0.07) \\
1.8(0.07) \\
5.6(0.22) \\
4.3(0.17)\end{array}$ & $3.6(0.14)$ \\
\hline $\begin{array}{l}\text { - Average } \\
\text { - Average }\end{array}$ & $\begin{array}{l}\text { f } 2 \text { specimens. } \\
\text { f } 8 \text { specimens. }\end{array}$ & & & \\
\hline
\end{tabular}


error. As an example, such error could be introduced into the results because of the fact that the tests were not conducted under truly anoxic conditions, and the pH 11 test could have been exposed to higher concentrations of $\mathrm{O}_{2}$ than the $\mathrm{pH} 9$ test.

For comparison with the data of Table 6-5, the average corrosion rate for the same steels in anoxic Brine A for a 6-month test was $1.72 \mu \mathrm{m} / \mathrm{yr}$ (0.068 mpy). Because Brine A exhibited a posttest $\mathrm{pH}$ of $\sim 8.3$ under the $\mathrm{N}_{2}$-overpressure test conditions; the results of the Brine $A$ tests and the current ERDA- 6 brine tests are judged to be in excellent agreement. This comparison supports the earlier observation (Section 6.1.1.4) regarding the approximately equivalent corrosiveness of Brine $\mathrm{A}$ and ERDA- 6 brine toward low-carbon steels under anoxic conditions.

The pH 3 experiment (Table 6-5) was terminated early, because the specimens were reacting so vigorously with the acidified brine that there was concern that they would disintegrate.

The pH 5 experiment proceeded in a well-behaved fashion throughout the entire test duration. The specimens appeared to be film-free throughout the exposure.

In the $\mathrm{pH} 7$ experiment, the brine reached saturation with $\mathrm{Fe}$ after 38 days exposure, as no acid additions were called for after that time to maintain the $\mathrm{pH}$. The specimens appeared clean upon removal from test.

In the $\mathrm{pH} 9$ experiment, the brine became buffered during the first day of exposure and no acid additions were required after that time. A gray, gelatinous-appearing film formed on the specimens in the first few days and remained for the entire test exposure. A post-test XRD analysis of a specimen showed the corrosion product to be close to akaganeite, $\beta$-FeOOH.

In the $\mathrm{pH} 11$ experiment no acid additions were required to maintain the $\mathrm{pH}$ at 11 . When the specimens were removed from test, they were covered with a gelatinous film, similar to that observed on the $\mathrm{pH} 9$ specimens. When the specimens were rinsed to remove the gelatinous film, their surfaces were observed to be covered with a thin, whitish film and numerous shallow $(<2.5 \mu \mathrm{m})$ pits. An XRD analysis showed the residual corrosion product to have a crystal structure similar to that on the surface of the specimens from the $\mathrm{pH} 9$ tests. 


\subsubsection{High-Pressure Autoclave Tests}

The seal-welded container tests previously described were charged with overpressure gas to equilibrium pressures in the range of 5 to $12 \mathrm{~atm}$. These pressures are, of course, low by comparison with the pressure expected when the contents of the WIPP equilibrate with lithostatic pressure. Highpressure autoclave tests .were conducted to gain insights into the effect of high $\mathrm{CO}_{2}, \mathrm{H}_{2}$, and $\mathrm{N}_{2}$ pressures on the reaction kinetics, with equilibrium pressures in the range 36 to $127 \mathrm{~atm}$. The high-pressure testing regimen comprised tests AUT-1, $-2 ;-3,-4,-7,-8,-9,-10$, and -11 (Table 3-2). In general, the steel specimens were prepared pre-test and examined post-test in the same manner as for the seal-welded-container tests. The specimen area per test was much smaller in the autoclave tests, however, because emphasis was placed on gravimetric analysis of the specimens rather than following the pressure as a function of time. This basic difference in test approach is based on the fact that autoclave systems cannot be relied upon to be (essentially) leak free for very long periods of time, even though this is sometimes observed to be the case in practice.

The specimens were completely immersed in a Brine A test environment in all of the highpressure autoclave tests.

\subsubsection{1 $\mathrm{HIGH} \mathrm{H}_{2}$ PRESSURE TESTS}

Tests AUT-1, $-3,-4$, and -9 were initiated to determine to what extent, if any, high $\mathrm{H}_{2}$ pressures inhibit the progress of the $\mathrm{Fe}-\mathrm{H}_{2} \mathrm{O}$ (Brine A) reaction. Tests AUT-1, -3 , and -4 each used ten low-carbon-steel specimens, five of lot $J$ and five of lot $K$. (A summary of these tests was presented in SAND92-7347.) Test AUT-9, which extended the testing pressure to $127 \mathrm{~atm}$, used a total of 20 corrosion specimens, five each of lots $\mathrm{J}, \mathrm{K}, \mathrm{L}$, and $\mathrm{M}$ steel. The specimens measured $38 \times 76 \mathrm{~mm}(1.5 \times 3.0 \mathrm{in}$.). The detailed specimen data are given in Appendix B-5. The specimens were exposed with the different lots interspersed on the same insulated wire support rack. The test proceeded without incident, maintaining a stable $\mathrm{H}_{2}$ pressure of $1850 \mathrm{psig}$ (127 atm) throughout the 6-month test duration.

At the conclusion of test AUT-9 the specimens were clean and shiny. The brine had a bluishgreen color, as did the small amount of corrosion product lying in the bottom of the autoclave. The 
specimens obviously reacted with the brine forming a non-adherent corrosion product. The results of the gravimetric analysis are shown in Table 6-6.

Table 6-6. Corrosion of Low-Carbon Steels with $\mathrm{H}_{2}$ Overpressure. Test durations 6 and 12 months. Test temperature $30 \pm 5^{\circ} \mathrm{C}$. Tabulated corrosion rates are given in $\mu \mathrm{m} / \mathrm{yr}$ with standard deviation.

\begin{tabular}{|c|c|c|c|c|c|c|c|c|}
\hline \multirow[b]{2}{*}{$\begin{array}{c}\text { Steel } \\
\text { Lot }\end{array}$} & \multicolumn{4}{|c|}{ 6-Month Tests, $\mathrm{H}_{2}$ Pressure, atm } & \multicolumn{4}{|c|}{ 12-Month Tests, $\mathrm{H}_{2}$ Pressure, atm } \\
\hline & $2^{\mathbf{2}}$ & 36 & 70 & 127 & $2^{*}$ & 36 & 70 & 127 \\
\hline $\mathbf{J}$ & $1.61 \pm 0.07$ & b & $0.32 \pm 0.12$ & $1.16 \pm 0.12$ & $1.05 \pm 0.05$ & $0.20 \pm 0.01$ & $0.20 \pm 0.01$ & b \\
\hline $\mathbf{K}$ & $1.65 \pm 0.04$ & $\mathbf{b}$ & $0.40 \pm 0.04$ & $1.26 \pm 0.06$ & $1.26 \pm 0.04$ & $0.25 \pm 0.02$ & $0.27 \pm 0.03$ & $\mathbf{b}$ \\
\hline $\mathbf{L}$ & $1.91 \pm 0.04$ & $\mathbf{b}$ & b & $0.86 \pm 0.03$ & $1.31 \pm 0.04$ & $\mathbf{b}$ & b & b \\
\hline $\mathbf{M}$ & $1.71 \pm 0.08$ & $\mathbf{b}$ & b & $0.78 \pm 0.05$ & $1.29 \pm 0.03$ & $\mathbf{b}$ & $\mathbf{b}$ & b \\
\hline \multicolumn{9}{|c|}{$\begin{array}{l}\text { Approximate mean } \mathrm{H}_{2} \text { pressure in seal-welded container test with } \mathrm{N}_{2} \text { overpressure. Approximate mean } \\
\text { total pressure in container }=-12 \text { atm. } \\
\text { bot determined. }\end{array}$} \\
\hline
\end{tabular}

An analysis of low-carbon-steel corrosion rate as a function of $\mathrm{H}_{2}$ overpressure is somewhat hampered by the fact that the 36-atm tests were only carried out for 12 months, and the 127-atm tests were only carried out for 6 months. However, if it is assumed that the test results are not strongly time-dependent, because of the intrinsic non-protective nature of the corrosion product formed, then one can draw the conclusion that, over the range or pressures studied, the corrosion rate of lowcarbon steel in Brine A goes through a minimum at intermediate $\mathrm{H}_{2}$ pressures (36-70 atm), and is at a maximum at low pressures $(\sim 2 \mathrm{~atm})$ and high pressures $(127 \mathrm{~atm})$. Presumably, intermediate pressures of $\mathrm{H}_{2}$ retard the steel corrosion, due to a reaction-inhibiting effect associated with the presence of reaction product, whereas the higher pressures of $\mathrm{H}_{2}$ enhance the reaction, possibly because of pressure effects on the activated complex associated with the electron-accepting reaction product at the cathodic site. This latter reaction-enhancing pressure effect is seen when the system is pressurized with an inert gas, and was discussed in detail in SAND92-7347. (The foregoing analysis disregards system-associated variables, such as the difference in specimen surface/brine volume ratio between the 
seal-welded container tests and the autoclave tests. The potential importance of this variable to the conclusions drawn in the study is not currently known.)

The foregoing results show phenomenologically that the corrosion rates of steel expected at the pressure of the repository will not deviate substantially from those determined in the (essential) absence of $\mathrm{H}_{2}$, regardless of the pressure of $\mathrm{H}_{2}$ in the repository.

\subsubsection{HIGH N $\mathrm{N}_{2}$ PRESSURE TESTS}

Tests AUT-2 (described in SAND92-7347) and AUT-10 (Table 3-2) were initiated to determine the effect of high inert-gas pressures on the corrosion rate of low-carbon steels in Brine A. The specimen number and specimen dimensions in test AUT-10 match those of AUT-9, previously described. (Specimen details are given in Appendix B-6.)

Specimens removed from test AUT-10 were reasonably clean. A small amount of gray corrosion product was found on the specimens, the specimen rack, and the bottom of the autoclave.

Table 6-7. Corrosion of Low-Carbon Steels with $\mathrm{N}_{2}$ Overpressure. Test duration 6 months. Test temperature $30 \pm 5^{\circ} \mathrm{C}$. Tabulated corrosion rates are given in $\mu \mathrm{m} / \mathrm{yr}$ with standard deviation.

\begin{tabular}{|c|c|c|c|}
\hline \multirow[b]{2}{*}{$\begin{array}{l}\text { Steel } \\
\text { Lot }\end{array}$} & \multicolumn{3}{|c|}{$\mathrm{N}_{2}$ Pressure, atm } \\
\hline & $10^{2}$ & 73 & 127 \\
\hline $\mathbf{J}$ & $1.61 \pm 0.07$ & $2.76 \pm 0.24$ & $2.51 \pm 0.13$ \\
\hline $\mathbf{K}$ & $1.65 \pm 0.37$ & $3.17 \pm 0.04$ & $2.19 \pm 0.03$ \\
\hline L & $1.91 \pm 0.04$ & b & $2.91 \pm 0.11$ \\
\hline $\mathbf{M}$ & $1.71 \pm 0.08$ & b & $3.29 \pm 0.06$ \\
\hline
\end{tabular}

2 Seal-welded-container test data. Also present is $\mathrm{H}_{2}$ at 2 atm partial pressure, as noted in Table 6-6.

b Not determined. 
The results of the gravimetric analysis are shown in Table 6-7, and, as before, the assumption is made that the difference in gravimetric results tabulated is due to overpressure gas only, and has no dependence on test type. The corrosion rate found at $127 \mathrm{~atm}$ is clearly higher than that found at $10 \mathrm{~atm}$, but it appears that the effect of pressure on the corrosion rates between 73 and $127 \mathrm{~atm}$ would have to be considered statistically insignificant. On average, it appears that a rate enhancement between the $10 \mathrm{~atm}$ data and the $127 \mathrm{~atm}$ (repository pressure) data would amount to approximately $60 \%$. This degree of rate enhancement would probably be considered inconsequential in the production of a repository pressurization model when other factors $(\mathrm{pH}$, presence of reactive gases, presence of microbe metabolites) could have much more profound effects on gas generation rates.

\subsubsection{3 $\mathrm{HIGH} \mathrm{CO}_{2}$ PRESSURE TESTS}

Tests AUT-7 and AUT-8 (described in SAND92-7347) and AUT-11 (Table 3-2) were initiated to determine the effect of high $\mathrm{CO}_{2}$ pressure on the corrosion rate and passivation of low-carbon steels in Brine A. The specimen number and specimen dimensions in test AUT-11 match those of AUT-9, previously described (specimen details are given in Appendix B-7). The specimens removed from the high-pressure $\mathrm{CO}_{2}$ test were coated with the expected tenacious black $\mathrm{FeCO}_{3}$ (siderite) reaction product layer. The results of the gravimetric analysis are presented in Table 6-8.

As expected from past investigations (SAND92-7347), the higher-pressure tests result in a greater degree of attack, i.e., more $\mathrm{Fe}$ is consumed before a stable passive corrosion product layer forms. And, as in past autoclave studies, the specimens in the present test passivated after a time period of approximately 60 days. This time-to-passivation was estimated from the pressure readings on the autoclave pressure gauge, which reflected the overpressure of $\mathrm{H}_{2}$ formed during the course of the test. As the initial, or starting, fugacity of $\mathrm{CO}_{2}$ in a steel/Brine A system is increased, as in going from $10 \mathrm{~atm} \mathrm{CO}_{2}$ to $62 \mathrm{~atm} \mathrm{CO}_{2}$, the amount of steel reacting prior to its passivation increases, but at a rapidly diminishing rate.

\subsubsection{Simulated-Backfill Autoclave Tests}

When a WIPP disposal room has received its full complement of waste receptacles, the void space between the room walls and the waste receptacles will be filled with a particulate "backfill" 
Table 6-8. Corrosion of Low-Carbon Steels with $\mathrm{CO}_{2}$ Overpressure. Test duration 6 months. Test temperature $30 \pm 5^{\circ} \mathrm{C}$. Tabulated corrosion rates are given in $\mu \mathrm{m} / \mathrm{yr}$ with standard deviation.

\begin{tabular}{|c|c|c|c|}
\hline \multirow[b]{2}{*}{$\begin{array}{c}\text { Steel } \\
\text { Lot }\end{array}$} & \multicolumn{3}{|c|}{$\mathrm{CO}_{2}$ Pressure, atm } \\
\hline & $10^{2}$ & 36 & 62 \\
\hline J & $8.5 \pm 1.9$ & $22.1 \pm 1.8$ & $27.2 \pm 0.8$ \\
\hline $\mathbf{K}$ & $7.9 \pm 2.5$ & $24.9 \pm 1.0$ & $26.3 \pm 0.4$ \\
\hline $\mathrm{L}$ & $3.8 \pm 0.7$ & $36.0 \pm 1.3$ & $38.6 \pm 0.6$ \\
\hline $\mathbf{M}$ & $5.0 \pm 0.9$ & $35.8 \pm 1.7$ & $42.1 \pm 1.9$ \\
\hline
\end{tabular}

a Seal-welded-container test.

material. A candidate backfill that has received consideration has the composition $30 \mathrm{wt} \%$ bentonite clay and 70 wt\% WIPP-derived salt (halite).. The bentonite would be expected to 1) reduce the permeability of the backfill, and 2) aid in sealing the repository, because of its tendency to expand when it absorbs water. Sandia staff recognized that, should the decision be made to use such a backfill, the effect of bentonite on the corrosion of steel would constitute an unknown that would have to be resolved before such a backfill could be used. The present tests were designed to provide the required corrosion/gas generation information.

Two experiments, designated tests AUT-12 and AUT-13, closely paralleling the earlier particulate salt tests AUT-5 and AUT-6 (SAND92-7347), were initiated using high-pressure, 3.8L autoclave systems. The test arrangements are shown schematically in Figure 6-7.

Test AUT-12 was designed to investigate the effect of brine "wicking" to the surface of the specimens. In this test the bottom of the backfill mass was below the level of the brine but the bottom of the specimens in the lowest tier was above the brine liquid level. Test AUT-13 was designed to investigate the effect of vapor transport, so the bottom of the backfill mass was above the liquid level of the brine. In both tests the mass of backfill, with embedded specimens, was held in a stainless steel mesh basket. The low-carbon steel specimens were separated from the basket to avoid 


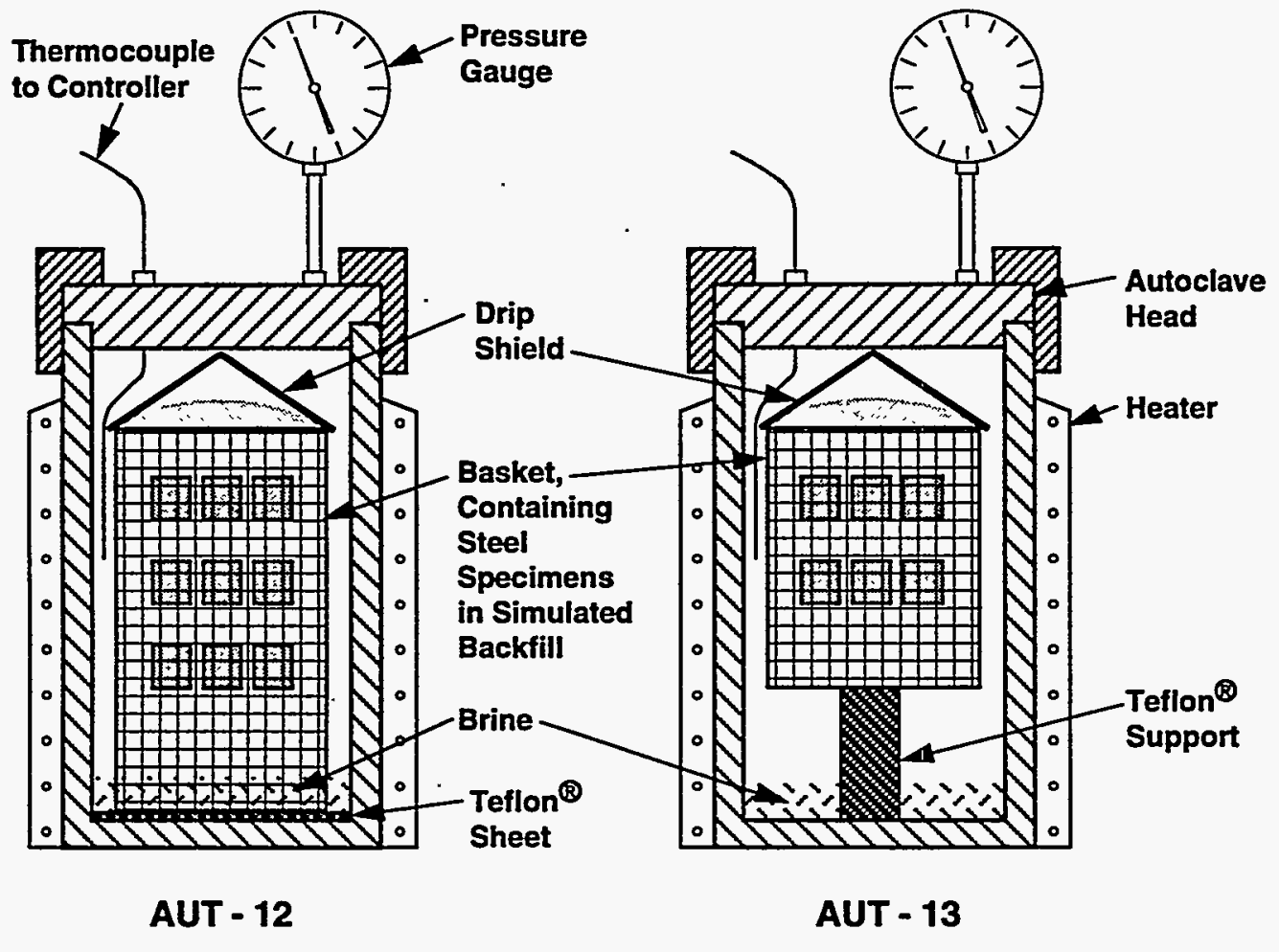

Figure 6-7. Test arrangements, tests AUT-12 and AUT-13

galvanic effects. A "drip shield" prevented condensate from dripping on the top of the backfill mass. The backfill was made up of $30 \mathrm{wt} \%$ bentonite and $70 \mathrm{wt} \%$ salt (nearly pure halite, from the WIPP site). The particle size of the salt used in the backfill blend was between 2.0 and $3.4 \mathrm{~mm}$. In both tests the overpressure gas was $\mathrm{N}_{2}$ at 10 atm pressure, the test temperature was $30 \pm 5^{\circ} \mathrm{C}$, and the test duration was 6 months.

The specific test parameters associated with each test, and the test results, are presented in the following two report subsections. 


\subsubsection{TEST AUT-12}

In test AUT-12, 18 specimens of lot $\mathrm{J}$ low-carbon steel were embedded in $2000 \mathrm{~g}$ (dry weight) of simulated backfill. A total of $530 \mathrm{ml}$ of Brine A was placed in the bottom of the autoclave. [A "dry run" had shown that this quantity of brine would rapidly (within hours) reach the top of the backfill by "wicking", while leaving a liquid brine residue having a liquid level well below $(\sim 25 \mathrm{~mm})$ the bottom of the bottom tier of specimens.] The specimens were arranged in three tiers of six specimens each. The specimen dimensions were $25 \mathrm{~mm} \times 25 \mathrm{~mm}(0.98 \mathrm{in} . \times 0.98 \mathrm{in}$.). The specimen tiers were separated by a distance of $\sim 15 \mathrm{~mm}$.

When the specimens were removed from the mass of simulated backfill at the conclusion of the test, no sign of a gray, green, or blue reaction product was observed in the vicinity of the specimens. (Corrosion products from anoxic brine tests commonly exhibit the hues noted.) The reaction product observed on the surfaces of the specimens was a uniform dark brown color. Because the specimens were "dredged" from the backfill very soon after autoclave disassembly, it is believed that the reaction products did not oxidize to the dark brown color observed upon air exposure, but that the reaction products formed were inherently of that color. The specimen weight change data are summarized in Table 6-9. It can be seen that the corrosion rate decreased with distance from the brine phase, and that the maximum corrosion rate observed (bottom specimen tier) is approximately twice the average corrosion rate observed in the six-month immersion test with $\mathrm{N}_{2}$ overpressure $(1.72 \mu \mathrm{m} / \mathrm{yr})$. The backfill was noticeably more moist in the vicinity of the bottom tier than the top, and visually there was more corrosion product associated with the bottom-tier than the top-tier coupons. Individual specimen data are presented in Appendix B-8.

Table 6-9. Average Corrosion Rates of Specimens from Test AUT-12, $\mu \mathrm{m} / \mathrm{yr}$. Six specimens per tier, with standard deviation.

$\begin{array}{ll}\text { Top Tier } & 2.18 \pm 0.54 \\ \text { Middle Tier } & 3.86 \pm 0.58 \\ \text { Bottom Tier } & 4.58 \pm 0.61\end{array}$


The amount of $\mathrm{H}_{2}$ in the gas phase at test completion (0.27 mol\%) did not agree well with the amount of metal reacted (equivalent to $0.57 \mathrm{~mol} \%$ in the gas phase, assuming divalent-Fe reaction product); this may be due to consumption of corrosion product $\mathrm{H}_{2}$ through redox reactions, or direct participation in the corrosion reaction by reactive oxidants present in the system (e.g., $\mathrm{Fe}^{+3}$ ).

\subsubsection{TEST AUT-13}

In test AUT-13, ten $25 \mathrm{~mm} \times 25 \mathrm{~mm}$ (0.98 in. $\times 0.98$ in.) specimens of Lot J material were embedded in a mass of simulated backfill, and arranged in two tiers of five specimens each. The backfill weighed $1672 \mathrm{~g}$; the brine pool consisted of $250 \mathrm{ml}$ of Brine $\mathrm{A}$; and the distance from the surface of the brine to the bottom of the basket was $\sim 25 \mathrm{~mm}$. The distance from the bottom of the basket to the bottom of the lowest tier of specimens was $\sim 25 \mathrm{~mm}$.

The pressure in the autoclave stayed essentially constant at $140 \mathrm{psig}$ during the run, indicating negligible gas loss from the autoclave. Gas samples were taken from the autoclave for analysis prior to dismantling the system for specimen recovery. The (duplicate) gas analyses showed only $\mathrm{N}_{2}$. The $\mathrm{H}_{2}$ present was below the detection level, i.e., $<0.001 \mathrm{~mol} \%$. This low $\mathrm{H}_{2}$ level is indicative of a very low corrosion rate.

Upon removal from the autoclave, the mass of simulated backfill did not appear to be moist. The salt crystals had maintained their original appearance. The specimens of low-carbon steel did not show any unusual characteristic that could be associated with position in the backfill. All specimens appeared basically uncorroded, except for many small splotches of dark brown corrosion product which covered perhaps 10 to $20 \%$ of the area of each specimen. The corrosion product was not raised, but had more of the appearance of a tarnish film. Compared to specimens removed from the "wicking" test, the extent of corrosion on the present specimens appeared to be negligible. A gravimetric analysis was performed to determine the amount of metal lost to corrosion. The results of the analysis are given in Table 6-10. Individual-specimen corrosion rate data are presented in Appendix B-9.

The corrosion rates observed in the test are very low for 6-month-duration tests. The average rate of all the specimens $(0.48 \mu \mathrm{m} / \mathrm{y})$ is about $30 \%$ of the rate that would be expected in a 6 -month Brine $\mathrm{A}$ immersion test with an $\mathrm{N}_{2}$ overpressure and no backfill present. The corrosion rates 


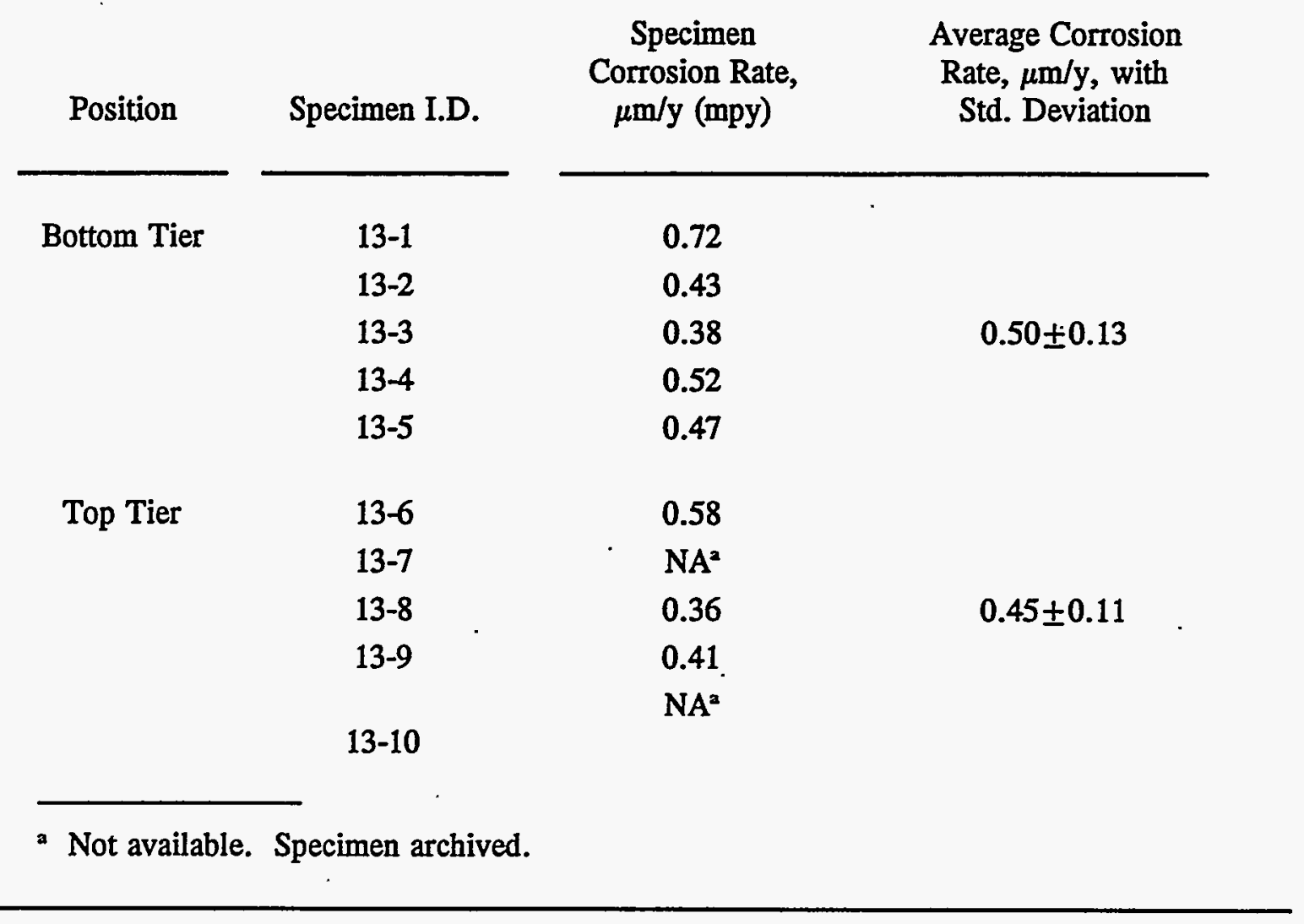

observed in the present autoclave test match closely the corrosion rates observed in the seal-weldedcontainer vapor-phase tests, without backfill, which produced basically "shiny" specimens with very little corrosion evident.

Because the backfill used in the present test was approximately $70 \%$ salt (halite), the test results appear to show that the results produced by the salt-only backfill test, test AUT-6 (SAND927347) in which condensate from the autoclave head dripped onto the salt mass during the course of the test, produced corrosion rates considerably higher than would have been produced if no water had dripped onto the salt. Test AUT-6 produced an average corrosion rate $\sim 50 \%$ higher than test AUT-13. 


\subsection{Alternative Packaging Material Tests}

The corrosion and gas-generation behavior of the four candidate alternative packaging materials [high-purity $\mathrm{Cu}$, cupronickel 90-10, commercial-purity $\mathrm{Ti}$ ( $\mathrm{Ti}$ Grade 2), and Ti Grade 12] was investigated in three environments-anoxic brine (Brine A with $\mathrm{N}_{2}$ ); Brine A with $\mathrm{CO}_{2}$; and Brine A with $\mathrm{H}_{2} \mathrm{~S}$. Only the.seal-welded-container method of testing .was used, as reliance was placed on gas-pressure measurements as well as gravimetric analyses of the test specimens to establish the behavior of the materials in the test environments. The test matrix summarizing these tests is shown in Table 3-4.

The manner of racking the specimens in the alternative material tests was different from the method of racking used in the low-carbon steel tests. In the latter tests, the specimens were held on a specimen rack with no effort made to produce well-defined metal-to-metal crevices between the test specimens. In the alternative materials tests, two specimen geometries were used: rectangular specimens $64 \mathrm{~mm} \times 190 \mathrm{~mm}$ (2.5 in. $\times 7.5$ in.), and circular specimens $38 \mathrm{~mm}$ (1.5 in.) in diameter. The rectangular specimens were provided with two holes, each $0.79 \mathrm{~cm}(0.31$ in.) in diameter for rack mounting; the circular specimens had one centrally located hole of the same size. The manner of racking the specimens is shown in Figure 6-8.

Each test contained 16 rectangular specimens and 16 circular specimens. The 16 circular specimens were tightly compressed between adjacent rectangular specimens, as shown in Figure 6-8, to provide regions for crevice corrosion if the tendency for that degradation mode existed in a given test system.

During alternative material testing, $\mathrm{Cu}$-base and Ti-base materials were always tested in separate containers. In tests of $\mathrm{Cu}$-base materials, all of the high-purity- $\mathrm{Cu}$ specimens ( 8 rectangular, 8 circular) were placed on one side of a specimen rack, and 16 equivalent specimens of cupronickel were situated on the other side of the rack. In a similar manner, in a test of Ti-base materials, specimens of Ti Grade 2 were placed on one side of a rack, and specimens of Ti Grade 12 on the other. The specimens were always completely immersed in Brine A during a test. All tests were conducted at $30 \pm 5^{\circ} \mathrm{C}$. 


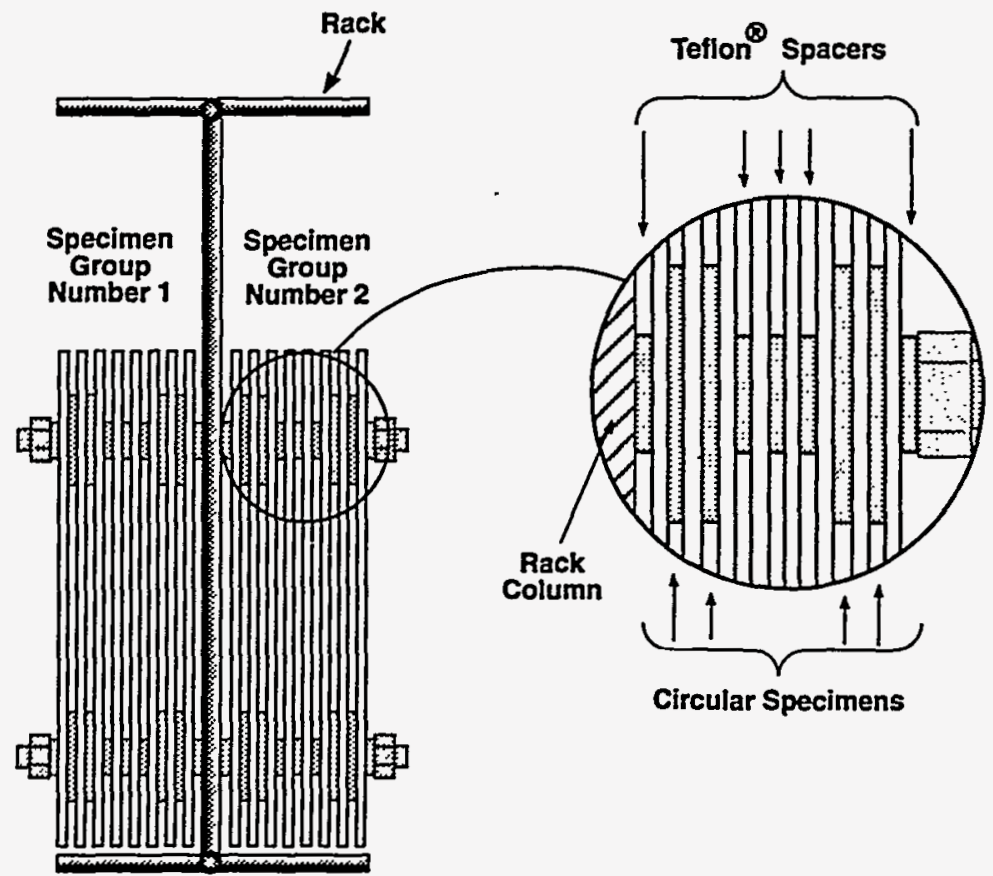

$39301036.5 \mathrm{FH}$

Figure 6-8. Method of mounting specimens on specimen rack for alternative packaging materials tests.

The alternative packaging materials investigation comprised tests 1A through 19A. Details of the tests, expanding on the information presented in Table 3-4, are presented in Table 6-11. Individual-specimen data for the 24-month tests are presented in Appendix B-10.

- No gravimetric investigations were performed on any of the specimens from the 24-month tests. A visual assessment of the condition of the specimens was made at the conclusion of these . tests, and a gas sample from each container was taken for analysis. 
Table 6-11. Initial Conditions, Alternative Packaging Material Tests 1A through 19A

\begin{tabular}{|c|c|c|c|c|c|}
\hline $\begin{array}{c}\text { Test } \\
\text { Identification }\end{array}$ & $\begin{array}{c}\text { Material } \\
\text { Base }\end{array}$ & $\begin{array}{c}\text { Initial } \\
\text { Overpressure } \\
\text { Gas/atm }\end{array}$ & $\begin{array}{c}\text { Total } \\
\text { Specimen } \\
\text { Area, } \mathrm{m}^{2}\end{array}$ & $\begin{array}{c}\text { Brine Volume, } \\
\text { L }\end{array}$ & $\begin{array}{l}\text { Actual Test } \\
\text { Duration, } \\
\text { Months }\end{array}$ \\
\hline $1 \mathrm{~A}$ & $\mathrm{Cu}$ & $\mathrm{N}_{2} / 10.6$ & 0.43 & 1.415 & 10 \\
\hline $2 A$ & $\mathrm{Cu}$ & $\mathrm{CO}_{2} / 11.5$ & 0.43 & 1.375 & 10. \\
\hline $3 A$ & $\mathrm{Cu}$ & $\mathrm{H}_{2} \mathrm{~S} / 4.9$ & 0.43 & 1.390 & 9 \\
\hline $4 \mathrm{~A}$ & $\mathrm{Ti}$ & $\mathrm{N}_{2} / 10.7$ & 0.44 & 1.435 & 10 \\
\hline $5 \mathrm{~A}$ & $\mathrm{Ti}$ & $\mathrm{CO}_{2} / 11.6$ & 0.44 & 1.360 & 10 \\
\hline $6 \mathrm{~A}$ & $\mathrm{Ti}$ & $\mathrm{H}_{2} \mathrm{~S} / 4.7$ & 0.44 & 1.415 & 9 \\
\hline 7A & $\mathrm{Cu}$ & $\mathrm{N}_{2} / 10.4$ & 0.43 & 1.420 & 15 \\
\hline $8 \mathrm{~A}$ & $\mathrm{Cu}$ & $\mathrm{CO}_{2} / 11.0$ & 0.43 & 1.405 & 15 \\
\hline $9 A$ & $\mathrm{Cu}$ & $\mathrm{H}_{2} \mathrm{~S} / 5.1$ & 0.43 & 1.405 & 15 \\
\hline $10 \mathrm{~A}$ & $\mathbf{T i}$ & $\mathrm{N}_{2} / 10.5$ & 0.44 & 1.420 & 15 \\
\hline $11 \mathrm{~A}$ & $\mathrm{Ti}$ & $\mathrm{CO}_{2} / 10.9$ & 0.44 & 1.400 & 15 \\
\hline $12 \mathrm{~A}$ & $\mathrm{Ti}$ & $\mathrm{H}_{2} \mathrm{~S} / 5.1$ & 0.44 & 1.360 & 15 \\
\hline $13 \mathrm{~A}$ & $\mathrm{Cu}$ & $\mathrm{N}_{2} / 10.2$ & 0.43 & 1.380 & 24 \\
\hline $14 \mathrm{~A}$ & $\mathrm{Cu}$ & $\mathrm{CO}_{2} / 10.9$ & 0.43 & 1.410 & 24 \\
\hline $15 \mathrm{~A}$ & $\mathrm{Cu}$ & $\mathrm{H}_{2} \mathrm{~S} / 4.9$ & 0.43 & 1.420 & 24 \\
\hline $16 \mathrm{~A}$ & $\mathrm{Ti}$ & $\mathrm{N}_{2} / 10.2$ & 0.44 & 1.365 & 24 \\
\hline $17 \mathrm{~A}$ & $\mathrm{Ti}$ & $\mathrm{CO}_{2} / 10.8$ & 0.44 & 1.360 & 24 \\
\hline $18 \mathrm{~A}$ & $\mathrm{Ti}$ & $\mathrm{H}_{2} \mathrm{~S} / 5.1$ & 0.44 & 1.360 & 24 \\
\hline $19 \mathrm{~A}$ & Control & $\mathrm{H}_{2} \mathrm{~S} / 4.5$ & - & 1.740 & 24 \\
\hline
\end{tabular}

\subsection{1. $\mathrm{Cu}$ in Brine $\mathrm{A}$ with $\mathbf{N}_{2}$}

$\mathrm{Cu}$ and cupronickel 90-10 specimens exposed to anoxic Brine A showed no significant reaction, as indicated by either pressure increase within the test container or by consumption of metal by a corrosion reaction. This is consistent with thermodynamic expectations (SAND92-7347). 
Specimens removed from test containers $1 \mathrm{~A}, 7 \mathrm{~A}$, and $13 \mathrm{~A}$ after test periods of 10,15 , and 24 months, respectively, exhibited freshly ground, as-received surface conditions reminiscent of the pre-test specimen conditions. A gravimetric analysis of specimens from test 7A (see SAND92-7347 for individual specimen weight-change data) showed that the weight changes undergone by the circular specimens were within the accuracy limits of the four-place balance used for the analysis. The rectangular specimens showed weight gains up to $0.0117 \mathrm{~g}$. The pressure changes in the three test containers over the entire period of the tests was within \pm 1 psi. A gas analysis performed at the conclusion of the 24-month test (test 13A) showed the gas to consist of $99.8 \% \mathrm{~N}_{2}$ and $0.009 \% \mathrm{H}_{2}$. Thus, it can be concluded, on the basis of the evidence currently available, that $\mathrm{Cu}$ and cupronickel 90-10 will not react with Brine $A$ to form significant $\mathrm{H}_{2}$ under the anoxic test conditions employed.

\subsection{2 $\mathrm{Cu}$ in Brine $\mathrm{A}$ with $\mathrm{CO}_{2}$}

$\mathrm{Cu}$ and cupronickel 90-10 specimens exposed to Brine $\mathrm{A}$ with $\mathrm{CO}_{2}$ showed no significant reaction, as indicated by either pressure increase within the test container or by consumption of metal by a corrosion reaction: This is consistent with thermodynamic expectations (SAND92-7347).

Specimens removed from test containers $2 \mathrm{~A}, 8 \mathrm{~A}$, and $14 \mathrm{~A}$ after test durations of 10,15 , and 24 months, respectively, appeared clean and uncorroded. The pressure in these containers dropped during the test periods by approximately 2 psi. The test specimens from test $8 \mathrm{~A}$ lost a small amount of weight during the test, possibly due to $\mathrm{Cu}$ dissolution or $\mathrm{Cu}$-complex dissolution effects. (See SAND92-7347 for individual specimen weight-change data.) A gas analysis performed at the conclusion of the 24-month test (test 14A) showed the gas to consist of $98.8 \% \mathrm{CO}_{2}$ and $0.015 \% \mathrm{H}_{2}$. It can be concluded, on the basis of the available evidence, that $\mathrm{Cu}$ and cupronickel 90-10 will not react with Brine $A$ to form significant $\mathrm{H}_{2}$ under the test conditions used.

\subsection{3 $\mathrm{Cu}$ in Brine A with $\mathrm{H}_{2} \mathrm{~S}$}

$\mathrm{Cu}$ and cupronickel $90-10$ specimens exposed to Brine $\mathrm{A}$ with $\mathrm{H}_{2} \mathrm{~S}$ show a rapid $\mathrm{H}_{2}$-generating reaction. These observations can be said to be consistent with thermodynamic predictions (SAND927347), though the upper limits of $\mathrm{H}_{2}$ pressure suggested by the thermodynamic calculations have not been nearly approached in the present tests. 
The pressure-time curves showing the reaction between the $\mathrm{Cu}$-base materials and $\mathrm{H}_{2} \mathrm{~S}$ were presented in SAND92-7347, through a time period of $\sim 16$ months. A gas analysis performed at the conclusion of the 24-month test (test 15A) showed the remaining gas to be $99.8 \% \mathrm{H}_{2}$. The specimens from this test were covered with a black $\mathrm{Cu}_{2} \mathrm{~S}$ corrosion product layer.

At this time it can be concluded that $\mathrm{Cu}$ and cupronickel $90-10$ react rapidly and essentially completely with $\mathrm{H}_{2} \mathrm{~S}$ under the test conditions imposed to form $\mathrm{Cu}_{2} \mathrm{~S}$ and $\mathrm{H}_{2}$ in the expected quantities, with little if any inhibition of reaction rate ascribable to the corrosion product film forming on the specimen surface. Because the reaction proceeds at a rapid rate (on a WIPP-relevant time scale) to very low activities of $\mathrm{H}_{2} \mathrm{~S}$, it is difficult to conceive of a useful Cu-alloy container if $\mathrm{H}_{2} \mathrm{~S}$ has a significant probability of being present in the environment.

\subsubsection{Ti in Brine $\mathrm{A}$ with $\mathrm{N}_{2}, \mathrm{CO}_{2}$, and $\mathrm{H}_{2} \mathrm{~S}$}

All alternative-material tests of Ti Grade 2 and Ti Grade 12 have shown essentially complete stability of the Ti-base materials in the test environments. The pressure changes observed in the $\mathrm{Ti}$ with $\mathrm{N}_{2}$ and $\mathrm{Ti}$ with $\mathrm{CO}_{2}$ tests were within 4 psi of the starting pressure over the entire period of the tests; the pressure changes observed were pressure drops. The Ti with $\mathrm{H}_{2} \mathrm{~S}$ tests, on the other hand, all showed a pressure increase of 9 to 10 psi within the first $30 \mathrm{~h}$ of gas addition, after which time the pressure stabilized, within $\pm 2 \mathrm{psi}$, for the remainder of the test. Gas taken from the 15-monthexposure test (test $12 \mathrm{~A}$ ) before test termination showed a trace of $\mathrm{H}_{2}(0.5 \mathrm{~mol} \%)$, consistent with a limited corrosion reaction at the beginning of the test. Gas taken from the 24-month Ti-base material tests had the compositions given in Table 6.12.

All of the Ti-base specimens appeared clean, shiny, and unreacted upon removal from the containers of terminated tests. A gravimetric analysis of a random sample of specimens from the 15 -month tests (tests $10 \mathrm{~A}, 11 \mathrm{~A}$, and $12 \mathrm{~A}$ ) showed that the majority of specimens from the $\mathrm{N}_{2} / \mathrm{brine}$ tests gained weight, up to $0.0024 \mathrm{~g}$; whereas all of the specimens from the other two environments (brine/ $\mathrm{CO}_{2}$ and brine/ $\mathrm{H}_{2} \mathrm{~S}$ ) lost weight, as much as $0.0014 \mathrm{~g}$ (see SAND92-7347 for individualspecimen weight change data). As in the case of the $\mathrm{Cu}$-base alloys, weight changes to the extent observed in the present tests have little significance in an assessment of gas-generation potential. 
Table 6-12. Compositions of Gas in Test Containers at Conclusion of 24-Month Ti-Base Material Tests

\begin{tabular}{cccc}
$\frac{1}{\text { Test }}$ & Gas/Initial Pressure & & Final Gas Analysis (mol \%) \\
\cline { 1 - 1 } $16 \mathrm{~A}$ & & & $99.8 \% \mathrm{~N}_{2}, 0.005 \% \mathrm{H}_{2}$ \\
$17 \mathrm{~A}$ & $\mathrm{CO}_{2} / 10 \mathrm{~atm}$ & & $98.8 \% \mathrm{CO}_{2}, 0.03 \% \mathrm{H}_{2}$ \\
$18 \mathrm{~A}$ & $\mathrm{H}_{2} \mathrm{~S} / 5 \mathrm{~atm}$ & & $94.5 \% \mathrm{H}_{2} \mathrm{~S}, 0.36 \% \mathrm{H}_{2}$ \\
$19 \mathrm{~A}^{\mathrm{a}}$ & $\mathrm{H}_{2} \mathrm{~S} / 5 \mathrm{~atm}$ & & $93.4 \% \mathrm{H}_{2} \mathrm{~S}, 0.35 \% \mathrm{H}_{2}$
\end{tabular}

a control test, duplicating 18A but containing no test specimens.

It appears, on the basis of the information obtained to date, that Ti Grade 2 and Ti Grade 12 could be used as alternative packaging materials in the WIPP without concern about gas generation.

The gas analyses from the 24-month tests support the observation previously made (SAND92-7347) concerning the lack of reactivity of Ti-base materials in WIPP-relevant environments.

\subsection{Al-Base Material Tests}

The corrosion and gas-generation behavior of the two Al-base materials selected for study (99.99\% $\mathrm{Al}$ and 6061 alloy) was investigated in three environments-anoxic brine (Brine $\mathrm{A}$ with $\mathrm{N}_{2}$ ); Brine $\mathrm{A}$ with $\mathrm{CO}_{2}$; and Brine $\mathrm{A}$ with $\mathrm{H}_{2} \mathrm{~S}$. In addition, certain tests included low-carbon steel test coupons, in order to purposefully contaminate the brine with $\mathrm{Fe}^{++}$ions, thereby promoting $\mathrm{Fe}$ deposition on the Al-base materials and concomitant corrosion enhancement. Because of the ubiquitous presence of steel in the repository, these Fe-containing tests are considered the most important and meaningful tests in the Al-base materials investigation. 
Only the seal-welded-container method of testing was used, as major reliance was placed on gas-pressure measurement to establish the corrosion/gas-generation behavior of the specimen materials in the test environments. The test matrix summarizing the test parameters is presented in Table 3-5.

The method used to rack the specimens in the Al-base materials tests was similar to that used in the alternative material tests described in the preceding section of this report, in that two specimen geometries of each material type was used, and an effort was made to produce crevices for the promotion of crevice corrosion, should such a mode of attack be feasible in the test environments employed. The method of racking the specimens, with and without steel coupons present, is shown in Figure 6-9. The racking shown is for immersed specimens. For vapor-phase specimens, the rack would be inverted. Steel coupons were not included in the vapor-phase tests. The circular specimens, $38 \mathrm{~mm}$ (1.5 in.) in diameter, were compressed between rectangular coupons $64 \mathrm{~mm} \times 190 \mathrm{~mm}$ (2.5 in. $\times 7.5 \mathrm{in}$.) of like material. Each test comprised 12 coupons of each Albase material, or 24 coupons $\left(0.33 \mathrm{~m}^{2}\right)$ total. On any one rack, the 6061 alloy was always on one side, and the $99.99 \%$ pure Al was on the other.

Each test with low-carbon steel. coupons (tests 4B, 5B, 6B, 13B, 14B, and 15B) contained four coupons of lot J steel. Each steel coupon was $64 \mathrm{~mm} \times 190 \mathrm{~mm}(2.5 \mathrm{in} . \times 7.5 \mathrm{in}$.), the same size as the rectangular Al-base material coupons. The steel coupons were electrically insulated from the rack and the Al-base material coupons.

The corrosion rates of the steel coupons were determined gravimetrically, so that some insight could be obtained regarding the influence of corroding $\mathrm{Al}$ on the corrosion rate of low-carbon steel in the test environments employed. The $\mathrm{H}_{2}$ produced by steel corrosion was inconsequential in the Fecontaining tests compared with the amount of $\mathrm{H}_{2}$ generated by the Al-base materials.

The raw presure-time data for the Al-base materials tests are presented in Appendix A-4. The individual specimen data are given in Appendix B-11.

\subsubsection{Anoxic Brine $\left(B r i n e / N_{2}\right)$ Tests}

The anoxic brine (brine/ $\mathrm{N}_{2}$ ) tests included immersed-specimen tests (tests $1 \mathrm{~B}$ and 10B); immersed-specimen tests with steel present (tests 4B and 13B); and vapor-phase-exposure tests (tests 


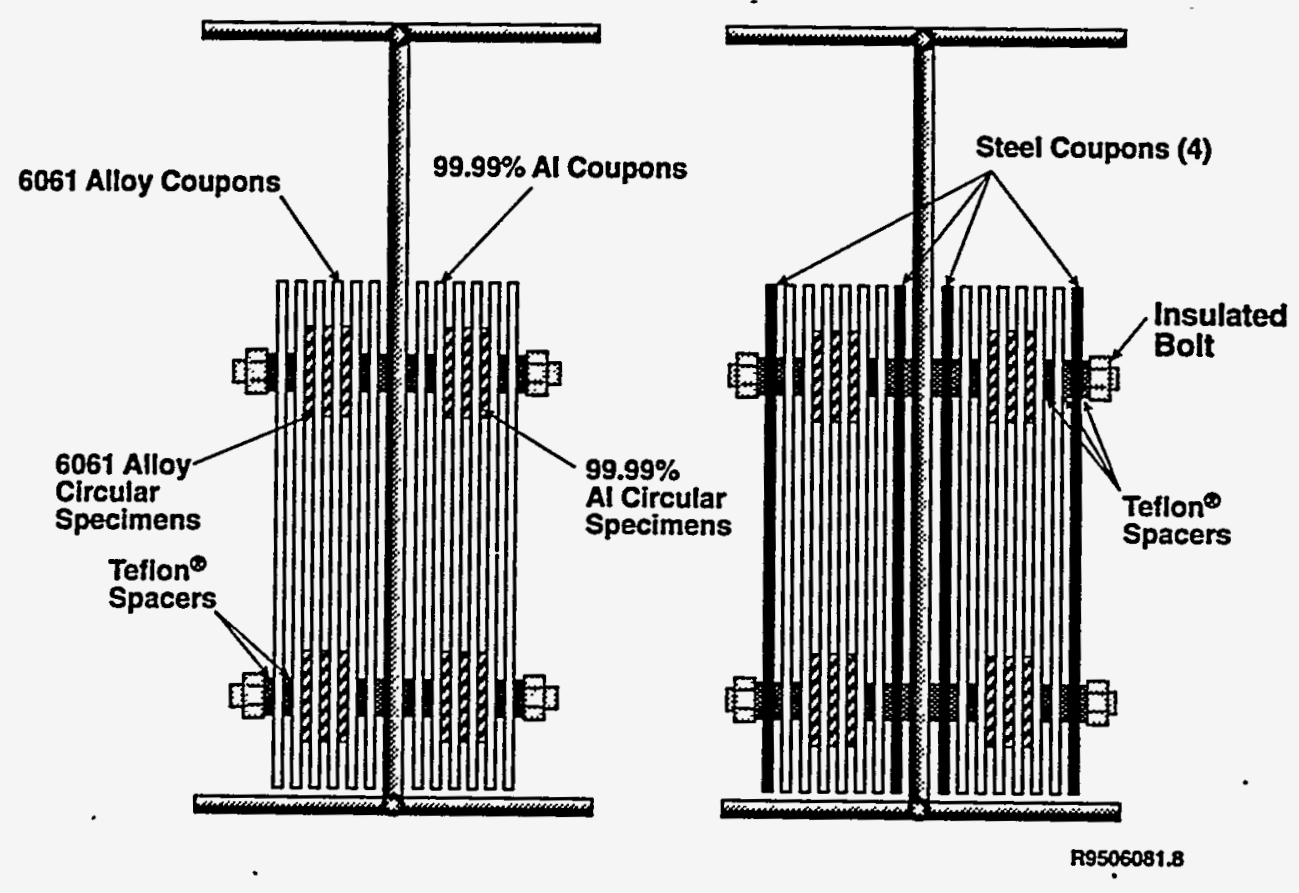

Figure 6-9. Method of racking Al-base material specimens for immersed-specimen tests. Method for including steel specimens is shown in the right-hand diagram.

7B and 16B). Duplicate tests were run for test durations of 13 months and 24 months. The pressuretime histories and gas analysis results for these tests are presented in Figure 6-10. (The raw pressuretime data for each test are presented in Appendix A; the individual-specimen data may be found in Appendix B.) 


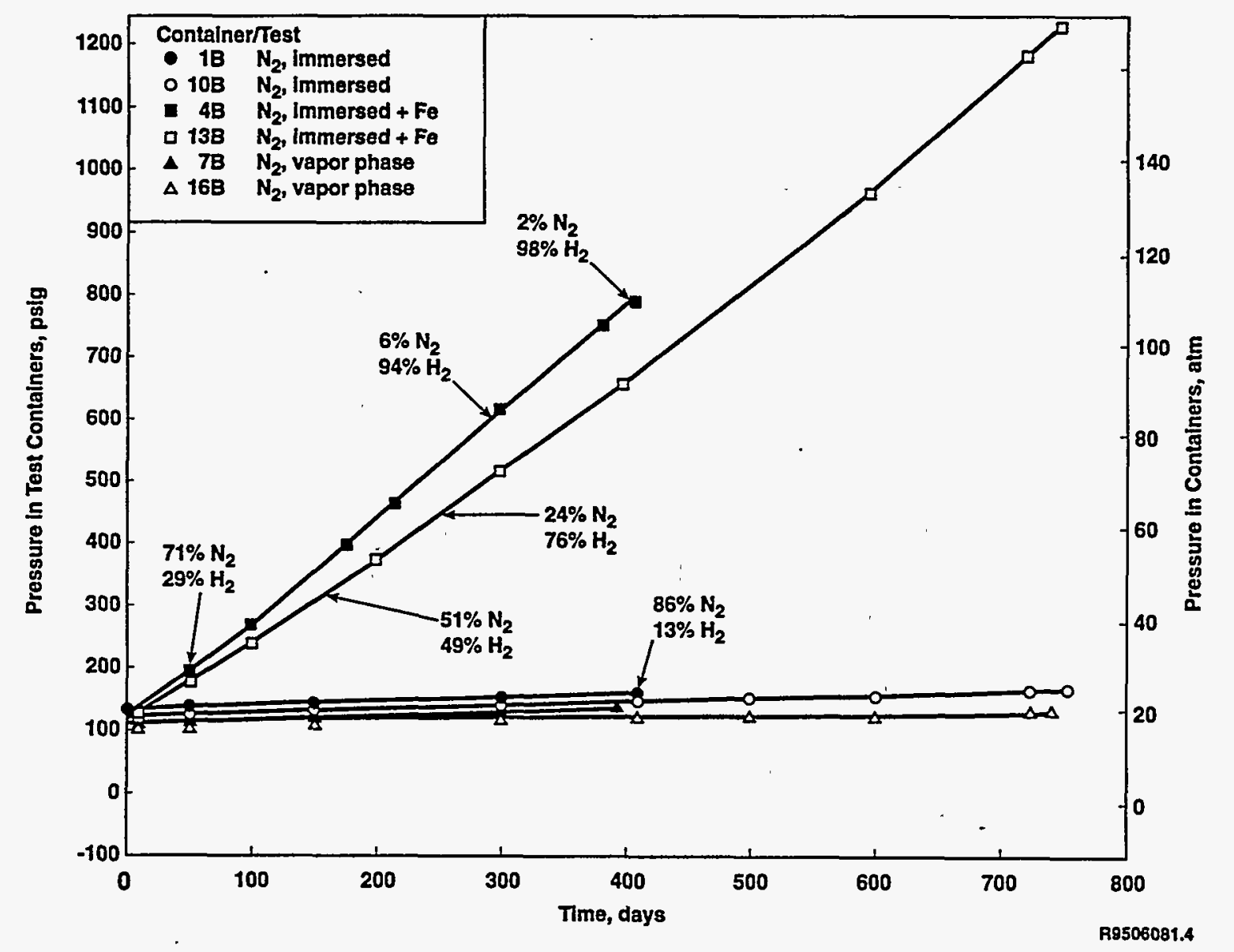

Figure 6-10. Pressure-time curves, Al-base materials in anoxic brine (Brine $A / \mathrm{N}_{2}$ ), $30 \pm 5^{\circ} \mathrm{C}$. Gas analysis results (in mole \%) are given for each test at the time the analyses were made.

The seal-welded test containers were limited to either 200 psig or to 300 psig because of the pressure gauge range restrictions. Test container gas ventings were therefore required in the case of tests exceeding the limit of the gauge used. (The ventings are tabulated in the data of Appendix A.) Where ventings were required, the amount of gas vented was determined by before-and-after pressure teadings. The vented gas was then included in the gas pressure "inventory" as though it had not been lost. Thus, the container pressures noted on the ordinate of Figure 6-10 for tests $4 \mathrm{~B}$ and $13 \mathrm{~B}$ are in 
reality "virtual pressures," the pressures that would have been attained if 1) a pressure gauge with an unlimited upper range had been used, and 2) if the reaction rate were independent of pressure over the range indicated on the ordinate. The assumption associated with item 1) is resolvable by simple computation; the assumption associated with item 2) is not believed to be significant over the pressure ranges involved.

The curves of Figure 6-10 show the profound effect of $\mathrm{Fe}$ in the environment on the corrosion rate of the Al-base materials. Presumably, the $\mathrm{Fe}^{++}$ion resulting from the corrosion of the lowcarbon steel is reduced by the oxidizing $\mathrm{Al}$, deposits on the $\mathrm{Al}$ surface as metallic $\mathrm{Fe}$, and participates as the cathode in the resulting electrochemical cell. Water would be reduced at the Fe cathode, liberating $\mathrm{H}_{2}$ as the final cathode reaction product.

As containers $4 B$ and $13 B$ underwent repeated ventings the $H_{2} / N_{2}$ ratio increased until essentially all of the $\mathrm{N}_{2}$ had been eliminated from the systems.

As would be expected from the pressure-time curves of Figure 6-10, the vapor-phase exposure specimens (tests 7B and 16B) showed essentially no corrosion attack when they were removed from their test containers, except where brine had splashed on the bottoms of the specimens during test container handling.

The specimens removed from the tests containing immersed specimens with no steel, tests $1 B$ and 10B, showed evidence of some corrosion attack. The attack was nonuniform, and in the case of both the $99.99 \% \mathrm{Al}$ and the 6061 alloy specimens, was frequently associated with the metal-to-metal crevices. The attack was either found within the prior crevices or in the vicinity of, and bordering on, the crevices. The $99.99 \% \mathrm{Al}$ specimens in this test showed approximately two times the corrosion attack of the 6061 alloy specimens.

The specimens removed from the tests containing immersed specimens with Fe (tests $4 \mathrm{~B}$ and 13B) were severely corroded, especially the specimens of $99.99 \% \mathrm{Al}$. The corrosion product was white, primarily paste-like (when wet), but was, in many regions, hard and adherent to the (dry) specimen surfaces. Because the attack was highly nonuniform on all of the samples, quantification of the degree of attack between the 99.99\% $\mathrm{Al}$ and the 6061 specimens was difficult. However, specimen-thickness measurements, coupled with visual observation and estimation of metal lost to corrosion, indicated that the $99.99 \%$ Al specimens had undergone $>90 \%$ of the total corrosion that had taken place. 
A common finding on the $99.99 \%$ Al specimens was an hourglass-shaped region, encompassing both metal-coupon crevices, of a relatively high degree of corrosion attack. Because a thick encrustation of corrosion product filled the gaps between the coupons, it is likely that the equivalent of a large crevice region, of chemistry different from the bulk brine, formed in these central zones. Because of the amphoteric nature of aluminum, either acid or basic conditions, resulting in a $\mathrm{pH}$ outside the Al-compatible range of 4 to 9, could have enhanced the corrosion rate in these "virtualcrevice" regions. The chemistry of the solution existing in these regions is not known with certainty. However, if the reactions are similar to those occurring, for example, within pits on stainless steel surfaces, with hydrolysis of the chloride salts formed from the corrosion reactions, one would expect low-pH (acid) conditions to prevail in the crevice regions. This conclusion is consistent with the aluminum-hydroxide type of corrosion products found on the specimen surfaces (see Section 6.3.4).

No attempt was made to obtain gravimetric corrosion-rate information from the individual coupons because of 1) the difficulty that would be entailed in cleaning all of the corrosion products from the specimens; 2) the nonuniformity of the attack; and 3) the generally clear message of the pressure-time curves of Figure 6-10 regarding the ready corrodibility of Al-base materials.

The post-test appearance of the specimens, as cleaned with deionized water and a soft bristle brush, is shown in Figure 6-11 (99.99\% Al) and Figure 6-12 (6061 alloy). The photographs do not accurately portray the disparity in corrosion between the two Al-base materials in the tests containing steel specimens.

Corrosion product samples were taken from the immersed-specimen tests for XRD analysis. Results of these investigations are presented in Section 6.3.5 of the report. The corrosion rates of the Al-base materials were estimated from the pressure-time curves of Figure 6-10. Because the 13-month and the 24-month curves are in generally good agreement, only the 24-month curves were used in the calculations. For the initial calculations reported here, all of the specimens were assumed to corrode at the same rate in each test container. This assumption "spreads" the corrosion uniformly between the $99.99 \% \mathrm{Al}$ and the 6061 alloy. The implications of this assumption are discussed in more detail in Section 6.3.4 of this report.

The procedure used to calculate the $\mathrm{H}_{2}$ generation rates in the Brine/ $\mathrm{N}_{2}$ studies is presented in Appendix C. 


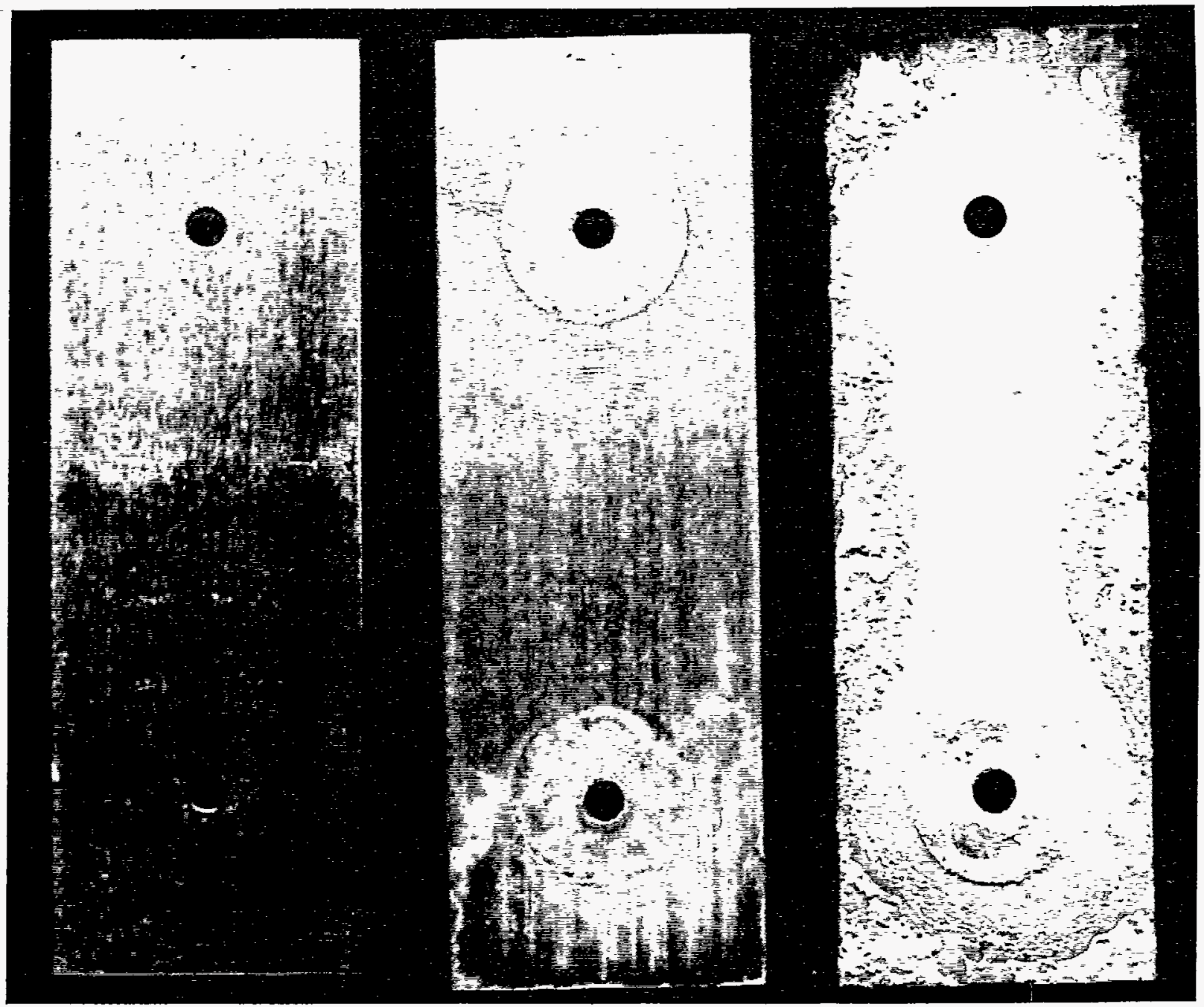

Specimen 1-292

Vapor-phase exposure Test 16B
Specimen 1-257

Immersed, no Fe Test 10B
Specimen 1-275 Immersed, with $\mathrm{Fe}$ Test 13B

Figure 6-11. Post-test appearance of $99.99 \% \mathrm{Al}$ specimens from Brine $\mathrm{A} / \mathrm{N}_{2}$ tests. Test temperature: $30 \pm 5^{\circ} \mathrm{C}$. Test duration: 24 months.

Shown approximately one-half actual size. 


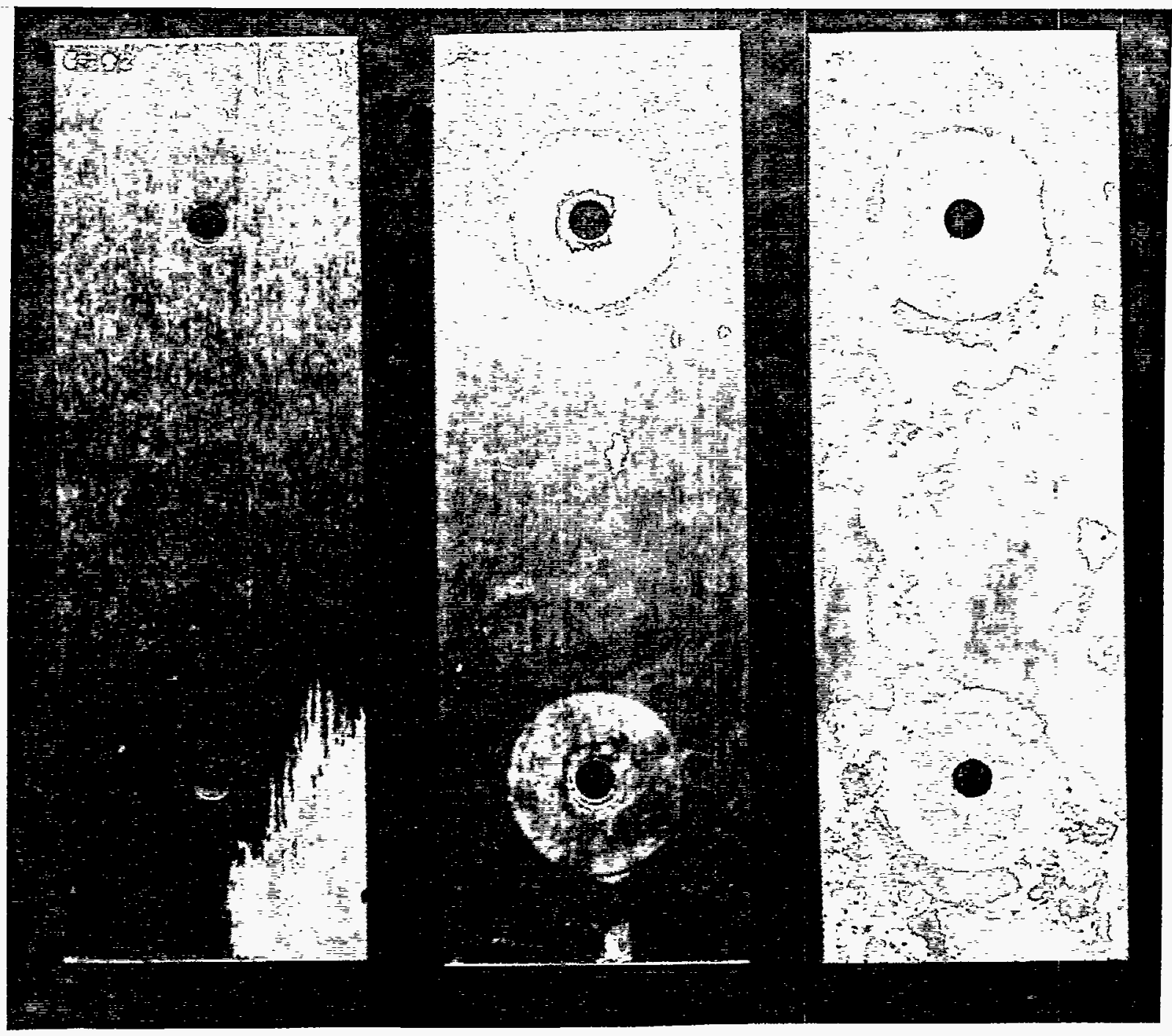

Specimen 6-292

Vapor-phase exposure Test $16 \mathrm{~B}$
Specimen 6-257

Immersed, no $\mathrm{Fe}$

Test 10B
Specimen 6-275

Immersed, with $\mathrm{Fe}$ Test 13B

Figure 6-12. Post-test appearance of 6061 alloy specimens from Brine $A / \mathrm{N}_{2}$ tests. Test temperature: $30 \pm 5^{\circ} \mathrm{C}$. Test duration: 24 months.

Shown approximately one-half actual size. 
For the 24-month Fe-containing tests, the $\mathrm{H}_{2}$ production rate was calculated to be $2.9 \mathrm{~mol}$ $\mathrm{H}_{2} / \mathrm{m}^{2}$ Al-base material-year. For the tests without steel, the $\mathrm{H}_{2}$ production rate was calculated to be $0.097 \mathrm{~mol} \mathrm{H}_{2} / \mathrm{m}^{2}$ Al-base material-yr. When these $\mathrm{H}_{2}$ production rates are compared with the $\mathrm{H}_{2}$ production rate of low-carbon steel in anoxic Brine $A$, viz., $0.10 \mathrm{~mol} \mathrm{H} / \mathrm{m}^{2}$ steel-year, it can be seen that the Fe-containing Al-base-material tests yield $\mathrm{H}_{2}$ production rates far higher than the steel tests; and that, without Fe present, the corrosion $/ \mathrm{H}_{2}$ production rate of the Al-base materials in anoxic brine is approximately equal to the corrosion/ $/ \mathrm{H}_{2}$ production rate of steel.

Further analysis of the $\mathrm{H}_{2}$ generation by Al-base materials is presented in Section 6.3 .4 of this report.

\subsubsection{Brine $/ \mathrm{CO}_{2}$ Tests}

The brine/ $\mathrm{CO}_{2}$ tests included immersed-specimen tests (tests $2 \mathrm{~B}$ and $11 \mathrm{~B}$ ), immersed-specimen tests with steel present (tests 5B and 14B), and vapor-phase-exposure tests (tests 8B and 17B). Duplicate tests were run for test durations of 13 months and 24 months. The pressure-time histories and gas analysis results for these tests are presented in Figure 6-13.

Several of the tests whose pressure-time curves are shown in Figure 6-13 would have exceeded the containers' pressure-gauge limits if gas were not vented prior to test termination. The procedure followed in those cases for determining the total pressure is the same as that described in Section 6.3.1 of this report. The timing and magnitude of the ventings are noted in the pressure-time tabulations of Appendix A-4.

The curves of Figure 6-13 show, as in the case of the anoxic brine tests, a profound effect of the presence of $\mathrm{Fe}^{++}$in the brine, essentially a total lack of reaction in the case of the vapor-phaseexposure tests, and intermediate corrosion rates in the case of immersed specimens with no Fe. It is not surprising that the corrosion rates of the immersed-specimen tests are significantly higher than those exhibited by the specimens in the equivalent brine/ $\mathrm{N}_{2}$ tests, because of the known pH-lowering ability of dissolved $\mathrm{CO}_{2}$ (SAND92-7347, Section 4.2.1). Crolet and Bonis (1984) have estimated that $\mathrm{CO}_{2}$ at $10 \mathrm{~atm}$ can lower the $\mathrm{pH}$ of a $0.5 \mathrm{M} \mathrm{NaCl}$ solution at $25^{\circ} \mathrm{C}$ to -3.4 . This is well below the 


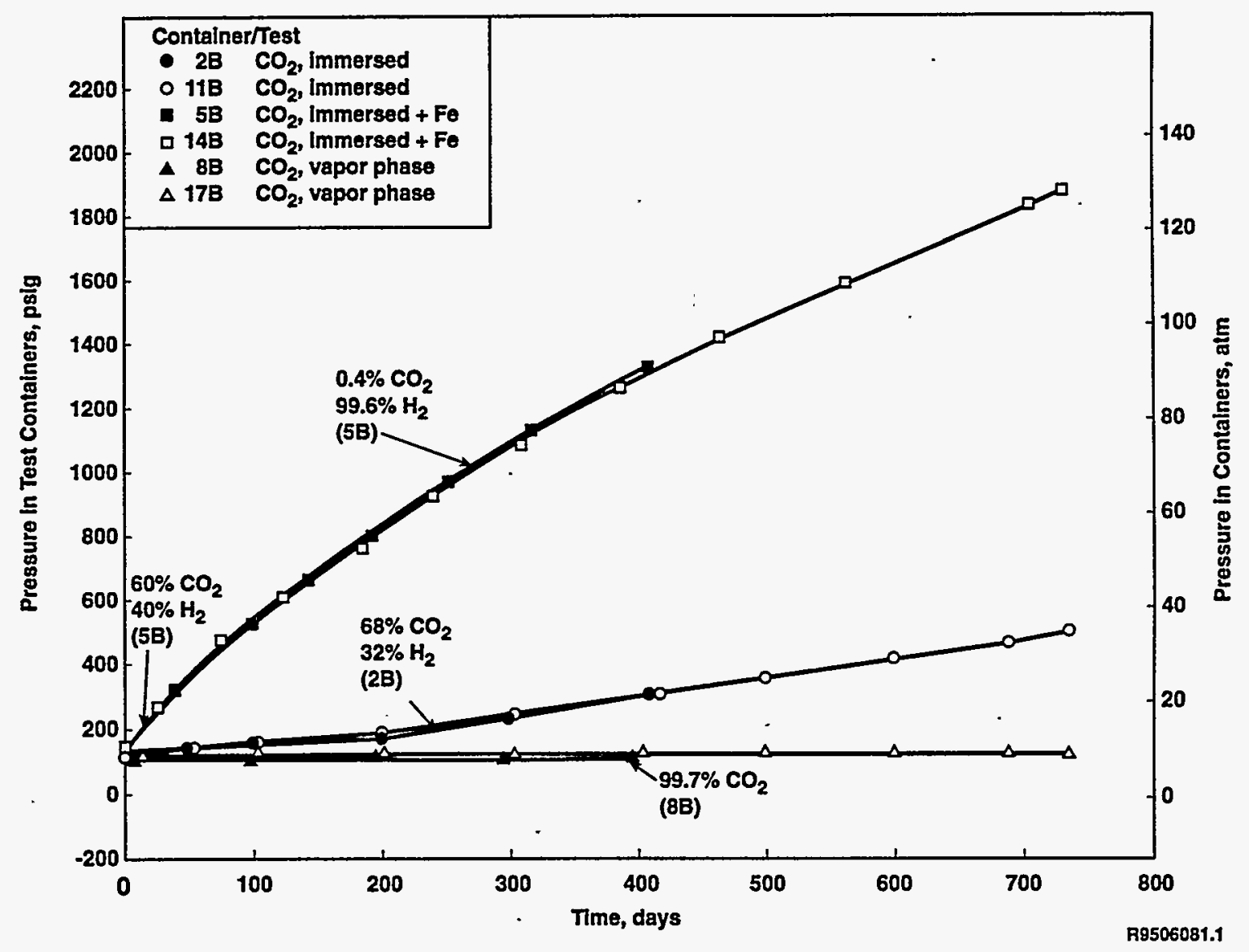

Figure 6-13. Pressure-time curves, Al-base materials in Brine A with $\mathrm{CO}_{2}, 30 \pm 5^{\circ} \mathrm{C}$. Gas analysis results (in mole \%) are given for each tests at the time the analyses were made.

$\mathrm{pH}$ value of 4 which roughly defines the lower $\mathrm{pH}$ boundary for $\mathrm{Al}$ alloy corrosion resistance. As $\mathrm{H}_{2}$ is generated and gas is vented from the test containers, the $\mathrm{CO}_{2}$ content of the vented containers steadily diminishes and solution $\mathrm{pH}$ rises.

The decrease of $\mathrm{CO}_{2}$ concentration in the container gas of the Fe-containing tests with time due to multiple gas ventings from the test containers, is evident from the gas analysis notations on the curve corresponding to test $5 \mathrm{~B}$ in Figure 6-13. After about 300 days the $\mathrm{CO}_{2}$ has been essentially eliminated from the Fe-containing systems, and the gas generation rate has decreased significantly. 
After the $\mathrm{CO}_{2}$ has been expelled, the slopes of the curves corresponding to tests $5 \mathrm{~B}$ and $14 \mathrm{~B}$, Figure 6-13, approximate the slopes of the brine/ $\mathrm{N}_{2}$ curves of tests $4 \mathrm{~B}$ and $13 \mathrm{~B}$, Figure $6-12$.

The post-test appearance of the specimens from the brine/ $\mathrm{CO}_{2}$ tests was similar to that of the specimens from the brine/ $\mathrm{N}_{2}$ tests, described in the previous section of this report. The degree of attack ranged from essentially no attack for the vapor-phase exposure specimens to extremely severe attack for the immersed specimens in systems containing Fe.

The corrosion of specimens from the immersed-specimen test without Fe showed a strong dependence on the material composition. While the two materials appeared to corrode at similar rates in a gross sense, the $99.99 \% \mathrm{Al}$ material appeared to corrode nonuniformly over fairly large planar areas, with a definite acceleration of corrosion in the vicinity of the metal-to-metal crevices, both internal and external to the crevices. The 6061 alloy, on the other hand, corroded by way of formation of pits and pit clusters, with no evidence of crevice involvement in the corrosion processes.

The specimens of $99.99 \% \mathrm{Al}$ from the immersed-specimen tests with $\mathrm{Fe}$ showed extreme corrosion attack, whereas the 6061 alloy showed very little, even less than that observed in the anoxic brine tests discussed in the previous section of this report. The $99.99 \% \mathrm{Al}$ specimens showed large areas of specimen thinning with pitting attack superimposed on the thinned substrate. Also evident was the hourglass-shaped areas of pronounced corrosion attack, encompassing the crevice regions. A definite enhancement of corrosion was found in the vicinity of the crevices. The 6061 alloy showed only a small amount of corrosion at the crevices, proximate to the crevice opening, and some small, isolated pitted regions on certain specimens. As in the case of the anoxic brine tests, it can be confidently stated that the corrosion of the $99.99 \%$ Al material was responsible for $>90 \%$ of the corrosion and gas generation in the tests containing Fe.

The post-test appearance of the specimens is shown in Figures 6-14 and 6-15. The specimens were cleaned with deionized water and a soft bristle brush prior to being photographed.

The procedure used to calculate the $\mathrm{H}_{2}$-generation rates for the brine/ $\mathrm{CO}_{2}$ tests is presented in Appendix C. It was arbitrarily decided to use a "mean" $\mathrm{H}_{2}$ generation rate corresponding to the linear rate resulting from passing a straight line from the origin of each curve through its 24-month end point. Using this method to arrive at the container pressurization rate, and assuming that all of the Al-base-material specimens in each container corrodes at the same rate, a gas-generation rate of 


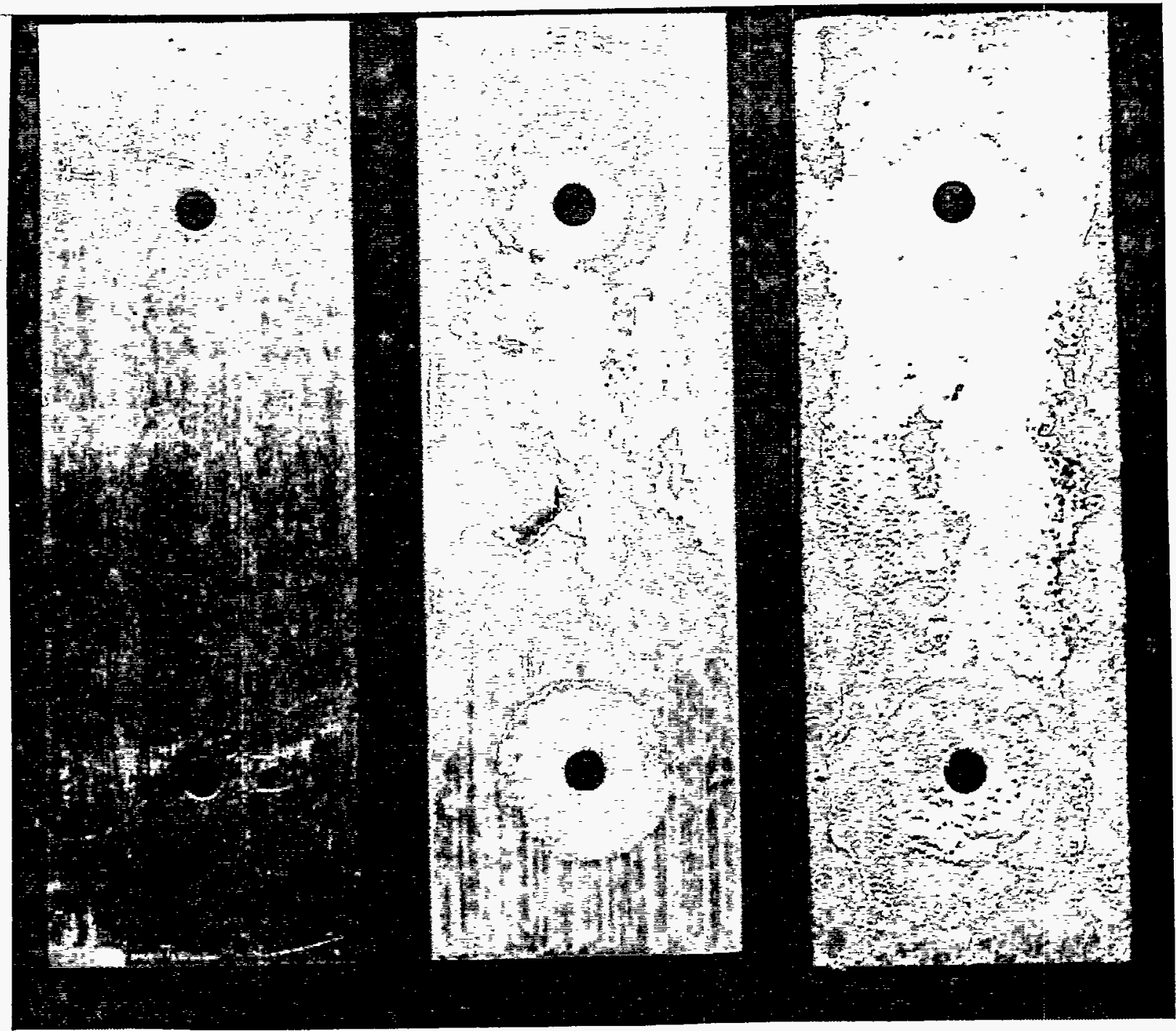

Specimen 1-301

Vapor-phase exposure Test 17B
Specimen 1-264

Immersed, no $\mathrm{Fe}$

Test 11B
Specimen 1-282

Immersed, with Fe

Test 14B

Figure 6-14. Post-test appearance of $99.99 \% \mathrm{Al}$ specimens from $\mathrm{Brine} \mathrm{A} / \mathrm{CO}_{2}$ tests. Test temperature: $30 \pm 5^{\circ} \mathrm{C}$. Test duration: 24 months.

Shown approximately one-half actual size. 


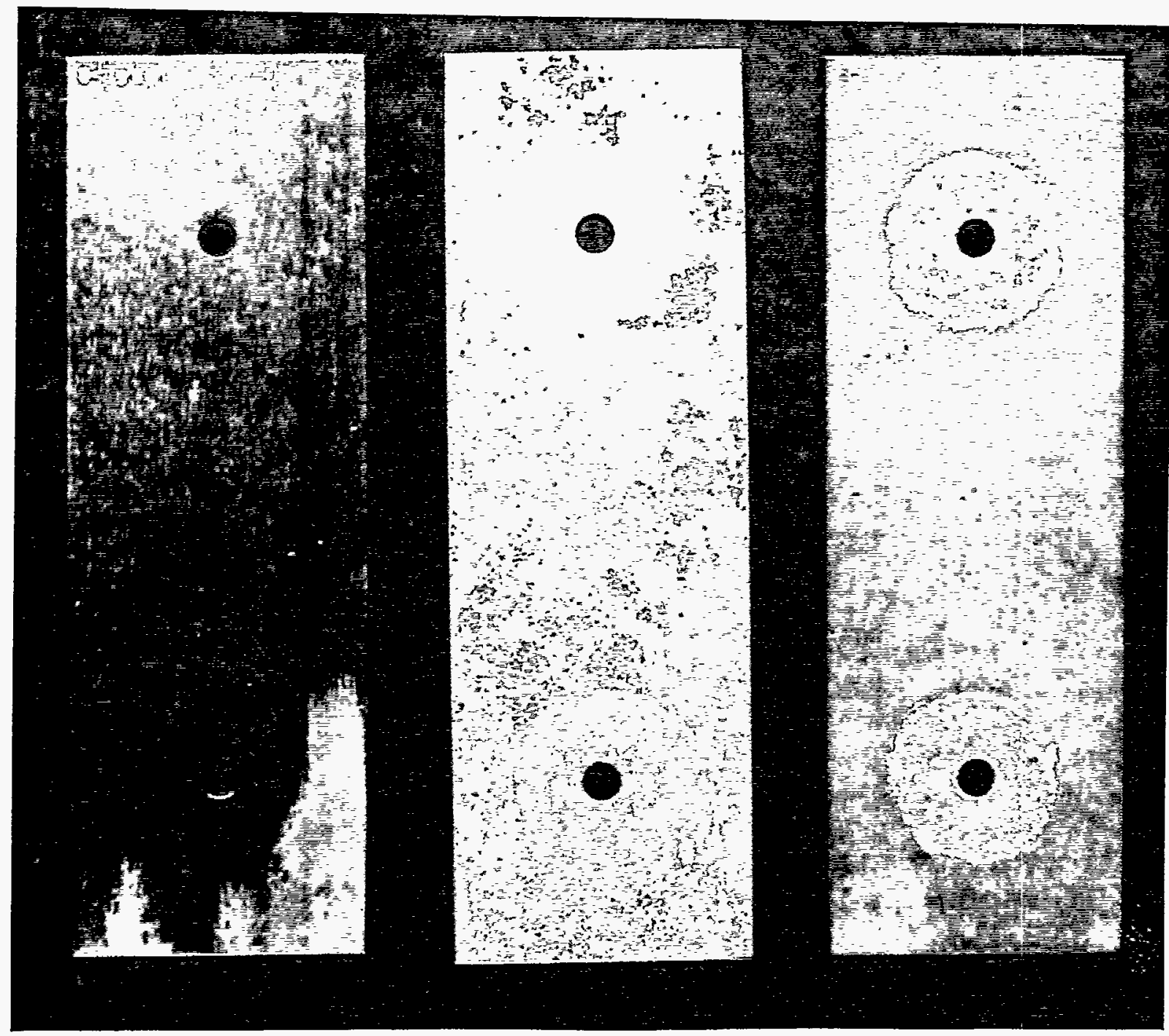

Specimen 6-298

Vapor-phase exposure Test 17B
Specimen 6-262

Immersed, no $\mathrm{Fe}$

Test 11B
Specimen 6-280 Immersed, with $\mathrm{Fe}$ Test 14B

Figure 6-15. Post-test appearance of 6061 alloy specimens from $\mathrm{Brine} \mathrm{A} / \mathrm{CO}_{2}$ tests. Test temperature: $30 \pm 5^{\circ} \mathrm{C}$. Test duration: 24 months.

Shown approximately one-half actual size. 
$4.4 \mathrm{~mol} \mathrm{H}_{2} / \mathrm{m}^{2}$ Al-base material-year was calculated for the immersed-specimen tests with Fe present, and a value of $0.90 \mathrm{~mol} \mathrm{H} / \mathrm{m}^{2}$ Al-base material-yr was determined for the immersed-specimen tests with no Fe.

Further analysis of the $\mathrm{H}_{2}$ generation rate of Al-base materials in brine environments is presented in Section 6.3.4 of this report; the results of XRD examination of the corrosion products is presented in Section 6.3.5.

\subsubsection{Brine $/ \mathrm{H}_{2} \mathrm{~S}$ Tests}

The brine/ $\mathrm{H}_{2} \mathrm{~S}$ tests included immersed-specimen tests (tests $3 \mathrm{~B}$ and $12 \mathrm{~B}$ ), immersed-specimen tests with steel present (tests 6B and 15B); and vapor-phase-exposure tests (tests $9 \mathrm{~B}$ and 18B). Duplicate tests were run for test durations of 13 months and 24 months. The pressure-time histories and gas analysis results for these tests are presented in Figure 6-16.

The gas-generation rates of the Brine $\mathrm{A} / \mathrm{H}_{2} \mathrm{~S}$ tests presented in Figure 6-16 show some similarity to the Brine $\mathrm{A} / \mathrm{N}_{2}$ tests (the immersed-specimen tests with $\mathrm{Fe}$ ) and to the Brine $\mathrm{A} / \mathrm{CO}_{2}$ tests (the immersed-specimen tests without $\mathrm{Fe}$ ). No $\mathrm{H}_{2}$ generation was observed in the case of the vapor-phase exposure. It is likely that the activity of $\mathrm{Fe}$ in the system was reduced by the passivation of the steel specimens through the formation of an FeS film. This diminution of the activity of $\mathrm{Fe}^{++}$could inhibit its reduction into metallic $\mathrm{Fe}$ on the surface of the Al-base-material specimens, making the steel-containing tests behave much like the tests containing no steel. The immersed-specimen tests containing no steel exhibited gas-generation rates similar to equivalent tests with $\mathrm{CO}_{2}$, consistent with the lowering of $\mathrm{pH}$ by both $\mathrm{H}_{2} \mathrm{~S}$ and $\mathrm{CO}_{2}$ [Crolet and Bonis (1984) give a $\mathrm{pH}$ value of $\sim 3.8$ for a $0.5 \mathrm{M} \mathrm{NaCl}$ solution in equilibrium with $\mathrm{H}_{2} \mathrm{~S}$ at $5 \mathrm{~atm}$ pressure.]

The usual post-test analysis of the specimens provided the following information:

- The vapor-phase exposure specimens appeared essentially clean, as in the brine/ $\mathrm{N}_{2}$ and the brine $/ \mathrm{CO}_{2}$ tests. 


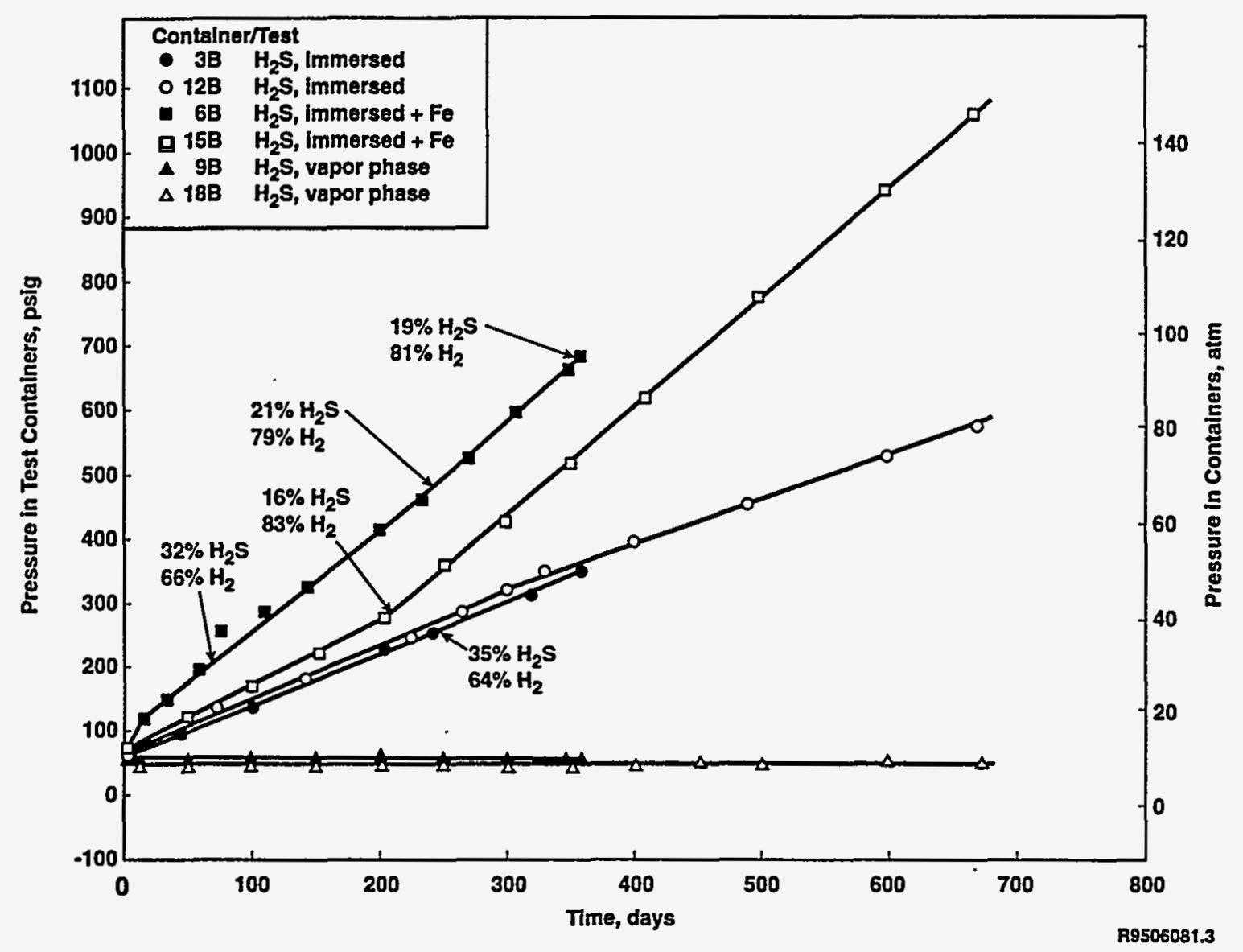

Figure 6-16. Pressure-time curves, Al-base materials in Brine A with $\mathrm{H}_{2} \mathrm{~S}, 30$ $\pm 5^{\circ} \mathrm{C}$. Gas analysis results (in mole $\%$ ) are given for each test at the time the analyses were made.

- The $99.99 \% \mathrm{Al}$ specimens appeared to corrode significantly more in the brine $/ \mathrm{H}_{2} \mathrm{~S}$ tests without $\mathrm{Fe}$ than in the brine/ $\mathrm{CO}_{2}$ tests without $\mathrm{Fe}$, whereas the 6061 alloy specimens corroded significantly less. It was (visually) estimated that the $99.99 \% \mathrm{Al}$ alloy corroded approximately four times as much as the 6061 alloy in these tests. Once again the $99.99 \% \mathrm{Al}$ specimens showed a strong tendency toward crevice corrosion, whereas the 6061 alloy did not.

- In the immersed tests with $\mathrm{Fe}$, once again the $99.99 \% \mathrm{Al}$ specimens suffered $>90 \%$ of the corrosion attack. The mode of attack of the two materials was similar to that presented for the brine/ $\mathrm{CO}_{2}$ tests in the previous section of this report. 
The post-test appearance of the specimens is shown in Figures 6-17 and 6-18. The specimens were cleaned with deionized water and a soft bristle brush prior to being photographed.

The 24-month curves of Figure 6-16 were linearized to obtain "mean" $\mathrm{H}_{2}$ generation rates (as they were for the brine $/ \mathrm{CO}_{2}$ tests), and the rate of gas generation by the corrosion specimens computed as it was for the brine/ $\mathrm{N}_{2}$ and the brine/ $\mathrm{CO}_{2}$ tests (Appendix $\mathrm{C}$ ). Assuming that the specimens corroded uniformly throughout the sample arrays, a gas-generation rate of $2.4 \mathrm{~mol} \mathrm{H} / \mathrm{m}^{2}$ Al-base material-year was arrived at for the immersed-specimen tests with $\mathrm{Fe}$, and a value of $1.3 \mathrm{~mol} \mathrm{H}_{2} / \mathrm{m}^{2}$ Al-base material-year was determined for the immersed-specimen tests with no Fe.

Additional information on the $\mathrm{H}_{2}$ generation rate of Al-base materials in brine environments is presented in Section 6.3.4 of this report; the results of XRD examination of the corrosion products is presented in Section 6.3.5.

\subsubsection{Summary of Corrosion Rates of Al-Base Materials}

A summary of the corrosion rate data presented in the preceding three subsections of the report, are presented in Table 6-13. For the tabulated values, the assumption is made that all of the specimens in each test corrode at the same rate. The vapor-phase tests are not included in the table.

In the brine/ $\mathrm{N}_{2}$ test without $\mathrm{Fe}$ present, the $99.99 \% \mathrm{Al}$ material was estimated to corrode at about twice the rate of the 6061 alloy. In the brine/ $\mathrm{CO}_{2}$ test without $\mathrm{Fe}$, the two materials corroded approximately equally. In the brine/ $\mathrm{H}_{2} \mathrm{~S}$ test without $\mathrm{Fe}$, the $99.99 \% \mathrm{Al}$ material was estimated to corrode at about 4 times the rate of the 6061 alloy.

It was noted in each of the preceding report subsections that the corrosion rate of the $99.99 \%$ Al material in the Fe-containing tests was far higher than the corrosion rate of the 6061 alloy, the disparity in corrosion being so great that it could be assumed that the $99.99 \% \mathrm{Al}$ material was responsible for $>90 \%$ of the corrosion observed. These results point to a sensitive dependence of Al-base material corrosion rate on alloy composition. Because only two Al-base material compositions were present in the tests, there is no way to correlate corrosion rate with alloy composition, or even alloy class. And, even if such detailed data were available, it would be necessary to know the composition of the Al-base materials in the waste in order to make proper use of the data. Because neither specific-alloy corrosion rates nor detailed waste composition is known, it is suggested that the Al-base 


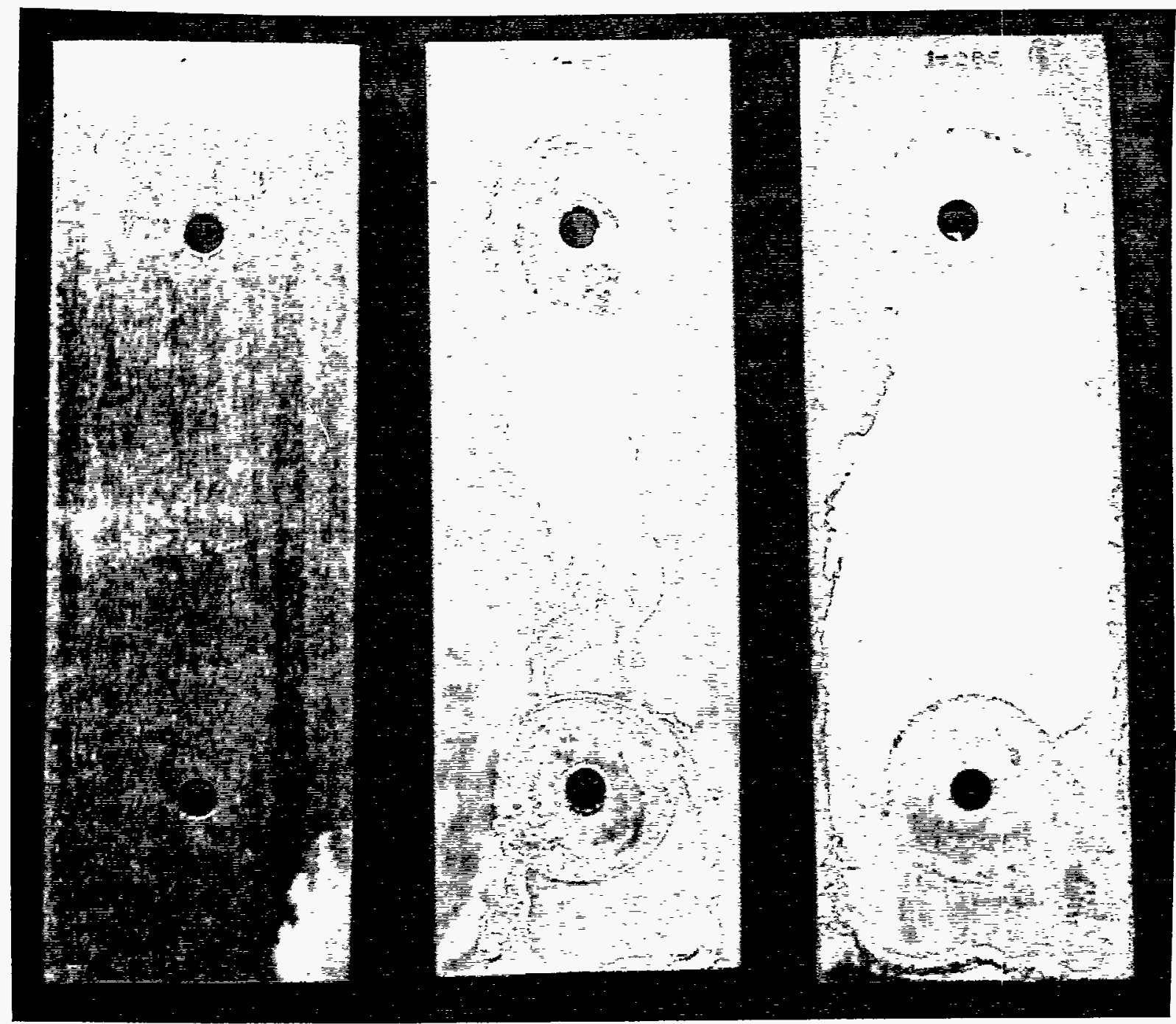

Specimen 1-305

Vapor-phase exposure

Test 18B
Specimen 1-270

Immersed, no Fe

Test 12B
Specimen 1-286

Immersed, with $\mathrm{Fe}$

Test 15B

Figure 6-17. Post-test appearance of $99.99 \% \mathrm{Al}$ specimens from Brine $\mathrm{A} / \mathrm{H}_{2} \mathrm{~S}$ tests. Test temperature: $30 \pm 5^{\circ} \mathrm{C}$. Test duration: 24 months.

Shown approximately one-half actual size. 


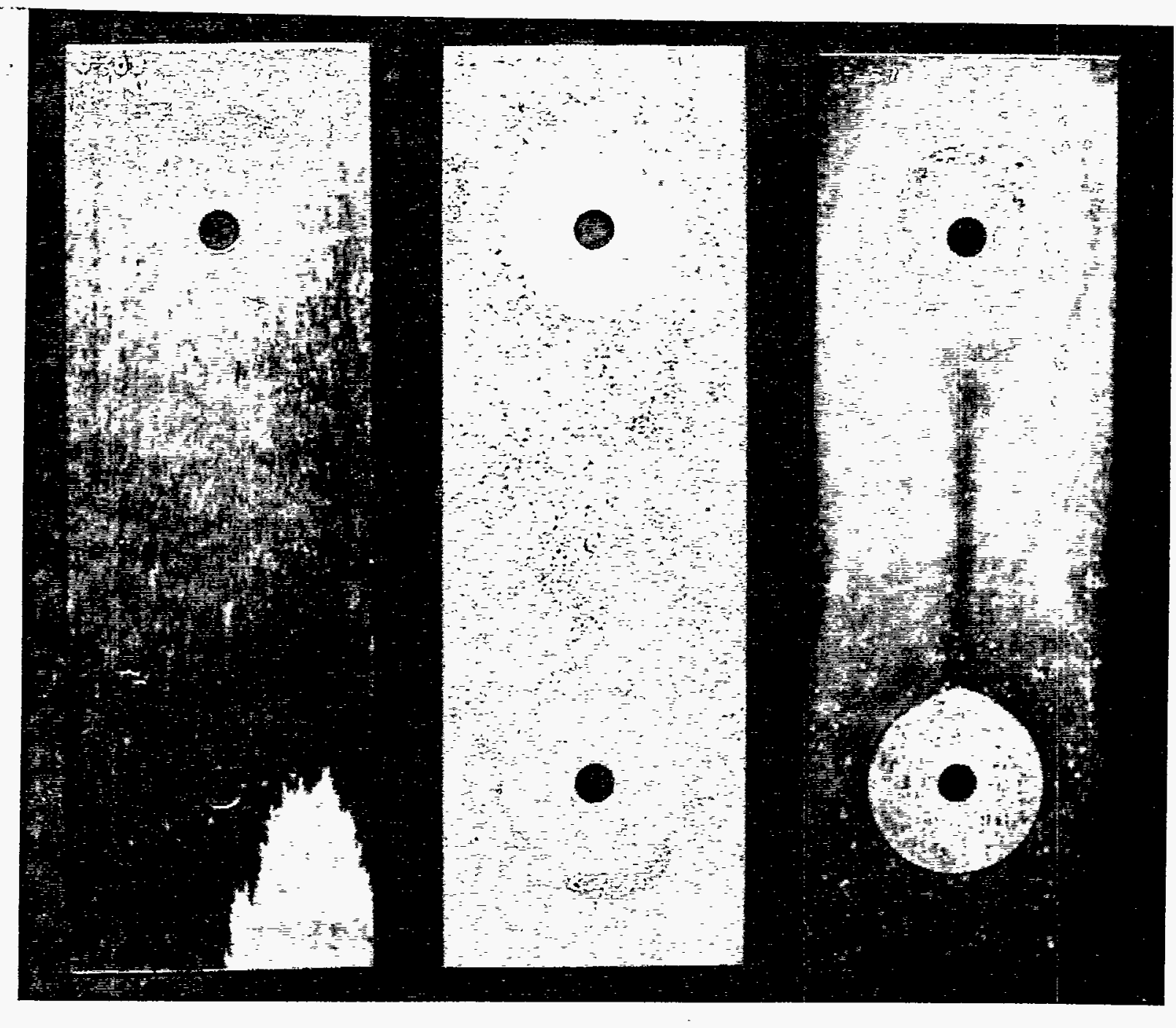

Specimen 6-305

Vapor-phase exposure

Test $18 \mathrm{~B}$
Specimen 6-270

Immersed, no $\mathrm{Fe}$

Test $12 \mathrm{~B}$
Specimen 6-287

Immersed, with $\mathrm{Fe}$

Test $15 B$

Figure 6-18. Post-test appearance of 6061 alloy specimens from Brine $\mathrm{A} / \mathrm{H}_{2} \mathrm{~S}$ tests. Test temperature: $30 \pm 5^{\circ} \mathrm{C}$. Test duration: 24 months. Shown approximately one-half actual size. 


\begin{tabular}{llc} 
Test & \multicolumn{1}{c}{$\begin{array}{c}\text { Environment, initial Gas } \\
\text { Pressure }\end{array}$} & $\begin{array}{c}\mathrm{H}_{2} \text { Generation Rate, } \\
\text { mol } \mathrm{H}_{2} / \mathrm{m}^{2} \text { Al-base } \\
\text { material-year }\end{array}$ \\
10B & Brine $/ \mathrm{N}_{2}(10 \mathrm{~atm})$ & 0.097 \\
13B & Brine $/ \mathrm{N}_{2}(10 \mathrm{~atm})$ with $\mathrm{Fe}$ & $2.9^{\mathrm{a}}$ \\
11B & Brine $/ \mathrm{CO}_{2}(10 \mathrm{~atm})$ & 0.90 \\
14B & Brine $/ \mathrm{CO}_{2}(10 \mathrm{~atm})$ with $\mathrm{Fe}$ & $4.4^{\mathrm{a}}$ \\
12B & Brine $/ \mathrm{H}_{2} \mathrm{~S}(5 \mathrm{~atm})$ & 1.3 \\
$15 \mathrm{~B}$ & Brine $/ \mathrm{H}_{2} \mathrm{~S}(5 \mathrm{~atm})$ with $\mathrm{Fe}$ & $2.4^{\mathrm{a}}$
\end{tabular}

A conservative approach would double these values, for reasons given in the text.

material corrosion rate data obtained in the present tests be used in the most conservative fasinion possible, which in turn would depend on the corrosion model being developed. If, for example, a rapid corrosion gas-generation rate would be considered inimical to repository integrity; a conservative approach would assume 1) that the brine is anoxic and contains a substantial amount of $\mathrm{Fe}^{++}$ions, and 2) that all of the Al-base material present corrodes at the rate of the $99.99 \% \mathrm{Al}$ material. The assumptions both appear to be intrinsically realistic. The first assumption is basic to the general view of the post-closure repository. The second assumes that the Al-base material present in the waste will demonstrate a corrosion behavior that is much closer to high-purity $\mathrm{Al}$ than 6061 alloy. This is consistent with the waste primarily containing Al-base materials having a very low concentration of alloying elements that import resistance to brine corrosion, such as $\mathrm{Mg}$ or $\mathrm{Mn}$. It is expected that $\mathrm{Al}$ foil, for example, would corrode in a manner similar to $99.99 \% \mathrm{Al}$. This rationale does not imply an understanding of the reasons for the sensitivity of high-purity aluminum to anoxic brine containing $\mathrm{Fe}^{++}$and the lack of sensitivity of the 6061 alloy. It could be related to the ability to reduce $\mathrm{Fe}^{++}$to metallic Fe on the Al-base material surface [Cook and McGeary (1964) suggest that only the most electronegative $\mathrm{Al}$ alloys could accomplish this]; the rapidity of the post-deposition cell reactions; or other reasons not yet identified. At the present time, the Al-base material corrosion must be 
considered largely phenomenological in nature. The assumptions would lead to a corrosion rate twice as high as the rate arrived at in the initial calculations, when it was assumed that all of the corrosion coupons corroded at the same rate. Thus, for the brine/ $\mathrm{N}_{2}$ tests, $2 \times 2.9 \mathrm{~mol} \mathrm{H} \mathrm{H}_{2} / \mathrm{m}^{2}$ Al-base material-year equals the conservative result of $5.8 \mathrm{~mol} \mathrm{H}_{2} / \mathrm{m}^{2} \mathrm{Al}$-base material-year.

The highest corrosion rates observed in the Al-base material tests were associated with a test environment containing an overpressure of $\mathrm{CO}_{2}$ gas and steel specimens. This combination resulted in a long-term corrosion rate (Table 6-13) 50\% greater than that associated with $\mathrm{N}_{2}$ gas and steel specimens. It is believed that availability of $\mathrm{Fe}$ has a strong influence on the corrosion rate observed. It is shown in Section 6.3.6 of this report that the steel specimens included in the brine/ $/ \mathrm{CO}_{2} / \mathrm{Fe}$ tests exhibited far more penetration (corrosion attack) than did steel specimens in the brine $/ \mathrm{N}_{2} / \mathrm{Fe}$ or the brine/ $/ \mathrm{H}_{2} \mathrm{~S} / \mathrm{Fe}$ tests, indicating more $\mathrm{Fe}$ was available in the $\mathrm{CO}_{2}$-containing system to "plate out" on the Al-base material specimens. The solubility product of $\mathrm{FeCO}_{3}$ is considerably greater than that of FeS (Blaedel and Meloche, 1963), further suggesting a greater $\mathrm{Fe}^{++}$availability in the test with a $\mathrm{CO}_{2}$ overpressure. Additionally, the $\mathrm{CO}_{2}$ overpressure tests will have a lower $\mathrm{pH}$ than the other tests, at least until the $\mathrm{CO}_{2}$ is dissipated by repeated container venting.

\subsubsection{Analysis of Corrosion Products of Al-Base Materials}

Corrosion products adhering to the surfaces of specimens of Al-base materials taken from tests 1B through 9B after 13 months exposure to a variety of brine environments were examined by means of XRD in an attempt to identify the principal compounds present. The analysis of the corrosion product specimens was not straightforward, as the corrosion products produced only weakly resolved patterns. In a few cases, the corrosion products were entirely amorphous. In those cases where the corrosion products were crystalline, only very tentative phase identification was considered to be possible by the analyst, who stated that "the information provided was in lieu of none at all regarding the possible compositions of the crystalline corrosion products."

The summary of corrosion product specimens analyzed, designated according to specimen serving as source of corrosion product, is given in Table 6-14. In addition, specimens of solids removed from the bottom of each test container were also analyzed. 
Table 6-14. Al-Base Material Corrosion Products Analyzed for Crystalline Constituents by XRD

\begin{tabular}{|c|c|c|c|c|}
\hline $\begin{array}{c}\text { Test } \\
\text { Container }\end{array}$ & Ove & $\begin{array}{l}\text { Ipressure } \\
\text { Gas }\end{array}$ & $\begin{array}{l}\text { Specimen D, } \\
\text { High-Purity Al }\end{array}$ & $\begin{array}{l}\text { Specimen ID, } \\
6061 \text { Alloy }\end{array}$ \\
\hline $1 B$ & $\mathrm{~N}_{2}$ & & $1-006$ & $6-205 D$ \\
\hline $2 B$ & $\mathrm{CO}_{2}$ & & $1-012$ & 6-211D \\
\hline $3 B$ & $\mathrm{H}_{2} \mathrm{~S}$ & & $1-018$ & 6-213D \\
\hline $4 B$ & & (with $\mathrm{Fe}$ ) & $1-022$ & $6-224 D$ \\
\hline $5 B$ & $\mathrm{CO}_{2}$ & (with $\mathrm{Fe}$ ) & $1-028$ & 6-230D \\
\hline $6 \mathrm{~B}$ & $\mathrm{H}_{2} \mathrm{~S}$ & (with $\mathrm{Fe}$ ) & $1-031$ & $6-235 \mathrm{D}$ \\
\hline
\end{tabular}

A summary of the results of the XRD analyses follows:

Specimens 1-006, 1-018, and 1-031

- $\mathrm{Al}_{10} \mathrm{Cl}_{3}(\mathrm{OH})_{27} \cdot 13 \mathrm{H}_{2} \mathrm{O}$ (aluminum chloride hydroxide hydrate)

and/or

- $\mathrm{Al}_{10} \mathrm{Cl}_{4}(\mathrm{OH})_{26} \times \mathrm{xH}_{2} \mathrm{O}$ (aluminum chloride hydroxide hydrate)

plus

- $\mathrm{Ca}_{4} \mathrm{Al}_{2} \mathrm{O}_{6}(\mathrm{CN})_{2} \cdot 10 \mathrm{H}_{2} \mathrm{O}$ (calcium aluminum oxide cyanide hydrate)

and/or

- $\mathrm{C}_{2} \mathrm{H}_{2} \mathrm{CaO}_{4} \cdot \mathrm{Al}_{2} \mathrm{O}_{3} \cdot 3 \mathrm{CaO} \cdot 11 \mathrm{H}_{2} \mathrm{O}$ (calcium aluminum oxide formate hydrate)

plus

- $\mathrm{CCa}_{0.5} \mathrm{O}_{2} \cdot 3 \mathrm{CaO} \cdot \mathrm{Al}_{2} \mathrm{O}_{3} \cdot 0.5 \mathrm{Ca}(\mathrm{OH})_{2} \cdot 9 \mathrm{H}_{2} \mathrm{O}$ (calcium aluminum oxide oxalate hydroxide hydrate)

Specimens 1-022 and 1-028

- $\mathrm{Al}_{10} \mathrm{Cl}_{3}(\mathrm{OH})_{27} \cdot 13 \mathrm{H}_{2} \mathrm{O}$ (aluminum chloride hydroxide hydrate)

and/or 
- $\mathrm{Al}_{10} \mathrm{Cl}_{4}(\mathrm{OH})_{26} \cdot \mathrm{xH}_{2} \mathrm{O}$ (aluminum chloride hydroxide hydrate)

plus

- $\mathrm{CCa}_{0.5} \mathrm{O}_{2} \cdot 3 \mathrm{CaO} \cdot \mathrm{Al}_{2} \mathrm{O}_{3} \cdot 0.5 \mathrm{Ca}(\mathrm{OH})_{2} \cdot 9 \mathrm{H}_{2} \mathrm{O}$ (calcium aluminum oxide oxalate hydroxide hydrate)

Specimen 1-012

- Specimen apparently entirely amorphous, as it yielded no crystalline peaks.

Specimens 6-205D, 6-213D, 6-230D, 6-235D, and 6-224D

- $\mathrm{CCa}_{0.5} \mathrm{O}_{2} \cdot 3 \mathrm{CaO} \cdot \mathrm{Al}_{2} \mathrm{O}_{3} \cdot 0.5 \mathrm{Ca}(\mathrm{OH})_{2} \cdot 9 \mathrm{H}_{2} \mathrm{O}$ (calcium aluminum oxide oxalate hydroxide hydrate)

Specimen 6-211D

- Specimen apparently entirely amorphous, as it yielded no crystalline peaks.

Specimens of Solids from Bottoms of Containers 1B through 6B

- No compounds of Al were identified in the solids from the bottoms of the containers.

The identifiable solids primarily consisted of some combination of the following compounds: $\mathrm{NaCl}, \mathrm{KMgCl} \cdot 6 \mathrm{H}_{2} \mathrm{O}$ (potassium. magnesium chloride hydrate), $\mathrm{MgCl}_{2} \cdot 6 \mathrm{H}_{2} \mathrm{O}$, $\mathrm{KCl}, \mathrm{CaCO}_{3}$, and $\left(\mathrm{NH}_{4}\right)_{3} \mathrm{Fe}\left(\mathrm{SO}_{4}\right)_{3}$ (ammonium iron sulfate).

The complexity of the corrosion products was alluded to earlier in this report (Section 4.2), when it was pointed out that a thermodynamic analysis of the Al-base material corrosion reactions could not be simply based on the supposition of an $\mathrm{Al}_{2} \mathrm{O}_{3}$ reaction product, even though that is the product commonly cited in the literature [for example, Hatch (1984)]. A survey of the corrosion products formed shows some possible $\mathrm{Al}_{2} \mathrm{O}_{3}$ corrosion product constituents, especially on the 6061 alloy, but aluminum chloride hydroxide hydrate compounds are also commonly found, especially on the $99.99 \% \mathrm{Al}$ material. The data presented strongly imply a basic difference in corrosion product formed between the $99.99 \% \mathrm{Al}$ material and the 6061 alloy. If the differences implied are indeed real, it appears that the $\mathrm{Ca}$ constituent of the brine ( $\mathrm{Ca}$ is a minor constituent, present at $\sim 560 \mathrm{mg} / \mathrm{L}$ ) 
could be important in the formation of the corrosion product on the 6061 alloy, but not necessarily on the $99.99 \% \mathrm{Al}$ alloy.

\subsubsection{Corrosion of Steel in the Presence of Al-Base Materiais}

A third of the seal-welded containers dedicated to corrosion testing of Al-base materials had coupons of low-carbon steel (Lot $\mathrm{J}$ ) included in them, to provide $\mathrm{Fe}^{++}$ions to the environment. Presence of $\mathrm{Fe}^{++}$generally accelerates the corrosion of Al-base materials via the replacement reaction that deposits metallic $\mathrm{Fe}$ on the surface of the Al-base material, and such corrosion acceleration was indeed found in all of the $\mathrm{Fe}^{++}$containing tests.

The low-carbon steel specimens that had been included in both the 13-month and the 24-month tests were analyzed to determine the effect of Al-base materials on the corrosion behavior of steel in the Brine A environments. Four steel coupons were available from each test container. As the initial weight of the coupons was known, the metal penetration could be determined by stripping the corrosion product from the coupons, weighing them, and determining the weight change. Because the $\mathrm{H}_{2}$ produced by the rapid corrosion of the Al-base-material coupons masked the $\mathrm{H}_{2}$ formed by the relatively inconsequential steel corrosion in the test containers, the kinetics of the steel corrosion could not be determined by pressure-gauge readout. The agreement in metal-penetration values between the four specimens in each environment was very good. The average metal penetration in each test environment after 13 and 24 months exposure is given in Table 6-15.

By comparison with the above-tabulated values of steel corrosion in Brine A with aluminum, at a one-year exposure time, the corrosion rate of the same steel immersed in Brine A with an $\mathrm{N}_{2}$ overpressure is $1.1 \mu \mathrm{m} / \mathrm{y}$; with a $\mathrm{CO}_{2}$ overpressure is $3.7 \mu \mathrm{m} / \mathrm{y}$ (passivated); and with an $\mathrm{H}_{2} \mathrm{~S}$ overpressure is $0.35 \mu \mathrm{m} / \mathrm{y}$ (passivated). Thus, at a test duration of about 1 year, the presence of $\mathrm{Al}$ had accelerated the corrosion of steel under $\mathrm{N}_{2}$-overpressure conditions by a factor of 7 , under $\mathrm{CO}_{2}$ overpressure conditions by a factor of 4 , and under $\mathrm{H}_{2} \mathrm{~S}$-overpressure conditions by a factor of 2 .

It is likely that this acceleration of corrosion is due to the continual scavenging of $\mathrm{Fe}^{++}$ion from the solution by the Al-base-material specimens, keeping the solution from saturating (at least in the near vicinity of the specimen surfaces) with that specie and thereby maintaining the corrosion rate 
Table 6-15. Penetration of Low-Carbon-Steel Specimens in Al-Base Material Corrosion Tests

\begin{tabular}{|c|c|c|}
\hline Initial Test Environment ${ }^{2}$ & Test Identification & Average Metal Penetration, $\mu \mathrm{m} / \mathrm{y}^{\mathrm{b}}$ \\
\hline Brine $A, N_{2}$ at $10 \mathrm{~atm}$ & $\begin{array}{r}4 B \\
13 B\end{array}$ & $\begin{array}{l}8.0 \pm 1.3 \\
3.9 \pm 0.27\end{array}$ \\
\hline Brine $\mathrm{A}, \mathrm{CO}_{2}$ at $10 \mathrm{~atm}$ & $\begin{array}{r}5 B \\
14 B\end{array}$ & $\begin{array}{c}15.0 \pm 1.7 \\
5.8 \pm 0.58\end{array}$ \\
\hline Brine $\mathrm{A}, \mathrm{H}_{2} \mathrm{~S}$ at $5 \mathrm{~atm}$ & $\begin{array}{r}6 \mathrm{~B} \\
15 \mathrm{~B}\end{array}$ & $\begin{array}{l}0.71 \pm 0.17 \\
0.46 \pm 0.11\end{array}$ \\
\hline
\end{tabular}

a The initial test environment does not maintain under the test conditions, most importantly in the case of the $\mathrm{CO}_{2}$ and the $\mathrm{H}_{2} \mathrm{~S}$ test environments. This is because the rapid corrosion of the Al-base materials required frequent gas ventings from the plenums of the test containers to avoid overpressurization of the gauges. The venting effectively dissipated the original overpressure gas. For example, after 10 months and 13 prior ventings, the gas in the plenum of test $5 \mathrm{~B}$ was $99.6 \% \mathrm{H}_{2}$, $0.4 \% \mathrm{CO}_{2}$; after 13 months and 8 prior ventings, the gas in the plenum of test $6 \mathrm{~B}$ was $81 \% \mathrm{H}_{2}, 19 \% \mathrm{H}_{2} \mathrm{~S}$. This subject is treated in more detail in Appendix C.

b Average of four coupons in each test. The standard deviation of the corrosion rate values is shown for each set of four coupons.

of steel at a higher rate than was observed in the tests without Al. The 24-month data, however, reveal a corrosion rate in all test environments approximately half that shown in the 13-month tests. This conclusion is consistent with essentially no corrosion occurring in the 13- to 24-month time period. This is understandable in the case of the environments containing $\mathrm{CO}_{2}$ and $\mathrm{H}_{2} \mathrm{~S}$, as passivation could possibly occur early in the exposure that could inhibit further corrosion.

In the case of the brine/ $\mathrm{N}_{2}$ environments, the reason for the cessation of corrosion is not clear. It is possible that a film, either corrosion-product or brine-derived, eventually formed on the steel specimens, effectively slowing the rate of corrosion. Regardless of the reason for the observed corrosion inhibition, it appears that the corrosion enhancement observed after 13 months is not an obvious reason for re-evaluation of the corrosion rates obtained from anoxic brine tests with no $\mathrm{Al}$ present, because the corrosion enhancement does not appear, on the basis of the limited tests performed, to be a long-lived effect. 


\subsection{CONCLUSIONS}

The present report constitutes the final deliverable to Sandia National Laboratories from the PNL WIPP-support gas-generation program. All of the conclusions developed during the course of the program, including those either wholly or partially alluded to in the previous report (SAND92-7347), are presented here.

\subsection{Steel with $\mathbf{N}_{2}$ Overpressure}

- The corrosion rate of low-carbon steel immersed in anoxic Brine $\mathrm{A}$ at $30^{\circ} \mathrm{C}$ for test durations of 24 months decreased slowly with time. The corrosion rate of the steel during the final 12 -month period of the 24-month test was $0.71 \mu \mathrm{m} / \mathrm{yr}$, equivalent to the generation of $0.10 \mathrm{~mol} \mathrm{H} / \mathrm{m}^{2}$-steel-yr. It is expected that this rate would continue to decrease with time beyond 24 months. In support of this expectation, a test similar to the anoxic brine tests described, except for the initial presence of a small, nonpassivating amount of $\mathrm{CO}_{2}$, showed a corrosion rate in the final 12 months of a 38-month test that was only $70 \%$ of the 12 -to- 24 month rate cited for the anoxic brine tests. At intermediate times the pressure-time data curves for the tests noted were in excellent agreement.

- In the long-term tests (12 and 24 months) of steel immersed in anoxic Brine A there was good agreement between moles of $\mathrm{Fe}$ reacted and moles of $\mathrm{H}_{2}$ produced, assuming the $\mathrm{Fe}$ in the corrosion product is in the divalent state. The nonadherent, green-blue gray corrosion product could not be identified by $x$-ray diffraction $(X R D)$ methods. Chemical analyses established the presence of a significant amount of $\mathrm{Mg}$ in the corrosion product. It is believed that the corrosion product is, or is a close relative to, an iron magnesium hydroxide $\left[\mathrm{Fe}, \mathrm{Mg}(\mathrm{OH})_{2}\right]$.

- Steel specimens exposed at $30^{\circ} \mathrm{C}$ to the vapor phase of Brine $A$ with an $\mathrm{N}_{2}$ overpressure of $10 \mathrm{~atm}$ showed no discernible corrosion reaction. The corrosion product adhering to the bottoms of these specimens where they were contacted by the brine during handling of the containers was $\beta \mathrm{Fe}_{2}(\mathrm{OH})_{3} \mathrm{Cl}$ in all cases investigated.

- Steel specimens immersed for 6 months in Brine $\mathrm{A}$ at $30^{\circ} \mathrm{C}$ showed a gas-generation/ corrosion rate enhancement of about a factor of two when the $\mathrm{N}_{2}$ overpressure was increased from 10 to $73 \mathrm{~atm}$. No further increase was observed when the pressure was increased to $127 \mathrm{~atm}$. Imposition of full WIPP lithostatic pressure is not expected to have a profound effect on the corrosion/gas generation reaction of steel in Brine A, or brines similar to Brine $\mathrm{A}$. 
- The corrosion rate of low-carbon steel specimens immersed in modified ERDA-6 brine (a $\mathrm{Na}, \mathrm{K}$ chloride-sulfate brine) was strongly dependent on the $\mathrm{pH}$ of the brine. At $\mathrm{pH} 3$ the average penetration rate was $7900 \mu \mathrm{m} / \mathrm{yr}$; at $\mathrm{pH} 5,89 \mu \mathrm{m} / \mathrm{yr}$; at $\mathrm{pH} 7$, $51 \mu \mathrm{m} / \mathrm{yr} ;$ at $\mathrm{pH} 9,2 \mu \mathrm{m} / \mathrm{yr}$; and at $\mathrm{pH} 11,3.6 \mu \mathrm{m} / \mathrm{yr}$.

- The corrosiveness of modified (Ca, $\mathrm{Mg}$, and $\mathrm{HCO}_{3}^{-}$constituents eliminated) ERDA-6 brine toward low-carbon steel specimens under $\mathrm{N}_{2}$ overpressure conditions, and without $\mathrm{pH}$ adjustment, was determined to be similar to that of Brine $\mathrm{A}$, as determined by 6-month tests at $30^{\circ} \mathrm{C}$.

- Steel specimens embedded in simulated backfill (30\% bentonite, $70 \%$ salt) wicking brine from a pool of Brine $A$ under anoxic $\left(\mathrm{N}_{2}\right.$ overpressure) test conditions at $30^{\circ} \mathrm{C}$ over a period of 6 months showed corrosion rates approximately twice those observed in 6-month immersion tests with no backfill present. A similar 6-month test was run in which the backfill/specimen array was suspended in the vapor phase over the Brine A pool. The steel corrosion rate under these circumstances was low, about $30 \%$ of that observed in a Brine $A$ immersion test under $\mathrm{N}_{2}$ with no backfill present.

- Steel specimens immersed in Brine $A$ with an $\mathrm{N}_{2}$ overpressure and with Al-base materials present in the environment revealed an initially rapid rate of reaction, as determined by a 13-month test exposure. The penetration rate was approximately a factor of 7 higher than expected from anoxic brine tests without $\mathrm{Al}$ present. However, the specimens appeared to be passive for the next 11 months (as determined by 24-month tests), suggesting that either a corrosion-derived or a deposition-derived passive film had formed on the specimen surfaces.

- The brine in the test containers did not, in general, undergo an appreciable change in composition during the $\mathrm{N}_{2}$ /immersed-specimen tests.

- Steel specimens embedded in a mass of simulated particulate salt (halite) backfill, with the salt mass "wicking" Brine A from a brine source, under an $\mathrm{N}_{2}$ overpressure at $30^{\circ} \mathrm{C}$ for a 3-month test duration, showed corrosion rates similar to those expected under Brine A/immersed test conditions.

\subsection{Steel with $\mathrm{CO}_{2}$ Overpressure}

- $\mathrm{CO}_{2}$ in Brine A causes an initial increase in the reaction rate of steel, relative to anoxic (brine/ $\mathrm{N}_{2}$ ) conditions. The initial reaction rate increases with the $\mathrm{CO}_{2}$ pressure imposed. Additions of $\mathrm{CO}_{2}$ beyond a certain threshold amount cause the reaction to essentially stop, however, typically in $<100$ days, due to the formation of an adherent carbonate reaction product $\left[\mathrm{FeCO}_{3}\right.$, siderite, or $\mathrm{Fe}, \mathrm{Mn}, \mathrm{Zn}\left(\mathrm{CO}_{3}\right)$, oligonite]. The amount of steel reacted (metal penetration) prior to passivation increases from $\sim 6 \mu \mathrm{m}$ at $10 \mathrm{~atm}$ initial $\mathrm{CO}_{2}$ pressure to $-34 \mu \mathrm{m}$ at $62 \mathrm{~atm}$. 
- The immersed-specimen tests in Brine $\mathrm{A}$ with $\mathrm{CO}_{2}$ showed fairly good agreement between moles of $\mathrm{Fe}$ reacted and moles of $\mathrm{H}_{2}$ produced, assuming that $\mathrm{Fe}$ is only in the divalent state in the corrosion product.

- The minimum amount of $\mathrm{CO}_{2}$ required to passivate low-carbon steel under the sealwelded container test conditions used in the present study (Brine $\mathrm{A}, 30^{\circ} \mathrm{C}$ ) lay in the range between 0.32 and $0.16 \mathrm{~mol} \mathrm{CO}_{2} / \mathrm{m}^{2}$ steel.

- Addition of $\mathrm{H}_{2} \mathrm{~S}$ to an equilibrium pressure of $\sim 1 \mathrm{~atm}$ to seal-welded test containers containing Brine $\mathrm{A}$ and $\mathrm{CO}_{2}$-passivated low-carbon steel specimens at $30^{\circ} \mathrm{C}$ resulted in activation of the previously passivated specimens. The de-passivated specimens exhibited gas generation characteristics approximately characteristic of low-carbon steel exposed to anoxic brine. The $\mathrm{H}_{2} \mathrm{~S}$ added did not cause repassivation of the steel specimens.

- Steel specimens exposed to a $10 \mathrm{~atm} \mathrm{CO}_{2}$ pressure and vapor of Brine $\mathrm{A}$ at $30^{\circ} \mathrm{C}$ showed insignificant corrosion. Corrosion product in the splash zone of the test specimens was siderite, $\mathrm{FeCO}_{3}$.

- The brine in the test containers underwent an appreciable change in composition during the $\mathrm{CO}_{2}$ /immersed tests. The post-test brines showed a relatively high $\mathrm{Fe}$ concentration, a relatively low $\mathrm{Ca}$ concentration, and a low $\mathrm{pH}$.

\subsection{Steel with $\mathrm{H}_{2} \mathrm{~S}$ Overpressure}

- Steel specimens exposed in the immersed and vapor-phase test conditions to Brine $\mathrm{A}$ at $30^{\circ} \mathrm{C}$ with a 5-atm equilibrium pressure of $\mathrm{H}_{2} \mathrm{~S}$ showed no significant reaction. The immersed specimens became passivated by a thin layer of FeS, mackinawite, which formed on the specimen surfaces and prevented further reaction. Approximately 0.056 $\mathrm{mol} \mathrm{Fe} / \mathrm{m}^{2}$ steel reacted to form the passive film.

- Addition of $\mathrm{H}_{2} \mathrm{~S}$ to $\sim 1$ atm equilibrium partial pressure in a related study $\left(\mathrm{CO}_{2}\right.$ with eventual $\mathrm{H}_{2} \mathrm{~S}$ addition) did not result in passivation of the steel specimens, and the $\mathrm{H}_{2} \mathrm{~S}$ destroyed the passive state of steel specimens previously passivated with $\mathrm{CO}_{2}$.

- Addition of $\mathrm{CO}_{2}$ to an equilibrium pressure of $\sim 0.5 \mathrm{~atm}$ to the test containers containing $\mathrm{H}_{2} \mathrm{~S}$-passivated steel specimens did not alter the specimens' passive state.

\subsection{Steel with $\mathrm{H}_{2}$ Overpressure}

- The corrosion rate of low-carbon steel immersed in Brine $\mathrm{A}$ at $30^{\circ} \mathrm{C}$ goes through a minimum at intermediate $\mathrm{H}_{2}$ pressures ( 36 to $70 \mathrm{~atm}$ ) and is at a maximum at low 
pressures ( $2 \mathrm{~atm})$ and high pressures $(127 \mathrm{~atm})$ in tests of 6-month duration. The overall effect of $\mathrm{H}_{2}$ pressure on corrosion of low-carbon steel is not believed to be significant at long times, even at $\mathrm{H}_{2}$ pressures equivalent to lithostatic pressure at the WIPP horizon.

\subsection{Alternative Packaging Materials}

- $\mathrm{Cu}$-base alternative packaging materials ( $\mathrm{Cu}$ and cupronickel 90-10) showed insignificant reaction when immersed in Brine $A$ at $30^{\circ} \mathrm{C}$ with overpressures of $\mathrm{N}_{2}$ or $\mathrm{CO}_{2}$ for time periods to 24 months. The Cu-base materials reacted rapidly with $\mathrm{H}_{2} \mathrm{~S}$, however, and produced $\mathrm{H}_{2}$ equivalent on a molar basis to the $\mathrm{H}_{2} \mathrm{~S}$ added. The reaction product was $\mathrm{Cu}_{2} \mathrm{~S}$, chalcocite. $\mathrm{Cu}$ based packaging materials could not be recommended for use in the WIPP if there were any possibility of $\mathrm{H}_{2} \mathrm{~S}$ being present in the repository environment.

- Ti-base alternative packaging materials (Ti Grade 2 and $\mathrm{Ti}$ Grade 12) showed insignificant reaction in all test environments, i.e., in $\mathrm{N}_{2}$ /immersed, $\mathrm{CO}_{2}$ /immersed, and $\mathrm{H}_{2} \mathrm{~S} /$ immersed environments, for test durations to 24 months. It appears at the present time that Ti-base packaging materials could be used in the WIPP site without concern for corrosion or gas generation.

\subsection{Al-Base Materials}

- Al-base materials (99.99\% $\mathrm{Al}$ and 6061 alloy) showed no reaction when exposed to the vapor phase of Brine $A$ with $\mathrm{N}_{2}, \mathrm{CO}_{2}$, or $\mathrm{H}_{2} \mathrm{~S}$ at $30^{\circ} \mathrm{C}$ for time periods to 24 months.

- Al-base materials exhibited significant corrosion and gas generation when immersed in Brine $\mathrm{A}$ at $30^{\circ} \mathrm{C}$. With an $\mathrm{N}_{2}$ overpressure the material-averaged, linearized 24-month gas generation rate was $0.097 \mathrm{~mol} \mathrm{H}_{2} / \mathrm{m}^{2}$ Al-base material-year, approximately equivalent to that of low-carbon steel under the same test conditions. The $99.99 \% \mathrm{Al}$ material corroded at about twice the rate of 6061 alloy in these tests. With a $\mathrm{CO}_{2}$ overpressure the material-averaged, linearized rate was $0.85 \mathrm{~mol} \mathrm{H}_{2} / \mathrm{m}^{2} \mathrm{Al}$-base material-yr. In these tests the $99.99 \% \mathrm{Al}$ and the 6061 alloy specimens appeared to corrode at approximately the same rate. With an $\mathrm{H}_{2} \mathrm{~S}$ overpressure the material-averaged, linearized rate was $1.3 \mathrm{~mol} \mathrm{H}_{2} / \mathrm{m}^{2}$ Al-base material-yr, with the $99.99 \%$ Al material corroding approximately four times as fast as the 6061 alloy.

- Al-base materials exhibited their highest corrosion rates when Fe, derived from steel coupons, was included in the environment as a brine contaminant. In all of these tests the $99.99 \% \mathrm{Al}$ material was responsible for $>90 \%$ of the corrosion taking place. Making the assumption that the rates were linear over the $24-$ month, $30^{\circ} \mathrm{C}$ tests, and assuming that all materials corroded at the same rate, the following $\mathrm{H}_{2}$ generation rates 
(given in mol $\mathrm{H}_{2} / \mathrm{m}^{2}$ Al-base material-yr) were found: with an $\mathrm{N}_{2}$ overpressure, 2.9; with a $\mathrm{CO}_{2}$ overpressure, 4.4; and with an $\mathrm{H}_{2} \mathrm{~S}$ overpressure, 2.4.

- The corrosion products from the brine/Al-base material tests were not easy to identify by $\mathrm{XRD}$, because of their complexity and/or their ill-defined crystallinity. In no case did a single, simple corrosion product [e.g., $\left.\mathrm{Al}_{2} \mathrm{O}_{3}, \mathrm{Al}(\mathrm{OH})_{3}\right]$ predominate.

- The greater corrosion attack of the Al-base materials in the $\mathrm{CO}_{2}$-overpressure tests containing $\mathrm{Fe}$ relative to the $\mathrm{H}_{2} \mathrm{~S}$ overpressure tests was ascribed to (a) a much greater corrosive attack of the steel specimens in the $\mathrm{CO}_{2}$-containing tests, and (b) a significantly greater solubility product of $\mathrm{FeCO}_{3}$ relative to $\mathrm{FeS}$. The corrosion observed in the Al-base material tests was, in general, highly nonuniform. The $99.99 \% \mathrm{Al}$ alloy specimens commonly exhibited irregular regions of varying degrees of specimen thinning, whereas the 6061 alloy exhibited some variable thinning but a great deal of pitting attack. Crevice corrosion was commonly observed in the metal-to-metal crevice regions; it was not, however, generally observed in the vicinity of the crevice formed by the insulating washer. 
This page intentionally left blank. 


\section{$=8.0$ REFERENCES}

American Colloid Company. 1995. "Technical Data Sheet, Volclay GPG 30." Arlington Heights, IL: American Colloid Company, Industrial Chemical Division. (Copy on file in the Sandia WIPP Central Files, Sandia National Laboratories, Albuquerque, NM as WPO\#39636.)

ASM (American Society for Metals). 1978. Metals Handbook. Volume 1 Properties and Selection: Irons and Steels. 9th ed. Metals Park, OH: American Society for Metals. 161.

ASM (American Society for Metals). 1987. Metals Handbook. Volume 13 Corrosion. 9th ed. Metals Park, OH: American Society for Metals. 598-607.

Bates, R.G. 1973. Determination of pH: Theory and Practice. New York, NY: John Wiley \& Sons. 31-39.

Blaedel, W.J., and V.W. Meloche. 1963. Elementary Quantitative Analysis: Theory and Practice. 2nd ed. New York, NY: Harper \& Row. Appendix V.

Brush, L.H. 1990. Test Plan for Laboratory and Modeling Studies of Repository and Radionuclide Chemistry for the Waste Isolation Pilot Plant. SAND90-0266. Albuquerque, NM: Sandia National Laboratories. (Available from the National Technical Information Service (NTIS), Springfield, VA as DE90013595/XAB.)

Brush, L.H., D. Grbic-Galic, D.T. Reed, X. Tong, R.H. Vreeland, and R.E. Westerman. 1991. "Preliminary Results of Laboratory Studies of Repository Chemistry for the Waste Isolation Pilot Plant," Scientific Basis for Nuclear Waste Management XIV, Materials Research Society Symposium Proceedings, Boston, MA, November 26-29, 1990. Eds. T.A. Abrajano, Jr. and L.H. Johnson. SAND90-1031C. Pittsburgh, PA: Materials Research Society. Vol. 212, 893-900. (SAND90-1031C is available from the National Technical Information Service (NTIS), Springfield, VA as DE90016219/XAB.)

Brush, L.H., M.A. Molecke, A.R. Lappin, R.E. Westerman, X. Tong, J.N.P. Black, D. GrbicGalic, R.H. Vreeland, and D.T. Reed. 1992. "Laboratory and Bin-Scale Tests of Gas Generation for the Waste Isolation Pilot Plant," Gas Generation and Release from Radioactive Waste Repositories, 3rd OECD/NEA Workshop: Near-Field Effects of Gas Release, Aix-en-Provence, France, September 23-26, 1991. SAND91-0675C. Paris, France: Organisation for Economic Co-Operation and Development. 142-154. (SAND910675C is available from the National Technical Information Service (NTIS), Springfield, $\mathrm{VA}$ as DE91019052/XAB.)

Butcher, B.M. 1990. Preliminary Evaluation of Potential Engineered Modifications for the Waste Isolation Pilot Plant (WIPP). SAND89-3095. Albuquerque, NM: Sandia National Laboratories. (Available from the National Technical Information Service (NTIS), Springfield, VA as DE90010165/XAB.) 
Cook, E.H., and F.L. McGeary. 1964. "Electrodeposition of Iron from Aqueous Solutions Onto an Aluminum Alloy," Corrosion. Vol. 20, no. 4, 111t-114t.

Crolet, J.L., and M.R. Bonis. 1984. "pH Measurements Under High Pressures of $\mathrm{CO}_{2}$ and $\mathrm{H}_{2} \mathrm{~S}$," Corrosion/84, International Corrosion Forum Devoted Exclusively to the Protection and Performance of Materials, New Orleans, LA, April 2-6, 1984. Paper No. 294. Houston, TX: National Association of Corrosion Engineers.

EATF (Engineered Alternatives Task Force). 1991. "Appendix H Report of the Waste Container Materials Panel," Evaluation of the Effectiveness and Feasibility of the Waste Isolation Pilot Plant Engineered Alternatives: Final Report of the Engineered Alternatives Task Force. DOE/WIPP-91-007. [Carlsbad, NM]: Waste Isolation Pilot Plant. Vol. 1.

Felmy, A.R. 1990. GMIN: A Computerized Chemical Equilibrium Model Using a Constrained Minimization of Gibbs Free Energy. PNL-7281. Richland, WA: Pacific Northwest Laboratory. (Available from the National Technical Information Service (NTIS), Springfield, VA as DE90010250/XAB.)

Garrels, R.M., and C.L. Christ. 1965. Solutions, Minerals, and Equilibria. San Francisco, CA: Freeman, Cooper, and Company. 403.

Guzowski, R.V. 1990. Preliminary Identification of Scenarios That May Affect the Escape and Transport of Radionuclides From the Waste Isolation Pilot Plant, Southeastern New Mexico. SAND89-7149. Albuquerque, NM: Sandia National Laboratories. (Available from the National Technical Information Service (NTIS), Springfield, VA as DE90011787/XAB.)

Hatch, J.E., ed. 1984. "Chapter 7 Corrosion Behavior," Aluminum: Properties and Physical Metallurgy. Metals Park, OH: American Society for Metals. 242-254.

Jackson, K.J. 1988. Verification and Validation Studies of the Addition of Pitzer $=s$ Equations to the EQ3/6 Brine Model. UCRL-53841. Livermore, CA: Lawrence Livermore National Laboratory. (Available from the National Technical Information Service (NTIS), Springfield, VA as DE89003708/XAB.)

JANAF. 1985. JANAF Thermochemical Tables. 3rd ed. Eds. M.W. Chase, Jr., C.A. Davies, J.R. Downey, Jr., D.J. Frurip, R.A. MacDonald, and A.N. Syverud. Journal of Physical and Chemical Reference Data Volume 14, Part 1. Washington, DC: American Chemical Society; New York, NY: American Institute of Physics. (Data for AlClO are found on page 79; data for $\mathrm{NaCl}$ are found on page 770.)

Knauss, K.G., T.J. Wolery, and K.J. Jackson. 1990. "A New Approach to Measuring pH in Brines and Other Concentrated Electrolytes," Geochimica et Cosmochimica Acta. Vol. 54, no. 5, 1519-1523. 
Lange's Handbook. 1985. Lange's Handbook of Chemistry. 13th ed. Ed. J.A. Dean. New York, NY: McGraw-Hill. 11-21.

Lappin, A.R., R.L. Hunter, D.P. Garber, and P.B. Davies, eds. 1989. Systems Analysis, Long-Term Radionuclide Transport, and Dose Assessments, Waste Isolation Pilot Plant (WIPP), Southeastern New Mexico; March 1989. SAND89-0462. Albuquerque, NM: Sandia National Laboratories. (Available from the National Technical Information Service (NTIS), Springfield, VA as DE89014586/XAB.)

Molecke, M.A. 1983. A Comparison of Brines Relevant to Nuclear Waste Experimentation. SAND830516. Albuquerque, NM: Sandia National Laboratories. (Available from the National Technical Information Service (NTIS), Springfield, VA as DE83012968/XAB.)

Pitzer, K.S. 1979. "Theory: Ion Interaction Approach," Activity Coefficients in Electrolyte Solutions. Ed. R.M. Pytkowicz. Boca Raton, FL: CRC Press, Inc. Vol. I, 157-208.

Pourbaix, M. 1974. Atlas of Electrochemical Equilibria in Aqueous Solutions. 2nd ed. Houston, TX: National Association of Corrosion Engineers. 307-321.

SAND92-7347. See Telander.and Westerman (1993).

Schweitzer, P.A. 1989. Corrosion and Corrosion Protection Handbook. 2nd ed. New York, NY: Marcel Dekker. 168.

Shreir, L.L., ed. 1963. Corrosion. Volume 1: Corrosion of Metals and Alloys. New York, NY: John Wiley \& Sons. 4.9-4.25.

Simpson, J.P., and R. Schenk. 1989. "Corrosion Induced Hydrogen Evolution on High Level Waste Overpack Materials in Synthetic Groundwaters and Chloride Solutions," Scientific Basis for Nuclear Waste Management XII, Materials Research Society Symposium Proceedings, Berlin, Germany, October 10-13, 1988. Eds. W. Lutze and R.C. Ewing. Pittsburgh, PA: Materials Research Society. Vol. 127, 389-396.

Telander, M.R., and R.E. Westerman. 1993. Hydrogen Generation by Metal Corrosion in Simulated Waste Isolation Pilot Plant Environments: Progress Report for the Period November 1989 Through December 1992. SAND92-7347. Albuquerque, NM: Sandia National Laboratories. (Available from the National Technical Information Service (NTIS), Springfield, VA as DE94001556/XAB.)

Westerman, R.E., J.H. Haberman, S.G. Pitman, K.H. Pool, K.C. Rhoads, and M.R. Telander. 1988. Corrosion Behavior of A216 Grade WCA Mild Steel and Ti Grade 12 Alloy in Hydrothermal Brines: Salt Repository Project. Annual Report FY 1986. PNL/SRP-6221. Richland, WA: Pacific Northwest Laboratory. (Available from the National Technical Information Service (NTIS), Springfield, VA as DE89000284/XAB.) 
This page intentionally left blank. 
APPENDIX A-1: PRESSURE HISTORIES, TESTS OF LOW-CARBON STEEL IN BRINE A WITH CONTROLLED $\mathrm{CO}_{2}$ (AND EVENTUAL $\mathrm{H}_{2} \mathrm{~S}$ ) ADDITIONS, SEAL-WELDED CONTAINER TEST METHOD 
APPENDIX A-1: PRESSURE HISTORIES, TESTS OF LOW-CARBON STEEL IN BRINE A WITH CONTROLLED $\mathrm{CO}_{2}$ (AND EVENTUAL $\mathrm{H}_{2} \mathrm{~S}$ ) ADDITIONS, SEAL-WELDED CONTAINER TEST METHOD

Summary of Initial Container Environments:

All specimens were completely immersed in Brine $A$ in each container (containers 33 through 38 )

Container 33: $0.32 \mathrm{~mol} \mathrm{CO} / \mathrm{m} 2$ steel

Container 34: $0.16 \mathrm{~mol} \mathrm{CO} 2 / \mathrm{m} 2$ steel

Container 35: $0.063 \mathrm{~mol} \mathrm{CO2} / \mathrm{m} 2$ steel

Container 36: $0.032 \mathrm{~mol} \mathrm{CO} / \mathrm{m} 2$ steel + N2

Container 37: $0.016 \mathrm{~mol} \mathrm{CO2} / \mathrm{m} 2$ steel + N2

Container 38: $0.00 \mathrm{~mol} \mathrm{CO} / \mathrm{m} 2$ Steel (N2 only)

Test Temperature: $30 \pm 5^{\circ} \mathrm{C}$

Pressure in Container, psig

\section{Time, days}

0

8

14

22

29

36

43

50

71

85

99

113

127

141

155

162

176

190

212

225
Cont. 33

\section{9}

69

73

77

80

82

84

85

88

89

90

92

93

94

94

94

94

94

95

95
Cont. 34

21

30

33

37

38

40

42

43

44

45

46

46

46

47

47

47

48

48

48

49
Cont. 35 -2 (est.)

0

4

6

8

10

10

10

12

13

14

15

17

19

21

22

24

26

30

32
Time, davs

0
6
12
20
27
34

41

48

69

83

97

111

125

139

153

160

174

188

210

223

Pressure in Container, psig

\section{Cont. 36}

22
25
27

27

28

30

31

31

32

34

34

36

38

41

44

46

48

51

53

57

60
Cont. 37

19

20

21

23

24

25

26

27

30

31

34

35

39

41

43

44

47

50

53

56
Cont. 38

31

34

34

35

36

37

38

39

42

44

46

49

52

56

58

60

63

65

70

72 
APPENDIX A-1 (CONT'D)

Pressure in Container, psig

Pressure in Container, psig

\begin{tabular}{|c|c|c|c|c|c|c|c|}
\hline $\begin{array}{c}\text { Time, davs } \\
239 \\
253 \\
267 \\
281\end{array}$ & $\begin{array}{r}\text { Cont. } 33 \\
95 \\
96 \\
95 \\
95\end{array}$ & $\begin{array}{r}\text { Cont. } 34 \\
49 \\
49 \\
50 \\
50\end{array}$ & $\begin{array}{r}\text { Cont. } 35 \\
34 \\
36 \\
38 \\
40\end{array}$ & $\begin{array}{c}\text { Time, davs } \\
237 \\
251 \\
265 \\
279\end{array}$ & $\begin{array}{r}\text { Cont. } 36 \\
62 \\
64 \\
67 \\
69\end{array}$ & $\begin{array}{r}\text { Cont. 37 } \\
58 \\
61 \\
63 \\
65\end{array}$ & $\begin{array}{r}\text { Cont. } 38 \\
75 \\
79 \\
81 \\
83\end{array}$ \\
\hline $\begin{array}{l}295 \\
350 \\
400 \\
450 \\
500 \\
570\end{array}$ & $\begin{array}{l}95 \\
95 \\
95 \\
95 \\
95 \\
95\end{array}$ & $\begin{array}{l}50 \\
51 \\
51 \\
52 \\
52 \\
53\end{array}$ & $\begin{array}{l}42 \\
48 \\
52 \\
60 \\
65 \\
69\end{array}$ & $\begin{array}{l}293 \\
350 \\
400 \\
450 \\
500 \\
570\end{array}$ & $\begin{array}{r}72 \\
79 \\
85 \\
92 \\
98 \\
105\end{array}$ & $\begin{array}{r}67 \\
76 \\
81 \\
87 \\
92 \\
100\end{array}$ & $\begin{array}{r}86 \\
95 \\
101 \\
109 \\
116 \\
125\end{array}$ \\
\hline $\begin{array}{c}575^{a} \\
578 \\
582 \\
589 \\
596 \\
600\end{array}$ & $\begin{array}{l}(11) \\
112 \\
129 \\
137 \\
140 \\
139\end{array}$ & $\begin{array}{r}(13) \\
75 \\
94 \\
102 \\
100 \\
101\end{array}$ & $\begin{array}{r}(18) \\
88 \\
81 \\
81 \\
81 \\
82\end{array}$ & $\begin{array}{c}575^{a} \\
578 \\
582 \\
589 \\
596 \\
600\end{array}$ & $\begin{array}{r}(0) \\
106 \\
106 \\
107 \\
107 \\
107\end{array}$ & $\begin{array}{l}(21) \\
113 \\
103 \\
103 \\
105 \\
104\end{array}$ & $\begin{array}{r}(17) \\
81 \\
80 \\
75 \\
75 \\
76\end{array}$ \\
\hline $\begin{array}{l}650 \\
700 \\
750 \\
800 \\
850 \\
900\end{array}$ & $\begin{array}{l}141 \\
149 \\
152 \\
155 \\
156 \\
157\end{array}$ & $\begin{array}{l}112 \\
115 \\
117 \\
120 \\
123 \\
127\end{array}$ & $\begin{array}{r}86 \\
91 \\
95 \\
99 \\
102 \\
105\end{array}$ & $\begin{array}{l}650 \\
700 \\
750 \\
800 \\
850 \\
900\end{array}$ & $\begin{array}{l}113 \\
118 \\
123 \\
128 \\
131 \\
133\end{array}$ & $\begin{array}{l}112 \\
117 \\
120 \\
124 \\
127 \\
132\end{array}$ & $\begin{array}{l}81 \\
84 \\
87 \\
91 \\
93\end{array}$ \\
\hline $\begin{array}{c}950 \\
1000 \\
1050 \\
1100 \\
1128\end{array}$ & $\begin{array}{l}158 \\
159 \\
161 \\
163 \\
164\end{array}$ & $\begin{array}{l}130 \\
133 \\
135 \\
138 \\
140\end{array}$ & $\begin{array}{l}107 \\
109 \\
113 \\
115 \\
117\end{array}$ & $\begin{array}{c}950 \\
1000 \\
1050 \\
1100 \\
1128\end{array}$ & $\begin{array}{l}138 \\
142 \\
145 \\
148 \\
150\end{array}$ & $\begin{array}{l}135 \\
138 \\
143 \\
147 \\
149\end{array}$ & $\begin{array}{l}101 \\
104 \\
107 \\
109 \\
111\end{array}$ \\
\hline
\end{tabular}

- Tests Completed -

\footnotetext{
- $\mathrm{H}_{2} \mathrm{~S}$ was added to all test containers except Container 36 at 575 days. Sufficient $\mathrm{H}_{2} \mathrm{~S}$ was added to each test container to result in an equilibrium pressure increase of $\sim 1 \mathrm{~atm}$. The number in parentheses on the 575-day line represents the approximate quasi-equilibrium pressure of $\mathrm{H}_{2} \mathrm{~S}$ added to each test container (in psi). Because of simultaneous reaction of $\mathrm{H}_{2} \mathrm{~S}$ with the specimens in the container and the dissolution of the $\mathrm{H}_{2} \mathrm{~S}$ in the brine over a finite period of time, the exact amount of $\mathrm{H}_{2} \mathrm{~S}$ added to each test container cannot be known with certainty. Container 38 was vented to 70 psig before the $\mathrm{H}_{2} \mathrm{~S}$ was added.
} 
APPENDIX A-2: . PRESSURE HISTORIES, TESTS OF LOW-CARBON STEEL IN BRINE A WITH $\mathrm{H}_{2} S$ (AND EVENTUAL $\mathrm{CO}_{2}$ ) ADDITIONS, SEAL-WELDED CONTAINER TEST METHOD 
Summary of Initial Container Environments:

Containers with specimens immersed in Brine A - containers 40 and 41

Containers with specimens suspended over Brine A - containers 42 and 43

All containers initially charged with $\sim 5 \mathrm{~atm} \mathrm{H}_{2} \mathrm{~S}$ (equilibrated)

Test Temperature: $30 \pm 5^{\circ} \mathrm{C}$

\section{Pressure in Container, psig}

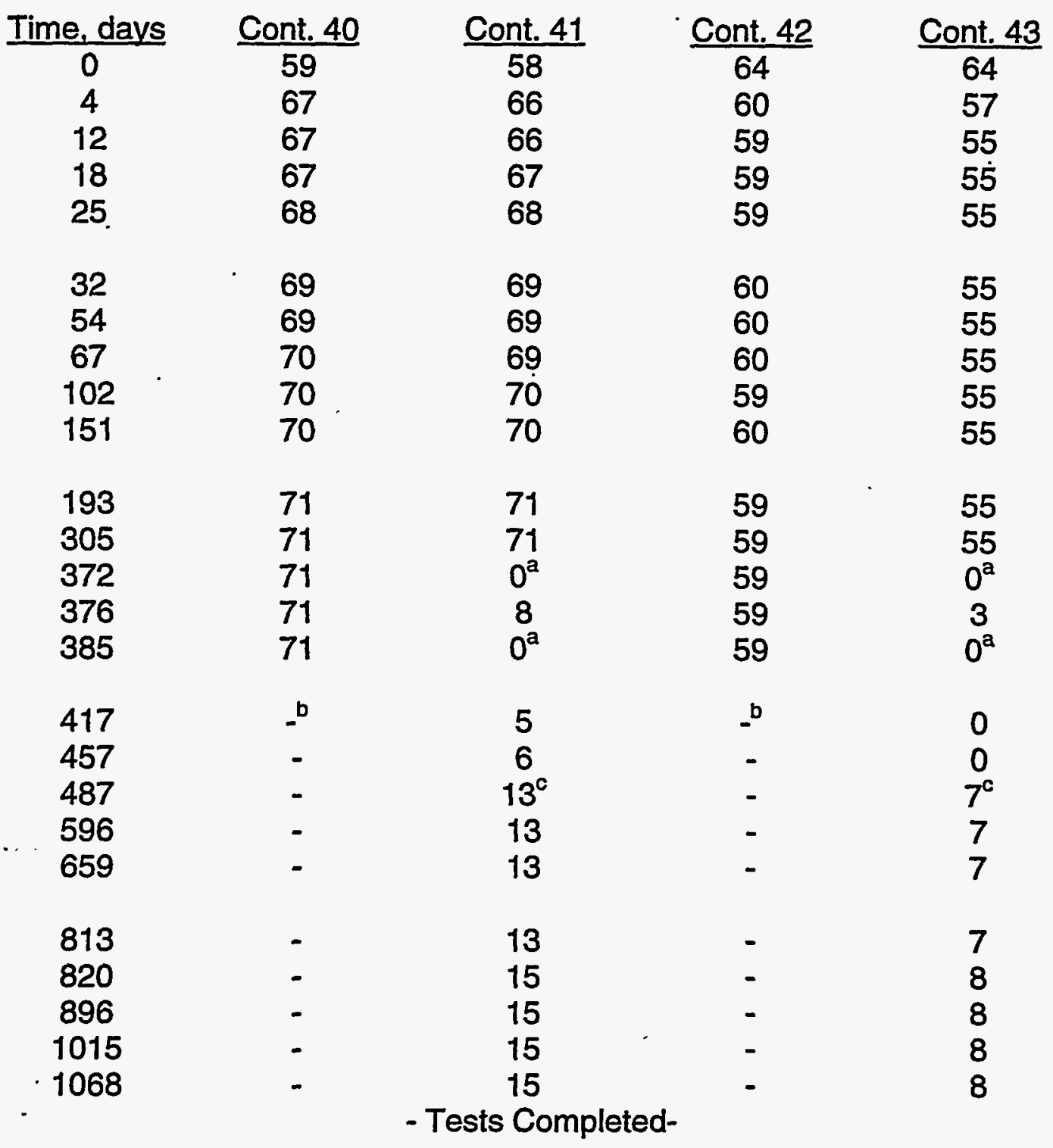

\footnotetext{
${ }^{a}$ Containers vented preparatory to $\mathrm{H}_{2} \mathrm{~S}$ charging

best completed, containers opened for specimen retrieval and analysis

${ }^{\circ} \mathrm{CO}_{2}$ added to containers, to produce pressure shown
} 
APPENDIX A-3: PRESSURE HISTORIES, TESTS OF LOW-CARBON

STEEL IN MODIFIED ERDA-6 BRINE WITH $\mathrm{N}_{2}$, SEALWELDED CONTAINER TEST METHOD 
APPENDIX A-3: PRESSURE HISTORIES, TESTS OF LOW-CARBON STEEL IN MODIFIED ERDA-6 BRINE WITH $\mathrm{N}_{2}$, SEALWELDED CONTAINER TEST METHOD

Summary of Test Parameters:

Specimens completely immersed in both tests (containers 44 and 45) Brine Environment: modified ERDA-6 brine

Overpressure Gas: $\mathrm{N}_{2}$ at $10 \mathrm{~atm}$

Test Temperature: $30 \pm 5^{\circ} \mathrm{C}$

Pressure in Container, psig

Time, days

0

7

14

28

49

Cont. 44

Cont. 45

135

129

134

136

135

136

135

138

136

70

140

139

98

119

145

142

148

152

140

157

145

148

168

160

152

196

164

156

224

168

159

252

171

173

161

165

302

- Tests Completed -

167 
APPENDIX A-4: PRESSURE HISTORIES, TESTS OF AI-BASE MATERIALS (99.99\% AI AND 6061 ALLOY) IMMERSED IN BRINE A AND IN VAPOR PHASE OF BRINE A, WITH $\mathrm{N}_{2}$, $\mathrm{CO}_{2}$, AND $\mathrm{H}_{2} \mathrm{~S}$, SEAL-WELDED CONTAINER TEST METHOD

Table A-4-1: Tests with $\mathrm{N}_{2}$

Table A-4-2: Tests with $\mathrm{CO}_{2}$

Table A-4-3: Tests with $\mathrm{H}_{2} \mathrm{~S}$ 
TABLE A-4-1

\section{Pressure Histories, Al-Base Materials \\ Seal-Welded Container Tests \\ Brine $A$ with $\mathrm{N}_{2}$ Overpressure}

Summary of Container Environments:

Container 1B: Immersed, 13-month exposure

Container 10B: Immersed, 24-month exposure

Container 4B: Immersed with steel specimens, 13-month exposure

Container 13B: Immersed with steel specimens, 24-month exposure

Container 7B: Vapor phase, 13-month exposure

Container 16B: Vapor phase, 24-month exposure

Test Temperature: $30 \pm 5^{\circ} \mathrm{C}$

\section{Pressure in Container, psig}

\begin{tabular}{|c|c|c|c|c|c|c|}
\hline Time, days & $1 \mathrm{~B}$ & $10 B$ & $4 B$ & $13 \mathrm{~B}$ & 7B & $16 \mathrm{~B}$ \\
\hline 0 & $\overline{133}$ & $\overline{129}$ & $\overline{131}$ & $\overline{131}$ & $\overline{134}$ & 133 \\
\hline 18 & 137 & 133 & 155 & 149 & 137 & 13 \\
\hline 47 & - & - & - & - & 136 & 13 \\
\hline 50 & 139 & 134 & 199 & 182 & - & \\
\hline 75 & 140 & 135 & $237 v^{a}$ & 211 & 137 & \\
\hline 106 & 143 & 136 & $283 v$ & 247 & 137 & \\
\hline 156 & 146 & 139 & $365 v$ & $312 v$ & 137 & \\
\hline 205 & 148 & 140 & $447 v$ & 383 & 137 & \\
\hline 240 & 151 & 142 & $513 v$ & 433 & 137 & \\
\hline 289 & 153 & 144 & $598 v$ & $501 v$ & 137 & \\
\hline 354 & 156 & 146 & $702 v$ & $589 v$ & 137 & \\
\hline 410 & 160 & 148 & $791 v$ & $671 v$ & 137 & \\
\hline & $T^{D}$ & - & $\mathrm{T}$ & - & $\mathrm{T}$ & \\
\hline 462 & - & 150 & - & $747 v$ & - & \\
\hline 565 & - & 154 & - & $907 v$ & - & \\
\hline 656 & - & 160 & - & $1057 v$ & - & \\
\hline 705 & - & 163 & - & $1144 v$ & - & \\
\hline 739 & - & - & - & - & - & \\
\hline 754 & - & 166 & - & 1232 & - & \\
\hline & - & $\mathrm{T}$ & - & $T$ & - & \\
\hline
\end{tabular}

\footnotetext{
${ }^{a}$ Gas was vented during time period, typically to a container pressure of $\sim 130$ psig. Frequency of venting depends on gas generation rate as well as maximum pressure rating of pressure gauge.

b Test terminated.
} 


\section{TABLE A-4-2}

\section{Pressure Histories, Al-Base Materials Seal-Welded Container Tests \\ Brine $\mathrm{A}$ with $\mathrm{CO}_{2}$ Overpressure}

Summary of Container Environments:

Container 2B: Immersed, 13-month exposure

Container 11B: Immersed, 24-month exposure

Container 5B: Immersed with steel specimens, 13-month exposure

Container 14B: Immersed with steel specimens, 24-month exposure

Container 8B: Vapor phase, 13-month exposure

Container 17B: Vapor phase, 24-month exposure

Test Temperature: $30 \pm 5^{\circ} \mathrm{C}$

Pressure in Container, psig

\begin{tabular}{ccccccc} 
Time, davs & $\cdot \frac{2 \mathrm{~B}}{131}$ & $\frac{11 \mathrm{~B}}{128}$ & $\frac{5 \mathrm{~B}}{130}$ & $\frac{14 \mathrm{~B}}{133}$ & $\frac{8 \mathrm{~B}}{131}$ & $\frac{17 \mathrm{~B}}{132}$ \\
\hline 0 & 138 & 139 & $197 \mathrm{v}^{\mathrm{a}}$ & 234 & 128 & 130 \\
18. & 138 & - & $-378 \mathrm{v}$ & 128 & 130 \\
47 & - & 146 & - & - & - & - \\
50 & 141 & - & $377 \mathrm{v}$ & - & - & 130 \\
75 & 144 & 153 & $461 \mathrm{v}$ & $476 \mathrm{v}$ & 128 & 130 \\
& & & & & & - \\
106 & 150 & - & $553 \mathrm{v}$ & - & - & - \\
110 & - & 164 & - & $569 \mathrm{v}$ & 129 & 131 \\
156 & 160 & - & $699 \mathrm{v}$ & - & - & - \\
159 & - & 180 & - & $696 \mathrm{v}$ & 128 & 131 \\
205 & 169 & - & $832 \mathrm{v}$ & - & - & - \\
& & & & & & \\
208 & - & 197 & - & $833 \mathrm{v}$ & 129 & 131 \\
254 & 186 & - & $972 \mathrm{v}$ & - & - & - \\
257 & - & 219 & - & $968 \mathrm{v}$ & 129 & 131 \\
354 & $234 \mathrm{v}$ & - & $1208 \mathrm{v}$ & - & - & - \\
355 & - & 259 & - & $1189 \mathrm{v}$ & 129 & 131 \\
& & - & & & & \\
401 & - & 283 & - & $1279 \mathrm{v}$ & 129 & 131 \\
410 & $256 \mathrm{v}$ & - & $1322 \mathrm{v}$ & - & - & - \\
467 & - & - & $\mathrm{T}$ & - & - & - \\
563 & - & $341 \mathrm{v}$ & - & $1421 \mathrm{v}$ & - & 132 \\
& - & 393 & - & $1587 \mathrm{v}$ & - & 131
\end{tabular}

${ }^{a}$ Gas was vented during time period, typically to a container pressure of $-130 \mathrm{psig}$. Frequency of venting depends on gas generation rate as well as maximum pressure rating of pressure gauge.

- Test terminated. 
TABLE A-4-2 (CONT'D)

\section{Pressure in Container, psig}

\begin{tabular}{|c|c|c|c|c|c|c|}
\hline Time, davs & $\underline{2 B}$ & $11 \mathrm{~B}$ & $\underline{5 \mathrm{~B}}$ & 14B & $\underline{8 B}$ & $17 \mathrm{~B}$ \\
\hline 661 & - & 450 & $=$ & $1752 v$ & - & 132 \\
\hline 710 & - & $487 v$ & - & $1834 v$ & - & 133 \\
\hline 738 & - & 501 & - & 1878 & - & - \\
\hline & - & $\mathrm{T}$ & - & $\mathrm{T}$ & - & - \\
\hline 139 & - & - & - & $=$ & - & $\begin{array}{c}133 \\
T\end{array}$ \\
\hline
\end{tabular}


TABLE A-4-3

\section{Pressure Histories, Al-Base Materials \\ Seal-Welded Container Tests \\ Brine A with $\mathrm{H}_{3} \mathrm{~S}$ Overpressure}

Summary of Container Environments:

Container 3B: Immersed, 13-month exposure

Container 12B: Immersed, 24-month exposure

Container 6B: Immersed with steel specimens, 13-month exposure

Container 15B: Immersed with steel specimens, 24-month exposure

Container 9B: Vapor phase, 13-month exposure

Container 18B: Vapor phase, 24-month exposure

Test Temperature: $30 \pm 5^{\circ} \mathrm{C}$

Pressure in Container, psig

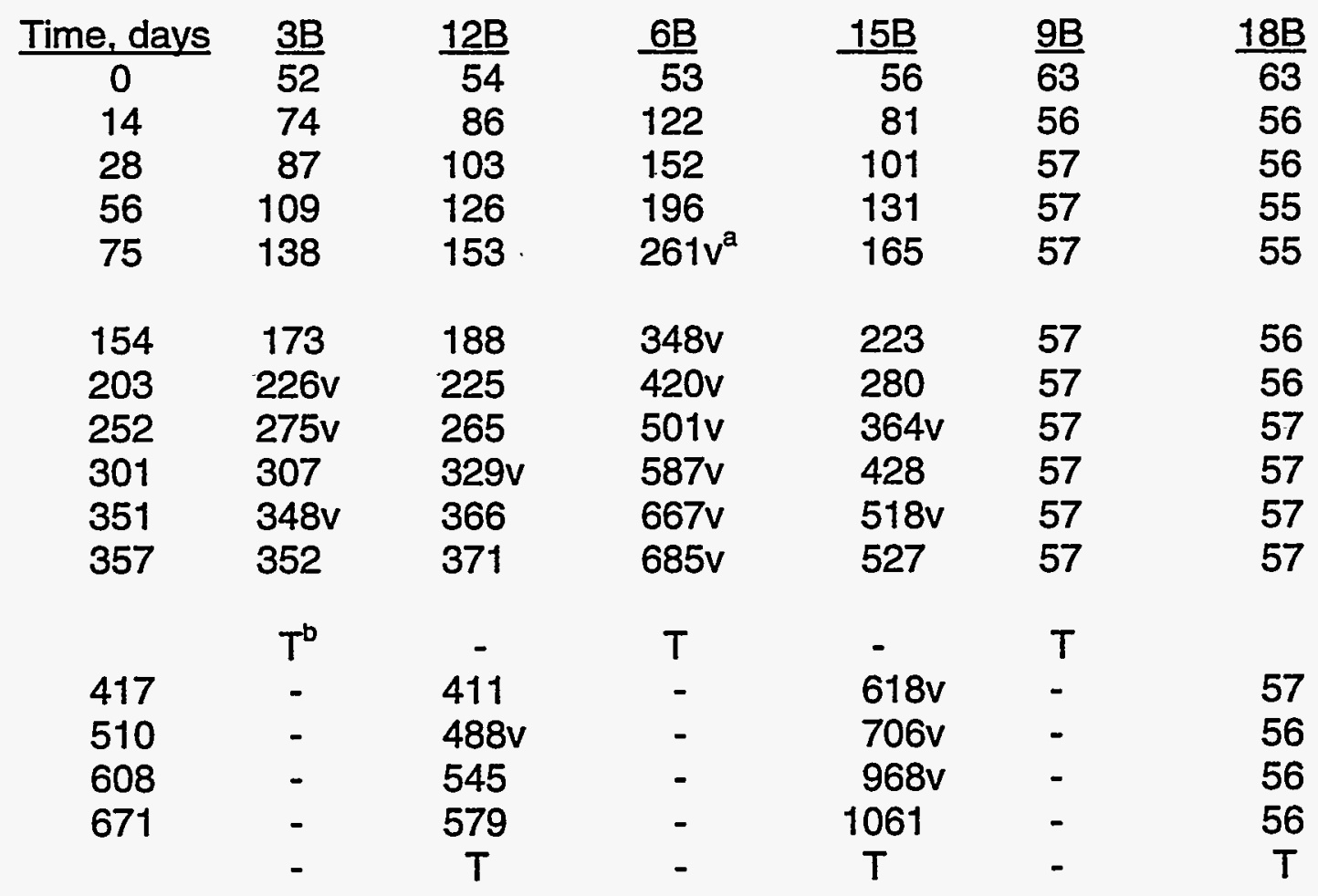

${ }^{a}$ Gas was vented during time period, typically to a container pressure of $\sim 130 \mathrm{psig}$. Frequency of venting depends on gas generation rate as well as maximum pressure rating of pressure gauge

b Test terminated. 


\section{APPENDIX B-1: INDIVIDUAL SPECIMEN DATA, TESTS OF LOW-CARBON}

STEEL IN BRINE A WITH CONTROLLED $\mathrm{CO}_{2}$ (AND EVENTUAL $\mathrm{H}_{2} \mathrm{~S}$ ) ADDITIONS, SEAL-WELDED CONTAINER . TEST METHOD

Table B-1-1: Test No. 33

Table B-1-2: Test No. 34

Table B-1-3: Test No. 35

Table B-1-4: Test No. 36

Table B-1-5: Test No. 37

Table B-1-6: Test No. 38 
TABLE B-1-1

Specimen Data. Test No. 33

Test Type: Immersion

Test Environment: Simulated WIPP Brine A, initial charge 111 psia CO2 overpressure.

Test Temperature: $30 \pm 5^{\circ} \mathrm{C}$

Addition of $1.2 \mathrm{~atm}$ of H2S was made after 19 months exposure.

Test Exposure: $38 \frac{1}{2}$ months

\begin{tabular}{|c|c|c|c|c|c|c|c|c|}
\hline Specimen & $\begin{array}{c}\text { Material } \\
\text { Type } \\
\end{array}$ & $\begin{array}{c}\text { Length, } \\
\mathrm{mm}\end{array}$ & $\begin{array}{c}\text { Width, } \\
\mathrm{mm}\end{array}$ & $\begin{array}{c}\text { Thickness, } \\
\mathrm{mm}\end{array}$ & $\begin{array}{c}\text { Top } \\
\text { Hole } \\
\text { ID, } \\
\mathrm{mm} \\
\end{array}$ & $\begin{array}{c}\text { Bottom } \\
\text { Hole } \\
\text { ID, } \\
\mathrm{mm} \\
\end{array}$ & $\begin{array}{l}\text { Area, } \\
\mathrm{dm} 2 \\
\end{array}$ & $\begin{array}{c}\text { Initial } \\
\text { Wt., } \\
\mathrm{g}\end{array}$ \\
\hline JW1 & Low-C Steel, Lot J & 190.33 & 85.74 & 0.720 & $\overline{8.15}$ & 8.17 & 3.286 & 88.1212 \\
\hline JW2 & Low-C Steel, Lot J & 190.59 & 85.42 & 0.697 & 8.15 & 8.32 & 3.277 & 86.3021 \\
\hline JW3 & Low-C Steel, Lot J & 190.75 & 85.40 & 0.696 & 8.19 & 8.41 & 3.278 & 85.8410 \\
\hline KW1 & Low-C Steel, Lot K & 189.91 & 84.93 & 0.868 & 7.97 & 8.01 & 3.258 & 107.2175 \\
\hline KW2 & Low-C Steel, Lot K & 189.97 & 85.28 & 0.854 & 7.98 & 8.00 & 3.271 & 104.9561 \\
\hline KW3 & Low-C Steel, Lot K & 189.86 & 84.90 & 0.828 & 7.96 & 7.99 & 3.253 & 103.4531 \\
\hline LW1 & Low-C Steel, Lot L & 190.40 & 85.09 & 1.516 & 7.93 & 7.94 & 3.312 & 190.3307 \\
\hline LW2 & Low-C Steel, Lot L & 190.30 & 84.99 & 1.538 & 7.95 & 7.94 & 3.307 & 190.9461 \\
\hline LW3 & Low-C Steel, Lot L & 189.99 & 85.04 & 1.507 & 7.93 & 7.94 & 3.302 & 186.9180 \\
\hline MW1 & Low-C Steel, Lot M & 190.54 & 84.81 & 1.602 & 7.96 & 7.95 & 3.308 & 197.7654 \\
\hline MW2 & Low-C Steel, Lot M & 190.34 & 85.01 & 1.590 & 7.94 & 7.97 & 3.312 & 198.1445 \\
\hline MW3 & Low-C Steel, Lot M & 190.24 & 85.06 & 1.590 & 7.97 & 7.94 & 3.312 & 194.4153 \\
\hline JN1 & Low-C Steel, Lot J & 190.62 & 50.57 & 0.693 & 7.96 & 7.92 & 1.945 & 51.0151 \\
\hline JN2 & Low-C Steel, Lot J & 190.57 & 50.47 & 0.700 & 8.14 & 8.12 & 1.940 & 50.6745 \\
\hline JN3 & Low-C Steel, Lot J & 190.47 & 50.52 & 0.687 & 7.98 & 8.12 & 1.941 & 49.8880 \\
\hline KN1 & Low-C Steel, Lot K & 190.24 & 50.08 & 0.857 & 7.97 & 7.97 & 1.931 & 62.7980 \\
\hline KN2 & Low-C Steel, Lot K & 190.02 & 50.07 & 0.863 & 7.98 & 7.98 & 1.929 & 62.8816 \\
\hline KN3 & Low-C Steel, Lot K & 189.94 & 50.11 & 0.870 & 7.99 & 8.00 & 1.930 & 63.9791 \\
\hline LN1 & Low-C Steel, Lot L & 190.30 & 50.19 & 1.551 & 7.93 & 7.93 & 1.973 & 111.6290 \\
\hline LN2 & Low-C Steel, Lot L & 190.18 & 50.31 & 1.522 & 7.92 & 7.92 & 1.975 & 111.1045 \\
\hline LN3 & Low-C Steel, Lot L & 190.12 & 51.03 & 1.519 & 7.95 & 7.91 & 2.001 & 112.8156 \\
\hline MN1 & Low-C Steel, Lot M & 190.64 & 50.15 & 1.573 & 7.88 & 7.92 & 1.976 & 116.3996 \\
\hline MN2 & Low-C Steel, Lot M & 190.72 & 50.10 & 1.594 & 7.92 & 7.92 & 1.976 & 116.7978 \\
\hline MN3 & Low-C Steel, Lot M & 190.52 & 50.26 & 1.587 & 7.93 & 7.91 & 1.980 & 116.2153 \\
\hline
\end{tabular}


TABLE B-1-2

Specimen Data. Test No. 34

Test Type: Immersion

Test Environment: Simulated WIPP Brine A, initial charge 56 psia $\mathrm{CO} 2$ overpressure.

Addition of $1.4 \mathrm{~atm}$ of $\mathrm{H} 2 \mathrm{~S}$ was made after 19 months exposure.

Test Temperature: $30 \pm 5^{\circ} \mathrm{C}$

Test Exposure: $381 / 2$ months

\begin{tabular}{|c|c|c|c|c|c|c|c|c|}
\hline Specimen & $\begin{array}{c}\text { Material } \\
\text { Type } \\
\end{array}$ & $\begin{array}{l}\text { Length, } \\
\mathrm{mm}\end{array}$ & $\begin{array}{l}\text { Width, } \\
\mathrm{mm}\end{array}$ & $\begin{array}{c}\text { Thickness, } \\
\mathrm{mm}\end{array}$ & $\begin{array}{c}\text { Top } \\
\text { Hole } \\
\text { ID, } \\
\mathrm{mm}\end{array}$ & $\begin{array}{c}\text { Bottom } \\
\text { Hole } \\
\text { ID, } \\
\mathrm{mm} \\
\end{array}$ & $\begin{array}{l}\text { Area, } \\
\text { dm2 }\end{array}$ & $\begin{array}{c}\text { Initial } \\
\text { Wt., } \\
\text { g }\end{array}$ \\
\hline JW4 & Low-C Steel, Lot J & 190.49 & 85.36 & 0.703 & 8.18 & 8.14 & 3.274 & 84.9027 \\
\hline JW5 & Low-C Steel, Lot J & 190.88 & 85.35 & 0.720 & 8.23 & 8.20 & 3.281 & 87.3236 \\
\hline JW6 & Low-C Steel, Lot J & 190.24 & 85.97 & 0.703 & 8.37 & 8.28 & 3.292 & 88.0031 \\
\hline $\mathrm{KW} 4$ & Low-C Steel, Lot K & 189.91 & 85.08 & 0.848 & 7.99 & 8.00 & 3.262 & 106.7222 \\
\hline KW5 & Low-C Steel, Lot K & 189.87 & 84.92 & 0.837 & 7.98 & 7.99 & 3.255 & 103.9743 \\
\hline KW6 & Low-C Steel, Lot K & 190.04 & 84.81 & 0.833 & 7.97 & 8.02 & 3.253 & 103.7588 \\
\hline LW4 & Low-C Steel, Lot L & 190.09 & 85.23 & 1.524 & 7.95 & 7.94 & 3.312 & 191.1092 \\
\hline LW5 & Low-C Steel, Lot L & 190.22 & 85.03 & 1.541 & 7.95 & 7.93 & 3.308 & 190.7076 \\
\hline LW6 & Low-C Steel, Lot L & 190.38 & 85.34 & 1.528 & 7.95 & 7.95 & 3.321 & 190.4544 \\
\hline MW4 & Low-C Steel, Lot M & 190.38 & 84.96 & 1.581 & 7.92 & 7.94 & 3.310 & 196.3483 \\
\hline MW5 & Low-C Steel, Lot M & 190.52 & 84.89 & 1.577 & 7.96 & 7.96 & 3.310 & 194.7741 \\
\hline MW6 & Low-C Steel, Lot M & 190.52 & 85.00 & 1.586 & 7.96 & 7.94 & 3.314 & 194.8852 \\
\hline $\mathrm{JN} 4$ & Low-C Steel, Lot J & 190.60 & 50.56 & 0.677 & 8.06 & 8.02 & 1.943 & 49.7823 \\
\hline JN5 & Low-C Steel, Lot J & 191.20 & 50.37 & 0.659 & 8.02 & 8.02 & 1.941 & 49.0095 \\
\hline JN6 & Low-C Steel, Lot J & 190.60 & 50.46 & 0.678 & 8.05 & 8.09 & 1.939 & 49.8886 \\
\hline KN4 & Low-C Steel, Lot K & 189.92 & 49.99 & 0.871 & 7.93 & 7.97 & 1.925 & 63.5955 \\
\hline KN5 & Low-C Steel, Lot K & 189.95 & 50.28 & 0.862 & 8.00 & 7.98 & 1.936 & 63.1999 \\
\hline KN6 & Low-C Steel, Lot K & 190.09 & 50.01 & 0.859 & 7.99 & 8.00 & 1.927 & 62.3230 \\
\hline LN4 & Low-C Steel, Lot L & 189.96 & 49.95 & 1.515 & 7.93 & 7.93 & 1.958 & 110.0661 \\
\hline LN5 & Low-C Steel, Lot L & 190.26 & 50.26 & 1.526 & 7.93 & 7.94 & 1.974 & 111.6656 \\
\hline LN6 & Low-C Steel, Lot L & 189.55 & 50.07 & 1.536 & 7.94 & 7.93 & 1.960 & 110.9448 \\
\hline MN4 & Low-C Steel, Lot M & 190.59 & 50.07 & 1.588 & 7.91 & 7.87 & 1.973 & 115.8499 \\
\hline MN5 & Low-C Steel, Lot M & 190.70 & 50.19 & 1.592 & 7.92 & 7.91 & 1.979 & 116.2775 \\
\hline MN6 & Low-C Steel, Lot M & 190.68 & 50.12 & 1.568 & 7.92 & 7.90 & 1.975 & 114.8387 \\
\hline
\end{tabular}


TABLE B-1-3

\section{Specimen Data, Test No, 35}

Test Type: Immersion

Test Environment: Simulated WIPP Brine A, initial charge 22 psia CO2 overpressure.

Addition of $1.2 \mathrm{~atm}$ of $\mathrm{H} 2 \mathrm{~S}$ was made after 19 months exposure.

Test Temperature: $30 \pm 5^{\circ} \mathrm{C}$

Test Exposure: $38 \frac{1}{2}$ months

\begin{tabular}{|c|c|c|c|c|c|c|c|c|}
\hline Specimen & $\begin{array}{c}\text { Material } \\
\text { Type } \\
\end{array}$ & $\begin{array}{l}\text { Length, } \\
\mathrm{mm}\end{array}$ & $\begin{array}{c}\text { Width, } \\
\text { mm }\end{array}$ & $\begin{array}{c}\text { Thickness, } \\
\mathrm{mm}\end{array}$ & $\begin{array}{c}\text {. Top } \\
\text { Hole ID, } \\
\text { mm } \\
\end{array}$ & $\begin{array}{c}\text { Bottom } \\
\text { Hole } \\
\text { ID, } \\
\text { mm }\end{array}$ & $\begin{array}{l}\text { Area, } \\
\mathrm{dm2}\end{array}$ & $\begin{array}{c}\text { Initial } \\
\text { Wt., } \\
\text { g }\end{array}$ \\
\hline JW7 & Low-C Steel, Lot J & 190.25 & 85.34 & 0.715 & 8.27 & 8.26 & 3.269 & 87.0807 \\
\hline JW8 & Low-C Steel, Lot J & 190.00 & 85.17 & 0.695 & 8.08 & 8.16 & 3.258 & 85.3121 \\
\hline JW9 & Low-C Steel, Lot J & 190.37 & 85.07 & 0.704 & 8.10 & 8.43 & 3.260 & 85.3889 \\
\hline KW7 & Low-C Steel, Lot K & 189.90 & 84.87 & 0.836 & 7.97 & 7.98 & 3.254 & 104.0760 \\
\hline KW8 & Low-C Steel, Lot K & 189.56 & 84.59 & 0.821 & 7.96 & 8.05 & 3.236 & 103.6197 \\
\hline KW9 & Low-C Steel, Lot K & 189.92 & 84.92 & 0.835 & 8.05 & 7.99 & 3.256 & 103.5790 \\
\hline LW7 & Low-C Steel, Lot L & 190.33 & 85.11 & 1.511 & 7.95 & 7.94 & 3.311 & 187.1416 \\
\hline LW8 & Low-C Steel, Lot L & 190.35 & 85.18 & 1.521 & 7.95 & 7.95 & 3.314 & 188.6702 \\
\hline LW9 & Low-C Steel, Lot L & 190.34 & 85.16 & 1.502 & 7.95 & 7.94 & 3.312 & 186.2714 \\
\hline MW7 & Low-C Steel, Lot M & 190.97 & 85.09 & 1.607 & 7.97 & 7.96 & 3.327 & 196.8036 \\
\hline MW8 & Low-C Steel, Lot M & 190.40 & 85.05 & 1.599 & 7.96 & 7.98 & 3.315 & 199.0834 \\
\hline MW9 & Low-C Steel, Lot M & 190.29 & 85.24 & 1.585 & 7.96 & 7.95 & 3.319 & 199.1392 \\
\hline JN7 & Low-C Steel, Lot J & 190.51 & 50.21 & 0.699 & 8.11 & 8.06 & 1.930 & 49.6171 \\
\hline JN8 & Low-C Steel, Lot J & 190.52 & 50.51 & 0.684 & 8.05 & 8.13 & 1.941 & 49.9949 \\
\hline JN9 & Low-C Steel, Lot J & 191.36 & 50.42 & 0.653 & 8.25 & 8.07 & 1.944 & 48.4476 \\
\hline KN7 & Low-C Steel, Lot K & 190.10 & 50.00 & 0.862 & 7.94 & 7.94 & 1.927 & 62.7686 \\
\hline KN8 & Low-C Steel, Lot K & 190.17 & 50.10 & 0.862 & 7.92 & 8.00 & 1.931 & 62.5218 \\
\hline KN9 & Low-C Steel, Lot K & 190.18 & 50.15 & 0.872 & 7.97 & 7.95 & 1.934 & 63.2507 \\
\hline LN7 & Low-C Steel, Lot L & 190.19 & 50.27 & 1.551 & 7.94 & 7.95 & 1.975 & 112.5286 \\
\hline LN8 & Low-C Steel, Lot L & 190.01 & 50.30 & 1.541 & 7.93 & 7.95 & 1.973 & 112.0774 \\
\hline LN9 & Low-C Steel, Lot L & 190.08 & 50.26 & 1.548 & 7.95 & 7.93 & 1.973 & 111.9558 \\
\hline MN7 & Low-C Steel, Lot M & 190.86 & 50.13 & 1.570 & 7.92 & 7.93 & 1.977 & 114.8986 \\
\hline MN8 & Low-C Steel, Lot M & 190.57 & 50.42 & 1.563 & 7.94 & 7.92 & 1.985 & 115.0848 \\
\hline MN9 & Low-C Steel, Lot M & 190.48 & 50.66 & 1.524 & 7.92 & 7.91 & 1.991 & 113.7382 \\
\hline
\end{tabular}


TABLE B-1-4

Specimen Data, Test No. 36

Test Type: Immersion

Test Environment: Simulated WIPP Brine A, initial charge 11psia of $\mathrm{CO} 2+30$ psia of N2. $\mathrm{No}_{2} \mathrm{~S}$ addition made.

Test Temperature: $30 \pm 5^{\circ} \mathrm{C}$

Test Exposure: $381 \frac{1}{2}$ months

\begin{tabular}{|c|c|c|c|c|c|c|c|c|}
\hline Specimen & $\begin{array}{c}\text { Material } \\
\text { Type }\end{array}$ & $\begin{array}{l}\text { Length, } \\
\mathrm{mm}\end{array}$ & $\begin{array}{l}\text { Width, } \\
\text { mm }\end{array}$ & $\begin{array}{c}\text { Thickness, } \\
\mathrm{mm}\end{array}$ & $\begin{array}{c}\text { Top } \\
\text { Hole } \\
\text { ID, } \\
\mathrm{mm}\end{array}$ & $\begin{array}{c}\text { Bottom } \\
\text { Hole } \\
\text { ID, } \\
\mathrm{mm}\end{array}$ & $\begin{array}{l}\text { Area, } \\
\text { dm2 }\end{array}$ & $\begin{array}{c}\text { Initial } \\
\text { Wt., } \\
\text { g }\end{array}$ \\
\hline JW10 & Low-C Steel, Lot J & 190.01 & 85.22 & 0.718 & 8.26 & 8.15 & 3.261 & 86.2623 \\
\hline JW11 & Low-C Steel, Lot J & 190.80 & 86.10 & 0.692 & 8.09 & 8.39 & 3.306 & 86.4216 \\
\hline $\mathrm{JW} 12$ & Low-C Steel, Lot J & 190.51 & 85.49 & 0.701 & 8.11 & 8.18 & 3.279 & 85.2159 \\
\hline KW10 & Low-C Steel, Lot K & 189.73 & 84.95 & 0.827 & 7.96 & 7.99 & 3.253 & 104.9050 \\
\hline KW11 & Low-C Steel, Lot K & 189.71 & 84.77 & 0.862 & 7.99 & 7.98 & 3.248 & 107.4346 \\
\hline KW12 & Low-C Steel, Lot K & 189.72 & 84.78 & 0.845 & 7.99 & 7.98 & 3.247 & 105.3387 \\
\hline LW10 & Low-C Steel, Lot L & 190.33 & 84.95 & 1.512 & 7.95 & 7.95 & 3.305 & 187.2511 \\
\hline LW11 & Low-C Steel, Lot L & 190.25 & 84.99 & 1.494 & 7.95 & 7.94 & 3.304 & 187.0021 \\
\hline $\mathrm{LW} 12$ & Low-C Steel, Lot L & 190.64 & 85.56 & 1.465 & 7.95 & 7.94 & 3.331 & 183.3987 \\
\hline MW10 & Low-C Steel, Lot M & 190.30 & 84.69 & 1.580 & 7.96 & 7.95 & 3.298 & 196.2899 \\
\hline MW11 & Low-C Steel, Lot M & 190.38 & 85.08 & 1.576 & 7.96 & 7.95 & 3.314 & 196.7680 \\
\hline MW12 & Low-C Steel, Lot M & 190.74 & 84.94 & 1.584 & 7.95 & 7.95 & 3.316 & 196.9510 \\
\hline JN10 & Low-C Steel, Lot J & 191.16 & 50.42 & 0.654 & 8.08 & 8.05 & 1.942 & 48.0890 \\
\hline JN11 & Low-C Steel, Lot J & 191.13 & 50.48 & 0.652 & 8.18 & 8.14 & 1.944 & 48.8352 \\
\hline $\mathrm{JN} 12$ & Low-C Steel, Lot J & 190.57 & 49.35 & 0.666 & 8.11 & 8.15 & 1.896 & 47.9686 \\
\hline KN10 & Low-C Steel, Lot K & 189.98 & 50.00 & 0.866 & 7.94 & 7.98 & 1.926 & 63.0152 \\
\hline KN11 & Low-C Steel, Lot K & 190.18 & 50.12 & 0.866 & 7.96 & 7.99 & 1.932 & 63.7764 \\
\hline $\mathrm{KN} 12$ & Low-C Steel, Lot K & 189.93 & 50.04 & 0.858 & 8.00 & 7.96 & 1.926 & 63.0786 \\
\hline LN10 & Low-C Steel, Lot L & 190.16 & 50.24 & 1.541 & 7.92 & 7.91 & 1.973 & 111.4649 \\
\hline LN11 & Low-C Steel, Lot L & 190.44 & 50.24 & 1.537 & 7.94 & 7.94 & 1.975 & 111.7071 \\
\hline LN12 & Low-C Steel, Lot L & 189.89 & 50.16 & 1.538 & 7.88 & 7.89 & 1.967 & 111.4004 \\
\hline MN10 & Low-C Steel, Lot M & 190.47 & 50.26 & 1.533 & 7.93 & 7.94 & 1.976 & 113.4046 \\
\hline MN11 & Low-C Steel, Lot M & 190.46 & 50.17 & 1.549 & 7.92 & 7.94 & 1.974 & 112.1868 \\
\hline MN12 & Low-C Steel, Lot M & 190.35 & 50.14 & 1.576 & 7.90 & 7.94 & 1.973 & 113.9416 \\
\hline
\end{tabular}




\section{TABLE B-1-5}

\section{Specimen Data. Test No. 37}

Test Type: Immersion

Test Environment: Simulated WIPP Brine A, initial charge 5.7 psia of $\mathrm{CO}+30$ psia of N2 overpressure.

Test Temperature: $30 \pm 5^{\circ} \mathrm{C}$ Addition of 0.9 atm of $\mathrm{H} 2 \mathrm{~S}$ was made after 19 months exposure.

Test Exposure: $38 \frac{1}{2}$ months

\begin{tabular}{|c|c|c|c|c|c|c|c|c|}
\hline Specimen & $\begin{array}{c}\text { Material } \\
\text { Type } \\
\end{array}$ & $\begin{array}{l}\text { Length, } \\
\mathrm{mm}\end{array}$ & $\begin{array}{l}\text { Width, } \\
\mathrm{mm}\end{array}$ & $\begin{array}{c}\text { Thickness, } \\
\mathrm{mm}\end{array}$ & $\begin{array}{l}\text { Top } \\
\text { Hole } \\
\text { ID, } \\
\text { mm } \\
\end{array}$ & $\begin{array}{c}\text { Bottom } \\
\text { Hole } \\
\text { ID, } \\
\mathrm{mm} \\
\end{array}$ & $\begin{array}{l}\text { Area, } \\
\text { dm2 }\end{array}$ & $\begin{array}{c}\text { Initial } \\
\text { Wt., } \\
\mathbf{g}\end{array}$ \\
\hline $\mathrm{JW} 13$ & Low-C Steel, Lot J & 190.30 & 85.24 & 0.701 & 8.37 & 8.26 & 3.265 & 84.9404 \\
\hline JW14 & Low-C Steel, Lot J & 190.08 & 85.41 & 0.695 & 8.16 & 8.14 & 3.268 & 84.4024 \\
\hline JW15 & Low-C Steel, Lot J & 190.53 & 85.31 & 0.697 & 8.20 & 8.20 & 3.272 & 85.8943 \\
\hline KW13 & Low-C Steel, Lot K & 189.64 & 84.81 & 0.841 & 7.97 & 8.03 & 3.247 & 106.3402 \\
\hline KW14 & Low-C Steel, Lot K & 189.64 & 84.68 & 0.866 & 8.05 & 7.98 & 3.243 & 106.3181 \\
\hline KW15 & Low-C Steel, Lot K & 189.84 & 84.82 & 0.832 & 8.00 & 8.06 & 3.250 & 104.6479 \\
\hline LW13 & Low-C Steel, Lot L & 190.72 & 85.71 & 1.493 & 7.94 & 7.95 & 3.339 & 185.2357 \\
\hline LW14 & Low-C Steel, Lot L & 190.66 & 85.73 & 1.465 & 7.96 & 7.96 & 3.337 & 184.9999 \\
\hline LW15 & Low-C Steel, Lot L & 190.77 & 85.63 & 1.500 & 7.96 & 7.94 & 3.338 & 186.7577 \\
\hline MW13 & Low-C Steel, Lot M & 190.48 & 84.93 & 1.554 & 7.92 & 7.96 & 3.309 & 194.2971 \\
\hline MW14 & Low-C Steel, Lot M & 190.85 & 84.90 & 1.590 & 7.94 & 7.95 & 3.316 & 196.8647 \\
\hline MW15 & Low-C Steel, Lot M & 190.81 & 84.95 & 1.590 & 7.95 & 7.94 & 3.318 & 197.5009 \\
\hline JN13 & Low-C Steel, Lot J & 190.91 & 50.67 & 0.663 & 7.96 & 7.89 & 1.950 & 48.1501 \\
\hline JN14 & Low-C Steel, Lot J & 191.09 & 50.69 & 0.641 & 8.12 & 8.06 & 1.951 & 48.8142 \\
\hline JN15 & Low-C Steel, Lot J & 191.23 & 50.78 & 0.658 & 8.04 & 8.17 & 1.957 & 48.4822 \\
\hline $\mathrm{KN} 13$ & Low-C Steel, Lot K & 190.00 & 50.00 & 0.876 & 7.96 & 7.97 & 1.927 & 63.5386 \\
\hline $\mathrm{KN} 14$ & Low-C Steel, Lot K & 189.98 & 50.17 & 0.868 & 7.99 & 7.97 & 1.932 & 63.5974 \\
\hline KN15 & Low-C Steel, Lot K & 190.02 & 50.11 & 0.867 & 7.94 & 8.00 & 1.930 & 63.6225 \\
\hline LN13 & Low-C Steel, Lot L & 190.37 & 50.11 & 1.531 & 7.95 & 7.93 & 1.969 & 110.6430 \\
\hline LN14 & Low-C Steel, Lot L & 190.44 & 50.05 & 1.517 & 7.93 & 7.93 & 1.967 & 110.6268 \\
\hline LN15 & Low-C Steel, Lot L & 190.62 & 50.09 & 1.542 & 7.93 & 7.92 & 1.972 & 110.7552 \\
\hline MN13 & Low-C Steel, Lot M & 190.43 & 49.95 & 1.553 & 7.94 & 7.92 & 1.965 & 111.5338 \\
\hline$\dot{\mathrm{MN}} 14$ & Low-C Steel, Lot M & 190.52 & 50.35 & 1.548 & 7.95 & 7.95 & 1.981 & 112.6598 \\
\hline MN15 & Low-C Steel, Lot M & 189.81 & 50.07 & 1.523 & 7.94 & 7.90 & 1.962 & 110.7545 \\
\hline
\end{tabular}


TABLE B-1-6

Specimen Data. Test No. 38

Test Type: Immersion

Test Environment: Simulated WIPP Brine A, initial charge 45 psia $\mathrm{N}_{2}$ overpressure. Addition of $0.8 \mathrm{~atm}$ of $\mathrm{H} 2 \mathrm{~S}$ was made after 19 months exposure.

Test Temperature: $30 \pm 5^{\circ} \mathrm{C}$

Test Exposure: $381 \frac{1}{2}$ months

\begin{tabular}{|c|c|c|c|c|c|c|c|c|}
\hline Specimen & $\begin{array}{c}\text { Material } \\
\text { Type } \\
\end{array}$ & $\begin{array}{l}\text { Length, } \\
\mathrm{mm}\end{array}$ & $\begin{array}{l}\text { Width, } \\
\mathrm{mm}\end{array}$ & $\begin{array}{c}\text { Thickness, } \\
\text { mm }\end{array}$ & $\begin{array}{l}\text { Top } \\
\text { Hole } \\
\text { ID, } \\
\text { mm } \\
\end{array}$ & $\begin{array}{c}\text { Bottom } \\
\text { Hole } \\
\text { ID, } \\
\text { mm } \\
\end{array}$ & $\begin{array}{l}\text { Area, } \\
\text { dm2 }\end{array}$ & $\begin{array}{c}\text { Initial } \\
\text { Wt., } \\
\mathrm{g} \\
\end{array}$ \\
\hline JW16 & Low-C Steel, Lot J & 190.27 & 85.96 & 0.668 & 8.08 & 8.10 & 3.291 & 84.2522 \\
\hline JW17 & Low-C Steel, Lot J & 190.22 & 85.14 & 0.684 & 8.22 & 8.33 & 3.259 & 82.7062 \\
\hline JW18 & Low-C Steel, Lot J & 190.42 & 85.39 & 0.690 & 8.16 & 8.28 & 3.272 & 83.8789 \\
\hline $\mathrm{KW} 16$ & Low-C Steel, Lot K & 189.60 & 85.07 & 0.838 & 7.96 & 7.98 & 3.256 & 104.7348 \\
\hline KW17 & Low-C Steel, Lot K & 189.44 & 84.81 & 0.842 & 7.99 & 7.99 & 3.244 & $104.54 \dot{9} 3$ \\
\hline$K W 18$ & Low-C Steel, Lot K & 189.60 & 84.83 & 0.839 & 7.99 & 8.01 & 3.247 & 103.9338 \\
\hline LW16 & Low-C Steel, Lot L & 190.74 & 85.00 & 1.476 & 7.96 & 7.94 & 3.312 & 183.8760 \\
\hline LW17 & Low-C Steel, Lot L & 190.34 & 84.52 & 1.533 & 7.94 & 7.94 & 3.290 & 189.6979 \\
\hline LW18 & Low-C Steel, Lot L & 190.27 & 84.36 & 1.547 & 7.95 & 7.94 & 3.283 & 190.9421 \\
\hline MW16 & Low-C Steel, Lot M & 191.08 & 85.00 & 1.573 & 7.93 & 7.95 & 3.323 & 196.5668 \\
\hline MW17 & Low-C Steel, Lot M & 190.86 & 85.06 & 1.569 & 7.98 & 7.94 & 3.321 & 196.3437 \\
\hline MW18 & Low-C Steel, Lot M & 190.78 & 85.01 & 1.608 & 7.93 & 7.98 & 3.320 & 199.7132 \\
\hline JN16 & Low-C Steel, Lot J & 190.34 & 50.65 & 0.680 & 8.05 & 8.03 & 1.944 & 49.9990 \\
\hline JN17 & Low-C Steel, Lot J & 190.75 & 50.63 & 0.665 & 8.15 & 8.08 & 1.946 & 50.3541 \\
\hline JN18 & Low-C Steel, Lot J & 190.58 & 50.61 & 0.676 & 8.18 & 8.12 & 1.944 & 50.9490 \\
\hline KN16 & Low-C Steel, Lot K & 190.00 & 50.10 & 0.865 & 8.00 & 7.94 & 1.930 & 63.2493 \\
\hline KN17 & Low-C Steel, Lot K & 190.01 & 50.09 & 0.858 & 8.01 & 8.00 & 1.929 & 62.6792 \\
\hline KN18 & Low-C Steel, Lot K & 189.70 & 49.98 & 0.864 & 7.98 & 7.95 & 1.922 & 62.6678 \\
\hline LN16 & Low-C Steel, Lot L & 190.10 & 50.98 & 1.541 & 7.90 & 7.94 & 2.001 & 113.7395 \\
\hline LN17 & Low-C Steel, Lot L & 190.21 & 49.14 & 1.538 & 7.95 & 7.92 & 1.931 & 110.5290 \\
\hline LN18 & Low-C Steel, Lot L & 190.33 & 50.75 & 1.538 & 7.97 & 8.49 & 1.993 & 113.7133 \\
\hline MN16 & Low-C Steel, Lot M & 190.63 & 50.08 & 1.561 & 7.95 & 7.88 & 1.973 & 113.9053 \\
\hline MN17. & Low-C Steel, Lot M & 189.90 & 50.14 & 1.538 & 7.94 & 7.94 & 1.966 & 111.2087 \\
\hline MN18 & Low-C Steel, Lot M & 190.62 & 50.11 & 1.564 & 7.94 & 7.94 & 1.974 & 113.6006 \\
\hline
\end{tabular}


APPENDIX B-2: INDIVIDUAL SPECIMEN CORROSION-RATE DATA, TESTS OF LOW-CARBON STEEL IN BRINE A WITH $\mathrm{H}_{2} S$ (AND EVENTUAL $\mathrm{CO}_{2}$ ) ADDITIONS, SEAL-WELDED CONTAINER TEST METHOD

Table B-2-1: Test No. 40 Table B-2-2: Test No. 41 Table B-2-3: Test No. 42

Table B-2-4: Test No. 43 
TABLE B-2-1

Specimen Data. Test No. 40

Test Type: Immersion

Test Environment: Simulated WIPP Brine A, H2S overpressure (5 atm)

Test Temperature: $30 \pm 5^{\circ} \mathrm{C}$

Test Exposure: 14 months

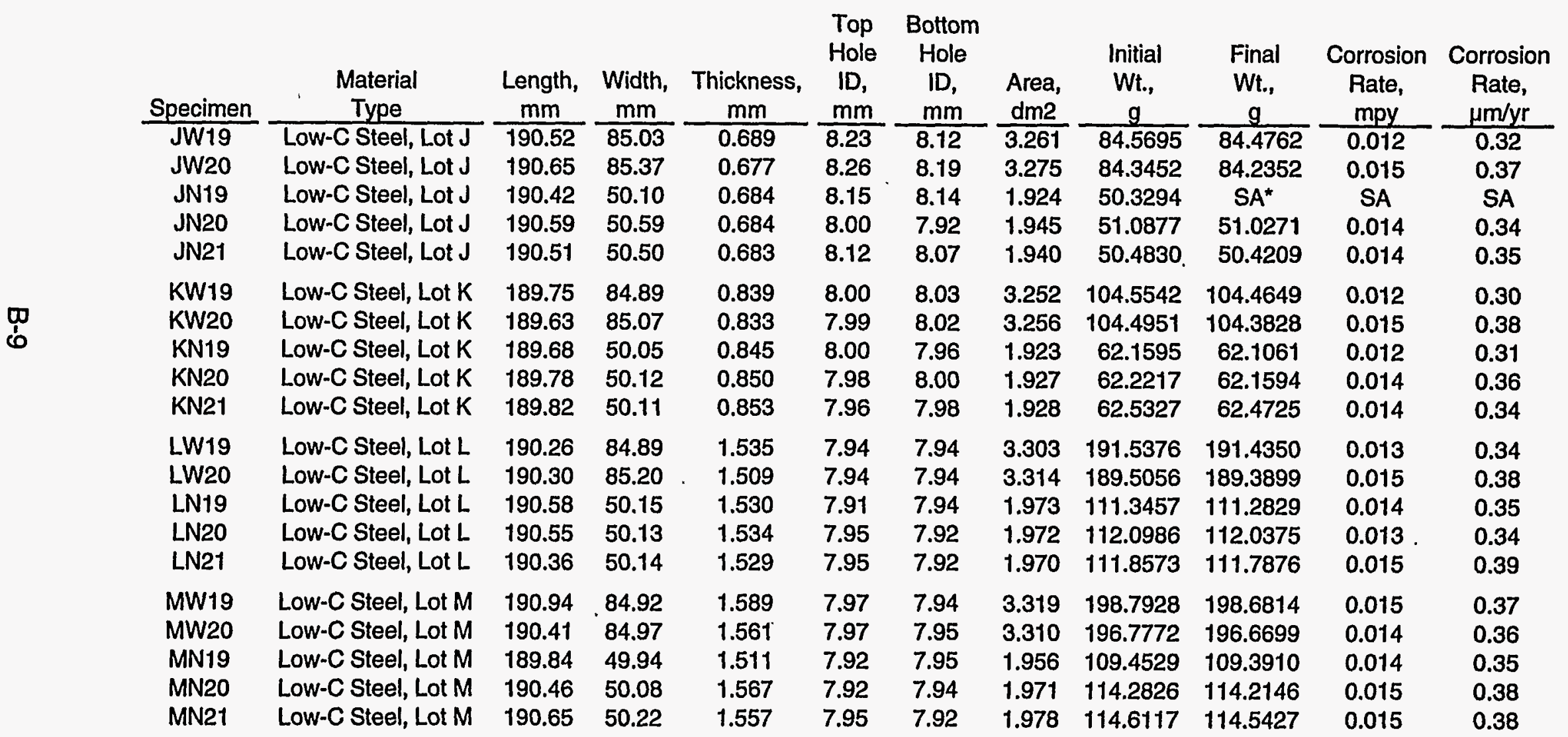

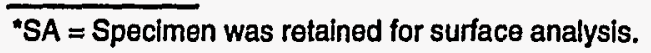


TABLE B-2-2

Specimen Data. Test No. 41

Test Type: Immersion

Test Environment: Simulated WIPP Brine A, H2S Overpressure (5 atm); 7 psi $\mathrm{CO} 2$ was added after 16 months exposure

Test Temperature: $30 \pm 5^{\circ} \mathrm{C}$

Test Exposure: 35 months

\begin{tabular}{|c|c|c|c|c|c|c|c|c|}
\hline Specimen & $\begin{array}{c}\text { Material } \\
\text { Type }\end{array}$ & $\begin{array}{c}\text { Length, } \\
\mathrm{mm}\end{array}$ & $\begin{array}{c}\text { Width, } \\
\mathrm{mm}\end{array}$ & $\begin{array}{c}\text { Thickness, } \\
\mathrm{mm}\end{array}$ & $\begin{array}{c}\text { Top } \\
\text { Hole } \\
\text { ID, } \\
\text { mm }\end{array}$ & $\begin{array}{c}\text { Bottom } \\
\text { Hole } \\
\text { ID, } \\
\mathrm{mm} \\
\end{array}$ & $\begin{array}{l}\text { Area, } \\
\text { dm2 }\end{array}$ & $\begin{array}{c}\text { Initial } \\
\text { Wt., } \\
\text { g }\end{array}$ \\
\hline JW21 & Low-C Steel, Lot J & 190.58 & 85.33 & 0.664 & 8.06 & 8.35 & 3.271 & 83.4695 \\
\hline JW22 & Low-C Steel, Lot J & 189.94 & 85.70 & 0.685 & 8.10 & 8.02 & 3.276 & 85.1118 \\
\hline JN22 & Low-C Steel, Lot J & 190.61 & 50.47 & 0.676 & 8.04 & 8.10 & 1.940 & 50.0161 \\
\hline JN23 & Low-C Steel, Lot J & 190.64 & 50.52 & 0.675 & 8.09 & 8.11 & 1.942 & 49.9827 \\
\hline JN24 & Low-C Steel, Lot J & & 50.48 & 0.676 & 8.07 & 8.13 & & 50.4879 \\
\hline KW21 & Low-C Steel, Lot K & 189.68 & 85.00 & 0.845 & 8.00 & 7.99 & 3.255 & 104.8541 \\
\hline KW22 & Low-C Steel, Lot K & 189.63 & 85.04 & 0.848 & 7.98 & 8.02 & 3.256 & 104.4074 \\
\hline KN22 & Low-C Steel, Lot K & 189.83 & 49.99 & 0.848 & 8.00 & 7.97 & 1.923 & 62.2011 \\
\hline KN23 & Low-C Steel, Lot K & 189.97 & 50.18 & 0.850 & 7.98 & 7.96 & 1.932 & 62.2877 \\
\hline KN24 & Low-C Steel, Lot K & 189.60 & 50.16 & 0.848 & 7.99 & 8.01 & 1.927 & 61.8963 \\
\hline LW21 & Low-C Steel, Lot L & 190.15 & 84.92 & 1.506 & 7.96 & 7.94 & 3.300 & 189.4176 \\
\hline LW22 & Low-C Steel, Lot L & 190.15 & 84.97 & 1.492 & 7.94 & 7.94 & 3.301 & 186.6393 \\
\hline LN22 & Low-C Steel, Lot L & 190.06 & 50.24 & 1.536 & 7.93 & 7.92 & 1.971 & 112.5519 \\
\hline LN23 & Low-C Steel, Lot L & 190.56 & 50.11 & 1.530 & 7.95 & 7.92 & 1.971 & 111.7724 \\
\hline LN24 & Low-C Steel, Lot L & 190.72 & 50.91 & 1.545 & 7.94 & 7.91 & 2.005 & 114.2352 \\
\hline MW21 & Low-C Steel, Lot M & 190.88 & 84.85 & & 7.96 & 7.96 & 3.315 & 198.2044 \\
\hline MW22 & Low-C Steel, Lot M & 190.66 & 84.87 & 1.593 & 7.97 & 7.95 & 3.312 & 198.2775 \\
\hline MN22 & Low-C Steel, Lot M & 189.90 & 50.32 & 1.527 & 7.96 & 7.93 & 1.972 & 111.0662 \\
\hline MN23 & Low-C Steel, Lot M & 190.79 & 50.08 & 1.583 & 7.90 & 7.91 & 1.975 & 114.1351 \\
\hline MN24 & Low-C Steel, Lot M & 190.48 & 50.11 & 1.589 & 7.96 & 7.95 & 1.974 & 113.8557 \\
\hline
\end{tabular}


TABLE B-2-3

Specimen Data, Test No. 42

Test Type: Vapor Phase Exposure

Test Environment: Simulated WIPP Brine A vapor + H2S (5 atm)

Test Temperature: $30 \pm 5^{\circ} \mathrm{C}$

Test Exposure: 14 months

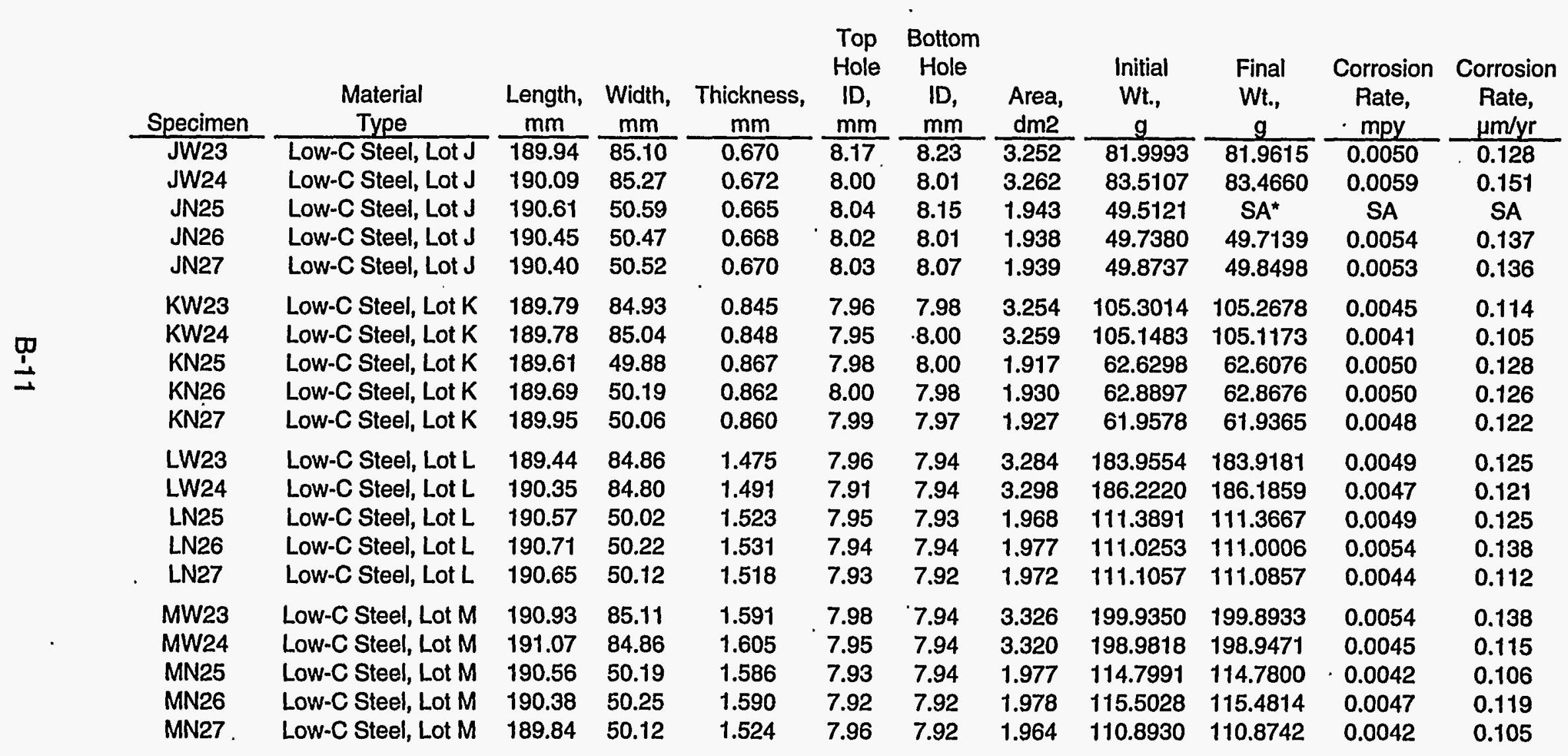

$\overline{\mathrm{SA}}=$ Specimen was retained for surface analysis. 
TABLE B-2-4

\section{Specimen Data. Test No. 43}

Test Type: Vapor Phase Exposure

Test Environment: Simulated WIPP Brine A vapor + H2S (5 atm);

Test Temperature: $30 \pm 5^{\circ} \mathrm{C}$

7 psi CO2 was added after 16 months exposure

Test Exposure: 35 months

\begin{tabular}{|c|c|c|c|c|c|c|c|c|}
\hline Specimen & $\begin{array}{c}\text { Material } \\
\text { Type } \\
\end{array}$ & $\begin{array}{l}\text { Length, } \\
\mathrm{mm} \\
\end{array}$ & $\begin{array}{c}\text { Width, } \\
\mathrm{mm}\end{array}$ & $\begin{array}{c}\text { Thickness, } \\
\mathrm{mm}\end{array}$ & $\begin{array}{c}\text { Top } \\
\text { Hole } \\
\text { ID, } \\
\mathrm{mm}\end{array}$ & $\begin{array}{c}\text { Bottom } \\
\text { Hole } \\
\text { ID, } \\
\mathrm{mm} \\
\end{array}$ & $\begin{array}{l}\text { Area, } \\
\mathrm{dm} 2\end{array}$ & $\begin{array}{c}\text { Initial } \\
\text { Wt., } \\
\text { g }\end{array}$ \\
\hline JW25 & Low-C Steel, Lot J & $\overline{190.89}$ & 86.10 & 0.691 & 7.95 & 7.94 & & $\overline{87.7441}$ \\
\hline JW26 & Low-C Steel, Lot J & 190.78 & 86.13 & 0.687 & 7.96 & 7.94 & & 87.2817 \\
\hline JN28 & Low-C Steel, Lot J & & 50.55 & & 8.04 & 8.05 & & 49.9632 \\
\hline JN29 & Low-C Steel, Lot J & & 50.50 & 0.668 & 8.00 & 7.96 & & 49.9180 \\
\hline JN30 & Low-C Steel, Lot J & 191.18 & 51.84 & 0.682 & 7.94 & 7.93 & 1.999 & 52.6037 \\
\hline KW25 & Low-C Steel, Lot K & 189.73 & 84.96 & 0.837 & 7.98 & 7.94 & 3.254 & 104.2601 \\
\hline KW26 & I, Lot K & & 84.93 & & 7.99 & 7.96 & & 104.4880 \\
\hline KN28 & Low-C Steel, Lot K & 190.00 & 50.02 & 0.862 & 7.95 & 7.99 & 1.927 & 62.9746 \\
\hline KN29 & Low-C Steel, Lot K & 190.13 & 50.17 & 0.869 & 7.94 & 7.98 & 1.934 & 63.9695 \\
\hline KN30 & Low-C Steel, Lot K & 189.82 & 49.88 & 0.867 & 7.93 & 7.98 & 1.920 & 62.5357 \\
\hline LW25 & Low-C Ste & 190.39 & 85.05 & & 7.95 & 7.95 & & 183.6378 \\
\hline & Low-C Steel, Lot L & & 85.38 & & 7.94 & 7.95 & 322 & 184.6739 \\
\hline LN28 & Low-C Steel, Lot L & 190.31 & 50.24 & 1.524 & 7.94 & 7.94 & 1.973 & 112.1188 \\
\hline LN29 & Low-C Stee & & 49.35 & 1.5 & 7.93 & 7. & & 111.0874 \\
\hline LN30 & Low-C Steel, Lot L & 189.94 & 49.92 & 1.518 & 7.95 & 7.96 & 1.957 & 111.6168 \\
\hline MW25 & Low-C Steel, Lot M & 191.26 & 85.22 & 1.578 & 7.95 & 7.98 & 3.335 & 198.2962 \\
\hline & $\mathrm{t} M$ & & 85. & & 7.94 & 7.5 & & 197.3339 \\
\hline MN28 & Low-C & & 50.11 & & 7.95 & 7.93 & 1.963 & 110.9017 \\
\hline MN29 & el, Lot M & 190.52 & 50.02 & & 7.93 & 7.92 & 1.967 & 111.9782 \\
\hline & Low-C Steel, Lot M & 190.48 & 50.17 & 1.553 & 7.94 & 7.93 & 1.974 & 112.4285 \\
\hline
\end{tabular}


APPENDIX B-3: INDIVIDUAL SPECIMEN CORROSION-RATE DATA, TESTS OF LOW-CARBON STEEL IN MODIFIED ERDA-6 BRINE WITH $N_{2}$, SEAL-WELDED CONTAINER TEST METHOD

Table B-3-1: Test No. 44

Table B-3-2: Test No. 45 
TABLE B-3-1

Specimen Data. Test No. 44

Test Type: Immersion

Test Environment: Simulated ERDA 6 Brine, N2 overpressure (10 atm)

Test Temperature: $30 \pm 5^{\circ} \mathrm{C}$

Test Exposure: 10 months

\begin{tabular}{|c|c|c|c|c|c|c|c|c|c|c|c|}
\hline Specimen & $\begin{array}{c}\text { Material } \\
\text { Type }\end{array}$ & $\begin{array}{c}\text { Length, } \\
\mathrm{mm}\end{array}$ & $\begin{array}{c}\text { Width, } \\
\mathrm{mm}\end{array}$ & $\begin{array}{c}\text { Thickness, } \\
\mathrm{mm}\end{array}$ & $\begin{array}{c}\text { Top } \\
\text { Hole } \\
\text { ID, } \\
\text { mm }\end{array}$ & $\begin{array}{c}\text { Bottom } \\
\text { Hole } \\
\text { ID, } \\
\mathrm{mm}\end{array}$ & $\begin{array}{l}\text { Area, } \\
\text { dm2 }\end{array}$ & $\begin{array}{l}\text { Initial } \\
\text { Wt., } \\
\text { g }\end{array}$ & $\begin{array}{c}\text { Final } \\
\text { Wt., } \\
\text { g }\end{array}$ & $\begin{array}{c}\text { Corrosion } \\
\text { Rate, } \\
\text { mpy }\end{array}$ & $\begin{array}{c}\text { Corrosion } \\
\text { Rate, } \\
\mu \mathrm{m} / \mathrm{yr}\end{array}$ \\
\hline JE1 & Low-C Steel, Lot J & 190.52 & 86.32 & 0.684 & $\overline{8.01}$ & 7.99 & $\overline{3.310}$ & 86.8435 & 86.3777 & 0.084 & 2.14 \\
\hline JE2 & Low-C Steel, Lot J & 190.62 & 85.97 & 0.691 & 8.00 & 8.01 & 3.299 & $87.716 i$ & 87.3552 & 0.066 & 1.67 \\
\hline JE3 & Low-C Steel, Lot J & 190.38 & 85.52 & 0.671 & 7.99 & 8.00 & .3 .277 & 83.8027 & 83.1783 & 0.114 & 2.90 \\
\hline JE7 & Low-C Steel, Lot J & 190.17 & 50.56 & 0.677 & 7.97 & 7.96 & 1.939 & 49.6954 & 49.5178 & 0.055 & 1.39 \\
\hline JE8 & Low-C Steel, Lot J & 190.21 & 50.93 & 0.686 & 7.97 & 7.98 & 1.954 & 50.8109 & 50.6256 & 0.057 & 1.44 \\
\hline JE9 & Low-C Steel, Lot J & 190.54 & 50.95 & 0.692 & 7.99 & 7.99 & 1.958 & 51.4767 & 51.3124 & 0.050 & 1.28 \\
\hline KE1 & Low-C Steel, Lot K & 190.51 & 85.91 & 0.841 & 7.95 & .7 .96 & 3.304 & 105.5749 & 105.2366 & 0.061 & $1.5 \dot{6}$ \\
\hline KE2 & Low-C Steel, Lot K & 190.48 & 85.68 & 0.837 & 7.92 & 7.80 & 3.295 & 105.9284 & 105.5609 & 0.067 & 1.70 \\
\hline KE3 & Low-C Steel, Lot K & 190.53 & 85.78 & 0.844 & 7.93 & 7.98 & 3.300 & 106.5590 & 106.2406 & 0.058 & 1.47 \\
\hline KE7 & Low-C Steel, Lot K & 190.41 & 50.94 & 0.861 & 8.01 & 7.96 & 1.966 & 63.6745 & 63.2625 & 0.126 & 3.19 \\
\hline KE8 & Low-C Steel, Lot K & 190.47 & 50.77 & 0.849 & 8.00 & 7.96 & 1.959 & 63.2525 & 63.0406 & 0.065 & 1.65 \\
\hline KE9 & Low-C Steel, Lot K & 190.64 & 50.91 & 0.846 & 7.95 & 7.98 & 1.966 & 63.4930 & 63.2601 & 0.071 & 1.80 \\
\hline LE1 & Low-C Steel, Lot L & 190.55 & 86.03 & 1.488 & 7.99 & 7.98 & 3.348 & 191.1520 & 190.8120 & 0.061 & 1.55 \\
\hline LE2 & Low-C Steel, Lot L & 190.62 & 85.95 & 1.521 & 7.99 & 8.00 & 3,348 & 194.6676 & 194.3416 & 0.058 & 1.48 \\
\hline LE3 & Low-C Steel, Lot L & 190.56 & 85.82 & 1.539 & 8.01 & 8.00 & 3.343 & 194.6512 & 194.3730 & 0.050 & 1.27 \\
\hline LE7 & Low-C Steel, Lot L & 190.51 & 51.08 & 1.543 & 7.97 & 7.99 & 2.009 & 115.4239 & 115.2229 & 0.060 & 1.52 \\
\hline LE8 & Low-C Steel, Lot L & 190.51 & 51.05 & 1.531 & 7.95 & 7.98 & 2.007 & 114.6376 & 114.4426 & 0.058 & 1.48 \\
\hline LE9 & Low-C Steel, Lot L & 190.51 & 51.08 & 1.517 & 7.98 & 7.99 & 2.007 & 113.1265 & 112.9628 & 0.049 & 1.24 \\
\hline ME1 & Low-C Steel, Lot M & 190.55 & 85.94 & 1.605 & 7.94 & 7.96 & 3.352 & 200.9110 & 200.5917 & 0.057 & 1.45 \\
\hline ME2 & Low-C Steel, Lot M & 190.49 & 85.95 & 1.586 & 7.95 & 7.96 & 3.350 & 199.1208 & 198.8266 & 0.053 & 1.34 \\
\hline ME3 & Low-C Steel, Lot M & 190.39 & 85.92 & 1.515 & 7.97 & 8.00 & 3.343 & 191.2219 & 190.8956 & 0.059 & 1.49 \\
\hline ME7 & Low-C Steel, Lot M & 190.68 & 50.85 & 1.626 & 7.93 & 7.97 & 2.006 & 119.3610 & 119.1557 & 0.061 & 1.56 \\
\hline ME8 & Low-C Steel, Lot M & 190.64 & 50.97 & 1.619 & 7.90 & 7.96 & 2.010 & 119.5325 & 119.1877 & 0.103 & 2.61 \\
\hline ME9 & Low-C Steel, Lot M & 190.59 & 50.96 & 1.614 & 7.90 & 7.93 & 2.009 & 119.3898 & 119.1508 & 0.071 & 1.81 \\
\hline
\end{tabular}


TABLE B-3-2

Specimen Data. Test No. 45

Test Type: Immersion

Test Environment: Simulated ERDA 6 Brine, N2 overpressure (10 atm)

Test Temperature: $30 \pm 5^{\circ} \mathrm{C}$

Test Exposure: 10 months

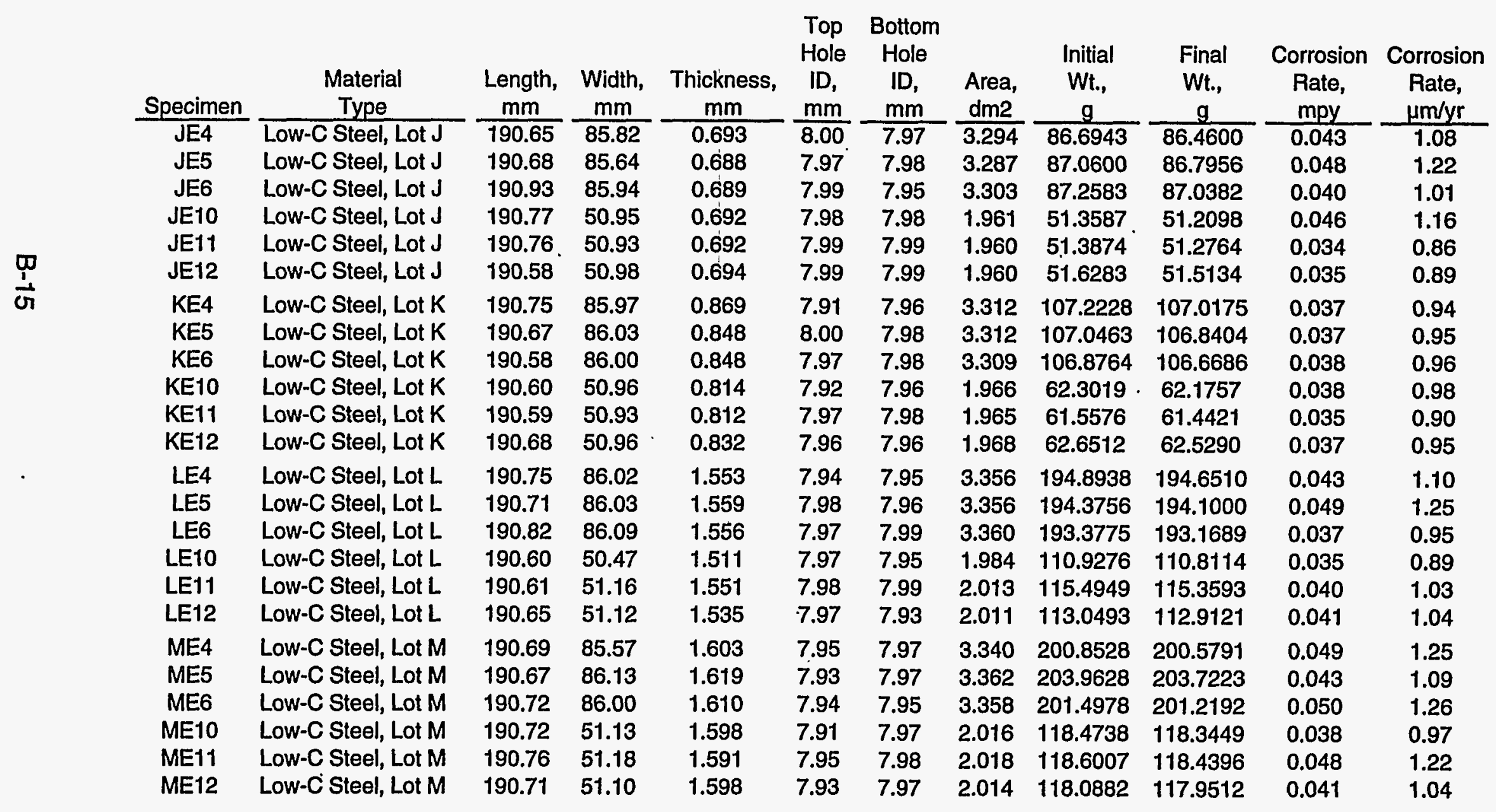


APPENDIX B-4: INDIVIDUAL SPECIMEN CORROSION-RATE DATA, TESTS OF LOW-CARBON STEEL IN MODIFIED ERDA-6 BRINE UNDER CONSTANT-pH CONDITIONS

Table B-4-1: pH 3 Test

Table B-4-2: pH 5 Test

Table B-4-3: $\mathrm{pH} 7$ Test

Table B-4-4: pH 9 Test

Table B-4-5: $\mathrm{pH} 11$ Test 
APPENDIX B-4: INDIVIDUAL SPECIMEN CORROSION-RATE DATA, TESTS OF LOW-CARBON STEEL IN MODIFIED ERDA-6 BRINE UNDER CONSTANT-pH CONDITIONS

TABLE B-4-1: pH 3 TEST

\begin{tabular}{|c|c|c|c|c|c|c|c|}
\hline Specimen & $\begin{array}{l}\text { Initial } \\
\text { Wt., g }\end{array}$ & $\begin{array}{l}\text { Final } \\
\text { Wt.. g }\end{array}$ & $\begin{array}{c}\text { Weight } \\
\text { Change, g }\end{array}$ & $\begin{array}{l}\text { Area, } \\
\mathrm{cm}^{2}\end{array}$ & $\begin{array}{c}\text { Time, } \\
\text { mo }\end{array}$ & $\begin{array}{l}\text { Corrosion } \\
\mu \mathrm{m} / \mathrm{vr}\end{array}$ & $\begin{array}{l}\text { Rate, } \\
\text { (mpv) }\end{array}$ \\
\hline $3 J 1$ & $\overrightarrow{6.9061}$ & 4.5478 & 2.3582 & 25.2 & 0.19 & 7800 & $(308)$ \\
\hline 3J2 & 6.8650 & 4.4430 & 2.4219 & 25.3 & 0.19 & 8000 & (316) \\
\hline $3 \mathrm{~K} 1$ & 8.5489 & 6.3004 & 2.2482 & 25.2 & 0.19 & 7400 & (291) \\
\hline $3 К 2$ & 8.5845 & 6.4496 & 2.1346 & 25.1 & 0.19 & 7000 & (277) \\
\hline $3 L 1$ & 14.5541 & 11.7820 & 2.7721 & 25.2 & 0.19 & 8800 & (345) \\
\hline 3L2 & 14.6813 & 11.8413 & 2.8399 & 25.2 & 0.19 & 9000 & (354) \\
\hline $3 M 1$ & 15.9061 & 13.6239 & 2.2821 & 25.2 & 0.19 & 7200 & (283) \\
\hline $3 \mathrm{M} 2$ & 15.9284 & 13.1112 & 2.8171 & 25.0 & 0.19 & 8800 & (348) \\
\hline
\end{tabular}

TABLE B-4-2: pH 5 TEST

\begin{tabular}{|c|c|c|c|c|c|c|c|}
\hline & Initial & Final & Weight & Area, & Time, & Corros & n Rate, \\
\hline Specimen & Wt.,g & Wt., g & Change, $\mathrm{g}$ & $\underline{\mathrm{cm}^{2}}$ & mo & $\underline{\mu \mathrm{m} / \mathrm{vr}}$ & \\
\hline & 6.7458 & 5.9463 & 0.7995 & 25.2 & 6 & 82 & (3.22) \\
\hline $3 \mathrm{~J} 10$ & 6.7979 & 5.8672 & 0.9307 & 25.2 & 6 & 95 & (3.76) \\
\hline $3 \mathrm{~K} 9^{\circ}$ & 8.5741 & 7.3324 & 1.2417 & 25.2 & 6 & 130 & (5.01) \\
\hline $3 \mathrm{~K} 10$ & 8.5864 & 7.6724 & 0.9140 & 25.2 & 6 & 94 & (3.69) \\
\hline 3L9 & 14.8138 & 14.1490 & 0.6648 & 25.2 & 6 & 68 & (2.68) \\
\hline $3 L 10$ & 14.6059 & 13.7074 & 0.8985 & 25.2 & 6 & 92 & (3.62) \\
\hline 3M9 & 15.9673 & 15.1659 & 0.8014 & 25.2 & 6 & 82 & (3.23) \\
\hline $3 \mathrm{M} 10$ & 15.8972 & 15.3407 & 0.5925 & 25.2 & 6 & 61 & (2.39) \\
\hline
\end{tabular}

${ }^{a}$ Primary calculation, carried out to three significant figures. Only two significant figures are justifiable. 


\section{APPENDIX B-4 (CONT'D)}

TABLE B-4-3: pH 7 TEST

\begin{tabular}{|c|c|c|c|c|c|c|c|}
\hline Specimen & $\begin{array}{l}\text { Initial } \\
\text { Wt..g }\end{array}$ & $\begin{array}{l}\text { Final } \\
\text { Wt.. g }\end{array}$ & $\begin{array}{c}\text { Weight } \\
\text { Change, g. }\end{array}$ & $\begin{array}{c}\text { Area, } \\
\mathrm{cm}^{2} \\
\end{array}$ & $\begin{array}{l}\text { Time, } \\
\text { mo }\end{array}$ & $\begin{array}{l}\text { Corro: } \\
\mu \mathrm{m} / \mathrm{yr}\end{array}$ & $\begin{array}{c}\text { on Rate } \\
\text { (mpy) }\end{array}$ \\
\hline $3 J 11$ & 6.8999 & 6.5770 & 0.3429 & $\overline{25.3}$ & $\overline{6}$ & 35 & $(1.38)$ \\
\hline $3 \mathrm{~J} 12$ & 6.8440 & 6.4995 & 0.3445 & 25.2 & 6 & 35 & $(1.39)$ \\
\hline $3 \mathrm{~K} 11$ & 8.5722 & 8.2201 & 0.3521 & 25.1 & 6 & 36 & (1.42) \\
\hline $3 \mathrm{~K} 12$ & 8.5593 & 8.2024 & 0.3569 & 25.1 & 6 & 37 & (1.45) \\
\hline 3L11 & 14.7188 & 14.0915 & 0.6273 & 25.2 & 6 & 64 & (2.52) \\
\hline $3 L 12$ & 14.3881 & 13.7533 & 0.6348 & 25.2 & 6 & 65 & (2.55) \\
\hline $3 M 11$ & 15.9061 & 15.2989 & 0.6075 & 25.2 & 6 & 62 & $(2.45)$ \\
\hline $3 M 12$ & 15.9284 & 15.2673 & 0.6611 & 25.2 & 6 & 68 & (2.67) \\
\hline
\end{tabular}

TABLE B-4-4: pH9 TEST

\begin{tabular}{|c|c|c|c|c|c|c|c|}
\hline Specimen & $\begin{array}{l}\text { Initial } \\
\text { Wt., g } \\
\end{array}$ & Final $\underline{\mathrm{Wt}} \underline{\mathrm{W}}$ & $\begin{array}{c}\text { Weight } \\
\text { Change, g }\end{array}$ & $\begin{array}{l}\text { Area, } \\
\mathrm{cm}^{2}\end{array}$ & $\begin{array}{c}\text { Time, } \\
\text { mo }\end{array}$ & $\begin{array}{l}\text { Corros } \\
\mu \mathrm{m} / \mathrm{yr}\end{array}$ & $\begin{array}{l}\text { Rate, } \\
\text { (mpy) }\end{array}$ \\
\hline $3 J 5$ & 6.8285 & 6.8146 & 0.0139 & 25.2 & 6 & 1.5 & $(0.06)$ \\
\hline $3 \mathrm{~J} 6$ & 6.8173 & 6.8033 & 0.0140 & 25.2 & 6 & 1.5 & $(0.06$ \\
\hline $3 K 5$ & 8.5864 & 8.5683 & 0.0181 & 25.1 & 6 & 1.8 & $\left(0.0^{\circ}\right.$ \\
\hline $3 K 6$ & 8.5662 & 8.5502 & 0.0160 & 25.1 & 6 & 1.5 & $(0.0$ \\
\hline 3L5 & 14.7278 & 14.7074 & 0.0204 & 25.2 & 6 & 2.0 & $(0.08$ \\
\hline 3L6 & 14.4894 & 14.4674 & 0.0220 & 25.2 & 6 & 2.3 & 10. \\
\hline $3 M 5$ & 15.8882 & 15.8648 & 0.0234 & 25.1 & 6 & 2.5 & $(0$. \\
\hline 3M6 & 15.9431 & 15.9106 & 0,0235 & 251 & 6 & 25 & $(0.70$ \\
\hline
\end{tabular}

TABLE B-4-5: pH11 TEST

\begin{tabular}{|c|c|c|c|c|c|c|c|}
\hline Specimen & $\begin{array}{l}\text { Initial } \\
\text { Wt. g }\end{array}$ & $\underset{\mathrm{g}}{\text { Final }} \underline{\mathrm{Wt} . \text {. }}$ & $\begin{array}{c}\text { Weight } \\
\text { Change, } \mathrm{g}\end{array}$ & $\begin{array}{l}\text { Area, } \\
\mathrm{cm}^{2}\end{array}$ & $\begin{array}{l}\text { Time, } \\
\text { mo. }\end{array}$ & $\begin{array}{l}\text { Corrosion } \\
\mu \mathrm{m} / \mathrm{yr}\end{array}$ & $\begin{array}{l}\text { Rate, } \\
\text { (mpy) }\end{array}$ \\
\hline $3 \mathrm{~J} 7$ & 6.8772 & 6.8571 & 0.0201 & 25.2 & 6 & 2.0 & $(0.08)$ \\
\hline 3J8 & 6.7332 & 6.7176 & 0.0156 & 25.2 & 6 & 1.5 & $(0.06)$ \\
\hline $3 \mathrm{~K} 7$ & 8.5866 & 8.5695 & 0.0171 & 25.1 & 6 & 1.8 & $(0.07)$ \\
\hline $3 \mathrm{~K} 8$ & 8.5430 & 8.5239 & 0.0191 & 25.0 & 6 & 2.0 & (0.08) \\
\hline $3 L 7$ & 14.6188 & 14.5962 & 0.0226 & 25.1 & 6 & 2.3 & (0.09) \\
\hline 3L8 & 14.5547 & 14.4675 & 0.0872 & 25.2 & 6 & 8.9 & (0.35) \\
\hline $3 \mathrm{M} 7$ & 15.8595 & 15.8348 & 0.0247 & 25.1 & 6 & 2.5 & $(0.10)$ \\
\hline 3M8 & 15.8950 & 15.8355 & 0.0595 & 25.1 & 6 & 6.1 & $(0.24)$ \\
\hline
\end{tabular}

\footnotetext{
${ }^{a}$ Primary calculation, carried out to three significant figures. Only two significant figures are justifiable.
} 
APPENDIX B-5: INDIVIDUAL SPECIMEN CORROSION-RATE DATA, TESTS OF LOW-CARBON STEEL IN BRINE A UNDER HIGH $\mathrm{H}_{2}$ PRESSURES, AUTOCLAVE TEST METHOD 
APPENDIX B-5: INDIVIDUAL SPECIMEN CORROSION-RATE DATA, TESTS OF LOW-CARBON STEEL IN BRINE A UNDER HIGH $\mathrm{H}_{2}$ PRESSURES, AUTOCLAVE TEST METHOD

Test No: AUT-9

Test Type: Immersion

Test Environment: Simulated WIPP Brine A,

Test Temperature: $30 \pm 5^{\circ} \mathrm{C}$

$$
\text { H2 overpressure (127 atm) }
$$

Test Exposure: 6 months

\begin{tabular}{|c|c|c|c|c|c|c|c|c|c|c|c|c|}
\hline Specimen & $\begin{array}{c}\text { Material } \\
\text { Type } \\
\end{array}$ & $\begin{array}{l}\text { Length, } \\
\mathrm{mm}\end{array}$ & $\begin{array}{c}\text { Width, } \\
\mathrm{mm} \\
\end{array}$ & $\begin{array}{c}\text { Thickness, } \\
\text { mm }\end{array}$ & $\begin{array}{c}\text { Top } \\
\text { Hole } \\
\text { ID, } \\
\text { mm } \\
\end{array}$ & $\begin{array}{c}\text { Bottom } \\
\text { Hole } \\
\text { ID, } \\
\text { mm } \\
\end{array}$ & $\begin{array}{l}\text { Area, } \\
\text { dim2 }\end{array}$ & $\begin{array}{c}\text { Initial } \\
\text { Wt., } \\
\mathrm{g} \\
\end{array}$ & $\begin{array}{c}\text { Final } \\
\text { Wt., } \\
\text { g }\end{array}$ & $\begin{array}{c}\text { Corrosion } \\
\text { Rate, } \\
\text { mpy }\end{array}$ & $\begin{array}{c}\text { Corrosion } \\
\text { Rate, } \\
\mu \mathrm{m} / \mathrm{yr}\end{array}$ & $\begin{array}{l}\text { Weight } \\
\text { Loss, } \\
\text { g }\end{array}$ \\
\hline J9-1 & Low-C Steel, Lot J & 76.07 & 38.15 & 0.673 & 7.92 & 0.00 & 0.588 & 14.8989 & 14.8766 & 0.038 & 0.95 & \\
\hline J9-2 & Low-C Steel, Lot J & 75.91 & 38.09 & 0.654 & 7.94 & 0.00 & 0.585 & 14.5719 & 14.5430 & 0.049 & 1.24 & \\
\hline J9-3 & Low-C Steel, Lot J & 75.78 & 38.11 & 0.654 & 7.95 & 0.00 & 0.584 & 14.6162 & 14.5872 & 0.049 & 1.25 & \\
\hline J9-4 & Low-C Steel, Lot J & 75.69 & 37.87 & 0.654 & 7.97 & 0.00 & 0.580 & 14.3539 & 14.3265 & 0.047 & 1.19 & \\
\hline J9-5 & Low-C Steel, Lot J & 75.99 & 37.94 & 0.671 & 7.97 & 0.00 & 0.584 & 14.8225 & $S A^{\star}$ & SA & $S A$ & \\
\hline K9-1 & Low-C Steel, Lot K & 75.65 & 37.80 & 0.862 & 8.08 & 0.00 & 0.583 & 18.8199 & 18.7902 & 0.050 & 1.28 & \\
\hline K9-2 & Low-C Steel, Lot K & 75.56 & 38.03 & 0.865 & 8.07 & 0.00 & 0.586 & 18.9457 & 18.9185 & 0.046 & 1.17 & \\
\hline K9-3 & Low-C Steel, Lot K & 75.67 & 38.06 & 0.860 & 7.98 & 0.00 & 0.588 & 18.9511 & 18.9203 & 0.052 & 1.32 & \\
\hline K9-4 & Low-C Steel, Lot K & 75.52 & 38.00 & 0.864 & 8.07 & 0.00 & 0.586 & 18.9174 & 18.8878 & 0.050 & 1.27 & \\
\hline L9-1 & Low-C Steel, Lot L & 75.89 & 37.96 & 1.483 & 8.06 & 0.00 & 0.603 & 32.6740 & 32.6534 & 0.034 & 0.86 & \\
\hline L9-2 & Low-C Steel, Lot L & 75.86 & 38.01 & 1.487 & 8.08 & 0.00 & 0.604 & 32.6707 & 32.6503 & 0.033 & 0.85 & \\
\hline L9-3 & Low-C Steel, Lot L & 75.95 & 37.92 & 1.491 & 8.09 & 0.00 & 0.603 & 32.5126 & 32.4926 & 0.033 & 0.83 & \\
\hline L9-4 & Low-C Șteel, Lot L & 76.01 & 37.96 & 1.506 & 8.05 & 0.00 & 0.605 & 32.8774 & 32.8556 & 0.036 & 0.91 & \\
\hline M9-1 & Low-C Steel, Lot M & 76.33 & 37.98 & 1.557 & 8.06 & 0.00 & 0.609 & 34.2958 & 34.2768 & 0.031 & 0.78 & \\
\hline M9-2 & Low-C Steel, Lot M & 74.48 & 37.97 & 1.575 & 8.07 & 0.00 & 0.595 & 33.8667 & 33.8493 & 0.029 & 0.74 & \\
\hline M9-3 & Low-C Steel, Lot M & 76.29 & 37.97 & 1.551 & 8.07 & 0.00 & 0.608 & 34.2358 & 34.2174 & 0.030 & 0.76 & \\
\hline M9-4 & Low-C Steel, Lot M & 75.49 & 37.96 & 1.595 & 8.08 & 0.00 & 0.603 & 34.7365 & 34.7160 & 0.034 & 0.86 & \\
\hline
\end{tabular}


APPENDIX B-6: INDIVIDUAL SPECIMEN CORROSION-RATE DATA, TESTS OF LOW-CARBON STEEL IN BRINE A UNDER HIGH N2 PRESSURES, AUTOCLAVE TEST METHOD 
APPENDIX B-6: INDIVIDUAL SPECIMEN CORROSION-RATE DATA, TESTS OF LOW-CARBON STEEL IN BRINE A UNDER HIGH $\mathrm{N}_{2}$ PRESSURES, AUTOCLAVE TEST METHOD

Test No: AUT-10

Test Type: Immersion

Test Environment: Simulated WIPP Brine A,

Test Temperature: $30 \pm 5^{\circ} \mathrm{C}$

N2 overpressure (127 atm)

Test Exposure: 6 months

\begin{tabular}{|c|c|c|c|c|c|c|c|c|c|c|c|c|}
\hline Specimen & $\begin{array}{c}\text { Material } \\
\text { Type }\end{array}$ & $\begin{array}{c}\text { Length, } \\
\mathrm{mm}\end{array}$ & $\begin{array}{l}\text { Width, } \\
\mathrm{mm}\end{array}$ & $\begin{array}{c}\text { Thickness, } \\
\text { mm }\end{array}$ & $\begin{array}{l}\text { Top } \\
\text { Hole } \\
\text { ID, } \\
\mathrm{mm} \\
\end{array}$ & $\begin{array}{c}\text { Bottom } \\
\text { Hole } \\
\text { ID, } \\
\mathrm{mm} \\
\end{array}$ & $\begin{array}{l}\text { Area, } \\
\mathrm{dm} 2\end{array}$ & $\begin{array}{c}\text { Initial } \\
\text { Wt., } \\
\text { g }\end{array}$ & $\begin{array}{l}\text { Final } \\
\text { Wt., } \\
\text { g }\end{array}$ & $\begin{array}{c}\text { Corrosion } \\
\text { Rate, } \\
\text { mpy }\end{array}$ & $\begin{array}{c}\text { Corrosion } \\
\text { Rate, } \\
\mu \mathrm{m} / \mathrm{yr}\end{array}$ & $\begin{array}{c}\text { Weight } \\
\text { Loss, } \\
\text { g }\end{array}$ \\
\hline$\sqrt{10-1}$ & Low-C Steel, Lot J & 75.73 & 38.06 & 0.656 & $\overline{7.96}$ & $\overline{0.00}$ & $\overline{0.583}$ & 14.5830 & 14.5181 & 0.107 & 2.7 & \\
\hline J10-2 & Low-C Steel, Lot J & 75.93 & 37.89 & 0.662 & 7.94 & 0.00 & 0.582 & 14.7302 & 14.6729 & 0.095 & 2.4 & \\
\hline J10-3 & Low-C Steel, Lot J & 76.20 & 38.07 & 0.676 & 7.97 & 0.00 & 0.587 & 15.0554 & 14.9982 & 0.094 & 2.4 & \\
\hline J10-4 & Low-C Steel, Lot J & 75.62 & 38.43 & 0.651 & 7.96 & 0.00 & 0.588 & 14.6560 & 14.5959 & 0.099 & 2.5 & \\
\hline J10-5 & Low-C Steel, Lot J & 75.81 & 38.04 & 0.653 & 7.95 & 0.00 & 0.583 & 14.5415 & $S A^{*}$ & SA & SA & \\
\hline $\mathrm{K} 10-1$ & Low-C Steel, Lot K & 75.62 & 37.97 & 0.865 & 7.99 & 0.00 & 0.586 & 18.9339 & 18.8821 & 0.085 & 2.2 & \\
\hline $\mathrm{K} 10-2$ & Low-C Steel, Lot K & 75.43 & 38.01 & 0.863 & 7.99 & 0.00 & 0.585 & 18.9285 & 18.8748 & 0.088 & 2.2 & \\
\hline K10-3 & Low-C Steel, Lot K & 75.82 & 36.86 & 0.863 & 7.94 & 0.00 & 0.571 & 18.4164 & 18.3656 & 0.086 & 2.2 & \\
\hline $\mathrm{K} 10-4$ & Low-C Steel, Lot K & 75.71 & 38.02 & 0.860 & 7.98 & 0.00 & 0.587 & 18.9269 & 18.8746 & 0.086 & 2.2 & \\
\hline L10-1 & Low-C Steel, Lot L & 75.92 & 37.95 & 1.488 & 8.07 & 0.00 & 0.604 & 32.7516 & 32.6807 & 0.113 & 2.9 & \\
\hline L10-2 & Low-C Steel, Lot L & 75.89 & 37.99 & 1.483 & 8.08 & 0.00 & 0.604 & 32.7954 & 32.7269 & 0.109 & 2.8 & \\
\hline L10-3 & Low-C Steel, Lot L & 75.88 & 37.93 & 1.462 & 8.07 & 0.00 & 0.602 & 32.2653 & 32.1893 & 0.122 & 3.1 & \\
\hline L10-4 & Low-C Steel, Lot L & 75.94 & 37.96 & 1.493 & 8.04 & 0.00 & 0.604 & 32.5210 & 32.4496 & 0.114 & 2.9 & \\
\hline M10-1 & Low-C Steel, Lot M & 76.36 & 38.00 & 1.561 & 8.03 & 0.00 & 0.610 & 34.2332 & 34.1494 & 0.132 & 3.4 & \\
\hline M10-2 & Low-C Steel, Lot M & 75.77 & 37.96 & 1.609 & 8.04 & 0.00 & 0.606 & 35.0051 & $34.9237^{\circ}$ & 0.130 & 3.3 & \\
\hline M10-3 & Low-C Steel, Lot M & 74.82 & 38.01 & 1.567 & 8.07 & 0.00 & 0.598 & 33.9798 & 33.9018 & 0.126 & 3.2 & \\
\hline M10-4 & Low-C Steel, Lot M & 76.09 & 37.96 & 1.568 & 8.04 & 0.00 & 0.607 & 34.6229 & 34.5413 & 0.130 & 3.3 & \\
\hline
\end{tabular}


APPENDIX B-7: INDIVIDUAL SPECIMEN CORROSION-RATE DATA, TESTS OF LOW-CARBON STEEL IN BRINE A UNDER HIGH $\mathrm{CO}_{2}$ PRESSURES, AUTOCLAVE TEST METHOD

Table B-7-1: Test AUT-8, 36 atm $\mathrm{CO}_{2}$

Table B-7-2: Test AUT-11, $62 \mathrm{~atm} \mathrm{CO}_{2}$ 
TABLE B-7-1

Test Type: Immersion

Specimen Data. Test AUT-8, 36 atm $\mathrm{CO}_{2}$

Test Environment: Simulated WIPP Brine A,

Test Temperature: $30 \pm 5^{\circ} \mathrm{C}$

CO2 overpressure ( $36 \mathrm{~atm}$ )

Test Exposure: 12 months

\begin{tabular}{|c|c|c|c|c|c|c|c|c|c|c|c|c|}
\hline Specimen & $\begin{array}{c}\text { Material } \\
\text { Type } \\
\end{array}$ & $\begin{array}{c}\text { Length, } \\
\mathrm{mm}\end{array}$ & $\begin{array}{l}\text { Width, } \\
\mathrm{mm}\end{array}$ & $\begin{array}{c}\text { Thickness, } \\
\text { mm }\end{array}$ & $\begin{array}{c}\text { Top } \\
\text { Hole } \\
\text { ID, } \\
\text { mm } \\
\end{array}$ & $\begin{array}{c}\text { Bottom } \\
\text { Hole } \\
\text { ID, } \\
\mathrm{mm} \\
\end{array}$ & $\begin{array}{l}\text { Area, } \\
\mathrm{dm} 2\end{array}$ & $\begin{array}{c}\text { Initial } \\
\text { Wt., } \\
\text { g }\end{array}$ & $\begin{array}{c}\text { Final } \\
\text { Wt., } \\
\text { g }\end{array}$ & $\begin{array}{c}\text { Corrosion } \\
\text { Rate, } \\
\text { mpy } \\
\end{array}$ & $\begin{array}{c}\text { Corrosion } \\
\text { Rate, } \\
\mu \mathrm{m} / \mathrm{yr} \\
\end{array}$ & $\begin{array}{c}\text { Weight } \\
\text { Loss, } \\
\mathrm{g} \\
\end{array}$ \\
\hline J8 1 & Low-C Steel, Lot J & 75.86 & 37.31 & 0.701 & 7.97 & 0.00 & 0.574 & 14.8788 & 14.3960 & 0.42 & 11 & 0.4828 \\
\hline J8 2 & Low-C Steel, Lot J & 76.42 & 37.76 & 0.705 & 8.00 & 0.00 & 0.585 & 15.1086 & 14.5475 & 0.47 & 12 & 0.5611 \\
\hline 583 & Low-C Steel, Lot J & 74.89 & 37.76 & 0.696 & 8.00 & 0.00 & 0.573 & 14.9006 & $S A^{*}$ & $S A$ & SA & $S A^{\star}$ \\
\hline J8 4 & Low-C Steel, Lot J & 76.02 & 37.43 & 0.700 & 8.00 & 0.00 & 0.577 & 15.1812 & 14.6709 & 0.44 & 11 & 0.5103 \\
\hline K8 1 & Low-C Steel, Lot K & 76.64 & 37.17 & 0.857 & 8.00 & 0.00 & 0.581 & 18.4704 & 17.9017 & 0.48 & 12 & 0.5687 \\
\hline K8 2 & Low-C Steel, Lot K & 75.97 & 37.37 & 0.844 & 7.93 & 0.00 & 0.579 & 18.0844 & 17.5036 & 0.50 & 13 & 0.5808 \\
\hline K8 3 & Low-C Steel, Lot K & 75.98 & 37.68 & 0.846 & 7.96 & 0.00 & 0.584 & 18.0115 & 17.4310 & 0.49 & 12 & 0.5805 \\
\hline K8 4 & Low-C Steel, Lot K & 76.17 & 36.93 & 0.863 & 7.85 & 0.00 & 0.575 & 18.0118 & 17.4675 & 0.47 & 12 & 0.5443 \\
\hline L8 1 & Low-C Steel, Lot L & 76.00 & 37.59 & 1.475 & 7.96 & 0.00 & 0.599 & 31.9348 & 31.0279 & 0.75 & 19 & 0.9069 \\
\hline L8 2 & Low-C Steel, Lot L & 74.61 & 37.85 & 1.480 & 7.97 & 0.00 & 0.592 & 31.3200 & 30.4520 & 0.72 & 18 & 0.868 \\
\hline L8 3 & Low-C Steel, Lot L & 75.70 & 37.80 & 1.505 & 7.97 & 0.00 & 0.600 & 32.4604 & 31.5429 & 0.75 & 19 & 0.9175 \\
\hline L8 4 & Low-C Steel, Lot L & 75.27 & 37.61 & 1.473 & 7.95 & 0.00 & 0.593 & 31.4263 & 30.5748 & 0.71 & 18 & 0.8515 \\
\hline M8 1 & Low-C Steel, Lot M & 76.18 & 37.80 & 1.559 & 7.97 & 0.00 & 0.605 & 34.1104 & 33.2333 & 0.72 & 18 & 0.8771 \\
\hline M8 2 & Low-C Steel, Lot M & 76.27 & 37.91 & 1.559 & 7.95 & 0.00 & 0.608 & 34.4325 & 33.6245 & 0.66 & 17 & 0.808 \\
\hline M8 3 & Low-C Steel, Lot M & 76.40 & 37.01 & 1.567 & 7.97 & 0.00 & 0.595 & 33.9265 & 33.0796 & 0.70 & 18 & 0.8469 \\
\hline M8 4 & Low-C Steel, Lot M & 76.09 & 36.92 & 1.562 & 7.93 & 0.00 & 0.591 & 33.4735 & 32.7177 & 0.63 & 16 & 0.7558 \\
\hline
\end{tabular}


TABLE B-7-2

Test Type: Immersion

Specimen Data. Test AUT-11,62 atm $\mathrm{CO}_{2}$

Test Environment: Simulated WIPP Brine A,

Test Temperature; $30 \pm 5^{\circ} \mathrm{C}$

CO2 overpressure (62 atm)

Test Exposure: 6 months

\begin{tabular}{|c|c|c|c|c|c|c|c|c|c|c|c|c|}
\hline Specimen & $\begin{array}{c}\text { Material } \\
\text { Type }\end{array}$ & $\begin{array}{l}\text { Length, } \\
\mathrm{mm}\end{array}$ & $\begin{array}{l}\text { Width, } \\
\mathrm{mm}\end{array}$ & $\begin{array}{l}\text { Thickness, } \\
\text {. } \mathrm{mm}\end{array}$ & $\begin{array}{l}\text { Top } \\
\text { Hole } \\
\text { ID, } \\
\mathrm{mm}\end{array}$ & $\begin{array}{c}\text { Bottom } \\
\text { Hole } \\
\text { ID, } \\
\mathrm{mm}\end{array}$ & $\begin{array}{l}\text { Area, } \\
\text { dm2. }\end{array}$ & $\begin{array}{l}\text { Initial } \\
\text { Wt., } \\
\mathbf{g}\end{array}$ & $\begin{array}{l}\text { Final } \\
\text { Wt., } \\
\text { g }\end{array}$ & $\begin{array}{c}\text { Corrosion } \\
\text { Rate, } \\
\text { mpy }\end{array}$ & $\begin{array}{c}\text { Corrosion } \\
\text { Rate, } \\
\text { رm/yr }\end{array}$ & $\begin{array}{l}\text { Weight } \\
\text { Loss, } \\
\text { g }\end{array}$ \\
\hline$\sqrt{11-1}$ & Low-C Steel, Lot J & 75.78 & 38.15 & 0.650 & 7.96 & 0.00 & 0.585 & 14.5363 & 13.8617 & 1.12 & 29 & \\
\hline$J 11-2$ & Low-C Steel, Lot J & 76.22 & 38.09 & 0.666 & 7.94 & 0.00 & 0.588 & 14.9788 & 14.3403 & 1.06 & 27 & \\
\hline$J 11-3$ & Low-C Steel, Lot J & 75.68 & 38.09 & 0.653 & 7.96 & 0.00 & 0.583 & 14.6614 & 14.0359 & 1.04 & 27 & \\
\hline$J 11-4$ & Low-C Steel, Lot J & 76.58 & 38.06 & 0.661 & 7.95 & 0.00 & 0.590 & 15.0194 & 14.3824 & 1.05 & 27 & \\
\hline J11-5 & Low-C Steel, Lot J & 76.37 & 38.07 & 0.668 & 7.93 & 0.00 & 0.589 & 14.9469 & $S A^{*}$ & SA & SA & \\
\hline$K 11-1$ & Low-C Steel, Lot K & 75.30 & 38.06 & 0.865 & 7.96 & 0.00 & 0.585 & 18.8652 & 18.2270 & 1.06 & 27 & \\
\hline $\mathrm{K} 11-2$ & Low-C Steel, Lot K & 75.64 & 38.05 & 0.870 & 7.96 & 0.00 & 0.588 & 18.9482 & 18.3254 & 1.03 & 26 & \\
\hline K11-3 & Low-C Steel, Lot K & 75.75 & 37.98 & 0.864 & 7.97 & 0.00 & 0.587 & 18.9901 & 18.3653 & 1.04 & 26 & \\
\hline $\mathrm{K} 11-4$ & Low-C Steel, Lot K & 75.73 & 38.03 & 0.858 & 7.96 & 0.00 & 0.588 & 18.9506 & 18.3380 & 1.02 & 26 & \\
\hline L11-1 & Low-C Steel, Lot L & 76.10 & 38.03 & 1.510 & 8.05 & 0.00 & 0.607 & 33.1199 & 32.1731 & 1.52 & 39 & \\
\hline L11-2 & Low-C Steel, Lot L & 75.89 & 37.99 & 1.478 & 8.08 & 0.00 & 0.604 & 32.4090 & 31.4687 & 1.52 & 39 & \\
\hline L11-3 & Low-C Steel, Lot L & 75.85 & 38.00 & 1.484 & 8.11 & 0.00 & 0.604 & 32.7295 & 31.7658 & 1.55 & 39 & \\
\hline L11-4 & Low-C Steel, Lot L & 75.98 & 37.97 & 1.513 & 8.06 & 0.00 & 0.605 & 33.1989 & 32.2720 & 1.49 & 38 & \\
\hline M11-1 & Low-C Steel, Lot M & 74.19 & 37.96 & 1.571 & 8.05 & 0.00 & 0.592 & 33.6877 & 32.7099 & 1.61 & 41 & \\
\hline M11-2 & Low-C Steel, Lot M & 75.20 & 37.96 & 1.574 & 8.07 & 0.00 & 0.600 & 34.3169 & 33.2791 & 1.68 & 43 & \\
\hline M11-3 & Low-C Steel, Lot M & 76.29 & 38.03 & 1.537 & 8.08 & 0.00 & 0.609 & 34.2141 & 33.1083 & 1.77 & 45 & \\
\hline$M 11-4$ & Low-C Steel, Lot M & 76.35 & 37.98 & 1.546 & 8.04 & 0.00 & 0.609 & 34.3062 & 33.3198 & 1.58 & 40 & \\
\hline
\end{tabular}

$\overline{-S A=S p e c i m e n ~ w a s ~ r e l a i n e d ~ f o r ~ s u r f a c e ~ a n a l y s i s . ~}$ 
APPENDIX B-8: INDIVIDUAL SPECIMEN CORROSION-RATE DATA, TESTS OF LOW-CARBON STEEL EMBEDDED IN SIMULATED BENTONITE-SALT BACKFILL CONTACTING BRINE A 
APPENDIX B-8: INDIVIDUAL SPECIMEN CORROSION-RATE DATA, TESTS OF LOW-CARBON STEEL EMBEDDED IN SIMULATED BENTONITE-SALT BACKFILL CONTACTING BRINE A

Test No: AUT-12

Test Type: Wicking

Test Environment: Specimens were embedded in simulated backfill (coarse particulate WIPP

salt and bentonite). The backfill was held in a mesh basket contacting simulated WIPP Brine A, permitting wicking of the liquid. The autoclave had a N2 overpressure of $10 \mathrm{~atm}$.

Test Temperature: $30 \pm 5^{\circ} \mathrm{C}$

Test Exposure: 6 months

\begin{tabular}{|c|c|c|c|c|c|c|c|c|c|c|c|c|}
\hline Specimen & $\begin{array}{c}\text { Material } \\
\text { Type } \\
\end{array}$ & $\begin{array}{c}\text { Length, } \\
\mathrm{mm} \\
\end{array}$ & $\begin{array}{c}\text { Width, } \\
\mathrm{mm}\end{array}$ & $\begin{array}{c}\text { Thickness, } \\
\mathrm{mm}\end{array}$ & $\begin{array}{l}\text { Top } \\
\text { Hole } \\
\text { ID*, } \\
\text { mm }\end{array}$ & $\begin{array}{l}\text { Bottom } \\
\text { Hole } \\
\text { ID*, } \\
\mathrm{mm} \\
\end{array}$ & $\begin{array}{l}\text { Area, } \\
\text { dm2 }\end{array}$ & $\begin{array}{c}\text { Initial } \\
\text { Wt.. } \\
\mathrm{g} \\
\end{array}$ & $\begin{array}{c}\text { Final } \\
\text { Wt., } \\
\text { g }\end{array}$ & $\begin{array}{c}\text { Corrosion } \\
\text { Rate, } \\
\text { mpy } \\
\end{array}$ & $\begin{array}{c}\text { Corrosion } \\
\text { Rate, } \\
\mu \mathrm{m} / \mathrm{yr} \\
\end{array}$ & $\begin{array}{c}\text { Weight } \\
\text { Loss, } \\
\mathrm{g}\end{array}$ \\
\hline $12-1$ & Low-C Steel, Lot J & 24.86 & 24.91 & 0.694 & 0.00 & 0.00 & 0.131 & 3.3570 & 3.3355 & 0.158 & 4.0 & 0.0215 \\
\hline $12-2$ & Low-C Steel, Lot J & 24.84 & 24.78 & 0.695 & 0.00 & 0.00 & 0.130 & 3.3630 & 3.3351 & 0.206 & 5.2 & 0.0279 \\
\hline $12-3$ & Low-C Steel, Lot J & 24.88 & 24.89 & 0.690 & 0.00 & 0.00 & 0.131 & 3.3657 & 3.3371 & 0.210 & 5.3 & 0.0286 \\
\hline $12-4$ & Low-C Steel, Lot J & 24.80 & 24.84 & 0.686 & 0.00 & 0.00 & 0.130 & 3.3335 & 3.3092 & 0.179 & 4.6 & 0.0243 \\
\hline $12-5$ & Low-C Steel, Lot J & 24.73 & 24.87 & 0.692 & 0.00 & 0.00 & 0.130 & 3.3646 & 3.3402 & 0.180 & 4.6 & 0.0244 \\
\hline $12-6$ & Low-C Steel, Lot J & 24.90 & 24.76 & 0.696 & 0.00 & 0.00 & 0.130 & 3.3527 & 3.3323 & 0.150 & 3.8 & 0.0204 \\
\hline $12-7$ & Low-C Steel, Lot J & 24.81 & 24.92 & 0.695 & 0.00 & 0.00 & 0.131 & 3.3471 & 3.3281 & 0.140 & 3.6 & 0.0190 \\
\hline $12-8$ & Low-C Steel, Lot J & 24.84 & 24.84 & 0.668 & 0.00 & 0.00 & 0.130 & 3.2339 & 3.2076 & 0.193 & 4.9 & 0.0263 \\
\hline $12-9$ & Low-C Steel, Lot J & 24.89 & 24.81 & 0.688 & 0.00 & 0.00 & 0.130 & 3.3392 & 3.3195 & 0.145 & 3.7 & 0.0197 \\
\hline $12-10$ & Low-C Steel, Lot J & 24.84 & 24.87 & 0.697 & 0.00 & 0.00 & 0.130 & 3.3748 & 3.3576 & 0.127 & 3.2 & 0.0172 \\
\hline $12-11$ & Low-C Steel, Lot J & 24.79 & 24.90 & 0.696 & 0.00 & 0.00 & 0.130 & 3.3572 & 3.3374 & 0.146 & 3.7 & 0.0198 \\
\hline $12-12$ & Low-C Steel, Lot J & 24.91 & 24.90 & 0.650 & 0.00 & 0.00 & 0.131 & 3.1178 & 3.0957 & 0.162 & 4.1 & 0.0221 \\
\hline $12-13$ & Low-C Steel, Lot J & 24.85 & 24.84 & 0.689 & 0.00 & 0.00 & 0.130 & 3.3311 & 3.3146 & 0.121 & 3.1 & 0.0165 \\
\hline $12-14$ & Low-C Steel, Lot J & 24.76 & 24.95 & 0.698 & 0.00 & 0.00 & 0.130 & 3.3455 & 3.3322 & 0.098 & 2.5 & 0.0133 \\
\hline $12-15$ & Low-C Steel, Lot J & 24.87 & 24.90 & 0.694 & 0.00 & 0.00 & 0.131 & 3.3362 & 3.3267 & 0.070 & 1.8 & 0.0095 \\
\hline $12-16$ & Low-C Steel, Lot J & 24.91 & 24.89 & 0.699 & 0.00 & 0.00 & 0.131 & 3.3502 & 3.3394 & 0.079 & 2.0 & 0.0108 \\
\hline $12-17$ & Low-C Steel, Lot J & 24.83 & 24.89 & 0.672 & 0.00 & 0.00 & 0.130 & 3.2318 & 3.2204 & 0.083 & 2.1 & 0.0114 \\
\hline $12-18$ & Low-C Steel, Lot J & 24.85 & 24.94 & 0.691 & 0.00 & 0.00 & 0.131 & 3.3435 & 3.3349 & 0.063 & 1.6 & 0.0086 \\
\hline
\end{tabular}

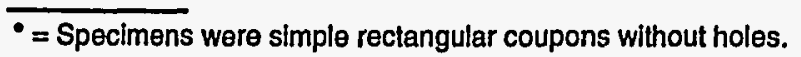


APPENDIX B-9: INDIVIDUAL SPECIMEN CORROSION-RATE DATA, TESTS OF LOW-CARBON STEEL EMBEDDED IN SIMULATED BENTONITE-SALT BACKFILL SUSPENDED IN VAPOR PHASE OF BRINE A 
APPENDIX B-9: INDIVIDUAL SPECIMEN CORROSION-RATE DATA, TESTS OF LOW-CARBON STEEL

EMBEDDED IN SIMULATED BENTONITE-SALT BACKFILL SUSPENDED IN VAPOR PHASE OF BRINE A

Test No: AUT-13

Test Type: Vapor

Test Environment: Specimens were embedded in simulated backfill (coarse particulate WIPP salt and bentonite).

The backfill was held in a mesh basket above the level of the simulated WIPP Brine $A$ in the autoclave.

The autoclave had an $\mathrm{N} 2$ overpressure of $10 \mathrm{~atm}$.

Test Temperature: $30 \pm 5^{\circ} \mathrm{C}$

Test Exposure: 6 months

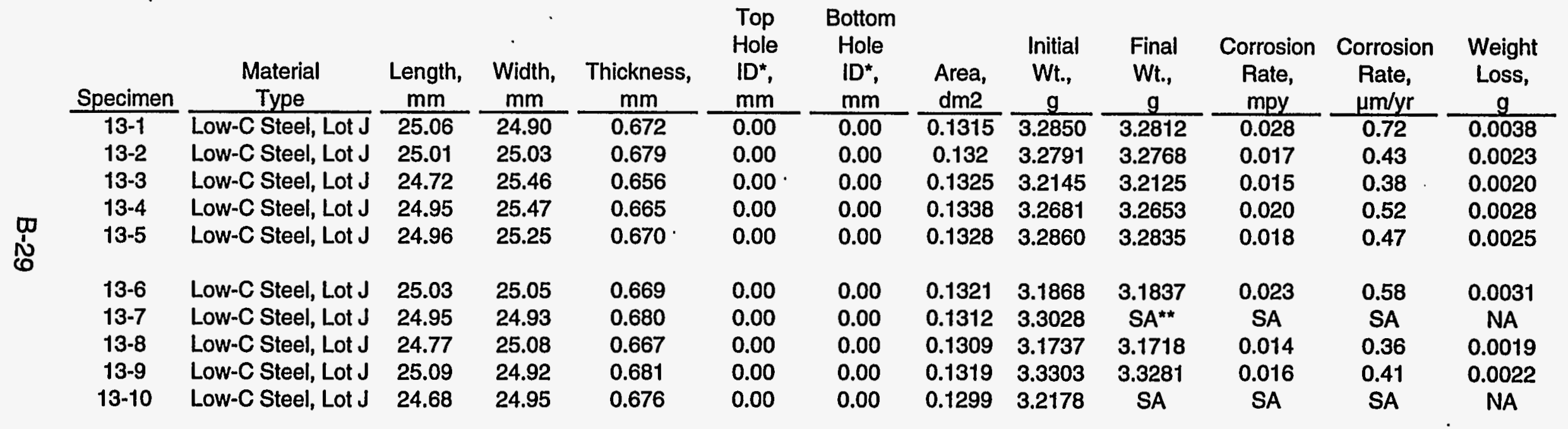

\footnotetext{
$=$ Specimens were simple rectangular coupons without holes.
}

" $\mathrm{SA}=$ Specimen was retained for surface analysis. 
APPENDIX B-10: INDIVIDUAL SPECIMEN DATA, TESTS OF ALTERNATIVE PACKAGING MATERIALS (CU-AND Ti-BASE MATERIALS) IMMERSED IN BRINE A, SEAL-WELDED CONTAINER TEST METHOD

Table B-10-1: Test No. 13A Table B-10-2: Test No. 14A Table B-10-3: Test No. 15A Table B-10-4: Test No. 16A Table B-10-5: Test No. 17A Table B-10-6: Test No. 18A 
TABLE B-10-1

\section{Specimen Data. Test No. 13A}

Test Type: Immersion

Test Environment: Simulated WIPP Brine A, N2 overpressure (10 atm)

Test Temperature: $30 \pm 5^{\circ} \mathrm{C}$

Test Exposure: 24 months

\begin{tabular}{|c|c|c|c|c|c|c|}
\hline Specimen & Material Type & $\begin{array}{c}\text { Outer Diameler, } \\
\mathrm{mm}\end{array}$ & $\begin{array}{c}\text { Hole ID, } \\
\mathrm{mm}\end{array}$ & $\begin{array}{c}\text { Thickness, } \\
\text { mm }\end{array}$ & $\begin{array}{l}\text { Area, } \\
\text { dm2 }\end{array}$ & $\begin{array}{c}\text { Initial Wt., } \\
\text { g }\end{array}$ \\
\hline C49 & Unalloyed Copper & 38.02 & 7.83 & 1.516 & 0.239 & 14.3807 \\
\hline C50 & Unalloyed Copper & 38.02 & 7.83 & 1.508 & 0.239 & 14.3428 \\
\hline C51 & Unalloyed Copper & 38.02 & 7.8 & 1.511 & 0.239 & 14.3613 \\
\hline C52 & Unalloyed Copper & 38.01 & 7.86 & 1.515 & 0.239 & 14.3538 \\
\hline $\mathrm{C53}$ & Unalloyed Copper & 38.00 & 7.84 & 1.525 & 0.239 & 14.4568 \\
\hline C54 & Unalloyed Copper & 38.00 & 7.86 & 1.530 & 0.239 & 14.5065 \\
\hline C55 & Unalloyed Copper & 38.03 & 7.83 & 1.550 & 0.240 & 14.7508 \\
\hline C56 & Unalloyed Copper & 38.01 & 7.82 & 1.544 & 0.239 & 14.7127 \\
\hline CN49 & Cupronickel 90-10 & 38.12 & 7.88 & 1.537 & 0.241 & 14.7515 \\
\hline CN50 & Cupronickel 90-10 & 38.11 & 7.88 & 1.536 & 0.240 & 14.7742 \\
\hline CN51 & Cupronickel 90-10 & 38.11 & 7.87 & 1.551 & 0.241 & 14.8546 \\
\hline CN52 & Cupronickel 90-10 & 37.78 & 7.87 & 1.525 & 0.236 & 14.3284 \\
\hline CN53. & Cupronickel 90-10 & 38.05 & 7.87 & 1.519 & 0.239 & 14.5190 \\
\hline CN54 & Cupronickel 90-10 & 37.98 & 7.87 & 1.522 & 0.239 & 14.5103 \\
\hline CN55 & Cupronickel $90-10$ & 38.18 & 7.87 & 1.519 & 0.241 & 14.6382 \\
\hline CN56 & Cupronickel 90-10 & 38.15 & 7.86 & 1.526 & 0.241 & 14.6935 \\
\hline
\end{tabular}

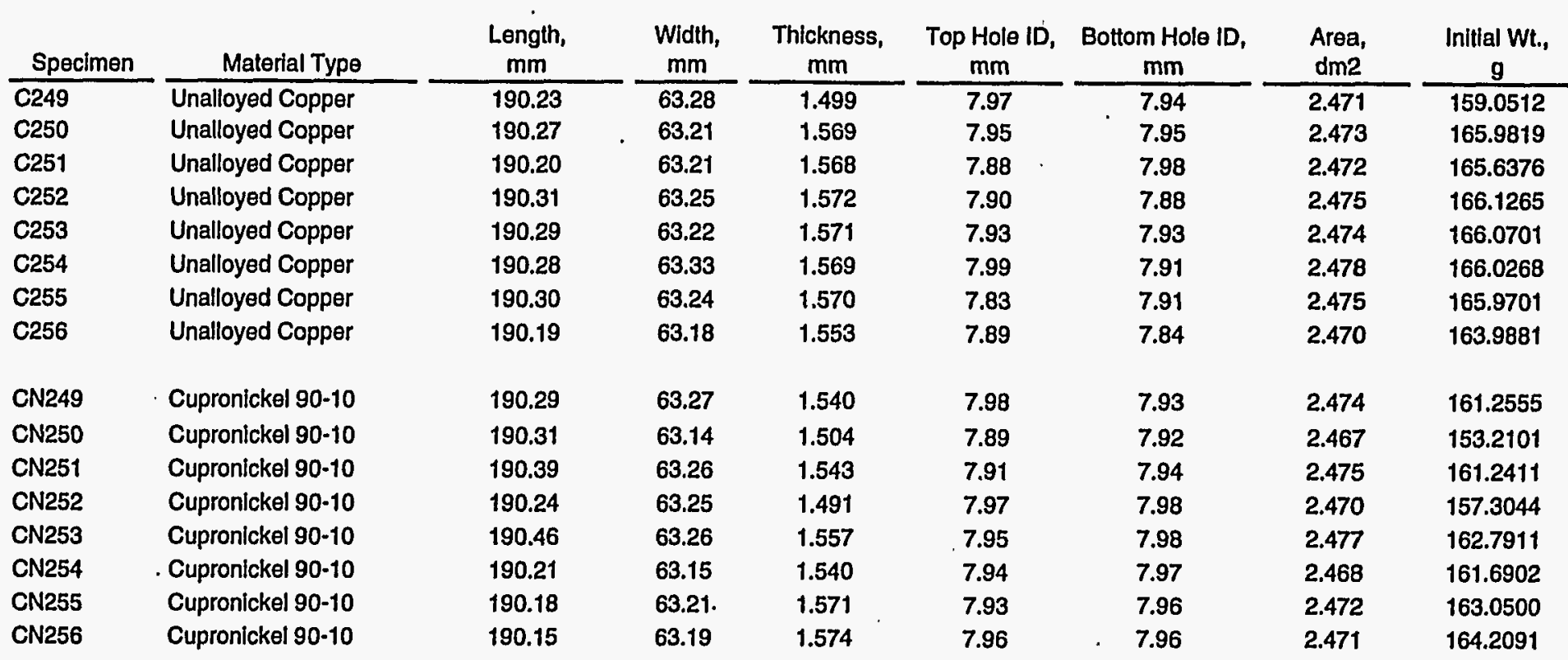


TABLE B-10-2

\section{Specimen Data. Test No. 14A}

Test Type: Immersion

Test Environment: Simulated WIPP Brine A, CO2 overpressure (10 atm)

Test Temperature: $30 \pm 5^{\circ} \mathrm{C}$

Test Exposure: 24 months

\begin{tabular}{|c|c|}
\hline Specimen & Material Type \\
\hline C57 & Unalloyed Copper \\
\hline C58 & Unalloyed Copper \\
\hline C59 & Unalloyed Copper \\
\hline $\mathrm{C60}$ & Unalloyed Copper \\
\hline C61 & Unalloyed Copper \\
\hline $\mathrm{C} 62$ & Unalloyed Copper \\
\hline $\mathrm{C63}$ & Unalloyed Copper \\
\hline C64 & Unalloyed Copper \\
\hline CN57 & Cupronickel 90-10 \\
\hline CN58 & Cupronickel 90-10 \\
\hline CN59 & Cupronickel 90-10 \\
\hline CN60 & Cupronickel 90-10 \\
\hline CN61 & Cupronickel 90-10 \\
\hline CN62 & Cupronickel 90-10 \\
\hline CN63 & Cupronickel 90-10 \\
\hline CN64 & Cupronickel $90-10$ \\
\hline
\end{tabular}

Outer Diameter,
$\mathrm{mm}$

Hole ID,

Thickness,
$\mathrm{mm}$

\begin{tabular}{ccc}
$\begin{array}{c}\text { Area, } \\
\text { dm2 }\end{array}$ & & $\begin{array}{c}\text { Initial Wt. } \\
\text { g }\end{array}$ \\
\hline 0.239 & & 14.6754 \\
0.239 & & 14.6894 \\
0.239 & & 14.6469 \\
0.239 & & 14.4693 \\
0.239 & & 14.5895 \\
0.239 & & 14.5983 \\
0.239 & & 14.4193 \\
0.239 & & 14.6461 \\
& & \\
0.241 & & 14.7260 \\
0.241 & & 14.8214 \\
0.240 & & 14.5815 \\
0.240 & & 14.6264 \\
0.240 & & 14.5286 \\
0.239 & & 14.6020 \\
0.235 & & 14.1152 \\
0.240 & & 14.5219
\end{tabular}

CN64

$\begin{array}{lll}38.02 & \mathrm{~mm} & \\ 38.01 & & 7.87 \\ 38.02 & & 7.85 \\ 38.02 & & 7.77 \\ 38.02 & & 7.87 \\ 38.01 & & 7.81 \\ 38.03 & & 7.86 \\ 38.01 & & 7.83 \\ & & \\ 38.16 & & 7.90 \\ 38.14 & & 7.87 \\ 38.08 & & 7.90 \\ 38.05 & & 7.86 \\ 38.07 & & 7.90 \\ 38.01 & & 7.89 \\ 37.66 & & 7.86 \\ 38.08 & & 7.90\end{array}$

1.542
1.539
1.538
1.518
1.534
1.529
1.521
1.540

1.535
1.545
1.524
1.531
1.523
1.530
1.509
1.519

Width, Thickness, Top Hole ID, Bottom Hole ID,

\begin{tabular}{|c|c|c|c|c|c|c|c|c|}
\hline Specimen & Material Type & Length, & $\mathrm{mm}$ & $\mathrm{mm}$ & $\mathrm{mm}$ & $\mathrm{mm}$ & $\mathrm{dm2}$ & Initial Wt., \\
\hline C̣257 & Unalloyed Copper & 190.15 & 63.23 & 1.574 & 7.83 & 7.81 & 2.473 & 166.0554 \\
\hline C258 & Unalloyed Copper & 190.23 & 63.28 & 1.582 & 7.82 & 7.85 & 2.476 & 166.9782 \\
\hline C259 & Unalloyed Copper & 190.15 & 63.12 & 1.579 & 7.83 & 7.77 & 2.469 & 166.6322 \\
\hline C260 & Unalloyed Copper & 190.10 & 63.24 & 1.573 & 7.90 & 7.91 & 2.472 & 165.7625 \\
\hline C261 & Unalloyed Copper & 190.07 & 63.08 & 1.591 & 7.80 & 7.85 & 2.467 & 166.7534 \\
\hline C262 & Unalloyed Copper & 190.00 & 63.19 & 1.597 & 7.91 & 7.90 & 2.470 & 167.2345 \\
\hline C263 & Unalloyed Copper & 190.14 & 63.10 & 1.575 & 7.92 & 7.80 & 2.468 & 165.6515 \\
\hline C264 & Unalloyed Copper & 190.05 & 63.34 & 1.542 & 7.84 & 7.82 & 2.474 & 161.5678 \\
\hline CN257 & Cupronickel 90-10 & 190.21 & 63.18 & 1.563 & 7.97 & 7.94 & 2.471 & 163.6655 \\
\hline CN258 & Cupronickel 90-10 & 190.14 & 63.20 & 1.582 & 7.94 & 7.98 & 2.472 & 164.2870 \\
\hline CN259 & Cupronickel 90-10 & 190.28 & 63.09 & 1.562 & 7.93 & 7.95 & 2.468 & 162.3155 \\
\hline CN260 & Cupronickel 90-10 & 190.21 & 63.29 & 1.550 & 7.91 & 7.96 & 2.474 & 162.0227 \\
\hline CN261 & Cupronickel 90-10 & 190.32 & 63.23 & 1.563 & 8.00 & 7.94 & 2.474 & 163.2696 \\
\hline CN262 & Cupronickel 90-10 & 190.43 & 63.23 & 1.562 & 7.98 & 7.95 & 2.475 & 162.9196 \\
\hline CN263 & Cupronickel 90-10 & 190.34 & 63.22 & 1.570 & 7.95 & 7.93 & 2.474 & 162.9507 \\
\hline CN264 & Cupronickel 90-10 & 190.24 & 63.13 & 1.553 & 7.96 & 7.96 & 2.469 & 161.8247 \\
\hline
\end{tabular}


TABLE B-10-3

Specimen Data, Test No. $15 \mathrm{~A}$

Test Typo: Immersion

Test Environment: Simulated WIPP Brine A, H2S overpressure (5 atm)

Test Temperature: $30 \pm 5^{\circ} \mathrm{C}$

Test Exposure: 24 months

\begin{tabular}{|c|c|c|c|c|c|c|}
\hline Specimen & Material Type & $\begin{array}{c}\text { Outer Diameter, } \\
\mathrm{mm} \\
\end{array}$ & $\begin{array}{c}\text { Hole ID, } \\
\mathrm{mm}\end{array}$ & $\begin{array}{c}\text { Thickness, } \\
\text { mm }\end{array}$ & $\begin{array}{c}\text { Area, } \\
\mathrm{dm} 2\end{array}$ & $\begin{array}{c}\text { Initial Wt., } \\
\mathrm{g} \\
\end{array}$ \\
\hline C65 & Unalloyed Copper & 38.02 & 7.86 & 1.524 & 0.239 & 14.4727 \\
\hline C66 & Unalloyed Copper & 38.01 & 7.85 & 1.510 & 0.239 & 14.3891 \\
\hline C67 & Unalloyed Copper & 38.03 & 7.83 & 1.512 & 0.239 & 14.3526 \\
\hline $\mathrm{C} 68$ & Unalloyed Copper & 38.02 & 7.84 & 1.538 & 0.239 & 14.6810 \\
\hline C69 & Unalloyed Copper & 38.02 & 7.85 & 1.523 & 0.239 & 14.5617 \\
\hline C70 & Unalloyed Copper & 38.00 & 7.86 & 1.530 & 0.239 & 14.5673 \\
\hline C71 & Unalloyed Copper & 38.02 & 7.80 & 1.538 & 0.240 & 14.6572 \\
\hline $\mathrm{C} 72$ & Unalloyed Copper & 38.02 & 7.82 & 1.522 & 0.239 & 14.5249 \\
\hline CN65 & Cupronickel 90-10 & 38.06 & 7.90 & 1.522 & 0.240 & 14.5151 \\
\hline CN66 & Cupronickel 90-10 & 38.06 & 7.87 & 1.520 & 0.240 & 14.5940 \\
\hline CN67 & Cupronickel 90-10 & 38.06 & 7.89 & 1.516 & 0.240 & 14.5300 \\
\hline CN68 & Cupronickel 90-10 & 38.07 & 7.90 & 1.522 & 0.240 & 14.5383 \\
\hline CN69 & Cupronickel 90-10 & 38.06 & 7.87 & 1.525 & 0.240 & 14.5186 \\
\hline CN70 & Cupronickel 90-10 & 38.04 & 7.87 & 1.525 & 0.239 & 14.5638 \\
\hline CN71 & Cupronickel 90-10 & 38.02 & 7.88 & 1.529 & 0.239 & 14.5693 \\
\hline CN72 & Cupronickel 90-10 & 37.61 & 7.89 & 1.540 & 0.234 & 14.3708 \\
\hline
\end{tabular}

\begin{tabular}{|c|c|c|c|c|c|c|c|c|}
\hline Specimen & Material Type & $\begin{array}{c}\text { Length, } \\
\mathrm{mm}\end{array}$ & $\begin{array}{l}\text { Width, } \\
\text { mm }\end{array}$ & $\begin{array}{c}\text { Thickness, } \\
\mathrm{mm}\end{array}$ & $\begin{array}{c}\text { Top Hole ID, } \\
\text { mm }\end{array}$ & $\begin{array}{c}\text { Bottom Hole ID, } \\
\mathrm{mm}\end{array}$ & $\begin{array}{l}\text { Area, } \\
\text { dm2 }\end{array}$ & $\begin{array}{c}\text { Initial Wt., } \\
\mathbf{g}\end{array}$ \\
\hline C265 & Unalloyed Copper & 189.99 & 63.44 & 1.508 & 7.92 & 7.86 & 2.475 & 157.2453 \\
\hline $\mathrm{C} 266$ & Unalloyed Copper & 189.97 & 63.41 & 1.494 & 7.78 & 7.83 & 2.473 & 157.5416 \\
\hline C267 & Unalloyed Copper & 190.20 & 63.19 & 1.584 & 7.88 & 7.89 & 2.472 & 165.8740 \\
\hline $\mathrm{C} 268$ & Unalloyed Copper & 190.33 & 63.22 & 1.578 & 7.83 & 7.76 & 2.475 & 166.037 .2 \\
\hline C269 & Unalloyed Copper & 190.24 & 63.18 & 1.564 & 7.81 & 7.78 & 2.472 & 165.2174 \\
\hline $\mathrm{C} 270$ & Unalloyed Copper & 190.27 & 63.32 & 1.584 & 7.82 & 7.84 & 2.478 & 166.5285 \\
\hline C271 & Unalloyed Copper & 190.34 & - 63.30 & 1.570 & 7.86 & 7.81 & 2.478 & 166.0302 \\
\hline C272 & Unalloyed Copper & 190.24 & 63.07 & 1.571 & 7.78 & 7.81 & 2.468 & 164.9797 \\
\hline CN265 & Cupronickel $90-10^{\circ}$ & 190.40 & 63.19 & 1.552 & 7.97 & 7.95 & 2.473 & 162.6055 \\
\hline CN266 & Cupronickel 90-10 & 190.33 & 63.16 & 1.577 & 7.95 & 7.96 & 2.472 & 164.4899 \\
\hline CN267 & Cupronickel 90-10 & 190.29 & 63.15 & 1.572 & 7.96 & 7.96 & 2.471 & 163.6594 \\
\hline CN268 & Cupronickel 90-10 & 190.45 & 63.24 & 1.577 & 7.96 & 7.93 & 2.477 & 164.8258 \\
\hline CN269 & Cupronickel 90-10 & 190.35 & 63.26 & 1.577 & 7.90 & 7.97 & - 2.476 & 164.8795 \\
\hline CN270 & Cupronickel 90-10 & 190.27 & 63.20 & 1.571 & 7.96 & 7.96 & 2.473 & 163.9865 \\
\hline CN271 & Cupronickel 90-10 & 190.35 & 63.18 & 1.585 & 7.94 & 7.94 & 2.474 & 164.8628 \\
\hline CN272 & Cupronickel 90-10 & 190.22 & 63.23 & 1.575 & 7.95 & 7.97 & 2.473 & 164.2231 \\
\hline
\end{tabular}


TABLE B-10-4

Test Type: Immersion

Specimen Data. Test No. $16 A$

Test Environment: Simulated WIPP Brine A, N2 overpressure (10 atm)

Test Temperature: $30 \pm 5^{\circ} \mathrm{C}$

Test Exposure: 24 months

\begin{tabular}{|c|c|c|c|c|c|c|}
\hline Specimen & Material Type & $\begin{array}{c}\text { Outer Diameter, } \\
\text { mm }\end{array}$ & $\begin{array}{c}\text { Hole ID, } \\
\mathrm{mm}\end{array}$ & $\begin{array}{c}\text { Thickness, } \\
\text { mm }\end{array}$ & $\begin{array}{l}\text { Area, } \\
\text { dm2 }\end{array}$ & $\begin{array}{c}\text { Initial Wt., } \\
\mathrm{g}\end{array}$ \\
\hline T49 & Titanium, Gr2 & 38.27 & 7.78 & 1.555 & 0.243 & 7.5706 \\
\hline T50 & Titanium, Gr2 & 38.24 & 7.77 & 1.550 & 0.242 & 7.4934 \\
\hline T51 & Titanium, Gr2 & 38.17 & 7.75 & 1.528 & 0.241 & 7.3737 \\
\hline T52 & Titanium, Gr2 & 38.16 & 7.78 & 1.534 & 0.241 & 7.3694 \\
\hline T53 & Titanlum, Gr2 & 38.18 & 7.78 & 1.557 & 0.242 & 7.5377 \\
\hline T54 & Titanium, Gr2 & 38.21 & 7.78 & 1.556 & 0.242 & 7.5610 \\
\hline T55 & Titanium, Gr2 & 38.18 & 7.77 & 1.518 & 0.241 & 7.3351 \\
\hline T56 & Titanium, Gr2 & 38.18 & 7.77 & 1.543 & 0.242 & 7.3993 \\
\hline TN49 & Titanium, Gr12 & 38.13 & 7.82 & 1.560 & 0.241 & 7.5127 \\
\hline TN50 & Titanium, Gr12 & 38.15 & 7.86 & 1.532 & 0.241 & 7.3810 \\
\hline TN51 & Titanium, Gr12 & 38.18 & 7.83 & 1.500 & 0.241 & 7.2700 \\
\hline TN52 & Titanium, Gr12 & 38.12 & 7.86 & 1.490 & 0.240 & 7.1963 \\
\hline TN53 & Titanium, Gr12 & 38.10 & 7.84 & 1.507 & 0.240 & 7.2359 \\
\hline TN54 & Titanium, Gr12 & 38.14 & 7.83 & 1.491 & 0.240 & 7.2053 \\
\hline TN55 & Titanium, Gr12 & 38.14 & 7.88 & 1.517 & 0.241 & 7.3597 \\
\hline TN56 & Titanium, Gr12 & 38.14 & 7.90 & 1.531 & 0.241 & 7.4162 \\
\hline
\end{tabular}

\begin{tabular}{|c|c|c|c|c|c|c|c|c|}
\hline Specimen & Material Type & $\begin{array}{c}\text { Length, } \\
\mathrm{mm}\end{array}$ & $\begin{array}{c}\text { Width, } \\
\mathrm{mm}\end{array}$ & $\begin{array}{c}\text { Thickness, } \\
\text { mm }\end{array}$ & $\begin{array}{c}\text { Top Hole ID, } \\
\mathrm{mm}\end{array}$ & $\begin{array}{c}\text { Bottom Hole ID, } \\
\mathrm{mm}\end{array}$ & $\begin{array}{l}\text { Area, } \\
\text { dm2 }\end{array}$ & $\begin{array}{c}\text { Initial Wt., } \\
\mathrm{g}\end{array}$ \\
\hline T249 & Titanium, Gr2 & 190.45 & 63.38 & 1.569 & 7.99 & 8.00 & 2.482 & 83.8036 \\
\hline T250 & Titanium, Gr2 & 190.42 & 63.44 & 1.557 & 7.99 & 7.98 & 2.483 & 83.2117 \\
\hline T251 & Titanium, Gr2 & 190.48 & 63.42 & 1.610 & 7.99 & 8.03 & 2.486 & 86.0366 \\
\hline T252 & Titanium, Gr2 & 190.49 & 63.29 & 1.603 & 7.96 & 7.96 & 2.481 & 85.4095 \\
\hline T253 & Titanium, Gr2 & 190.52 & 63.43 & 1.601 & 7.96 & 7.99 & 2.486 & 85.8162 \\
\hline T254 & Titanium, Gr2 & 190.46 & 63.39 & 1.596 & 7.97 & 8.00 & 2.484 & 85.6188 \\
\hline T255 & Titanium, Gr2 & 190.46 & 63.40 & 1.589 & 7.96 & 8.01 & 2.484 & 84.7301 \\
\hline T256 & Titanium, Gr2 & 190.47 & 63.37 & 1.611 & 7.98 & 7.98 & 2.484 & 86.1996 \\
\hline TN249 & Titanium, Gr12 & 190.55 & 63.41 & 1.533 & 7.86 & 7.86 & 2.483 & 82.8425 \\
\hline TN250 & Titanlum, Gr12 & 190.49 & 63.36 & 1.558 & 7.87 & 7.87 & 2.481 & 83.8907 \\
\hline TN251 & Titanium, Gr12 & 190.47 & 63.52 & 1.548 & 7.87 & 7.88 & 2.487 & 83.7361 \\
\hline TN252 & Titanium, Gr12 & 190.37 & 63.59 & 1.546 & 7.87 & 7.88 & 2.488 & 83.7410 \\
\hline TN253 & Titanium, Gr12 & 190.56 & 63.42 & 1.558 & 7.86 & 7.86 & 2.484 & 84.0397 \\
\hline TN254 & Titanium, Gr12 & 190.46 & 63.56 & 1.531 & 7.93 & 7.93 & 2.487 & 82.8461 \\
\hline TN255 & Titanium, Gr12 & 190.53 & 63.63 & 1.524 & 7.91 & 7.91 & 2.490 & 83.6466 \\
\hline TN256 & Titanium, Gr12 & 190.49 & 63.54 & 1.529 & 7.87 & 7.86 & 2.487 & 83.0086 \\
\hline
\end{tabular}


TABLE B-10-5

Specimen Data. Test No. 17A

Test Type: Immersion

Test Environment: Simulated WIPP Brine A, CO2 overpressure (10 atm)

Test Temperature: $30 \pm 5^{\circ} \mathrm{C}$

Test Exposure: 24 months

Outer Diameter, Hole ID, Thickness,

\begin{tabular}{|c|c|c|c|c|c|c|}
\hline Specimen & Material Type & $\mathrm{mm}$ & $\mathrm{mm}$ & $\mathrm{mm}$ & Area, & $\mathrm{g}$ \\
\hline T57 & Titanium, Gr2 & 38.20 & 7.79 & 1.537 & 0.242 & 7.4440 \\
\hline T58 & Titanium, Gr2 & 38.21 & 7.78 & 1.550 & 0.242 & 7.4997 \\
\hline T59 & Titanium, Gr2 & 38.22 & 7.77 & 1.550 & 0.242 & 7.5293 \\
\hline T60 & Titanium, Gre & 38.17 & 7.78 & 1.548 & 0.242 & 7.3794 \\
\hline T61 & Titanium, Gr2 & 38.22 & 7.79 & 1.548 & 0.242 & 7.4621 \\
\hline T62 & Titanium, Gra & 38.23 & 7.78 & 1.508 & 0.242 & 7.3093 \\
\hline T63 & Titanium, Gr2 & 38.23 & 7.79 & 1.547 & 0.242 & 7.4980 \\
\hline T64 & Titanium, Gr2 & 38.18 & 7.77 & 1.485 & 0.241 & 7.1855 \\
\hline TN57 & Titanium, Gr12 & 38.17 & 7.85 & 1.518 & 0.241 & 7.3367 \\
\hline TN58 & Titanium, Gr12 & 38.17 & 7.87 & 1.548 & 0.241 & 7.4928 \\
\hline TN59 & Titanium, Gr12 & 38.16 & 7.88 & 1.533 & 0.241 & 7.3558 \\
\hline TN60 & Titanium, Gr12 & 38.11 & 7.89 & 1.476 & 0.240 & 7.1907 \\
\hline TN61 & Titanium, Gr12 & 38.17 & 7.88 & 1.532 & 0.241 & 7.4107 \\
\hline TN62 & Titanium, Gr12 & 38.16 & 7.82 & 1.523 & 0.241 & 7.3919 \\
\hline TN63 & Titanium, Gr12 & 38.15 & 7.82 & 1.514 & 0.241 & 7.3466 \\
\hline TN64 & Titanium, Gr12 & 38.17 & 7.87 & 1.473 & 0.240 & 7.1270 \\
\hline
\end{tabular}

心

Length, Width, Thickness, Top Hole ID, Bottom Hole ID,

\begin{tabular}{|c|c|c|c|c|c|c|c|c|}
\hline Specimen & Material Type & $\mathrm{mm}$ & $\mathrm{mm}$ & $\mathrm{mm}$ & $\mathrm{mm}$ & $\mathrm{mm}$ & Area, $\mathrm{dm} 2$ & g \\
\hline T257 & Titanium, Gr2 & 190.50 & 63.42 & 1.600 & 7.97 & 7.98 & 2.486 & 85.8738 \\
\hline T258 & Titanium, Gr2 & 190.49 & 63.40 & 1.602 & 8.00 & 7.97 & 2.485 & 85.8648 \\
\hline T259 & Titanium, Gr2 & 190.49 & 63.51 & 1.592 & 7.97 & 7.95 & 2.489 & 85.6874 \\
\hline T260 & Titanium, Gr2 & 190.47 & 63.39 & 1.589 & 7.97 & 7.98 & 2.483 & 85.0525 \\
\hline T261 & Titanium, Gr2 & 190.45 & 63.34 & 1.606 & 7.96 & 7.96 & 2.482 & 85.6046 \\
\hline T262 & Titanium, Gr2 & 190.43 & 63.46 & 1.599 & 7.98 & 8.00 & 2.486 & 85.5254 \\
\hline T263 & Titanium, Gr2 & 190.35 & 63.51 & 1.593 & 7.99 & 7.98 & 2.487 & 84.9743 \\
\hline T264 & Titanlum, Gr2 & 190.37 & 63.51 & 1.598 & 7.99 & 7.98 & 2.487 & 85.6633 \\
\hline TN257 & Titanium, Gr12 & 190.43 & 63.21 & 1.544 & 7.87 & 7.87 & 2.474 & 83.5436 \\
\hline TN258 & Titanium, Gr12 & 190.34 & 63.27 & 1.550 & 7.86 & 7.87 & 2.475 & 83.7854 \\
\hline TN259 & Titanium, Gr12 & 190.52 & 63.51 & 1.534 & 7.86 & 7.89 & 2.486 & 83.4271 \\
\hline TN260 & Titanium, Gr12 & 190.45 & 63.59 & 1.553 & 7.88 & 7.88 & 2.489 & 83.9818 \\
\hline TN261 & Titanium, Gr12 & 190.45 & 63.30 & 1.555 & 7.84 & 7.84 & 2.478 & 83.8515 \\
\hline TN262 & Titanium, Gr12 & 190.60 & 63.62 & 1.492 & 7.84 & 7.85 & 2.489 & 80.7448 \\
\hline TN263 & Titanium, Gr12 & 190.41 & 63.60 & 1.555 & 7.85 & 7.86 & 2.489 & 84.6839 \\
\hline TN264 & Titanlum, Gr12 & 190.55 & 63.59 & 1.521 & 7.86 & 7.86 & 2.489 & 82.7873 \\
\hline
\end{tabular}


TABLE B-10-6

Specimen Data. Test No. $18 \mathrm{~A}$

Test Type: Immersion

Test Environment: Simulated WIPP Brine A, H2S overpressure (5 atm)

Test Temperature: $30 \pm 5^{\circ} \mathrm{C}$

Test Exposure: 24 months

\begin{tabular}{|c|c|c|c|c|c|c|}
\hline Specimen & Material Type & $\begin{array}{c}\text { Outer Diameter, } \\
\mathrm{mm}\end{array}$ & $\begin{array}{c}\text { Hole ID, } \\
\mathrm{mm}\end{array}$ & $\begin{array}{c}\text { Thickness, } \\
\text { mm }\end{array}$ & $\begin{array}{l}\text { Area, } \\
\text { dm2 }\end{array}$ & $\begin{array}{c}\text { Initial Wt., } \\
\text { g }\end{array}$ \\
\hline T65 & Titanium, Gr2 & 38.23 & 7.77 & 1.539 & 0.242 & 7.4438 \\
\hline T66 & Titanium, Gr2 & 38.22 & 7.77 & 1.542 & 0.242 & 7.5072 \\
\hline T67 & Titanium, Gr2 & 38.22 & 7.79 & 1.549 & 0.242 & 7.5079 \\
\hline T68 & Titanium, Gr2 & 38.19 & 7.78 & 1.504 & 0.241 & 7.3431 \\
\hline T69 & Titanium, Gr2 & 38.19 & 7.79 & 1.540 & 0.242 & 7.4867 \\
\hline$\pi 70$ & Titanium, Gr2 & 38.21 & 7.80 & 1.548 & 0.242 & 7.4889 \\
\hline T71 & Titanium, Gr2 & 38.24 & 7.78 & 1.577 & 0.243 & 7.5659 \\
\hline T72 & Titanium, Gr2 & 38.20 & 7.79 & 1.592 & 0.243 & 7.7209 \\
\hline TN65 & Titanium, Gr12 & 38.16 & 7.83 & 1.480 & 0.240 & 7.2012 \\
\hline TN66 & Titanium, Gr12 & 38.10 & 7.79 & 1.554 & 0.241 & 7.5075 \\
\hline TN67 & Titanium, Gr12 & 38.13 & 7.87 & 1.552 & 0.241 & 7.4566 \\
\hline TN68 & Titanium, Gr12 & 38.19 & 7.86 & 1.483 & 0.241 & 7.1790 \\
\hline TN69 & Titanium, Gr12 & 38.14 & 7.85 & 1.471 & 0.240 & 7.1208 \\
\hline TN70 & Titanium, Gr12 & 38.16 & 7.84 & 1.498 & 0.241 & 7.2381 \\
\hline TN71 & Titanium, Gr12 & 38.10 & 7.78 & 1.510 & 0.240 & 7.3490 \\
\hline TN72 & Titanium, Gr12 & 38.17 & 7.89 & 1.553 & 0.241 & 7.5236 \\
\hline
\end{tabular}

\begin{tabular}{|c|c|c|c|c|c|c|c|c|}
\hline Specimen & Material Typo & $\begin{array}{l}\text { Length, } \\
\mathrm{mm}\end{array}$ & $\begin{array}{l}\text { Width, } \\
\text { mm }\end{array}$ & $\begin{array}{c}\text { Thickness, } \\
\text { mm }\end{array}$ & $\begin{array}{c}\text { Top Hole ID, } \\
\mathrm{mm}\end{array}$ & $\begin{array}{c}\text { Bottom Hole ID, } \\
\mathrm{mm}\end{array}$ & Area, & $\begin{array}{c}\text { Initial Wt., } \\
\mathbf{g}\end{array}$ \\
\hline T265 & Titanlum, Gr2 & 190.44 & 63.37 & 1.587 & 7.96 & 7.97 & 2.482 & 84.8820 \\
\hline T266 & Titanium, Gr2 & 190.45 & 63.39 & 1.601 & 7.99 & 7.95 & 2.484 & 85.5991 \\
\hline T267 & Titanium, Gr2 & 190.42 & 63.52 & 1.607 & 7.98 & 7.95 & 2.489 & 86.2913 \\
\hline T268 & Titanium, Gr2 & 190.48 & 63.43 & 1.599 & 7.96 & 7.97 & 2.486 & 85.8925 \\
\hline T269 & Titanium, Gr2 & 190.46 & 63.36 & 1.592 & 7.96 & 7.96 & 2.482 & 85.5674 \\
\hline T270 & Titanium, Gr2 & 190.47 & 63.42 & 1.604 & 7.97 & 8.00 & 2.485 & 85.9347 \\
\hline T271 & Titanium, Gr2 & 190.48 & 63.43 & 1.589 & 7.94 & 7.94 & 2.485 & 85.4719 \\
\hline T272 & Titanlum, Gr2 & 190.49 & 63.35 & 1.596 & 7.98 & 8.01 & 2.482 & 85.5389 \\
\hline TN265 & Titanium, Gr12 & 190.42 & 63.33 & 1.554 & 7.85 & 7.85 & 2.479 & 84.2182 \\
\hline TN266 & Titanium, Gr12 & 190.53 & 63.57 & 1.547 & 7.88 & 7.87 & 2.489 & 84.7329 \\
\hline TN267 & Titanium, Gr12 & 190.61 & 63.25 & 1.557 & 7.88 & 7.87 & 2.478 & 84.3890 \\
\hline TN268 & Titanium, Gr12 & 190.68 & 63.44 & 1.484 & 7.88 & 7.87 & 2.483 & 81.5230 \\
\hline TN269 & Titanium, Gr12 & 190.32 & 63.24 & 1.525 & 7.88 & 7.87 & 2.473 & 82.0805 \\
\hline TN270 & Titanium, Gr12 & 190.38 & 63.29 & 1.517 & 7.88 & 7.89 & 2.475 & 81.8307 \\
\hline TN271 & Titanium, Gr12 & 190.43 & 63.42 & 1.510 & 7.88 & 7.88 & 2.480 & 82.0905 \\
\hline TN272 & Titanium, Gr12 & 190.51 & 63.21 & 1.535 & 7.87 & 7.88 & 2.474 & 83.7831 \\
\hline
\end{tabular}


APPENDIX B-11: INDIVIDUAL SPECIMEN DATA, TESTS OF ALUMINUMBASE MATERIALS (99.99\% AI AND 6061 ALLOY) IMMERSED IN BRINE A AND IN VAPOR PHASE OF BRINE A, SEAL-WELDED CONTAINER TEST METHOD

Table B-11-1: Test No. 1B Table B-11-2: Test No. 2B Table B-11-3: Test No. 3B Table B-11-4: Test No. 4B Table B-11-5: Test No. 5B Table B-11-6: Test No. 6B Table B-11-7: Test No. 7B Table B-11-8: Test No. 8B Table B-11-9: Test No. 9B
Table B-11-10: Test No. 10B Table B-11-11: Test No. 11B Table B-11-12: Test No. 12B Table B-11-13: Test No. 13B Table B-11-14: Test No. 14B Table B-11-15: Test No. 15B Table B-11-16: Test No. 16B Table B-11-17: Test No. 17B Table B-11-18: Test No. 18B 
TABLE B-11-1

Test Type: Immersion

Specimen Data. Test No. 1B

Test Environment: Simulated WIPP Brine A, N2 overpressure (10 atm)

Test Temperature: $30 \pm 5^{\circ} \mathrm{C}$

Test Exposure: 13 months

\begin{tabular}{|c|c|c|c|c|c|c|c|c|}
\hline Specimen & $\begin{array}{c}\text { Material } \\
\text { Type }\end{array}$ & $\begin{array}{c}\text { Outer } \\
\text { Diameter, } \\
\text { mm } \\
\end{array}$ & $\begin{array}{l}\text { Hole } \\
\text { ID, } \\
\mathrm{mm}\end{array}$ & $\begin{array}{c}\text { Thickness, } \\
\mathrm{mm}\end{array}$ & $\begin{array}{l}\text { Area, } \\
\text { dm2 }\end{array}$ & $\begin{array}{c}\text { Initial } \\
\text { Wt., } \\
\text { g }\end{array}$ & & \\
\hline $1-001$ & $99.99 \% \mathrm{Al}$ & 38.12 & 8.09 & 1.103 & 0.234 & 3.1393 & & \\
\hline $1-002$ & $99.99 \% \mathrm{Al}$ & 38.28 & 7.86 & 1.020 & 0.235 & 2.8740 & & \\
\hline $1-003$ & $99.99 \% \mathrm{Al}$ & 38.35 & 7.86 & 1.136 & 0.238 & 3.2123 & & \\
\hline $1-004$ & $99.99 \% \mathrm{Al}$ & 38.27 & 7.83 & 1.144 & 0.237 & 3.2561 & & \\
\hline $1-005$ & $99.99 \% \mathrm{Al}$ & 38.32 & 7.85 & 1.143 & 0.237 & 3.2660 & & \\
\hline $1-006$ & $99.99 \% \mathrm{Al}$ & 38.24 & 7.89 & 1.086 & 0.236 & 3.0786 & & \\
\hline 6-201D & Alloy 6061 & 38.31 & 8.00 & 1.430 & 0.241 & 4.2467 & & \\
\hline 6-202D & Alloy 6061 & 38.33 & 8.01 & 1.448 & 0.242 & 4.2770 & & \\
\hline 6-203D & Alloy 6061 & 38.32 & 7.97 & 1.409 & 0.241 & 4.1811 & & \\
\hline 6-204D & Alloy 6061 & 38.34 & 7.91 & 1.389 & 0.241 & 4.1548 & & \\
\hline 6-205D & Alloy 6061 & 38.33 & 7.99 & 1.367 & 0.241 & 4.1055 & & \\
\hline 6-206D & Alloy 6061 & 38.34 & 8.04 & 1.344 & 0.240 & 4.0641 & & \\
\hline Specimen & $\begin{array}{c}\text { Material } \\
\text { Type }\end{array}$ & $\begin{array}{c}\text { Length, } \\
\mathrm{mm}\end{array}$ & $\begin{array}{c}\text { Width, } \\
\mathrm{mm}\end{array}$ & $\begin{array}{c}\text { Thickness, } \\
\mathrm{mm}\end{array}$ & $\begin{array}{c}\text { Top } \\
\text { Hole } \\
\text { ID, } \\
\mathrm{mm} \\
\end{array}$ & $\begin{array}{c}\text { Bottom } \\
\text { Hole } \\
\mathrm{ID}, \\
\mathrm{mm} \\
\end{array}$ & $\begin{array}{l}\text { Area, } \\
\mathrm{dm} 2\end{array}$ & $\begin{array}{c}\text { Initial } \\
\text { Wt., } \\
\text { g }\end{array}$ \\
\hline $1-201$ & $99.99 \% \mathrm{Al}$ & 190.36 & 63.60 & 1.161 & 8.03 & 7.77 & 2.467 & 36.5657 \\
\hline $1-202$ & $99.99 \% \mathrm{Al}$ & 190.36 & 63.63 & 1.252 & 7.96 & 7.94 & 2.473 & 39.8147 \\
\hline $1-203$ & $99.99 \% \mathrm{Al}$ & 190.51 & 63.75 & 1.275 & 7.95 & 7.94 & 2.480 & 40.7251 \\
\hline $1-204$ & $99.99 \% \mathrm{Al}$ & 190.30 & 63.67 & 1.247 & 7.99 & 8.01 & 2.473 & 39.9754 \\
\hline $1-205$ & $99.99 \% \mathrm{Al}$ & 190.28 & 63.68 & 1.247 & 7.95 & 7.97 & 2.473 & 39.7972 \\
\hline $1-206$ & $99.99 \% \mathrm{Al}$ & 189.75 & 63.36 & 1.252 & 7.97 & 7.98 & 2.454 & 39.7625 \\
\hline $6-201$ & Alloy 6061 & 190.33 & 63.38 & 1.507 & 8.08 & 8.05 & 2.476 & 48.4405 \\
\hline $6-202$ & Alloy 6061 & 190.41 & 63.36 & 1.510 & 8.06 & 8.05 & 2.477 & 48.4161 \\
\hline $6-203$ & Alloy 6061 & 190.39 & 63.34 & 1.507 & 8.04 & 7.98 & 2.476 & 48.3179 \\
\hline $6-204$ & Alloy 6061 & 190.35 & 63.27 & 1.505 & 8.02 & 8.00 & 2.472 & 48.2349 \\
\hline $6-205$ & Alloy 6061 & 190.41 & 63.39 & 1.495 & 8.01 & 8.01 & 2.477 & 48.0071 \\
\hline $6-206$ & Alloy 6061 & 190.37 & 63.35 & 1.503 & 7.99 & 7.98 & 2.476 & 48.2260 \\
\hline
\end{tabular}


TABLE B-11-2

Test Type: Immersion

Specimen Data, Test No. 2B

Test Environment: Simulated WIPP Brine A, CO2 overpressure (10 atm)

Test Temperature: $30 \pm 5^{\circ} \mathrm{C}$

Test Exposure: 13 months

\begin{tabular}{|c|c|c|c|c|c|c|}
\hline Specimen & $\begin{array}{c}\text { Material } \\
\text { Type }\end{array}$ & $\begin{array}{c}\text { Outer } \\
\text { Diameter, } \\
\mathrm{mm}\end{array}$ & $\begin{array}{l}\text { Hole } \\
\text { ID, } \\
\text { mm }\end{array}$ & $\begin{array}{c}\text { Thickness, } \\
\mathrm{mm}\end{array}$ & $\begin{array}{l}\text { Area, } \\
\text { dm2 }\end{array}$ & $\begin{array}{c}\text { Initial } \\
\text { Wt., } \\
\text { g }\end{array}$ \\
\hline $1-007$ & $99.99 \% \mathrm{Al}$ & 38.15 & 7.84 & 1.091 & 0.235 & 3.1032 \\
\hline $1-008$ & $99.99 \% \mathrm{Al}$ & 38.28 & 7.90 & 1.092 & 0.236 & 3.2015 \\
\hline $1-009$ & $99.99 \% \mathrm{Al}$ & 38.33 & 7.89 & 1.075 & 0.236 & 2.9747 \\
\hline $1-010$ & $99.99 \% \mathrm{Al}$ & 38.27 & 7.90 & 1.003 & 0.235 & 2.9173 \\
\hline $1-011$ & $99.99 \% \mathrm{Al}$ & 38.18 & 7.85 & 1.031 & 0.234 & 3.0333 \\
\hline $1-012$ & $99.99 \% \mathrm{Al}$ & 38.18 & 7.93 & 1.122 & 0.235 & 3.2259 \\
\hline 6-207D & Alloy 6061 & 38.32 & 7.99 & 1.426 & 0.241 & 4.2544 \\
\hline 6-208D & Alloy 6061 & 38.34 & 7.96 & 1.345 & 0.240 & 4.0582 \\
\hline 6-209D & Alloy 6061 & 38.32 & 8.06 & 1.346 & 0.240 & 4.0485 \\
\hline $6-210 D$ & Alloy 6061 & 38.29 & 7.94 & 1.366 & 0.240 & 4.1203 \\
\hline 6-211D & Alloy 6061 & 38.33 & 7.99 & 1.345 & 0.240 & 4.0414 \\
\hline 6-212D & Alloy 6061 & 38.31 & 8.05 & 1.361 & 0.240 & 4.1389 \\
\hline & & & & & $\begin{array}{l}\text { Top } \\
\text { Hole }\end{array}$ & $\begin{array}{c}\text { Bottom } \\
\text { Hole }\end{array}$ \\
\hline
\end{tabular}

\begin{tabular}{|c|c|c|c|c|c|c|c|c|c|c|c|c|c|}
\hline Specimen & $\begin{array}{c}\text { Material } \\
\text { Type }\end{array}$ & $\begin{array}{c}\text { Length, } \\
\mathrm{mm}\end{array}$ & $\begin{array}{c}\text { Width, } \\
\mathrm{mm}\end{array}$ & $\begin{array}{c}\text { Thickness, } \\
\mathrm{mm}\end{array}$ & $\begin{array}{l}\text { ID, } \\
\mathrm{mm}\end{array}$ & $\begin{array}{l}\text { ID, } \\
\mathrm{mm}\end{array}$ & $\begin{array}{l}\text { Area, } \\
\text { dm2 }\end{array}$ & $\begin{array}{c}\text { Wt., } \\
\mathrm{g}\end{array}$ & Final Weight & $\begin{array}{l}\text { Rate } \\
\text { MPY }\end{array}$ & $\begin{array}{c}\text { Rate } \\
\text { Micron } / V_{r}\end{array}$ & $\begin{array}{c}\text { Weight Loss } \\
g\end{array}$ & Dummy \\
\hline $1-207$ & $99.99 \% \mathrm{Al}$ & 190.55 & 63.70 & 1.248 & 7.93 & 8.00 & 2.477 & 39.8004 & & \#REF! & \#REF! & 39.8004 & 24973.1032 \\
\hline $1-208$ & $99.99 \% \mathrm{Al}$ & 190.34 & 63.39 & 1.236 & 8.00 & 7.90 & 2.462 & 39.3304 & & \#REF! & \#REF! & 39.3304 & 24820.2343 \\
\hline $1-209$ & 99.99\%Al & 190.27 & 63.70 & 1.238 & 7.94 & 7.95 & 2.473 & 39.5786 & & \#REF! & \#REF! & 39.5786 & 24930.9972 \\
\hline $1-210$ & $99.99 \% \mathrm{Al}$ & 190.38 & 63.34 & 1.237 & 7.98 & 7.98 & 2.461 & 39.2889 & & \#REF! & \#REF! & 39.2889 & 24807.0332 \\
\hline $1-211$ & $99.99 \% \mathrm{Al}$ & 190.60 & 63.22 & 1.242 & 7.97 & 7.95 & 2.459 & 39.2955 & & \#REF! & \#REF! & 39.2955 & 24792.0390 \\
\hline $1-212$ & $99.99 \% \mathrm{Al}$ & 190.62 & 63.71 & 1.249 & 7.99 & 7.96 & 2.479 & 39.8300 & & \#REF! & $\#$ \#EF! & 39.8300 & 24986.6704 \\
\hline $6-207$ & Alloy 6061 & 190.24 & 63.44 & 1.506 & 8.00 & 7.98 & 2.478 & 48.1945 & & \#REF! & \#REFI & 48.1945 & 24977.3022 \\
\hline $6-208$ & Alloy 6061 & 190.43 & 63.39 & 1.502 & 8.00 & 8.01 & 2.478 & 48.0059 & & \#REF! & \#REF! & 48.0059 & 24980.6983 \\
\hline $6-209$ & Alloy 6061 & 190.39 & 63.43 & 1.517 & 8.02 & 8.03 & 2.480 & 48.3655 & & \#REFI & \#REF! & 48.3655 & 24999.4175 \\
\hline $6-210$ & Alloy 6061 & 190.34 & 63.27 & 1.517 & 8.04 & 8.02 & 2.473 & 48.2693 & & \#REF! & \#REF! & 48.2693 & 24931.5762 \\
\hline $6-211$ & Alloy 6061 & 190.41 & 63.43 & 1.513 & 8.00 & 8.00 & -0.020 & 48.2731 & & & & & \\
\hline $6-212$ & Alloy 6061 & 190.40 & 63.37 & 1.504 & 8.04 & 8.04 & -0.020 & 48.1301 & & & & & \\
\hline
\end{tabular}


TABLE B-11-3

Test Type: Immersion

\section{Specimen Data, Test No. 3B}

Test Environment: Simulated WIPP Brine A, H2S overpressure (5 atm)

Test Temperature: $30 \pm 5^{\circ} \mathrm{C}$

Test Exposure: 13 months

\begin{tabular}{|c|c|c|c|c|c|c|c|c|}
\hline Specimen & $\begin{array}{c}\text { Material } \\
\text { Type }\end{array}$ & $\begin{array}{c}\text { Outer } \\
\text { Diameter, } \\
\mathrm{mm} \\
\end{array}$ & $\begin{array}{l}\text { Hole } \\
\text { ID, } \\
\text { mm }\end{array}$ & $\begin{array}{c}\text { Thickness, } \\
\mathrm{mm}\end{array}$ & $\begin{array}{l}\text { Area, } \\
\mathrm{dm} 2\end{array}$ & $\begin{array}{c}\text { Initial } \\
\text { Wt., } \\
\text { g }\end{array}$ & & \\
\hline $1-013$ & $99.99 \% \mathrm{Al}$ & $38: 31$ & 7.96 & 1.075 & 0.236 & 3.2178 & & \\
\hline $1-014$ & $99.99 \% \mathrm{Al}$ & 38.27 & 8.00 & 1.061 & 0.235 & 3.0331 & & \\
\hline $1-015$ & $99.99 \% \mathrm{Al}$ & 38.29 & 7.93 & 1.009 & 0.235 & 2.9752 & & \\
\hline $1-016$ & $99.99 \% \mathrm{Al}$ & 38.27 & 7.88 & 1.136 & 0.237 & 3.2797 & & \\
\hline $1-017$ & $99.99 \% \mathrm{Al}$ & 38.25 & 7.96 & 1.111 & 0.236 & 3.2300 & & \\
\hline $1-018$ & $99.99 \% \mathrm{Al}$ & 38.29 & 7.90 & 1.086 & 0.236 & 3.1540 & & \\
\hline $6-213 D$ & Alloy 6061 & 38.35 & 7.98 & 1.349 & 0.241 & 4.1137 & & \\
\hline $6-214 D$ & Alloy 6061 & 38.34 & 7.99 & 1.282 & 0.239 & 3.9724 & & \\
\hline 6-215D & Alloy 6061 & 38.36 & 8.04 & 1.382 & 0.241 & 4.1194 & & \\
\hline $6-216 D$ & Alloy 6061 & 38.37 & 8.04 & 1.394 & 0.241 & 4.2013 & & \\
\hline 6-217D & Alloy 6061 & 38.31 & 8.03 & 1.392 & 0.241 & 4.1896 & & \\
\hline 6-218D & Alloy 6061 & 38.33 & 8.05 & 1.358 & 0.240 & 4.1024 & & \\
\hline Specimen & $\begin{array}{c}\text { Material } \\
\text { Type }\end{array}$ & $\begin{array}{l}\text { Length, } \\
\mathrm{mm}\end{array}$ & $\begin{array}{c}\text { Width, } \\
\mathrm{mm}\end{array}$ & $\begin{array}{c}\text { Thickness, } \\
\mathrm{mm}\end{array}$ & $\begin{array}{c}\text { Top } \\
\text { Hole } \\
\text { ID, } \\
\mathrm{mm} \\
\end{array}$ & $\begin{array}{c}\text { Bottom } \\
\text { Hole } \\
\text { ID, } \\
\mathrm{mm} \\
\end{array}$ & $\begin{array}{l}\text { Area, } \\
\mathrm{dm} 2\end{array}$ & $\begin{array}{c}\text { Initial } \\
\text { Wt., } \\
\mathrm{g} \\
\end{array}$ \\
\hline $1-213$ & $99.99 \% \mathrm{Al}$ & 190.36 & 63.66 & 1.213 & 7.94 & 7.89 & 2.472 & 38.5876 \\
\hline $1-214$ & $99.99 \% \mathrm{Al}$ & 190.79 & 63.43 & 1.260 & 7.95 & 8.01 & 2.471 & 40.2756 \\
\hline $1-215$ & $99.99 \% \mathrm{Al}$ & 190.01 & 63.15 & 1.263 & 7.95 & 7.97 & 2.450 & 39.9660 \\
\hline $1-216$ & $99.99 \% \mathrm{Al}$ & 190.62 & 63.85 & 1.267 & 7.95 & 8.01 & 2.485 & 40.7047 \\
\hline $1-217$ & $99.99 \% \mathrm{Al}$ & 190.23 & 63.41 & 1.255 & 7.93 & 7.92 & 2.463 & 40.0331 \\
\hline $1-218$ & $99.99 \% \mathrm{Al}$ & 190.42 & 63.46 & 1.246 & 7.97 & 7.99 & 2.466 & 39.5950 \\
\hline $6-213$ & Alloy 6061 & 190.35 & 63.30 & 1.488 & 8.02 & 8.03 & 2.473 & 47.6890 \\
\hline $6-214$ & Alloy 6061 & 190.25 & 63.17 & 1.510 & 7.87 & 7.89 & 2.468 & 48.1218 \\
\hline $6-215$ & Alloy 6061 & 190.30 & 63.11 & 1.503 & 7.92 & 7.93 & 2.466 & 48.0210 \\
\hline $6-216$ & Alloy 6061 & 190.31 & 63.34 & 1.502 & 7.92 & 7.92 & 2.475 & 48.1630 \\
\hline $6-217$ & Alloy 6061 & 190.26 & 63.30 & 1.511 & 7.92 & 7.92 & 2.473 & 48.3244 \\
\hline $6-218$ & Alloy 6061 & 190.29 & 63.21 & 1.518 & 7.92 & 7.92 & 2.470 & 48.4935 \\
\hline
\end{tabular}


TABLE B-11-4

Test Type: Immersion, with Fe contamination of the brine

Specimen Data. Test No. 4B

Test Environment: Simulated WIPP Brine A, N2 overpressure (10 atm)

Test Temperature: $30 \pm 5^{\circ} \mathrm{C}$

Test Exposure: 13 months

\begin{tabular}{|c|c|c|c|c|c|c|c|c|c|c|c|c|}
\hline Specimen & Malerial Type & $\begin{array}{c}\text { Outer } \\
\text { Diameter, } \\
\mathbf{m m}\end{array}$ & $\begin{array}{l}\text { Hole } \\
\text { ID, } \\
\mathrm{mm} \\
\end{array}$ & $\begin{array}{c}\text { Thickness, } \\
\mathrm{mm}\end{array}$ & $\begin{array}{l}\text { Area, } \\
\text { dm2 }\end{array}$ & $\begin{array}{c}\text { Initial } \\
\text { Wt., } \\
\mathbf{g}\end{array}$ & & & & & & \\
\hline 1.019 & $99.99 \% \mathrm{Al}$ & 38.16 & 7.96 & 1.127 & 0.235 & 3.2393 & & & & & & \\
\hline $1-020$ & $99.99 \% \mathrm{Al}$ & 38.09 & 8.06 & 1.071 & 0.233 & 3.0322 & & & & & & \\
\hline $1-021$ & $99.99 \% \mathrm{Al}$ & 38.14 & 7.91 & 1.155 & 0.235 & 3.3222 & & & & & & \\
\hline $1-022$ & $99.99 \% \mathrm{Al}$ & 38.22 & 8.16 & 1.145 & 0.236 & 3.2603 & & & & & & \\
\hline $1-023$ & $99.99 \% \mathrm{Al}$ & 38.28 & 7.89 & 1.131 & 0.237 & 3.2751 & & & & & & \\
\hline $1-024$ & $99.99 \% \mathrm{Al}$ & 38.30 & 8.00 & 1.050 & 0.236 & 2.9942 & & & & & & \\
\hline $6-219 D$ & Alloy 6061 & 38.31 & 8.02 & 1.358 & 0.240 & 4.1264 & & & & & & \\
\hline $6-220 D$ & Alloy 6061 & 38.29 & 8.06 & 1.359 & 0.240 & 4.1766 & & & & & & \\
\hline 6-221D & Alloy 6061 & 38.33 & 7.93 & 1.396 & 0.241 & 4.1801 & & & & & & \\
\hline $6-222 D$ & Alloy 6061 & 38.32 & 8.04 & 1.381 & 0.240 & 4.1383 & & . & & : & & \\
\hline 6-223D & Alloy 6061 & 38.30 & 8.03 & 1.341 & $0: 240$ & 4.1088 & & & & & & \\
\hline $6-224 D$ & Alloy 6061 & 38.31 & 7.93 & 1.378 & $0.24 t$ & 4.1031 & & & & & & \\
\hline Specimen & Material Type & $\begin{array}{c}\text { Length, } \\
\mathrm{mm}\end{array}$ & $\begin{array}{c}\text { Width, } \\
\mathrm{mm}\end{array}$ & $\begin{array}{c}\text { Thickness, } \\
\text { mm }\end{array}$ & $\begin{array}{c}\text { Top } \\
\text { Hole } \\
\text { ID, } \\
\mathrm{mm} \\
\end{array}$ & $\begin{array}{c}\text { Bottom } \\
\text { Hole } \\
\text { ID, } \\
\mathrm{mm} \\
\end{array}$ & $\begin{array}{l}\text { Area, } \\
\mathrm{dm} 2\end{array}$ & $\begin{array}{c}\text { Initial } \\
\text { Wt., } \\
\mathbf{g}\end{array}$ & $\begin{array}{c}\text { Final } \\
\text { Wt., } \\
\text { g }\end{array}$ & $\begin{array}{c}\text { Corrosion } \\
\text { Rate, } \\
\text { mpy }\end{array}$ & $\begin{array}{c}\text { Corrosion } \\
\text { Rate, } \\
\mu \mathrm{m} / \mathrm{yr}\end{array}$ & $\begin{array}{c}\text { Welght } \\
\text { Loss, } \\
\text { g }\end{array}$ \\
\hline $1-219$ & $99.99 \% A \mathrm{~A}$ & 190.53 & 63.68 & 1.232 & 7.97 & 7.97 & 2.475 & 39.2955 & & & & \\
\hline $1-220$ & $99.99 \% \mathrm{Al}$ & 190.51 & 63.74 & 1.251 & 7.96 & 8.00 & 2.479 & 39.8627 & & & & \\
\hline $1-221$ & $99.99 \% \mathrm{Al}$ & 190.37 & 63.70 & 1.241 & 7.99 & 8.00 & 2.475 & 39.8281 & & & & \\
\hline $1-222$ & $99.99 \% \mathrm{Al}$ & 190.52 & 63.67 & 1.272 & 8.00 & 7.97 & 2.477 & 40.8210 & & & & \\
\hline $1-223$ & $99.99 \% \mathrm{Al}$ & 190.40 & 63.69 & 1.274 & 7.97 & 7.96 & 2.477 & 40.7374 & & & & \\
\hline $1-224$ & $99.99 \% \mathrm{Al}$ & 190.45 & 63.71 & 1.235 & 7.97 & 7.96 & 2.476 & 39.3969 & & & & \\
\hline $6-219$ & Alloy 6061 & 190.28 & 63.22 & 1.503 & 7.92 & 7.92 & 2.470 & 48.1716 & & & & \\
\hline $6-220$ & Alloy 6061 & 190.31 & 63.31 & 1.506 & 7.88 & 7.90 & 2.474 & 48.0853 & & & & \\
\hline $6-221$ & Alloy 6061 & 190.33 & 63.26 & 1.515 & 7.93 & 7.90 & 2.473 & 48.4904 & & & & \\
\hline $6-222$ & Alloy 6061 & 190.34 & 63.28 & 1.513 & 7.92 & 7.93 & 2.473 & 48.2187 & & & & \\
\hline $6-223$ & Alloy 6061 & 190.38 & 63.29 & 1.516 & 7.92 & 7.88 & 2.475 & 48.3425 & & & & \\
\hline $6-224$ & Alloy 6061 & 190.33 & 63.28 & 1.513 & 7.93 & 7.91 & 2.473 & 48.3521 & & & & \\
\hline $4 B-1$ & - Low-C Steel, Lot J & 189.96 & 63.45 & 0.682 & 8.72 & 8.70 & 2.425 & 61.6307 & 59.7896 & 0.34 & 8.6 & 1.8411 \\
\hline $4 B-2$ & Low-C Steel, Lot J & 190.50 & 63.55 & 0.686 & 8.75 & 8.76 & 2.436 & 62.8733 & 60.9499 & 0.35 & 9.0 & 1.9234 \\
\hline $4 B-3$ & Low-C Steel, Lot J & 190.10 & 63.50 & 0.689 & 8.75 & 8.71 & 2.429 & 62.3124 & 60.5707 & 0.32 & 8.2 & 1.7417 \\
\hline $4 B-4$ & Low-C Steel, Lot J & 190.03 & 63.31 & 0.692 & 8.77 & 8.77 & 2.421 & 63.9032 & 62.6224 & 0.24 & 6.0 & 1.2808 \\
\hline
\end{tabular}


TABLE B-11-5

Specimen Data. Test No. $5 B$

Test Type: Immersion, with Fe contamination of the brine

Test Environment: Simulated WIPP Brine A, CO2 overpressure (10 atm)

Test Temperature: $30 \pm 5^{\circ} \mathrm{C}$

Test Exposure: 13 months

\begin{tabular}{|c|c|c|c|c|c|c|}
\hline Specimen & Material Type & $\begin{array}{c}\text { Outer } \\
\text { Dlameter, } \\
\mathrm{mm}\end{array}$ & $\begin{array}{c}\text { Hole } \\
\mathrm{ID}, \mathrm{mm} \\
\end{array}$ & $\begin{array}{c}\text { Thickness, } \\
\mathrm{mm}\end{array}$ & $\begin{array}{l}\text { Area, } \\
\text { dm2 }\end{array}$ & $\begin{array}{c}\text { Initial } \\
\text { Wt., } \\
\mathrm{g}\end{array}$ \\
\hline $1-025$ & $99.99 \% \mathrm{Al}$ & 38.31 & 7.86 & 0.995 & 0.235 & 2.8934 \\
\hline $1-026$ & $99.99 \% \mathrm{Al}$ & 38.24 & 7.88 & 1.126 & 0.236 & 3.3768 \\
\hline $1-027$ & $99.99 \% \mathrm{Al}$ & 38.09 & 7.92 & 1.127 & 0.234 & 3.3093 \\
\hline $1-028$ & $99.99 \% \mathrm{Al}$ & 38.08 & 7.92 & 0.977 & 0.232 & 2.8987 \\
\hline $1-029$ & $99.99 \% \mathrm{Al}$ & 38.00 & 7.79 & 1.022 & 0.232 & 3.0253 \\
\hline $1-030$ & $99.99 \% \mathrm{Al}$ & 38.24 & 7.89 & 1.151 & 0.236 & 3.4041 \\
\hline 6-225D & Alloy 6061 & 38.38 & 7.99 & 1.323 & 0.241 & 4.1123 \\
\hline 6-226D & Alloy 6061 & 38.37 & 7.86 & 1.391 & 0.242 & 4.1639 \\
\hline 6-227D & Alloy 6061 & 38.41 & 8.00 & 1.291 & 0.240 & 4.0832 \\
\hline 6-228D & Alloy 6061 & 38.33 & 7.96 & 1.350 & 0.240 & 4.0677 \\
\hline 6-229D & Alloy 6061 & 38.32 & 8.03 & 1.347 & 0.240 & 4.0675 \\
\hline $6-230 D$ & Alloy 6061 & 38.30 & 8.02 & 1.365 & 0.240 & 4.0687 \\
\hline
\end{tabular}

W

\begin{tabular}{|c|c|c|c|c|c|c|c|c|c|c|c|c|}
\hline Specimen & Material Type & $\begin{array}{c}\text { Length, } \\
\mathrm{mm}\end{array}$ & $\begin{array}{c}\text { Width, } \\
\mathrm{mm}\end{array}$ & $\begin{array}{c}\text { Thickness, } \\
\text { mm }\end{array}$ & $\begin{array}{c}\text { Top } \\
\text { Hole } \\
\text { ID, } \\
\text { mm }\end{array}$ & $\begin{array}{c}\text { Boittom } \\
\text { Hole } \\
\text { ID, } \\
\text { mm }\end{array}$ & $\begin{array}{l}\text { Area, } \\
\text { dm2 }\end{array}$ & $\begin{array}{c}\text { Initial } \\
\text { Wt., } \\
g\end{array}$ & $\begin{array}{c}\text { Final } \\
\text { Wt., } \\
\mathbf{g}\end{array}$ & $\begin{array}{c}\text { Corrosion } \\
\text { Rate, } \\
\text { mpy }\end{array}$ & $\begin{array}{c}\text { Corrosion } \\
\text { Rate, } \\
\mu \mathrm{m} / \mathrm{yr}\end{array}$ & $\begin{array}{c}\text { Weight } \\
\text { Loss, } \\
g\end{array}$ \\
\hline $1-225$ & $99.99 \% \mathrm{Al}$ & 190.34 & 63.62 & 1.278 & 7.95 & 7.96 & 2.473 & 40.7449 & & & & \\
\hline $1-226$ & $99.99 \% \mathrm{Al}$ & 190.47 & 63.68 & 1.253 & 7.95 & 7.95 & 2.476 & 39.9847 & & & & \\
\hline $1-227$ & $99.99 \% \mathrm{Al}$ & 190.47 & 63.53 & 1.247 & 7.98 & 8.00 & 2.470 & 39.5457 & & & & \\
\hline $1-228$ & $99.99 \% \mathrm{Al}$ & 190.28 & 63.16 & 1.240 & 7.96 & 7.96 & 2.453 & 39.4258 & & & & \\
\hline $1-229$ & $99.99 \% \mathrm{Al}$ & 190.57 & 63.66 & 1.260 & 7.95 & 7.95 & 2.477 & 40.4703 & & & & \\
\hline $1-230$ & $99.99 \% \mathrm{Al}$ & 190.60 & 63.59 & 1.265 & 7.96 & 7.97 & 2.475 & 40.3240 & & & & \\
\hline $6-225$ & Alloy 6061 & 190.17 & 63.28 & 1.500 & .7 .96 & 7.95 & 2.470 & 47.8202 & & & & \\
\hline $6-226$ & Alloy 6061 & 190.30 & 63.27 & 1.516 & 7.90 & 7.92 & 2.473 & 48.1935 & & & & \\
\hline $6-227$ & Alloy 6061 & 190.28 & 63.26 & .1 .514 & 7.90 & 7.91 & 2.472 & 48.2704 & & & & \\
\hline $6-228$ & Alloy 6061 & 190.34 & 63.35 & 1.509 & 7.91 & 7.92 & 2.476 & 48.3091 & & & & \\
\hline $6-229$ & Alloy 6061 & 190.27 & 63.36 & 1.512 & 7.94 & 7.92 & 2.476 & 48.2524 & & & & \\
\hline $6-230$ & Alloy 6061 & 190.26 & 63.32 & 1.516 & 7.92 & 7.91 & 2.474 & 48.2136 & & & & \\
\hline $5 \mathrm{~B}-1$ & Low-C Steel, Lot J & 190.31 & 64.49 & 0.691 & 8.75 & 8.68 & 2.470 & 65.3742 & 62.0017 & 0.61 & 16 & 3.3725 \\
\hline $58-2$ & Low-C Steol, Lot J & 190.25 & 63.91 & 0.678 & 8.73 & 8.75 & 2.446 & 63.2545 & 60.3776 & 0.53 & 13 & 2.8769 \\
\hline $5 B-3$ & Low-C Steel, Lot J & 190.25 & 63.67 & 0.688 & 8.78 & 8.74 & 2.437 & 63.7629 & 60.9643 & 0.51 & 13 & 2.7986 \\
\hline $5 B-4$ & Low-C Steel, Lot J & 190.30 & 64.32 & 0.686 & 8.77 & 8.78 & 2.463 & 64.1755 & 60.7919 & 0.62 & 16 & 3.3836 \\
\hline
\end{tabular}


TABLE B-11-6

Test Type: Immersion, with Fe contamination of the brine

Test Environment: Simulated WIPP Brine A, H2S overpressure (5 atm)

Test Temperature: $30 \pm 5^{\circ} \mathrm{C}$

Test Exposure: 13 months

\begin{tabular}{|c|c|c|c|c|c|c|c|c|c|c|c|c|}
\hline Specimen & Material Type & $\begin{array}{c}\text { Outer } \\
\text { Diameter, } \\
\mathrm{mm}\end{array}$ & $\begin{array}{l}\text { Hole } \\
\text { ID, } \\
\text { mm }\end{array}$ & $\begin{array}{c}\text { Thickness, } \\
\mathrm{mm}\end{array}$ & $\begin{array}{l}\text { Area, } \\
\text { dm2 }\end{array}$ & $\begin{array}{c}\text { Initial } \\
\text { Wt., } \\
\mathbf{g}\end{array}$ & & & & & & - \\
\hline $1-031$ & $99.99 \% \mathrm{Al}$ & 38.20 & 8.02 & 1.020 & 0.234 & 3.0490 & & & & & . & \\
\hline $1-032$ & $99.99 \% \mathrm{Al}$ & 38.16 & 7.82 & 1.035 & 0.234 & 3.0484 & & & & & & \\
\hline $1-033$ & $99.99 \% \mathrm{Al}$ & 38.05 & 8.12 & 1.037 & 0.232 & 3.0889 & & & & & & \\
\hline $1-034$ & $99.99 \% \mathrm{Al}$ & 38.27 & 7.96 & 1.004 & 0.235 & 3.0109 & & & & & & \\
\hline $1-035$ & $99.99 \% \mathrm{Al}$ & 37.97 & 7.80 & 0.972 & 0.231 & 2.8789 & & & & & & \\
\hline $1-036$ & $99.99 \% \mathrm{Al}$ & 38.25 & 7.80 & 1.113 & 0.236 & 3.2670 & & & & & & \\
\hline 6-231D & Alloy 6061 & 38.35 & 8.08 & 1.391 & 0.241 & 4.1300 & & & & & & \\
\hline 6-232D & Alloy 6061 & 38.34 & 8.03 & 1.356 & 0.240 & 4.0701 & & & & & & \\
\hline 6-233D & Alloy 6061 & 38.35 & 8.01 & 1.377 & 0.241 & 4.1072 & & & & & & \\
\hline $6-2340$ & Alloy 6061 & 38.33 & 8.08 & 1.323 & 0.240 & 4.0466 & & & & & & \\
\hline $6-235 D$ & Alloy 6061 & 38.33 & 7.99 & 1.383 & 0.241 & 4.1263 & & & & & & \\
\hline $6-236 D$ & Alloy 6061 & 38.34 & 8.04 & 1.342 & 0.240 & 4.0745 & & & & & & \\
\hline Specimen & Material Type & $\begin{array}{c}\text { Length, } \\
\mathrm{mm}\end{array}$ & $\begin{array}{c}\text { Width, } \\
\mathrm{mm}\end{array}$ & $\begin{array}{c}\text { Thickness, } \\
\mathrm{mm}\end{array}$ & $\begin{array}{c}\text { Top } \\
\text { Hole } \\
\text { ID, } \\
\text { mm } \\
\end{array}$ & $\begin{array}{c}\text { Bottom } \\
\text { Hole } \\
\text { ID, } \\
\text { mm } \\
\end{array}$ & $\begin{array}{l}\text { Area, } \\
\mathrm{dm2}\end{array}$ & $\begin{array}{c}\text { Initial Wt., } \\
\mathbf{g} \\
\end{array}$ & $\begin{array}{c}\text { Final Wt., } \\
\mathbf{g}\end{array}$ & $\begin{array}{c}\text { Corrosion } \\
\text { Rate, } \\
\text { mpy }\end{array}$ & $\begin{array}{c}\text { Corrosion } \\
\text { Rate, } \\
\mu \mathrm{m} / \mathrm{yr}\end{array}$ & $\begin{array}{c}\text { Weight } \\
\text { Loss, } \\
\mathbf{g}\end{array}$ \\
\hline $1-231$ & $99.99 \% A \mathrm{Al}$ & 190.68 & 63.69 & 1.250 & 7.94 & 7.97 & 2.479 & 40.4210 & & & & \\
\hline $1-232$ & 99.99\%Al & 190.77 & 63.86 & 1.236 & 8.04 & 7.97 & 2.486 & 39.5340 & & & & \\
\hline $1-233$ & $99.99 \% \mathrm{Al}$ & 190.62 & 63.62 & 1.245 & 7.96 & 8.00 & 2.475 & 39.9841 & & & & \\
\hline $1-234$ & $99.99 \% \mathrm{Al}$ & 190.31 & 63.26 & 1.229 & 8.00 & 7.96 & 2.456 & 38.9747 & & & & \\
\hline $1-235$ & $99.99 \% \mathrm{Al}$ & 190.41 & 63.69 & 1.266 & 7.95 & 7.98 & 2.476 & 40.1710 & & & & \\
\hline $1-236$ & $99.99 \% \mathrm{Al}$ & 191.16 & 63.70 & 1.262 & 7.98 & 7.96 & 2.486 & 40.4370 & & & & \\
\hline $6-231$ & Alloy 6061 & 190.30 & 63.30 & 1.490 & 7.90 & 7.97 & 2.472 & 47.7713 & & & & \\
\hline $6-232$ & Alloy 6061 & 190.28 & 63.30 & 1.500 & 7.92 & 7.93 & 2.473 & 47.8912 & & & & \\
\hline $6-233$ & Alloy 6061 & 190.30 & 63.34 & 1.505 & 7.92 & 7.89 & 2.475 & 48.1043 & & & & \\
\hline $6-234$ & Alloy 6061 & 190.30 & 63.17 & 1.490 & 7.92 & 7.94 & 2.467 & 47.7506 & & & & \\
\hline $6-235$ & Alloy 6061 & 190.29 & 63.24 & 1.496 & 7.93 & 7.92 & 2.470 & 47.8839 & & & & \\
\hline $6-236$ & Alloy 6061 & 190.30 & 63.27 & 1.495 & 7.93 & 7.94 & 2.472 & 47.9197 & & & & \\
\hline $6 B-1$ & Low-C Ste日l, Lot J & 190.15 & 64.50 & 0.700 & 8.71 & 8.78 & 2.468 & 64.0074 & 63.8926 & 0.024 & 0.60 & 0.1148 \\
\hline $6 B \cdot 2$ & Low-C Steel, Lot J & 190.67 & 64.18 & 0.691 & 8.76 & 8.75 & 2.462 & 65.0774 & 64.9670 & 0.023 & 0.58 & 0.1104 \\
\hline $6 B-3$ & Low-C Steel, Lot J & 190.20 & 62.95 & 0.685 & 8.77 & 8.76 & 2.409 & 62.8579 & 62.6805 & 0.037 & 0.95 & 0.1774 \\
\hline $6 B-4$ & Low-C Steel, Lot J & 190.25 & 64.10 & 0.689 & 8.78 & 8.75 & 2.454 & 64.8808 & 64.7475 & 0.028 & 0.70 & 0.1333 \\
\hline
\end{tabular}


TABLE B-11-7

Test Type: Vapor phase exposure

Specimen Data. Test No. 7B

Test Environment: Simulated WIPP Brine A vapor + N2 (10 atm)

Test Temperature: $30 \pm 5^{\circ} \mathrm{C}$

Test Exposure: 13 months

Outer

Diameter, Hole ID, Thickness, Area, Initial Wt.,

\begin{tabular}{|c|c|c|c|c|c|c|c|c|}
\hline Specimen & Material Type & $\mathrm{mm}$ & $\mathrm{mm}$ & $\mathrm{mm}$ & $\mathrm{dm} 2$ & $\mathrm{~g}$ & & \\
\hline $1-037$ & $99.99 \% \mathrm{Al}$ & 38.17 & 7.91 & 1.062 & 0.234 & 3.1588 & & \\
\hline $1-038$ & $99.99 \% \mathrm{Al}$ & 37.78 & 7.91 & 1.053 & 0.229 & 3.0558 & & \\
\hline $1-039$ & $99.99 \% \mathrm{Al}$ & 38.20 & 7.82 & 1.055 & 0.235 & 3.1982 & & \\
\hline $1-040$ & $99.99 \% \mathrm{Al}$ & 38.27 & 8.03 & 1.095 & 0.236 & 3.2357 & & \\
\hline $1-041$ & $99.99 \% \mathrm{Al}$ & 38.20 & 7.93 & 1.096 & 0.235 & 3.2256 & & \\
\hline $1-042$ & $99.99 \% \mathrm{Al}$ & 38.04 & 8.03 & 1.159 & 0.234 & 3.3837 & & \\
\hline 6-237D & Alloy 6061 & 38.36 & 8.07 & 1.352 & 0.241 & 4.1158 & & \\
\hline 6-238D & Alloy 6061 & 38.33 & 8.02 & 1.376 & 0.241 & 4.1346 & & \\
\hline $6-239 D$ & Alloy 6061 & 38.34 & 8.04 & 1.350 & 0.240 & 4.1669 & & \\
\hline 6-240D & Alloy 6061 & 38.36 & 8.00 & 1.351 & 0.241 & 4.1230 & & \\
\hline 6-241D & Alloy 6061 & 38.31 & 8.04 & 1.386 & 0.240 & 4.1540 & & \\
\hline 6-242D & Alloy 6061 & 38.39 & 8.02 & 1.304 & 0.240 & 4.0083 & & \\
\hline Specimen & Material Type & $\begin{array}{c}\text { Length, } \\
\mathrm{mm}\end{array}$ & $\begin{array}{c}\text { Width, } \\
\mathrm{mm}\end{array}$ & $\begin{array}{c}\text { Thickness, } \\
\mathrm{mm}\end{array}$ & $\begin{array}{c}\text { Top } \\
\text { Hole } \\
\text { ID, } \\
\mathrm{mm} \\
\end{array}$ & $\begin{array}{c}\text { Bottom } \\
\text { Hole } \\
\text { ID, } \\
\mathrm{mm} \\
\end{array}$ & $\begin{array}{l}\text { Area, } \\
\text { dm2 }\end{array}$ & $\begin{array}{c}\text { Initial Wt., } \\
\mathrm{g}\end{array}$ \\
\hline $1-237$ & $99.99 \% \mathrm{Al}$ & 190.51 & 63.41 & 1.260 & 7.97 & 8.00 & 2.466 & 39.9411 \\
\hline $1-238$ & $99.99 \% \mathrm{Al}$ & 190.33 & 63.61 & 1.247 & 7.97 & 7.97 & 2.471 & 39.9761 \\
\hline $1-239$ & $99.99 \% \mathrm{Al}$ & 190.49 & 63.84 & 1.261 & 8.02 & 7.99 & 2.483 & 40.6702 \\
\hline $1-240$ & $99.99 \% \mathrm{Al}$ & 190.45 & 63.69 & 1.265 & 7.99 & 7.97 & 2.477 & 40.2138 \\
\hline $1-241$ & $99.99 \% \mathrm{Al}$ & 190.47 & 63.60 & 1.257 & 7.95 & 7.96 & 2.473 & 40.2200 \\
\hline $1-242$ & $99.99 \% \mathrm{Al}$ & 190.65 & 63.65 & 1.244 & 7.96 & 7.95 & 2.477 & 39.9268 \\
\hline $6-237$ & Alloy 6061 & 190.28 & 63.16 & 1.493 & 7.90 & 7.92 & 2.467 & 47.5386 \\
\hline $6-238$ & Alloy 6061 & 190.26 & 63.20 & 1.513 & 7.91 & 7.91 & 2.469 & 48.3812 \\
\hline $6-239$ & Alloy 6061 & 190.28 & 63.31 & 1.518 & 7.92 & 7.91 & 2.474 & 48.4311 \\
\hline $6-240$ & Alloy 6061 & 190.33 & 63.34 & 1.525 & 7.91 & 7.92 & 2.476 & 48.5384 \\
\hline $6-241$ & Alloy 6061 & 190.33 & 63.33 & 1.517 & 7.91 & 7.91 & 2.476 & 48.4810 \\
\hline $6-242$ & Alloy 6061 & 190.33 & 63.33 & 1.514 & 7.93 & 7.94 & 2.475 & 48.4727 \\
\hline
\end{tabular}


TABLE B-11-8

Specimen Data. Test No. 8B

Test Type: Vapor phase exposure

Test Environment: Simulated WIPP Brine A vapor $+\mathrm{CO} 2$ (10 atm)

Test Temperature: $30 \pm 5^{\circ} \mathrm{C}$

Test Exposure: 13 months

\begin{tabular}{|c|c|c|c|c|c|c|c|c|}
\hline Specimen & Material Type & $\begin{array}{c}\text { Outer } \\
\text { Diameter, } \\
\mathrm{mm} \\
\end{array}$ & $\begin{array}{c}\text { Hole ID, } \\
\mathrm{mm}\end{array}$ & $\begin{array}{c}\text { Thickness, } \\
\mathrm{mm}\end{array}$ & $\begin{array}{l}\text { Area, } \\
\text { dm2 }\end{array}$ & Initial Wt., & & \\
\hline $1-043$ & $99.99 \% \mathrm{Al}$ & 38.13 & 7.89 & 0.995 & 0.233 & 2.9669 & & \\
\hline $1-044$ & $99.99 \% \mathrm{Al}$ & 38.13 & 8.03 & 1.074 & 0.234 & 3.1067 & & \\
\hline $1-045$ & $99.99 \% \mathrm{Al}$ & 38.19 & 7.89 & 1.073 & 0.235 & 3.1943 & & \\
\hline $1-046$ & $99.99 \% \mathrm{Al}$ & 38.08 & 7.82 & 0.969 & 0.232 & 2.9388 & & \\
\hline $1-047$ & $99.99 \% \mathrm{Al}$ & 38.12 & 7.80 & 0.983 & 0.233 & 2.9314 & & \\
\hline $1-048$ & $99.99 \% \mathrm{Al}$ & 38.19 & 7.94 & 1.049 & 0.234 & 3.0870 & & \\
\hline $6-243 D$ & Alloy 6061 & 38.32 & 8.08 & 1.333 & 0.240 & 4.0680 & & \\
\hline $6-244 D$ & Alloy 6061 & 38.30 & 7.99 & 1.427 & 0.241 & 4.2350 & & \\
\hline $6-245 D$ & Alloy 6061 & 38.33 & 8.02 & 1.404 & 0.241 & 4.1664 & & \\
\hline $6-246 D$ & Alloy 6061 & 38.35 & 8.08 & 1.351 & 0.240 & 4.1326 & & \\
\hline 6-247D & Alloy 6061 & 38.34 & 8.03 & 1.299 & 0.240 & 4.0354 & & \\
\hline $6-248 D$ & Alloy 6061 & 38.34 & 8.06 & 1.399 & 0.241 & 4.2238 & & \\
\hline Specimen & Material Type & $\begin{array}{c}\text { Length, } \\
\mathrm{mm}\end{array}$ & $\begin{array}{c}\text { Width, } \\
\mathrm{mm}\end{array}$ & $\begin{array}{c}\text { Thickness, } \\
\mathrm{mm}\end{array}$ & $\begin{array}{c}\text { Top Hole ID, } \\
\mathrm{mm}\end{array}$ & $\begin{array}{c}\text { Bottom Hole ID, } \\
\mathrm{mm}\end{array}$ & $\begin{array}{l}\text { Area, } \\
\mathrm{dm} 2\end{array}$ & $\begin{array}{c}\text { Initial Wt., } \\
\mathrm{g}\end{array}$ \\
\hline $1-243$ & $99.99 \% \mathrm{Al}$ & 190.49 & 63.61 & 1.254 & 7.96 & 7.96 & 2.474 & 40.0667 \\
\hline $1-244$ & $99.99 \% \mathrm{Al}$ & 190.51 & 63.66 & 1.238 & 7.98 & 7.97 & 2.475 & 39.7234 \\
\hline $1-245$ & $99.99 \% \mathrm{Al}$ & 190.52 & 63.22 & 1.243 & 7.97 & 7.95 & 2.458 & 39.6685 \\
\hline $1-246$ & $99.99 \% \mathrm{Al}$ & 191.16 & 63.85 & 1.236 & 7.99 & 8.00 & 2.490 & 40.1407 \\
\hline $1-247$ & $99.99 \% \mathrm{Al}$ & 190.52 & 63.69 & 1.259 & 7.95 & 7.94 & 2.477 & 40.1177 \\
\hline $1-248$ & $99.99 \% \mathrm{Al}$ & 190.13 & 63.67 & 1.250 & 7.95 & 7.95 & 2.471 & 39.7866 \\
\hline $6-243$ & Alloy 6061 & 190.23 & 63.28 & 1.507 & 7.93 & 7.92 & 2.472 & 48.4863 \\
\hline $6-244$ & Alloy 6061 & 190.18 & 63.34 & 1.516 & 7.91 & 7.92 & 2.474 & 48.2613 \\
\hline $6-245$ & Alloy 6061 & 190.29 & 63.28 & 1.527 & 7.94 & 7.94 & 2.474 & 48.4501 \\
\hline $6-246$ & Alloy 6061 & 190.28 & 63.27 & 1.522 & 7.93 & 7.93 & 2.473 & 48.3887 \\
\hline $6-247$ & Alloy 6061 & 190.28 & 63.20 & 1.512 & 7.93 & 7.93 & 2.470 & 47.9519 \\
\hline $6-248$ & Alloy 6061 & 190.24 & 63.22 & 1.504 & 7.94 & 7.92 & 2.469 & 48.0471 \\
\hline
\end{tabular}


TABLE B-11-9

Test Type: Vapor phase exposure

Specimen Data. Test No. 9B

Test Environment: Simulated WIPP Brine A vapor + H2S (5 atm)

Test Temperature: $30 \pm 5^{\circ} \mathrm{C}$

Test Exposure: 13 months

Outer

Diameter, Hole ID, Thickness, Area, Initial Wt.,

\begin{tabular}{|c|c|c|c|c|c|c|}
\hline Specimen & Material Type & $\mathrm{mm}$ & $\mathrm{mm}$ & $\mathrm{mm}$ & $\mathrm{dm} 2$ & $\dot{g}$ \\
\hline $1-049$ & $99.99 \% \mathrm{Al}$ & 38.20 & 7.83 & 1.014 & 0.234 & 3.0713 \\
\hline $1-050$ & $99.99 \%$ Al & 38.16 & 8.00 & 1.135 & 0.235 & 3.3136 \\
\hline $1-051$ & $99.99 \% \mathrm{Al}$ & 38.10 & 8.01 & 1.115 & 0.234 & 3.2823 \\
\hline $1-052$ & $99.99 \% \mathrm{Al}$ & 38.13 & 7.92 & 1.088 & 0.234 & 3.1793 \\
\hline $1-053$ & $99.99 \% \mathrm{Al}$ & 38.20 & 7.97 & 1.110 & 0.235 & 3.2571 \\
\hline $1-054$ & $99.99 \% \mathrm{Al}$ & 37.95 & 7.82 & 0.961 & 0.230 & 2.7499 \\
\hline 6-249D & Alloy 6061 & 38.33 & 8.07 & 1.412 & 0.241 & 4.2321 \\
\hline 6-250D & Alloy 6061 & 38.32 & 8.00 & 1.362 & 0.240 & 4.0930 \\
\hline 6-251D & Alloy 6061 & 38.31 & 8.05 & 1.325 & 0.240 & 4.0482 \\
\hline 6-252D & Alloy 6061 & 38.30 & 8.01 & 1.381 & 0.240 & 4.1415 \\
\hline 6-253D & Alloy 6061 & 38.32 & 8.02 & 1.401 & 0.241 & 4.1314 \\
\hline $6-254 D$ & Alloy 6061 & 38.33 & 8.03 & 1.375 & 0.241 & 4.1322 \\
\hline
\end{tabular}

Top Bottom Hole

\begin{tabular}{|c|c|c|c|c|c|c|c|c|}
\hline Specimen & Material Type & $\begin{array}{c}\text { Lengin, } \\
\mathrm{mm}\end{array}$ & $\begin{array}{c}\text { Widn, } \\
\mathrm{mm}\end{array}$ & $\begin{array}{c}\text { Inickness, } \\
\mathrm{mm}\end{array}$ & $\begin{array}{c}\text { Hole ID, } \\
\mathrm{mm}\end{array}$ & $\begin{array}{l}\mathrm{ID}, \\
\mathrm{mm}\end{array}$ & $\begin{array}{l}\text { Area, } \\
\text { dm2 }\end{array}$ & $\begin{array}{c}\text { Initial Wt., } \\
\mathrm{g}\end{array}$ \\
\hline $1-249$ & $99.99 \% \mathrm{Al}$ & 190.65 & 63.59 & 1.252 & 7.93 & 7.95 & 2.475 & 40.0539 \\
\hline $1-250$ & $99.99 \% \mathrm{Al}$ & 190.53 & 63.66 & 1.243 & 7.95 & 7.95 & 2.475 & 39.9383 \\
\hline $1-251$ & $99.99 \% \mathrm{Al}$ & 190.37 & 63.67 & 1.254 & 7.94 & 7.98 & 2.474 & 40.0093 \\
\hline $1-252$ & $99.99 \% \mathrm{Al}$ & 190.66 & 63.31 & 1.243 & 8.00 & 7.97 & 2.463 & 39.8360 \\
\hline $1-253$ & $99.99 \% \mathrm{Al}$ & 190.50 & 63.41 & 1.225 & 7.99 & 7.97 & 2.464 & 39.2710 \\
\hline $1-254$ & $99.99 \% \mathrm{Al}$ & 190.33 & 63.57 & 1.241 & 7.95 & 7.99 & 2.469 & 39.7999 \\
\hline $6-249$ & Alloy 6061 & 190.29 & 63.29 & 1.506 & 7.92 & 7.89 & 2.473 & 48.0900 \\
\hline $6-250$ & Alloy 6061 & 190.37 & 63.26 & 1.519 & 7.93 & 7.95 & 2.473 & 48.3939 \\
\hline $6-251$ & Alloy 6061 & 190.31 & 63.13 & 1.514 & 7.94 & 7.91 & 2.467 & 48.2575 \\
\hline $6-252$ & Alloy 6061 & 190.38 & 63.37 & 1.521 & 7.95 & 7.93 & 2.478 & 48.4967 \\
\hline $6-253$ & Alloy 6061 & 190.32 & 63.38 & 1.521 & 7.93 & 7.93 & 2.478 & 48.5862 \\
\hline $6-254$ & Alloy 6061 & 190.36 & 63.27 & 1.523 & 7.93 & 7.91 & 2.474 & 48.3707 \\
\hline
\end{tabular}


TABLE B-11-10

Test Type: Immersion

Specimen Data. Test No. 10B

Test Environment: Simulated WIPP Brine A, N2 overpressure (10 atm)

Test Temperature: $30 \pm 5^{\circ} \mathrm{C}$

Test Exposure: 24 months

Outer Hole Initial

Material Diameter, ID, Thickness, Area, Wt.,

\begin{tabular}{|c|c|c|c|c|c|c|c|c|}
\hline Specimen & Type & $\mathrm{mm}$ & $\mathrm{mm}$ & $\mathrm{mm}$ & $\mathrm{dm} 2$ & $\mathrm{~g}$ & & \\
\hline $1-055$ & $99.99 \% \mathrm{Al}$ & 37.95 & 7.92 & 1.059 & $\overline{0.232}$ & 3.1231 & & \\
\hline $1-056$ & $99.99 \% \mathrm{Al}$ & 38.13 & 7.93 & 1.088 & 0.234 & 3.2160 & & \\
\hline $1-057$ & $99.99 \% \mathrm{Al}$ & 37.99 & 7.92 & 1.113 & 0.233 & 3.2130 & & \\
\hline $1-058$ & $99.99 \% \mathrm{Al}$ & 38.01 & 7.90 & 0.953 & 0.231 & 2.8195 & & \\
\hline $1-059$ & $99.99 \% \mathrm{Al}$ & 38.08 & 7.82 & 1.050 & 0.233 & 3.1782 & & \\
\hline $1-060$ & $99.99 \% \mathrm{Al}$ & 37.91 & 7.89 & 0.936 & 0.229 & 2,6772 & & \\
\hline 6-255D & Alloy 6061 & 38.30 & 8.05 & 1.362 & 0.240 & 4.1548 & & \\
\hline $6-256 D$ & Alloy 6061 & 38.35 & 8.01 & 1.440 & 0.242 & 4.2704 & & \\
\hline 6-257D & Alloy 6061 & 38.32 & 7.93 & 1.451 & 0.242 & 4.3278 & & \\
\hline $6-258 D$ & Alloy 6061 & 38.34 & 8.05 & 1.399 & 0.241 & 4.2003 & & \\
\hline 6-259D & Alloy 6061 & 38.32 & 8.05 & 1.427 & 0.241 & 4.2761 & & \\
\hline $6-260 D$ & Alloy 6061 & 38.32 & 7.86 & 1.400 & 0.241 & 4.1992 & & \\
\hline Specimen & $\begin{array}{c}\text { Material } \\
\text { Type }\end{array}$ & $\begin{array}{l}\text { Length, } \\
\mathrm{mm}\end{array}$ & $\begin{array}{c}\text { Width, } \\
\mathrm{mm}\end{array}$ & $\begin{array}{c}\text { Thickness, } \\
\mathrm{mm}\end{array}$ & $\begin{array}{l}\text { Top } \\
\text { Hole } \\
\text { ID, } \\
\mathrm{mm} \\
\end{array}$ & $\begin{array}{c}\text { Bottom } \\
\text { Hole } \\
\text { ID, } \\
\mathrm{mm} \\
\end{array}$ & $\begin{array}{l}\text { Area, } \\
\text { dm2 }\end{array}$ & $\begin{array}{l}\text { Initial } \\
\text { Wt., } \\
\text { g }\end{array}$ \\
\hline $1-255$ & $99.99 \% A 1$ & 190.59 & $\overline{63.74}$ & 1.256 & 7.97 & 7.97 & 2.480 & 40.2687 \\
\hline $1-256$ & $99.99 \% \mathrm{Al}$ & 190.36 & 63.35 & 1.251 & 7.99 & 7.98 & 2.462 & 39.6495 \\
\hline $1-257$ & $99.99 \% \mathrm{Al}$ & 190.63 & 63.87 & 1.248 & 7.97 & 8.00 & 2.485 & 39.9391 \\
\hline $1-258$ & $99.99 \% \mathrm{Al}$ & 189.90 & 63.49 & 1.262 & 7.99 & 7.97 & 2.462 & 40.0350 \\
\hline $1-259$ & $99.99 \% \mathrm{Al}$ & 190.70 & 63.64 & 1.236 & 7.96 & 7.97 & 2.476 & 39.3253 \\
\hline $1-260$ & $99.99 \% \mathrm{Al}$ & 191.20 & 63.66 & 1.242 & 7.98 & 7.96 & 2.484 & 40.0699 \\
\hline $6-255$ & Alloy 6061 & 190.27 & 63.22 & 1.517 & 7.93 & 7.95 & 2.470 & 48.3906 \\
\hline $6-256$ & Alloy 6061 & 190.33 & 63.33 & 1.513 & 7.93 & 7.94 & 2.475 & 48.1070 \\
\hline $6-257$ & Alloy 6061 & 190.36 & 63.32 & 1.509 & 7.94 & 7.93 & 2.475 & 48.3393 \\
\hline $6-258$ & Alloy 6061 & 190.30 & 63.24 & 1.511. & 7.94 & 7.92 & 2.471 & 48.3041 \\
\hline $6-259$ & Alloy 6061 & 190.30 & 63.25 & 1.498 & 7.95 & 7.92 & 2.471 & 47.7606 \\
\hline $6-260$ & Alloy 6061 & 190.30 & 63.30 & 1.512 & 7.93 & 7.95 & 2.474 & 48.0220 \\
\hline
\end{tabular}


TABLE B-11-11

Specimen Data. Test No. 11B

Test Type: Immersion

Test Environment: Simulated WIPP Brine A, CO2 overpressure (10 atm)

Test Temperature: $30 \pm 5^{\circ} \mathrm{C}$

Test Exposure: 24 months

\begin{tabular}{|c|c|c|c|c|c|c|c|c|}
\hline Specimen & $\begin{array}{c}\text { Material } \\
\text { Type }\end{array}$ & $\begin{array}{c}\text { Outer } \\
\text { Diameter, } \\
\mathrm{mm} \\
\end{array}$ & $\begin{array}{l}\text { Hole } \\
\text { ID, } \\
\mathrm{mm}\end{array}$ & $\begin{array}{c}\text { Thickness, } \\
\text { mm }\end{array}$ & $\begin{array}{l}\text { Area, } \\
\mathrm{dm} 2\end{array}$ & $\begin{array}{c}\text { Initial } \\
\text { Wt., } \\
\mathrm{g}\end{array}$ & & \\
\hline $1-061$ & $99.99 \% \mathrm{Al}$ & 37.96 & 7.86 & 0.926 & 0.230 & 2.7521 & & \\
\hline $1-062$ & $99.99 \% \mathrm{Al}$ & 38.00 & 7.90 & 1.156 & 0.234 & 3.3804 & & \\
\hline $1-063$ & $99.99 \% \mathrm{Al}$ & 38.11 & 7.86 & 0.990 & 0.233 & 2.9357 & & \\
\hline $1-064$ & $99.99 \% \mathrm{Al}$ & 38.04 & 7.93 & 0.985 & 0.232 & 3.0418 & & \\
\hline $1-065$ & $99.99 \% \mathrm{Al}$ & 38.01 & 7.90 & 1.106 & 0.233 & 3.3011 & & \\
\hline $1-066$ & $99.99 \% \mathrm{Al}$ & 38.12 & 8.05 & 0.934 & 0.232 & 2.7630 & & \\
\hline 6-261D & Alloy 6061 & 38.31 & 7.89 & 1.445 & 0.242 & 4.3040 & & \\
\hline $6-262 D$ & Alloy 6061 & 38.37 & 7.98 & 1.473 & 0.243 & 4.3897 & & \\
\hline 6-263D & Alloy 6061 & 38.31 & 8.03 & 1.448 & 0.241 & 4.3126 & & \\
\hline $6-264 D$ & Alloy 6061 & 38.29 & 7.92 & 1.455 & 0.241 & 4.3392 & & \\
\hline $6-265 D$ & Alloy 6061 & 38.33 & 8.06 & 1.421 & 0.241 & 4.2544 & & \\
\hline $6-266 \mathrm{D}$ & Alloy 6061 & 38.33 & 8.01 & 1.454 & 0.242 & 4.3592 & & \\
\hline Specimen & $\begin{array}{c}\text { Material } \\
\text { Type }\end{array}$ & $\begin{array}{l}\text { Length, } \\
\text { mm }\end{array}$ & $\begin{array}{c}\text { Width, } \\
\mathrm{mm}\end{array}$ & $\begin{array}{c}\text { Thickness, } \\
\mathrm{mm}\end{array}$ & $\begin{array}{c}\text { Top } \\
\text { Hole } \\
\text { ID, } \\
\mathrm{mm}\end{array}$ & $\begin{array}{c}\text { Bottom } \\
\text { Hole } \\
\text { ID, } \\
\mathrm{mm} \\
\end{array}$ & $\begin{array}{l}\text { Area, } \\
\mathrm{dm} 2\end{array}$ & $\begin{array}{c}\text { Initial } \\
\text { Wt., } \\
\text { g }\end{array}$ \\
\hline $1-261$ & 99.99\%Al & 190.63 & 63.80 & 1.259 & 7.98 & 8.00 & 2.483 & 40.4237 \\
\hline $1-262$ & $99.99 \% \mathrm{Al}$ & 190.93 & 63.68 & 1.254 & 7.96 & 7.96 & 2.482 & 40.2165 \\
\hline $1-263$ & $99.99 \% \mathrm{Al}$ & 191.33 & 63.66 & 1.259 & 7.97 & 7.95 & 2.487 & 40.5759 \\
\hline $1-264$ & $99.99 \% \mathrm{Al}$ & 190.49 & 63.29 & 1.218 & 7.98 & 7.98 & 2.459 & 38.8940 \\
\hline $1-265$ & $99.99 \% \mathrm{Al}$ & 190.20 & 63.60 & 1.259 & 7.97 & 7.98 & 2.470 & 40.2051 \\
\hline $1-266$ & $99.99 \% \mathrm{Al}$ & 190.28 & 63.65 & 1.265 & 8.00 & 7.96 & 2.473 & 40.2797 \\
\hline $6-261$ & Alloy 6061 & 190.26 & 63.27 & 1.508 & 7.94 & 7.94 & 2.472 & 48.0363 \\
\hline $6-262$ & Alloy 6061 & 190.20 & 63.27 & 1.504 & 7.92 & 7.94 & 2.471 & 47.7762 \\
\hline $6-263$ & Alloy 6061 & 190.26 & 63.31 & 1.508 & 7.97 & 7.96 & 2.473 & 48.3746 \\
\hline $6-264$ & Alloy 6061 & 190.34 & 63.37 & 1.518 & 7.92 & 7.92 & 2.477 & 48.5035 \\
\hline $6-265$ & Alloy 6061 & 190.31 & 63.29 & 1.517 & 7.92 & 7.95 & 2.474 & 48.4314 \\
\hline $6-266$ & Alloy 6061 & 190.33 & 63.35 & 1.526 & 7.94 & 7.94 & 2.477 & 48.5505 \\
\hline
\end{tabular}


TABLE B-11-12

Test Type: Immersion

\section{Specimen Data. Test No. 12B}

Test Environment: Simulated WIPP Brine A, H2S overpressure (5 atm)

Test Temperature: $30 \pm 5^{\circ} \mathrm{C}$

Test Exposure: 24 months

\begin{tabular}{|c|c|c|c|c|c|c|c|c|}
\hline Specimen & $\begin{array}{c}\text { Material } \\
\text { Type }\end{array}$ & $\begin{array}{c}\text { Outer } \\
\text { Diameter, } \\
\mathrm{mm} \\
\end{array}$ & $\begin{array}{l}\text { Hole } \\
\mathrm{ID}, \\
\mathrm{mm}\end{array}$ & $\begin{array}{c}\text { Thickness, } \\
\mathrm{mm}\end{array}$ & $\begin{array}{l}\text { Area, } \\
\text { dm2 }\end{array}$ & $\begin{array}{c}\text { Initial } \\
\text { Wt., } \\
\mathrm{g}\end{array}$ & & \\
\hline $1-067$ & $99.99 \% \mathrm{Al}$ & 38.05 & 8.12 & 1.108 & 0.233 & 3.2292 & & \\
\hline $1-068$ & $99.99 \% \mathrm{Al}$ & 37.99 & 8.09 & 0.922 & 0.230 & 2.7408 & & \\
\hline $1-069$ & $99.99 \% \mathrm{Al}$ & 38.02 & 7.87 & 1.031 & 0.232 & 3.0993 & & \\
\hline $1-070$ & $99.99 \% \mathrm{Al}$ & 38.06 & 7.86 & 0.968 & 0.232 & 2.8577 & & \\
\hline $1-071$ & $99.99 \% \mathrm{Al}$ & 38.17 & 7.89 & 1.029 & 0.234 & 3.0132 & & \\
\hline $1-072$ & $99.99 \% \mathrm{Al}$ & 38.03 & 7.96 & 1.058 & 0.232 & 3.2115 & & \\
\hline 6-267D & Alloy 6061 & 38.37 & 8.06 & 1.486 & 0.243 & 4.3851 & & \\
\hline 6-268D & Alloy 6061 & 38.33 & 7.98 & 1.473 & 0.242 & 4.2856 & & \\
\hline 6-269D & Alloy 6061 & 38.42 & 8.05 & 1.441 & 0.243 & 4.2453 & & \\
\hline 6-270D & Alloy 6061 & 38.33 & 8.03 & 1.430 & 0.241 & 4.2399 & & \\
\hline 6-271D & Alloy 6061 & 38.31 . & 8.02 & 1.426 & 0.241 & 4.2791 & & \\
\hline 6-272D & Alloy 6061 & $38.28^{\circ}$ & 7.82 & 1.418 & 0.241 & 4.2376 & & \\
\hline Specimen & $\begin{array}{c}\text { Material } \\
\text { Type }\end{array}$ & $\begin{array}{c}\text { Length, } \\
\mathrm{mm}\end{array}$ & $\begin{array}{c}\text { Width, } \\
\mathrm{mm}\end{array}$ & $\begin{array}{c}\text { Thickness, } \\
\mathrm{mm}\end{array}$ & $\begin{array}{c}\text { Top } \\
\text { Hole } \\
\text { ID, } \\
\mathrm{mm}\end{array}$ & $\begin{array}{c}\text { Bottom } \\
\text { Hole } \\
\text { ID, } \\
\mathrm{mm} \\
\end{array}$ & $\begin{array}{l}\text { Area, } \\
\text { dm2 }\end{array}$ & $\begin{array}{c}\text { Initial } \\
\text { Wt., } \\
\mathrm{g} \\
\end{array}$ \\
\hline $1-267$ & $99.99 \% \mathrm{Al}$ & 190.11 & 63.61 & 1.275 & 7.98 & 8.02 & 2.470 & 40.3981 \\
\hline $1-268$ & $99.99 \% \mathrm{Al}$ & 190.24 & 63.72 & 1.265 & 7.98 & 7.97 & 2.475 & 40.4642 \\
\hline $1-269$ & $99.99 \% \mathrm{Al}$ & 190.14 & 63.66 & 1.261 & 7.95 & 7.98 & 2.471 & 40.0830 \\
\hline $1-270$ & $99.99 \% \mathrm{Al}$ & 190.28 & 63.70 & 1.251 & 7.96 & 7.99 & 2.474 & 39.7859 \\
\hline $1-271$ & $99.99 \% \mathrm{Al}$ & 190.36 & 63.41 & 1.245 & 7.96 & 7.99 & 2.464 & 39.1949 \\
\hline $1-272$ & $99.99 \% \mathrm{Al}$ & 190.44 & 63.72 & 1.257 & 7.99 & 7.99 & 2.477 & 40.1987 \\
\hline $6-267$ & Alloy 6061 & 190.29 & 63.21 & 1.516 & 7.93 & 7.94 & 2.470 & 48.4382 \\
\hline $6-268$ & Alloy 6061 & 190.32 & 63.30 & 1.521 & 7.95 & 7.93 & 2.474 & 48.5040 \\
\hline $6-269$ & Alloy 6061 & 190.32 & 62.90 & 1.525 & 7.96 & 7.94 & 2.459 & 48.1297 \\
\hline $6-270$ & Alloy 6061 & 190.36 & 63.15 & 1.518 & 8.01 & 8.01 & 2.469 & 48.3763 \\
\hline $6-271$ & Alloy 6061 & 190.33 & 63.21 & 1.512 & 7.93 & 7.92 & 2.471 & 48.2867 \\
\hline $6-272$ & Alloy 6061 & 190.38 & 63.21 & 1.511 & 7.95 & 7.92 & 2.471 & 48.3925 \\
\hline
\end{tabular}


TABLE B-11-13

Test Type: Immersion, with Fe contamination of the brine

Specimen Data. Test No. 13B

Test Environment: Simulated WIPP Brine A, N2 overpressure (10 atm)

Test Temperature: $30 \pm 5^{\circ} \mathrm{C}$

Test Exposure: 24 months

Outer Hole Initial

Diameter, ID, Thickness, Area, Wt.,

\begin{tabular}{|c|c|c|c|c|c|c|}
\hline Specimen & Material Type & $\mathrm{mm}$ & $\mathrm{mm}$ & $\mathrm{mm}$ & $\mathrm{dm} 2$ & $g$ \\
\hline $1-073$ & $99.99 \% \mathrm{Al}$ & 38.14 & 7.91 & 1.027 & 0.233 & 2.9968 \\
\hline $1-074$ & $99.99 \% \mathrm{Al}$ & 38.24 & 7.93 & 1.144 & 0.236 & 3.3341 \\
\hline $1-075$ & $99.99 \% \mathrm{Al}$ & 38.13 & 7.79 & 1.123 & 0.235 & 3.3039 \\
\hline $1-076$ & $99.99 \% \mathrm{Al}$ & 37.83 & 7.94 & 1.075 & 0.230 & 3.0902 \\
\hline $1-077$ & $99.99 \% \mathrm{Al}$ & 38.03 & 7.94 & 1.152 & 0.234 & 3.3466 \\
\hline $1-078$ & $99.99 \% \mathrm{Al}$ & 38.07 & 7.93 & 1.164 & 0.234 & 3.3750 \\
\hline 6-273D & Alloy 6061 & 38.34 & 7.98 & 1.442 & 0.242 & 4.2879 \\
\hline 6-274D & Alloy 6061 & 38.37 & 7.94 & 1.427 & 0.242 & 4.2554 \\
\hline 6-275D & Alloy 6061 & 38.32 & 7.99 & 1.490 & 0.242 & 4.3831 \\
\hline $6-276 D$ & Alloy 6061 & 38.34 & 7.97 & 1.482 & 0.242 & 4.3500 \\
\hline 6-277D & Alloy 6061 & 38.31 & 8.03 & 1.481 & 0.242 & 4.3421 \\
\hline \multirow[t]{2}{*}{ 6-278D } & Alloy 6061 & 38.37 & 8.05 & 1.428 & 0.242 & 4.2855 \\
\hline & & & & & $\begin{array}{l}\text { Top } \\
\text { Hole }\end{array}$ & $\begin{array}{c}\text { Bottom } \\
\text { Hole }\end{array}$ \\
\hline
\end{tabular}

\begin{tabular}{|c|c|c|c|c|c|c|c|c|c|c|c|c|}
\hline Specimen & Material Type & $\begin{array}{c}\text { Length, } \\
\mathrm{mm}\end{array}$ & $\begin{array}{l}\text { Width } \\
, \mathrm{mm} \\
\end{array}$ & $\begin{array}{c}\text { Thickness, } \\
\mathrm{mm}\end{array}$ & $\begin{array}{l}\text { ID, } \\
\mathrm{mm}\end{array}$ & $\begin{array}{l}\text { ID, } \\
\mathrm{mm}\end{array}$ & $\begin{array}{l}\text { Area, } \\
\mathrm{dm} 2\end{array}$ & $\begin{array}{c}\text { Wt., } \\
\mathrm{g}\end{array}$ & $\begin{array}{c}\text { Wt., } \\
\text { g }\end{array}$ & $\begin{array}{l}\text { Rate, } \\
\text { mpy }\end{array}$ & $\begin{array}{l}\text { Rate, } \\
\mu \mathrm{m} / \mathrm{yr}\end{array}$ & $\begin{array}{c}\text { Loss, } \\
\mathrm{g}\end{array}$ \\
\hline $1-273$ & . $99.99 \% \mathrm{Al}$ & 190.66 & 63.69 & 1.247 & 7.98 & 7.99 & 2.478 & 39.9262 & & & & \\
\hline $1-274$ & 99.99\%Al & 190.01 & 63.67 & 1.262 & 7.97 & 7.96 & 2.470 & 40.0972 & & & & \\
\hline $1-275$ & $99.99 \% \mathrm{Al}$ & 190.25 & 63.30 & 1.232 & 7.98 & 7.98 & 2.457 & 39.1179 & & & & \\
\hline $1-277$ & $99.99 \% \mathrm{Al}$ & 190.47 & 63.29 & 1.225 & 7.98 & 7.99 & 2.459 & 38.8048 & & & & \\
\hline $1-278$ & $99.99 \% \mathrm{Al}$ & 190.36 & 63.61 & 1.273 & 7.95 & 7.98 & 2.473 & 40.7018 & & & & \\
\hline $6-273$ & Alloy 6061 & 190.31 & 63.17 & 1.514 & 7.95 & 7.95 & 2.469 & 48.5242 & & & & \\
\hline $6-276$ & Alloy 6061 & 190.37 & 63.28 & 1.514 & 7.94 & 7.96 & 2.474 & 48.1198 & & & & \\
\hline $6-277$ & Alloy 6061 & 190.36 & 63.19 & 1.517 & 7.94 & 7.96 & 2.470 & 48.1501 & & & & \\
\hline $6-278$ & Alloy 6061 & 190.30 & 63.32 & 1.508 & 7.95 & 7.90 & 2.474 & 48.1010 & & & & \\
\hline 13B-1 & Low-C Steel, Lot J & 190.31 & 63.92 & 0.703 & 8.76 & 8.76 & 2.448 & 64.7701 & 63.3106 & 0.14 & 3.7 & 1.4595 \\
\hline 13B-2 & Low-C Steel, Lot J & 190.58 & 64.54 & 0.692 & 8.76 & 8.72 & 2.475 & 65.4726 & 63.7635 & 0.17 & 4.3 & 1.7091 \\
\hline 13B-3 & Low-C Steel, Lot J & 190.19 & 63.78 & 0.688 & 8.72 & 8.77 & 2.441 & 63.3974 & 61.8764 & 0.15 & 3.8 & 1.5210 \\
\hline 13B-4 & Low-C Steel, Lot J & 190.09 & 63.06 & 0.671 & 8.79 & 8.76 & 2.411 & 60.8953 & 59.4184 & 0.15 & 3.8 & 1.4769 \\
\hline
\end{tabular}


TABLE B-11-14

Test Type: Immersion, with Fe contamination of the brine

Test Environment: Simulated WIPP Brine A, CO2 overpressure (10 atm)

Test Temperature: $30 \pm 5^{\circ} \mathrm{C}$

Test Exposure: 24 months

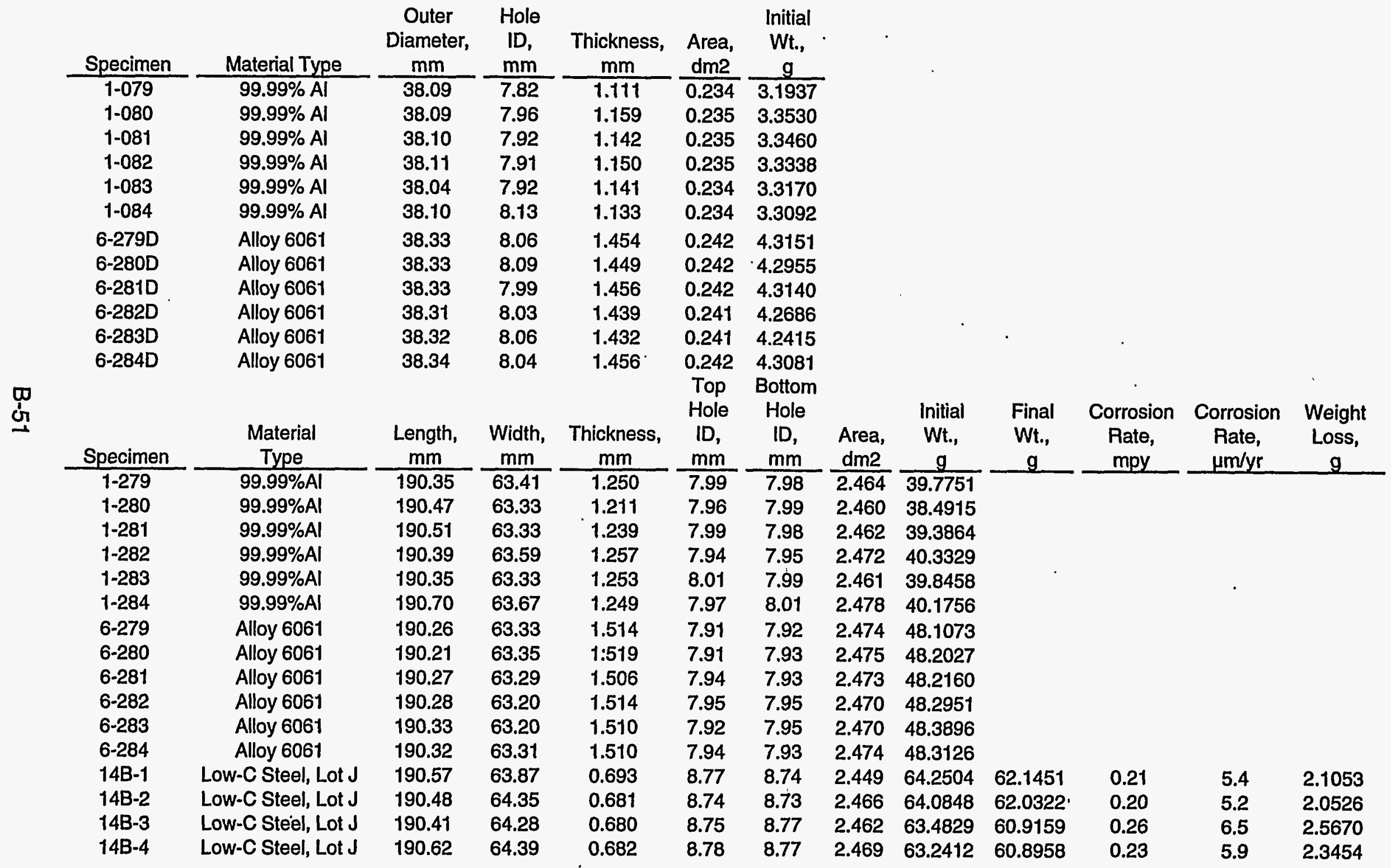


TABLE B-11-15

Specimen Data. Test No. 15B

Test Type: Immersion, with $\mathrm{Fe}$ contamination of the brine

Test Environment: Simulated WIPP Brine A, H2S overpressure (5 atm)

Test Temperature: $30 \pm 5^{\circ} \mathrm{C}$

Test Exposure: 24 months

\begin{tabular}{|c|c|c|c|c|c|c|c|c|c|c|c|}
\hline Specimen & Material Type & $\begin{array}{c}\text { Outer } \\
\text { Diameter, } \\
\mathrm{mm}\end{array}$ & $\begin{array}{l}\text { Hole } \\
\text { ID, mm }\end{array}$ & $\begin{array}{c}\text { Thickness, } \\
\text { mm }\end{array}$ & $\begin{array}{l}\text { Area, } \\
\text { dm2 }\end{array}$ & $\begin{array}{c}\text { Initial } \\
\text { Wt., } \\
\text { g }\end{array}$ & & & & & \\
\hline $1-085$ & $99.99 \% \mathrm{Al}$ & 38.03 & 7.96 & 1.166 & 0.234 & 3.3833 & & & & & \\
\hline $1-086$ & $99.99 \% \mathrm{Al}$ & 38.12 & 7.88 & 1.147 & 0.235 & 3.3368 & & & & & \\
\hline $1-087$ & $99.99 \% \mathrm{Al}$ & 38.06 & 7.94 & 1.163 & 0.234 & 3.3651 & & & & & \\
\hline 1.088 & $99.99 \% \mathrm{Al}$ & 38.08 & 8.01 & 1.149 & 0.234 & 3.3570 & & & & & \\
\hline $1-089$ & $99.99 \% \mathrm{Al}$ & 38.01 & 7.94 & 1.090 & 0.233 & 3.2488 & & & & & \\
\hline $1-090$ & $99.99 \% \mathrm{Al}$ & 37.84 & 7.89 & 1.121 & 0.231 & 3.2348 & & & & & \\
\hline $6-285 D$ & Alloy 6061 & 38.31 & 8.03 & 1.385 & 0.240 & 4.1871 & & & & & \\
\hline $6-286 D$ & Alloy 6061 & 38.40 & 8.01 & 1.441 & 0.242 & 4.3164 & & & & & \\
\hline $6-287 D$ & Alloy 6061 & $38.33^{\circ}$ & 7.96 & 1.451 & 0.242 & 4.3312 & & & & & \\
\hline $6-288 D$ & Alloy 6061 & 38.39 & 7.97 & 1.424 & 0.242 & 4.2332 & & & & & \\
\hline 6-289D & Alloy 6061 & 38.37 & 8.03 & 1.430 & 0.242 & 4.2799 & & & & & \\
\hline $6-290 \mathrm{D}$ & Alloy 6061 & 38.38 & 7.98 & 1.452 & 0.242 & 4.3071 & & & & & \\
\hline Specimen & $\begin{array}{c}\text { Material } \\
\text { Type }\end{array}$ & $\begin{array}{c}\text { Length, } \\
\mathrm{mm}\end{array}$ & $\begin{array}{c}\text { Width, } \\
\text { mm }\end{array}$ & $\begin{array}{c}\text { Thickness, } \\
\mathrm{mm}\end{array}$ & $\begin{array}{l}\text { Top } \\
\text { Hole } \\
\text { ID, } \\
\text { mm }\end{array}$ & $\begin{array}{c}\text { Bottom } \\
\text { Hole } \\
\text { ID, } \\
\text { mm }\end{array}$ & $\begin{array}{l}\text { Area, } \\
\text { dm2 }\end{array}$ & $\begin{array}{c}\text { Initial } \\
\text { Wt., } \\
\text { g }\end{array}$ & $\begin{array}{c}\text { Final } \\
\text { Wt., } \\
\mathbf{g}\end{array}$ & $\begin{array}{c}\text { Corrosion } \\
\text { Rate, } \\
\text { mpy }\end{array}$ & $\begin{array}{c}\text { Corrosion } \\
\text { Rate, } \\
\mu \mathrm{m} / \mathrm{yr}\end{array}$ \\
\hline $1-285$ & $99.99 \% \mathrm{Al}$ & 190.39 & 63.42 & 1.246 & 8.01 & 8.01 & 2.464 & 39.7158 & & & \\
\hline $1-286$ & $99.99 \% \mathrm{Al}$ & 190.40 & 63.89 & 1.264 & 7.99 & 8.01 & 2.483 & 40.5932 & . & & \\
\hline $1-287$ & $99.99 \% \mathrm{Al}$ & 190.52 & 63.64 & 1.259 & 7.98 & 8.00 & 2.475 & 40.2146 & & & \\
\hline $1-288$ & $99.99 \% \mathrm{Al}$ & 190.99 & 63.49 & 1.244 & 7.97 & 7.97 & 2.475 & 39.6913 & & & \\
\hline $1-289$ & $99.99 \% \mathrm{Al}$ & 190.63 & 63.60 & 1.264 & 7.98 & 7.98 & 2.475 & 40.1521 & & & \\
\hline $1-290$ & $99.99 \% \mathrm{Al}$ & 190.39 & 63.69 & 1.259 & 7.99 & 7.97 & 2.475 & 40.1533 & & & \\
\hline $6-285$ & Alloy 6061 & 190.25 & 63.30 & 1.517 & 7.94 & 7.94 & 2.473 & 48.5646 & . & & \\
\hline $6-286$ & Alloy 6061 & 190.27 & 63.29 & 1.512 & 7.94 & 7.94 & 2.473 & 48.4968 & & & \\
\hline $6-287$ & Alloy 6061 & 190.26 & 63.29 & 1.514 & 7.92 & 7.94 & 2.473 & 48.5970 & & & \\
\hline $6-288$ & Alloy 6061 & 190.35 & 63.27 & 1.529 & 7.94 & 7.94 & 2.474 & 48.7206 & & & \\
\hline $6-289$ & Alloy 6061 & 190.29 & 63.14 & 1.514 & 7.95 & 7.93 & 2.467 & 48.5583 & & & \\
\hline $6-290$ & Alloy 6061 & 190.33 & 63.34 & 1.517 & 7.92 & 7.91 & 2.476 & 48.6147 & & & \\
\hline $15 B-1$ & Low-C Ste日I, Lot J & 190.30 & 62.81 & 0.675 & 8.73 & 8.76 & 2.404 & 61.4087 & 61.2788 & 0.013 & 0.34 \\
\hline 15B-2 & Low-C Steol, Lot J & 190.21 & 64.28 & 0.703 & 8.75 & 8.76 & 2.461 & 65.2710 & 65.1139 & 0.016 & 0.40 \\
\hline $15 B-3$ & Low-C Steel, Lot J & 190.79 & 63.62 & 0.693 & 8.74 & 8.73 & 2.443 & 64.6320 & 64.4035 & 0.023 & 0.59 \\
\hline $15 B-4$ & Low-C Steel, Lot J & 190.78 & 64.23 & 0.700 & 8.77 & 8.77 & 2.466 & 65.4615 & 65.2620 & 0.020 & 0.51 \\
\hline
\end{tabular}


TABLE B-11-16

Specimen Data. Test No. 16B

Test Type: Vapor phase exposure

Test Environment: Simulated WIPP Brine A vapor + N2 (10 atm)

Test Temperature: $30 \pm 5^{\circ} \mathrm{C}$

Test Exposure: 24 months

\begin{tabular}{|c|c|c|c|c|c|c|c|c|}
\hline Specimen & $\begin{array}{c}\text { Material } \\
\text { Type }\end{array}$ & $\begin{array}{c}\text { Outer } \\
\text { Diameter, } \\
\mathrm{mm} \\
\end{array}$ & $\begin{array}{l}\text { Hole } \\
\text { ID, } \\
\mathrm{mm}\end{array}$ & $\begin{array}{c}\text { Thickness, } \\
\text { mm }\end{array}$ & $\begin{array}{l}\text { Area, } \\
\mathrm{dm} 2 \\
\end{array}$ & $\begin{array}{c}\text { Initial } \\
\text { Wt., } \\
\mathrm{g}\end{array}$ & & \\
\hline $1-091$ & $99.99 \% \mathrm{Al}$ & 38.01 & 7.89 & 1.111 & 0.233 & 3.2100 & & \\
\hline $1-092$ & $99.99 \% \mathrm{Al}$ & 38.08 & 7.87 & 1.155 & 0.235 & 3.3751 & & \\
\hline $1-093$ & $99.99 \% \mathrm{Al}$ & 38.04 & 7.94 & 1.199 & 0.235 & 3.4793 & & \\
\hline $1-094$ & $99.99 \% \mathrm{Al}$ & 37.94 & 7.88 & 1.112 & 0.232 & 3.2707 & & \\
\hline $1-095$ & $99.99 \% \mathrm{Al}$ & 38.10 & 7.92 & 1.134 & 0.234 & 3.2199 & & \\
\hline $1-096$ & $99.99 \% \mathrm{Al}$ & 38.04 & 7.99 & 1.138 & 0.234 & 3.2175 & & \\
\hline 6-291D & Alloy 6061 & 38.36 & 8.03 & 1.374 & 0.241 & 4.2311 & & \\
\hline 6-292D & Alloy 6061 & 38.34 & 8.03 & 1.388 & 0.241 & 4.2069 & & \\
\hline 6-293D & Alloy 6061 & 38.31 & 8.08 & 1.414 & 0.241 & 4.2396 & & \\
\hline 6-294D & Alloy 6061 & 38.31 & 8.05 & 1.401 & 0.241 & 4.2164 & & \\
\hline 6-295D & Alloy 6061 & 38.29 & 8.06 & 1.401 & 0.240 & 4.2490 & & \\
\hline $6-296 \mathrm{D}$ & Alloy 6061 & 38.33 & 8.05 & 1.401 & 0.241 & 4.2178 & & \\
\hline Specimen & $\begin{array}{c}\text { Material } \\
\text { Type }\end{array}$ & $\begin{array}{c}\text { Length, } \\
\mathrm{mm}\end{array}$ & $\begin{array}{c}\text { Width, } \\
\mathrm{mm}\end{array}$ & $\begin{array}{c}\text { Thickness, } \\
\mathrm{mm}\end{array}$ & $\begin{array}{c}\text { Top } \\
\text { Hole } \\
\text { ID, } \\
\mathrm{mm} \\
\end{array}$ & $\begin{array}{c}\text { Bottom } \\
\text { Hole } \\
\text { ID, } \\
\mathrm{mm} \\
\end{array}$ & $\begin{array}{l}\text { Area, } \\
\mathrm{dm} 2\end{array}$ & $\begin{array}{c}\text { Initial } \\
\text { Wt., } \\
\text { g }\end{array}$ \\
\hline $1-291$ & $99.99 \% \mathrm{Al}$ & 190.46 & 63.62 & 1.239 & 8.02 & 7.99 & 2.472 & 39.6809 \\
\hline $1-292$ & $99.99 \% A l$ & 190.39 & 63.64 & 1.249 & 7.99 & 8.00 & 2.473 & 39.8249 \\
\hline $1-293$ & $99.99 \% \mathrm{Al}$ & 190.39 & 63.70 & 1.239 & 7.99 & 8.01 & 2.475 & 39.5840 \\
\hline $1-294$ & $99.99 \% \mathrm{Al}$ & 190.32 & 63.88 & 1.278 & 8.01 & 8.00 & 2.483 & 40.8600 \\
\hline $1-295$ & $99.99 \% \mathrm{Al}$ & 190.40 & 63.76 & 1.269 & 7.99 & 8.01 & 2.479 & 40.4974 \\
\hline $1-296$ & $99.99 \% \mathrm{Al}$ & 190.69 & 63.74 & 1.274 & 7.98 & 7.99 & 2.482 & 40.8422 \\
\hline 6-291 & Alloy 6061 & 190.21 & 63.37 & 1.512 & 7.95 & 7.92 & 2.475 & 48.4372 \\
\hline $6-292$ & Alloy 6061 & 190.30 & 63.29 & 1.517 & 7.92 & 7.94 & 2.474 & 48.6265 \\
\hline $6-293$ & Alloy 6061 & 190.26 & 63.27 & 1.507 & 7.94 & 7.95 & 2.472 & 48.4339 \\
\hline $6-294$ & Alloy 6061 & 190.21 & 63.32 & 1.514 & 7.93 & 7.96 & 2.473 & 48.4364 \\
\hline $6-295$ & Alloy 6061 & 190.29 & 63.21 & 1.515 & 7.94 & 7.93 & 2.470 & 48.3972 \\
\hline $6-296$ & Alloy 6061 & 190.29 & 63.30 & 1.514 & 7.95 & 7.96 & 2.474 & 48.4300 \\
\hline
\end{tabular}


TABLE B-11-17

Test Type: Vapor phase exposure

Specimen Data. Test No. 17B

Test Environment: Simulated WIPP Brine A vapor + CO2 (10 atm)

Test Temperature: $30 \pm 5^{\circ} \mathrm{C}$

Test Exposure: 24 months

\begin{tabular}{|c|c|c|c|c|c|c|c|c|}
\hline Specimen & $\begin{array}{c}\text { Material } \\
\text { Type }\end{array}$ & $\begin{array}{c}\text { Outer } \\
\text { Diameter, } \\
\mathrm{mm}\end{array}$ & $\begin{array}{l}\text { Hole } \\
\text { ID, } \\
\mathrm{mm}\end{array}$ & $\begin{array}{c}\text { Thickness, } \\
\mathrm{mm}\end{array}$ & $\begin{array}{l}\text { Area, } \\
\text { dm2 }\end{array}$ & $\begin{array}{l}\text { Initial } \\
\text { Wt., } \\
\text { g }\end{array}$ & & \\
\hline $1-097$ & $99.99 \% \mathrm{Al}$ & 38.06 & 7.89 & 1.116 & 0.234 & 3.2190 & & \\
\hline $1-098$ & $99.99 \% \mathrm{Al}$ & 37.96 & 7.91 & 1.125 & 0.233 & 3.2084 & & \\
\hline $1-099$ & $99.99 \% \mathrm{Al}$ & 38.00 & 7.89 & 1.120 & 0.233 & 3.2788 & & \\
\hline $1-100$ & $99.99 \% \mathrm{Al}$ & 38.01 & 7.90 & 1.063 & 0.232 & 3.1006 & & \\
\hline $1-101$ & $99.99 \% \mathrm{Al}$ & 38.08 & 8.05 & 1.093 & 0.233 & 3.1910 & & \\
\hline $1-102$ & $99.99 \% \mathrm{Al}$ & 37.91 & 7.87 & 1.109 & 0.232 & 3.2231 & & \\
\hline 6-297D & Alloy 6061 & 38.31 & 8.04 & 1.447 & 0.241 & 4.3010 & & \\
\hline 6-298D & Alloy 6061 & 38.32 & 8.04 & 1.395 & 0.241 & 4.2450 & & \\
\hline 6-299D & Alloy 6061 & 38.33 & 8.04 & 1.396 & 0.241 & 4.2295 & & \\
\hline $6-300 D$ & Alloy 6061 & 38.33 & 8.09 & 1.475 & 0.242 & 4.4090 & & \\
\hline 6-301D & Alloy 6061 & 38.33 & 8.03 & 1.476 & 0.242 & 4.3789 & & \\
\hline 6-302D & Alloy 6061 & 38.27 & 8.04 & 1.448 & 0.241 & 4.2822 & & \\
\hline Specimen & $\begin{array}{c}\text { Material } \\
\text { Type }\end{array}$ & $\begin{array}{c}\text { Length, } \\
\mathrm{mm}\end{array}$ & $\begin{array}{c}\text { Width, } \\
\mathrm{mm}\end{array}$ & $\begin{array}{c}\text { Thickness, } \\
\mathrm{mm}\end{array}$ & $\begin{array}{l}\text { Top } \\
\text { Hole } \\
\text { ID, } \\
\mathrm{mm}\end{array}$ & $\begin{array}{c}\text { Bottom } \\
\text { Hole } \\
\text { ID, } \\
\mathrm{mm}\end{array}$ & Area, dm2 & $\begin{array}{c}\text { Initial } \\
\text { Wt., } \\
\text { g }\end{array}$ \\
\hline $1-297$ & $99.99 \% \mathrm{Al}$ & 190.75 & 63.71 & 1.279 & 8.00 & 8.00 & 2.482 & 40.8751 \\
\hline $1-298$ & $99.99 \% \mathrm{Al}$ & 190.50 & 63.79 & 1.277 & 7.99 & 7.99 & 2.482 & 40.7267 \\
\hline $1-299$ & $99.99 \% \mathrm{Al}$ & 190.71 & 63.78 & 1.275 & 7.99 & 7.98 & 2.484 & 40.9679 \\
\hline $1-300$ & $99.99 \% \mathrm{Al}$ & 190.40 & 63.76 & 1.285 & 8.01 & 8.00 & 2.480 & 41.1400 \\
\hline $1-301$ & $99.99 \% \mathrm{Al}$ & 190.31 & 63.65 & 1.250 & 8.01 & 8.00 & 2.472 & 40.1466 \\
\hline $1-302$ & $99.99 \% \mathrm{Al}$ & 190.75 & 63.75 & 1.268 & 8.00 & 7.99 & 2.483 & 40.8212 \\
\hline $6-297$ & Alloy 6061 & 190.32 & 63.29 & 1.517 & 7.94 & 7.95 & 2.474 & 48.4855 \\
\hline $6-298$ & Alloy 6061 & 190.31 & 63.21 & 1.509 & 7.94 & 7.97 & 2.470 & 48.4435 \\
\hline $6-299$ & Alloy 6061 & 190.18 & 63.27 & 1.509 & 7.96 & 7.96 & 2.471 & 48.4057 \\
\hline $6-300$ & Alloy 6061 & 190.26 & 63.29 & 1.525 & 7.95 & 7.96 & 2.473 & 48.6283 \\
\hline $6-301$ & Alloy 6061 & 190.28 & 63.25 & 1.518 & 7.95 & 7.96 & 2.472 & 48.6375 \\
\hline $6-302$ & Alloy 6061 & 190.30 & 63.28 & 1.517 & 7.94 & 7.96 & 2.473 & 48.6323 \\
\hline
\end{tabular}


TABLE B-11-18

Specimen Data. Test No. 18B

Test Type: Vapor phase exposure

Test Environment: Simulated WIPP Brine A vapor + H2S (5 atm)

Test Temperature: $30 \pm 5^{\circ} \mathrm{C}$

Test Exposure: 24 months

\begin{tabular}{|c|c|c|c|c|c|c|c|c|}
\hline Specimen & $\begin{array}{c}\text { Material } \\
\text { Type } \\
\end{array}$ & $\begin{array}{c}\text { Outer } \\
\text { Diameter, } \\
\mathrm{mm} \\
\end{array}$ & $\begin{array}{l}\text { Hole } \\
\text { ID, } \\
\mathrm{mm}\end{array}$ & $\begin{array}{c}\text { Thickness, } \\
\mathrm{mm}\end{array}$ & $\begin{array}{l}\text { Area, } \\
\text { dm2 }\end{array}$ & $\begin{array}{c}\text { Initial } \\
\text { Wt., } \\
\text { g } \\
\end{array}$ & & \\
\hline $1-103$ & $99.99 \% \mathrm{Al}$ & 38.00 & 7.87 & 1.132 & 0.233 & 3.3566 & & \\
\hline $1-104$ & $99.99 \% \mathrm{Al}$ & 38.07 & 7.79 & 1.165 & 0.235 & 3.4170 & & \\
\hline $1-105$ & $99.99 \% \mathrm{Al}$ & 38.02 & 7.74 & 1.104 & 0.233 & 3.2600 & & \\
\hline $1-106$ & $99.99 \% \mathrm{Al}$ & 38.08 & 7.93 & 1.191 & 0.235 & 3.4906 & & \\
\hline $1-107$ & $99.99 \% \mathrm{Al}$ & 37.88 & 7.91 & 1.157 & 0.232 & 3.3550 & & \\
\hline $1-108$ & $99.99 \% \mathrm{Al}$ & 37.93 & 7.79 & 1.155 & 0.233 & 3.3622 & & \\
\hline 6-303D & Alloy 6061 & 38.40 & 8.03 & 1.416 & 0.242 & 4.2395 & & \\
\hline 6-304D & Alloy 6061 & 38.31 & 8.00 & 1.424 & 0.241 & 4.2347 & & \\
\hline 6-305D & Alloy 6061 & 38.35 & 8.01 & 1.389 & 0.241 & 4.1738 & & \\
\hline 6-306D & Alloy 6061 & 38.40 & 8.02 & 1.373 & 0.241 & 4.1888 & & \\
\hline 6-307D & Alloy 6061 & 38.33 & 8.05 & 1.353 & 0.240 & 4.1920 & & \\
\hline 6-308D & Alloy 6061 & 38.34 & 8.04 & 1.439 & 0.242 & 4.3312 & & \\
\hline Specimen & $\begin{array}{c}\text { Material } \\
\text { Type }\end{array}$ & $\begin{array}{c}\text { Length, } \\
\mathrm{mm}\end{array}$ & $\begin{array}{c}\text { Width, } \\
\mathrm{mm}\end{array}$ & $\begin{array}{c}\text { Thickness, } \\
\mathrm{mm}\end{array}$ & $\begin{array}{l}\text { Top } \\
\text { Hole } \\
\text { ID, } \\
\mathrm{mm} \\
\end{array}$ & $\begin{array}{c}\text { Bottom } \\
\text { Hole } \\
\text { ID, } \\
\mathrm{mm} \\
\end{array}$ & $\begin{array}{l}\text { Area, } \\
\text { dm2 }\end{array}$ & $\begin{array}{c}\text { Initial } \\
\text { Wt., } \\
g\end{array}$ \\
\hline $1-303$ & $99.99 \% \mathrm{Al}$ & 190.56 & $\overline{63.78}$ & 1.262 & 7.97 & 7.99 & 2.481 & 40.4683 \\
\hline $1-304$ & $99.99 \% \mathrm{Al}$ & 190.48 & 63.80 & 1.265 & 7.99 & 7.99 & 2.481 & 40.3735 \\
\hline $1-305$ & $99.99 \% \mathrm{Al}$ & 190.76 & 63.55 & 1.245 & 7.99 & 8.01 & 2.474 & 39.6295 \\
\hline $1-306$ & $99.99 \% \mathrm{Al}$ & 190.26 & 63.76 & 1.253 & 8.01 & 8.00 & 2.476 & 40.0268 \\
\hline $1-307$ & $99.99 \% \mathrm{Al}$ & 190.52 & 63.86 & 1.264 & 8.00 & 7.99 & 2.484 & 40.3958 \\
\hline $1-308$ & $99.99 \% \mathrm{Al}$ & 190.56 & 63.83 & 1.265 & 7.99 & 7.99 & 2.483 & 40.5445 \\
\hline $6-303$ & Alloy 6061 & 190.34 & 63.35 & 1.522 & 7.95 & 7.92 & 2.477 & 48.6840 \\
\hline $6-304$ & Alloy 6061 & 190.32 & 63.36 & 1.517 & 7.94 & 7.93 & 2.476 & 48.6350 \\
\hline $6-305$ & Alloy 6061 & 190.30 & 63.32 & 1.503 & 7.96 & 7.98 & 2.474 & 48.1777 \\
\hline $6-306$ & Alloy 6061 & 190.12 & 63.05 & 1.502 & 7.96 & 7.99 & 2.461 & 47.9921 \\
\hline $6-307$ & Alloy 6061 & 190.27 & 63.28 & 1.497 & 7.95 & 7.95 & 2.472 & 48.0312 \\
\hline $6-308$ & Alloy 6061 & 190.27 & 63.26 & $1.5 i 1$ & 7.95 & 7.96 & 2.472 & 48.2507 \\
\hline
\end{tabular}


This page intentionally left blank. 
APPENDIX C: ESTIMATION OF $\mathrm{H}_{2}$ GENERATION RATES RESULTING FROM CORROSION OF AI-BASE MATERIALS IMMERSED IN BRINE A

C-1 


\section{APPENDIX C: ESTIMATION OF $\mathrm{H}_{2}$ GENERATION RATES RESULTING FROM CORROSION OF AI-BASE MATERIALS IMMERSED IN BRINE A}

\section{APPROACH}

The $\mathrm{H}_{2}$ generation rate per unit area of specimen exposed to the brine environment was estimated through a knowledge of the gas pressure within the plenum, the volume of the plenum, the temperature of the gas, the total specimen area, and application of the ideal gas law. The gas generation kinetics were assumed to be linear with time. The basic equation used is given below:

$$
\mathrm{n}=\frac{\mathrm{PV}}{2 \mathrm{RTA}} \mathrm{mol} \mathrm{H}_{2} \text { produced } / \mathrm{m}^{2} \mathrm{Al} \text {-base material-yr }
$$

where $\mathrm{P}=$ pressure increase in 24 months, due to $\mathrm{H}_{2}$ generation

$\mathrm{V}=$ volume of plenum $(0.634 \mathrm{~L})$

$\mathrm{R}=$ gas constant $(0.082 \mathrm{~atm}-\mathrm{L} / \mathrm{K}-\mathrm{mol})$

$\mathrm{T}=$ absolute temperature, $\mathrm{K}$

$\mathrm{A}=$ area of Al-base material specimens in test $\left(0.33 \mathrm{~m}^{2}\right)$

2 = factor to convert 24 -month data to 12 -month data

The determination of $\mathrm{P}$ is straightforward in the case of tests in which the overpressure gas is nonreactive and insoluble in the brine, i.e., tests with a $\mathrm{N}_{2}$ gas overpressure. In these tests "P" is simply the difference between the initial pressure and final pressures in the system, and venting of the system is readily accounted for by simply summing the aliquots vented.

In the case of overpressure gases that are potentially directly reactive with the metal specimens, or significantly soluble in the brine phase, the determination of $\mathrm{H}_{2}$ generation is not as straightforward, especially if venting of the container during test is required. If the overpressure gas reacts directly with the metal specimens, a pressure-differential approach to estimating $\mathrm{H}_{2}$ present becomes difficult, because the "background" pressure of overpressure gas is decreasing at an unknown rate, making it impossible to determine the $\mathrm{H}_{2}$ pressure accurately without frequent (system-perturbing) gas analysis.

Presence of a soluble (and unreactive) overpressure gas presents no difficulty in $\mathrm{H}_{2}$ estimation if the container is never vented, as any pressure increase over the starting pressure can be directly attributable to $\mathrm{H}_{2}$ from water decomposition. However, if the gas is soluble, a venting will release some of the gas from the plenum, leaving a disproportionate (nonequilibrium) amount dissolved in the brine. When the venting is concluded, gas will move from the brine into the plenum, causing a gas-phase pressure increase that will mimic $\mathrm{H}_{2}$ generation. For this reason, corrections have to be made to the overall $\Delta P$ in such test containers that take such emissions into account. It can be readily seen that a "no venting" situation leads to a straightforward $\mathrm{H}_{2}$ determination, because the total pressure increase can be ascribed to $\mathrm{H}_{2}$; and that a large number of ventings also eliminates the soluble-gas accountability problem, because (a) the original total overpressure gas pressure (the virtual pressure of the total original charge) can be subtracted from the final gas pressure (including summation of ventings), to obtain an accurate assessment 
of the $\mathrm{H}_{2}$ generated, and (b) a large number of ventings is associated with such large $\mathrm{H}_{2}$ generation rates that the original pressure of overpressure gas loses significance. A correction lying between the extremes described above is required in the case of an intermediate number (e.g., 1 to 10) of ventings.

Both $\mathrm{CO}_{2}$ and $\mathrm{H}_{2} \mathrm{~S}$ are soluble to some extent in the brine, so corrections must be made for ventedvessel $\mathrm{H}_{2}$ determinations, as outlined above. To correct for solubility effects, the following assumptions were made:

- The overpressure gas solubility is given by a Henry's law constant that is invariant with pressure, i.e., the fraction of the gas charge residing in the container plenum remains constant.

- In each venting operation, the pressure is reduced from $20 \mathrm{~atm}$ (300 psi) to $10 \mathrm{~atm}$ (150 psi).

- The ideal gas law holds throughout.

- The venting operation only removes a homogeneous aliquot of the plenum gas. No gas is removed from the brine phase during venting.

- The pressure in the plenum is directly proportional to the total amount of overpressure gas remaining in the system, and an equilibrium condition is arrived at shortly after each venting operation, i.e., a time period of a few hours.

- The Al-base material specimens do not react directly with the overpressure gas, but only with the water present in the brine phase.

- The plenum pressure is $10 \mathrm{~atm}$ prior to the initiation of the $\mathrm{H}_{2}$-generation reaction for brine $/ \mathrm{CO}_{2}$ tests, and $5 \mathrm{~atm}$ for the brine $/ \mathrm{H}_{2} \mathrm{~S}$ tests.

All of the foregoing assumptions are reasonable, and it is judged that errors introduced through the assumptions are relatively small compared with the errors that would result from not engaging in the gas-pressure correction procedure.

Only the 24-month tests are considered in the calculations of $\mathrm{H}_{2}$ generation, and, as Equation C-1 implies, the rates are considered linear over the course of the 24-month tests.

\section{RESULTS, BRINE/N 2 TESTS}

\section{Brine/ $\mathbf{N}_{2}$ Test 13B (Fe Present)}

From Equation C-1,

$$
n=0.0386 P
$$




$$
\begin{gathered}
\mathrm{P}=\frac{1245 \mathrm{psi}-135 \mathrm{psi}}{14.7 \mathrm{psi} / \mathrm{atm}}=75.5 \mathrm{~atm} \text { due to } \mathrm{H}_{2} \\
\mathrm{n}=\underline{2.9 \mathrm{~mol} \mathrm{H} / \mathrm{m}^{2} \text { Al-base material-yr }}
\end{gathered}
$$

\section{Brine/ $\mathbf{N}_{2}$ Test 10B (No Fe Present)}

$$
\begin{aligned}
& \mathrm{n}=0.0386 \mathrm{P} \\
& \mathrm{P}=\frac{171 \mathrm{psi}-144 \mathrm{psi}}{14.7 \mathrm{psi} / \mathrm{atm}}=2.52 \text { atm due to } \mathrm{H}_{2} \\
& \mathrm{n}=\underline{0.097 \mathrm{~mol} \mathrm{H} / \mathrm{m}^{2} \text { Al-base material-yr }}
\end{aligned}
$$

\section{RESULTS, BRINE/ $/ \mathrm{CO}_{2}$ TESTS}

\section{General Approach}

A determination must be made of the degree to which dissolved $\mathrm{CO}_{2}$ mimics $\mathrm{H}_{2}$ by repressurizing the container plenum after a venting has taken place. The original $\mathrm{CO}_{2}$ charge is $10.5 \mathrm{~L}$-atm at $30^{\circ} \mathrm{C}$. The effect of $\mathrm{CO}_{2}$ can be estimated in the following manner, assuming a temperature of $30^{\circ} \mathrm{C}$ throughout:

1st plenum inventory: All $\triangle \mathrm{P}$ is $\mathrm{H}_{2}$. Final $\mathrm{P}=20 \mathrm{~atm} ; 10 \mathrm{~atm} \mathrm{CO}_{2}$ and $10 \mathrm{~atm} \mathrm{H}_{2}$. After venting, $5 \mathrm{~atm} \mathrm{CO}_{2}$ and $5 \mathrm{~atm} \mathrm{H}_{2}$ remain. 1st venting eliminates $5 \mathrm{~atm} \mathrm{CO}_{2}$, or $5 \times 0.634=3.2 \mathrm{~L}$-atm. There is no effect of $\mathrm{CO}_{2}$ repressuration at this time.

2nd plenum inventory: $\begin{array}{r}\mathrm{CO}_{2} \text { can recharge to a pressure of }\left[10 \times \frac{10.5-3.2}{10.5}\right] \text { atm, or } 7.0 \mathrm{~atm} \text {. } \\ \qquad \mathrm{P} \text { due to } \mathrm{CO}_{2}=7.0 \mathrm{~atm}-5.0 \mathrm{~atm}, \text { or } 2.0 \mathrm{~atm} \text {. This is equivalent to } 29 \mathrm{psi},\end{array}$ which must be subtracted from total $\mathrm{P}$ in order to obtain $\mathrm{P}_{\mathrm{H}_{2}}$. 2nd venting eliminates

$$
\frac{7.0}{2} \times 0.634 \mathrm{~L}-\mathrm{atm} \mathrm{CO}_{2} \text {, or } 2.2 \mathrm{~L}-\mathrm{atm} \mathrm{CO}_{2} \text {. }
$$

3rd plenum inventory: $\mathrm{CO}_{2}$ can recharge to a pressure of $\left[10 \times \frac{10.5-3.2-2.2}{10.5}\right]$ atm, or $4.9 \mathrm{~atm} . \Delta \mathrm{P}$ due to $\mathrm{CO}_{2}=4.9 \mathrm{~atm}-3.5 \mathrm{~atm}=1.4 \mathrm{~atm}$, or $21 \mathrm{psi}$, which must

$$
\frac{4.9}{2} \times 0.634 \mathrm{~L}-\mathrm{atm} \mathrm{CO}_{2} \text {, or } 1.6 \mathrm{~L}-\mathrm{atm} \mathrm{CO}_{2} \text {. }
$$

Similar calculations were made for the 4th plenum inventory ( 13 psi due to $\left.\mathrm{CO}_{2}\right)$ and 5 th plenum inventory $\left(9 \mathrm{psi}\right.$ due to $\mathrm{CO}_{2}$ ). Additional inventories are arbitrarily assigned $5 \mathrm{psi} \mathrm{CO}_{2}$. However, 
regardless of the number of ventings, the virtual pressure of the initial charge in a $0.634 \mathrm{~L}$ plenum (244 psi) cannot be surpassed. ing steps:

In summary, the procedure used for correcting the container pressure for $\mathrm{CO}_{2}$ involves the follow-

1. Determine overall $\Delta \mathrm{P}$ in test. Initial (zero) pressure begins at the beginning of the test, when the pressure gauge reads $10 \mathrm{~atm}$, and ends at the final pressure reading. Pressure differentials due to ventings are summed.

2. For each venting, subtract the pressure of $\mathrm{CO}_{2}$ recharging the plenum masquerading as $\mathrm{H}_{2}$. These values were calculated in the foregoing computations.

3. Calculate the rate of $\mathrm{H}_{2}$ formation by means of Equation $\mathrm{C}-1$ and the corrected pressure.

Brine/ $\mathrm{CO}_{2}$ Test 14B (Fe Present)

$$
\Delta \mathrm{P}=\frac{1893 \mathrm{psi}-148 \mathrm{psi}}{14.7 \mathrm{psi} / \mathrm{atm}}=119 \mathrm{~atm} \text { in } 24 \text { months }
$$

Correction due to ventings (12 container ventings performed):

First five ventings $=(0 \mathrm{psi}+29 \mathrm{psi}+21 \mathrm{psi}+13 \mathrm{psi}+9 \mathrm{psi})=72 \mathrm{psi}$

Next seven ventings $=7 \times 5 \mathrm{psi}$

$$
=\frac{35 \mathrm{psi}}{107 \mathrm{psi}}
$$

[Check: initial charge $(150 \mathrm{psi})+107 \mathrm{psi}=257 \mathrm{psi}$. This exceeds virtual pressure of initial charge (244 psi). Therefore, a correction of $244-150$, or $94 \mathrm{psi}$, will be made to the pressure differential rather than the 107 psi calculated.]

$$
\text { corrected } \begin{aligned}
\Delta \mathrm{P} & =119 \mathrm{~atm}-\frac{94 \mathrm{psi}}{14.7 \frac{\mathrm{psi}}{\mathrm{atm}}} \\
\text { corrected } \Delta \mathrm{P} & =113 \mathrm{~atm} \\
\mathrm{n} & =0.0386 \mathrm{P} \\
\mathrm{n} & =4.4 \mathrm{~mol} \mathrm{\textrm {H } _ { 2 }} / \mathrm{m}^{2} \text { Al-base material-yr }
\end{aligned}
$$

\section{Brine $/ \mathrm{CO}_{2}$ Test $11 \mathrm{~B}$ (No Fe Present)}

$$
\Delta \mathrm{P}=\frac{516 \mathrm{psi}-143 \mathrm{psi}}{14.7 \frac{\mathrm{psi}}{\mathrm{atm}}}=25.4 \mathrm{~atm} \text { in } 24 \text { months }
$$


Correction due to ventings:

Two ventings: 0 psi $+29 \mathrm{psi}=29 \mathrm{psi}$

$$
\text { corrected } \begin{aligned}
\Delta \mathrm{P} & =25.4 \mathrm{~atm}-\frac{29 \mathrm{psi}}{14.7 \frac{\mathrm{psi}}{\mathrm{atm}}} \\
\text { corrected } \Delta \mathrm{P} & =23.4 \mathrm{~atm} \\
\mathrm{n} & =0.0386 \mathrm{P} \\
\mathrm{n} & =0.90 \mathrm{~mol} \mathrm{H}_{2} / \mathrm{m}^{2} \text { Al-base material-yr }
\end{aligned}
$$

\section{RESULTS, BRINE/ $\mathrm{H}_{2} \mathrm{~S}$ TESTS}

\section{General Approach}

The basic approach taken is the same as that previously presented for the $\mathrm{CO}_{2}$ /brine studies, except that the starting pressure of $\mathrm{H}_{2} \mathrm{~S}$ in the gas phase is $5 \mathrm{~atm}$, and the virtual pressure of the overall gas charge (11.2 L-atm) in the $0.634 \mathrm{~L}$ plenum is 260 psi at $30^{\circ} \mathrm{C}$.

1st plenum inventory: All $\Delta \mathrm{P}$ is $\mathrm{H}_{2}$. Final $\mathrm{P}=20 \mathrm{~atm} ; 5 \mathrm{~atm} \mathrm{H}_{2} \mathrm{~S}$ and $15 \mathrm{~atm} \mathrm{H}_{2}$. After venting, $2.5 \mathrm{~atm} \mathrm{H}_{2} \mathrm{~S}$ and $7.5 \mathrm{~atm} \mathrm{H}_{2}$ remain. 1st venting eliminates $2.5 \mathrm{~atm} \times 0.634 \mathrm{~L}=1.6 \mathrm{~L}$-atm of $\mathrm{H}_{2} \mathrm{~S}$. There is no impact of $\mathrm{H}_{2} \mathrm{~S}$ on $\mathrm{H}_{2}$ estimation at this point:

2nd plenum inventory: $\mathrm{H}_{2} \mathrm{~S}$ can recharge to a pressure of $\left[5 \times \frac{11.2-1.6}{11.2}\right]$ atm, or $4.3 \mathrm{~atm} . \Delta \mathrm{P}$ due to $\mathrm{H}_{2} \mathrm{~S}$ is $4.3 \mathrm{~atm}-2.5 \mathrm{~atm}=\mathrm{I} .8 \mathrm{~atm}$, or 26 psi due to $\mathrm{H}_{2} \mathrm{~S}$. 2nd venting eliminates $4.3 / 2 \times 0.634=1.4 \mathrm{~L}$-atm of $\mathrm{H}_{2} \mathrm{~S}$.

3rd plenum inventory: $\mathrm{H}_{2} \mathrm{~S}$ can recharge to a pressure of $\left[5 \times \frac{11.2-1.6-1.4}{11.2}\right]$ atm, or $3.7 \mathrm{~atm}$. $\Delta \mathrm{P}$ due to $\mathrm{H}_{2} \mathrm{~S}$ is $3.7 \mathrm{~atm}-2.2 \mathrm{~atm}=1.5 \mathrm{~atm}$, or 22 psi due to $\mathrm{H}_{2} \mathrm{~S}$. 3rd venting eliminates $3.7 / 2 \times 0.634=1.2 \mathrm{~L}$-atm of $\mathrm{H}_{2} \mathrm{~S}$.

Similar calculations were made for the 4th plenum inventory (19 psi due to $\mathrm{H}_{2} \mathrm{~S}$ ) and the 5 th plenum inventory ( 16 psi due to $\mathrm{H}_{2} \mathrm{~S}$ ). Succeeding inventories are arbitrarily assigned $10 \mathrm{psi}_{2} \mathrm{~S}$, until the virtual pressure of the initial charge $(260 \mathrm{psi})$ is attained.

\section{Brine/ $\mathrm{H}_{2} \mathrm{~S}$ Test 15B (Fe Present)}




$$
\Delta \mathrm{P}=\frac{1076 \mathrm{psi}-71 \mathrm{psi}}{14.7 \frac{\mathrm{psi}}{\mathrm{atm}}}=68.4 \mathrm{~atm}
$$

Corrections due to ventings ( 5 container ventings total):

$0 \mathrm{psi}+26 \mathrm{psi}+22 \mathrm{psi}+19 \mathrm{psi}+16 \mathrm{psi}=83 \mathrm{psi}$

$$
\text { corrected } \begin{aligned}
\Delta \mathrm{P} & =68.4 \mathrm{~atm}-\frac{83 \mathrm{psi}}{14.7 \frac{\mathrm{psi}}{\mathrm{atm}}} \\
\text { corrected } \Delta \mathrm{P} & =62.8 \mathrm{psi} \\
\mathrm{n} & =0.0386 \mathrm{P} \\
\mathrm{n} & =2.4 \mathrm{~mol} \mathrm{H}_{2} / \mathrm{m}^{2} \text { Al-base material-yr }
\end{aligned}
$$

\section{Brine/ $/ \mathrm{H}_{2} \mathrm{~S}$ Test 12B (No Fe Present)}

$$
\Delta \mathrm{P}=\frac{594 \mathrm{psi}-69 \mathrm{psi}}{14.7 \frac{\mathrm{psi}}{\mathrm{atm}}}=35.7 \mathrm{~atm}
$$

Corrections due to ventings ( 2 container ventings total):

$0 \mathrm{psi}+26 \mathrm{psi}=26 \mathrm{psi}$

$$
\text { corrected } \begin{aligned}
\Delta \mathrm{P} & =35.7 \mathrm{~atm}-\frac{26 \mathrm{psi}}{14.7 \frac{\mathrm{psi}}{\mathrm{atm}}} \\
\text { corrected } \Delta \mathrm{P} & =33.9 \mathrm{psi} \\
\mathrm{n} & =0.0386 \mathrm{P} \\
\mathrm{n} & =1.3 \mathrm{~mol} \mathrm{H} / \mathrm{m}^{2} \text { Al-base material-yr }
\end{aligned}
$$


This page intentionally left blank. 


\section{WIPP \\ UC721 - DISTRIBUTION LIST \\ SAND96-2538}

\section{Federal Agencies}

US Department of Energy (4)

Office of Civilian Radioactive Waste Mgmt.

Attn: Deputy Director, RW-2

Acting Director, RW-10

Office of Human Resources \& Admin.

Director, RW-30

Office of Program Mgmt. \& Integ.

Director, RW-40

Office of Waste Accept., Stor., \& Tran.

Forrestal Building

Washington, DC 20585

Attn: Project Director

Yucca Mountain Site Characterization Office Director, RW-3

Office of Quality Assurance

P. O. Box 98608

Las Vegas, NV 89193-8608

US Department of Energy

Albuquerque Operations Office

Attn: National Atomic Museum Library

P.O. Box 5400

Albuquerque, NM 87185-5400

US Department of Energy

Research \& Waste Management Division

Attn: Director

P.O. Box E

Oak Ridge, TN 37831

US Department of Energy (5)

Carlsbad Area Office

Attn: G. Dials

D. Galbraith

M. McFadden

R. Lark

J. A. Mewhinney

P.O. Box 3090

Carlsbad, NM 88221-3090

US Department of Energy

Office of Environmental Restoration and

Waste Management

Attn: J. Lytle, EM-30

Forrestal Building

Washington, DC 20585-0002
US Department of Energy (3)

Office of Environmental Restoration and Waste Management

Attn: M. Frei, EM-34, Trevion II.

Washington, DC 20585-0002

US Department of Energy

Office of Environmental Restoration and Waste Management

Attn: S. Schneider, EM-342, Trevion II Washington, DC 20585-0002

US Department of Energy (2)

Office of Environment, Safety \& Health

Attn: C. Borgstrom, EH-25

R. Pelletier, EH-231

Washington, DC 20585

US Department of Energy (2)

Idaho Operations Office

Fuel Processing \& Waste Mgmt. Division 785 DOE Place

Idaho Falls, ID 83402

US Environmental Protection Agency (2)

Radiation Protection Programs

Attn: M. Oge

ANR-460

Washington, DC 20460

\section{Boards}

Defense Nuclear Facilities Safety Board

Attn: D. Winters

625 Indiana Ave. NW, Suite 700

Washington, DC 20004

Nuclear Waste Technical Review Board (2)

Attn: Chairman

S. J. S. Parry

1100 Wilson Blvd., Suite 910

Arlington, VA 22209-2297 


\section{State Agencies}

Attorney General of New Mexico

P.O. Drawer 1508

Santa Fe, NM 87504-1508

Environmental Evaluation Group (3)

Attn: Library

7007 Wyoming NE

Suite F-2

Albuquerque, NM 87109

NM Energy, Minerals, and Natural

Resources Department

Attn: Library

2040 S. Pacheco

Santa Fe, NM 87505

NM Environment Department (3)

Secretary of the Environment

Attn: Mark Weidler

1190 St. Francis Drive

Santa Fe, NM 87503-0968

NM Bureau of Mines \& Mineral Resources

Socorro, NM 87801

NM Environment Department

WIPP Project Site

Attn: P. McCasland

P.O. Box 3090

Carlsbad, NM 88221

\section{Laboratories/Corporations}

Battelle Pacific Northwest Laboratories (2)

Attn: S. Pitman

M. Telander

Battelle Blvd.

Richland, WA 99352

INTERA, Inc.

Attn: G. A. Freeze

1650 University Blvd. NE, Suite 300

Albuquerque, NM 87102

INTERA, Inc.

Attn: J. F. Pickens

6850 Austin Center Blvd., Suite 300

Austin, TX 78731
Brookhaven National Laboratory (2)

Attn: A. J. Francis

J. B. Gillow

Dept. of Applied Sciences

Upton, NY 11973

INTERA, Inc.

Attn: W. Stensrud

P.O. Box 2123

Carlsbad, NM 88221

Los Alamos National Laboratory

Attn: B. Erdal, INC-12

P.O. Box 1663

Los Alamos, NM 87544

RE/SPEC, Inc

Attn: Angus Robb

4775 Indian School NE, Suite 300

Albuquerque, NM 87110-3927

RE/SPEC, Inc

Attn: J. L. Ratigan

P.O. Box 725

Rapid City, SD 57709

Tech Reps, Inc. (3)

Attn: J. Chapman (1)

Loretta Robledo (2)

5000 Marble NE, Suite 222

Albuquerque, NM 87110

Westinghouse Electric Corporation (5)

Attn: Library

J. Epstein

J. Lee

B. A. Howard

R. Kehrman

P.O. Box 2078

Carlsbad, NM 88221

S. Cohen \& Associates

Attn: Bill Thurber

1355 Beverly Road

McLean, VA 22101

\section{National Academy of Sciences,} WIPP Panel

Howard Adler

Oxyrase, Incorporated

7327 Oak Ridge Highway

Knoxville, TN 37931 
Bob Andrews

Board of Radioactive Waste Management GF456

2101 Constitution Ave.

Washington, DC 20418

Rodney C. Ewing

Department of Geology

University of New Mexico

Albuquerque, NM 87131

Charles Fairhurst

Department of Civil and Mineral Engineering

University of Minnesota

500 Pillsbury Dr. SE

Minneapolis, MN 55455-0220

B. John Garrick

PLG Incorporated

4590 MacArthur Blvd., Suite 400

Newport Beach, CA 92660-2027

Leonard F. Konikow

US Geological Survey

431 National Center

Reston, VA 22092

Carl A. Anderson, Director

Board of Radioactive Waste Management

National Research Council

HA 456

2101 Constitution Ave. NW

Washington, DC 20418

Christopher G. Whipple

ICF Kaiser Engineers

1800 Harrison St., 7th Floor

Oakland, CA 94612-3430

John O. Blomeke

720 Clubhouse Way

Knoxville, TN 37909

Sue B. Clark

University of Georgia

Savannah River Ecology Lab

P.O. Drawer E

Aiken, SC 29802

Konrad B. Krauskopf

Department of Geology

Stanford University

Stanford, CA 94305-2115
Della Roy

Pennsylvania State University

217 Materials Research Lab

Hastings Road

University Park, PA 16802

David A. Waite

$\mathrm{CH}_{2} \mathrm{M}$ Hill

P.O. Box 91500

Bellevue, WA 98009-2050

Thomas A. Zordon

Zordan Associates, Inc.

3807 Edinburg Drive

Murrysville, PA 15668

Universities

University of New Mexico

Geology Department

Attn: Library

141 Northrop Hall

Albuquerque, NM 87131

University of Washington

College of Ocean \& Fishery Sciences

Attn: G. R. Heath

583 Henderson Hall, HN-15

Seattle, WA 98195

\section{Libraries}

Thomas Brannigan Library

Attn: D. Dresp

$106 \mathrm{~W}$. Hadley St.

Las Cruces, NM 88001

Government Publications Department

Zimmerman Library

University of New Mexico

Albuquerque, NM 87131

New Mexico Junior College

Pannell Library

Attn: R. Hill

Lovington Highway

Hobbs, NM 88240

New Mexico State Library

Attn: N. McCallan

325 Don Gaspar

Santa Fe, NM 87503

Distribution - 3 
New Mexico Tech

Martin Speere Memorial Library

Campus Street

Socorro, NM 87810

WIPP Public Reading Room

Carlsbad Public Library

$101 \mathrm{~S}$. Halagueno St.

Carlsbad, NM 88220

\section{Foreign Addresses}

Atomic Energy of Canada, Ltd.

Whiteshell Laboratories

Attn: B. Goodwin

Pinawa, Manitoba, CANADA R0E IL0

Francois Chenevier (2)

ANDRA

Route de Panorama Robert Schumann

B. P. 38

92266 Fontenay-aux-Roses, Cedex

FRANCE

Claude Sombret

Centre d'Etudes Nucleaires de la Vallee Rhone

CEN/VALRHO

S.D.H.A. B.P. 171

30205 Bagnols-Sur-Ceze, FRANCE

Commissariat a L'Energie Atomique

Attn: D. Alexandre

Centre d'Etudes de Cadarache

13108 Saint Paul Lez Durance Cedex

FRANCE

Bundesanstalt fur Geowissenschaften und

Rohstoffe

Attn: M. Langer

Postfach 510153

D-30631 Hannover, GERMANY

Bundesministerium fur Forschung und

Technologie

Postfach 200706

5300 Bonn 2, GERMANY

Institut fur Tieflagenung

Attn: K. Kuhn

Theodor-Heuss-Strasse 4

D-3300 Braunschweig, GERMANY
Gesellschaft fur Anlagen und Reaktorsicherheit (GRS)

Attn: B. Baltes

Schwertnergasse 1

D-50667 Cologne, GERMANY

Shingo Tashiro

Japan Atomic Energy Research Institute

Tokai-Mura, Ibaraki-Ken, 319-11

JAPAN

Netherlands Energy Research Foundation ECN

Attn: J. Prij

3 Westerduinweg

P.O. Box 1

1755 ZG Petten

THE NETHERLANDS

Svensk Karnbransleforsorjning AB

Attn: F. Karlsson

Project KBS (Karnbranslesakerhet)

Box 5864

S-102 48 Stockholm

SWEDEN

Nationale Genossenschaft fur die Lagerung

Radioaktiver Abfalle (2)

Attn: S. Vomvoris

P. Zuidema

Hardstrasse 73

CH-5430 Wettingen

SWITZERLAND

AEA Technology

Attn: J. H. Rees

D5W/29 Culham Laboratory

Abington, Oxfordshire OX14 3DB

UNITED KINGDOM

AEA Technology

Attn: W. R. Rodwell

044/A31 Winfrith Technical Centre

Dorchester, Dorset DT2 8DH

UNITED KINGDOM

AEA Technology

Attn: J. E. Tinson

B4244 Harwell Laboratory

Didcot, Oxfordshire OX11 ORA

UNITED KINGDOM 
Other

R. E. Westerman (25)

1804 Marshall

Richland, WA 99352

\section{Internal}

$\begin{array}{lll}\frac{\text { MS }}{1324} & \frac{\text { Org. }}{6115} & \text { P. B. Davies } \\ 1320 & 6831 & \text { E. J. Nowak } \\ 1322 & 6121 & \text { J. R. Tillerson } \\ 1328 & 6849 & \text { D. R. Anderson } \\ 1328 & 6848 & \text { H. N. Jow } \\ 1335 & 6801 & \text { M. Chu } \\ 1341 & 6832 & \text { J. T. Holmes } \\ 1395 & 6800 & \text { L. Shephard } \\ 1395 & 6821 & \text { M. Marietta } \\ 1395 & 6841 & \text { V. H. Slaboszewicz } \\ 1341 & 6832 & \text { L. Brush (25) } \\ 1341 & 6832 & \text { A. C. Peterson (2) } \\ 1341 & 6832 & \text { Y. Wang (5) } \\ 1341 & 6832 & \text { L. J. Storz } \\ 1320 & 6832 & \text { H. W. Papenguth } \\ 0706 & 6113 & \text { M.A. Molecke (2) } \\ 1330 & 6811 & \text { K. Hart (2) } \\ 1330 & 4415 & \text { NWM Library (20) } \\ 9018 & 8940-2 & \text { Central Technical Files } \\ 0899 & 4414 & \text { Technical Library (5) } \\ 0619 & 12630 & \text { Review and Approval Desk (2), } \\ & & \text { For DOE/OSTI }\end{array}$

Distribution - 5 